\title{
Novel aspects of the Renin-Angiotensin-Aldosterone System
}

Citation for published version (APA):

Piazza, M. (2021). Novel aspects of the Renin-Angiotensin-Aldosterone System: A focus on hyperaldosteronism and glycation. [Doctoral Thesis, Maastricht University, Università degli Studi di Padova]. Maastricht University. https://doi.org/10.26481/dis.20211004mp

Document status and date:

Published: 01/01/2021

DOI:

10.26481/dis.20211004mp

Document Version:

Publisher's PDF, also known as Version of record

\section{Please check the document version of this publication:}

- A submitted manuscript is the version of the article upon submission and before peer-review. There can be important differences between the submitted version and the official published version of record.

People interested in the research are advised to contact the author for the final version of the publication, or visit the DOI to the publisher's website.

- The final author version and the galley proof are versions of the publication after peer review.

- The final published version features the final layout of the paper including the volume, issue and page numbers.

Link to publication

\footnotetext{
General rights rights.

- You may freely distribute the URL identifying the publication in the public portal. please follow below link for the End User Agreement:

www.umlib.nl/taverne-license

Take down policy

If you believe that this document breaches copyright please contact us at:

repository@maastrichtuniversity.nl

providing details and we will investigate your claim.
}

Copyright and moral rights for the publications made accessible in the public portal are retained by the authors and/or other copyright owners and it is a condition of accessing publications that users recognise and abide by the legal requirements associated with these

- Users may download and print one copy of any publication from the public portal for the purpose of private study or research.

- You may not further distribute the material or use it for any profit-making activity or commercial gain

If the publication is distributed under the terms of Article $25 \mathrm{fa}$ of the Dutch Copyright Act, indicated by the "Taverne" license above, 


\section{Novel aspects of the}

\section{Renin-Angiotensin-Aldosterone System}

A focus on hyperaldosteronism and glycation 
() Maria Piazza, Maastricht 2021

No part of this book may be reproduced or transmitted in any form or by any means, without prior permission in writing by the author, or when appropriate, by the publishers of the publications.

Cover design: ProefschriftMaken

Printed by: ProefschriftMaken

ISBN: 978-94-6423-396-4 


\title{
Novel aspects of the
}

\section{Renin-Angiotensin-Aldosterone System}

\section{A focus on hyperaldosteronism and glycation}

\author{
DISSERTATION \\ to obtain the degree of Doctor at Maastricht \\ University, on the authority of the Rector \\ Magnificus, Prof. dr. Rianne M. Letschert, in \\ accordance with the decision of the Board \\ of Deans, to be defended in public on \\ Monday 4 October 2021 at 13:00 hours
}

by

Maria Piazza 
Supervisors

Prof. Dr. Casper G. Schalkwijk

Prof Dr. Gian Paolo Rossi

Co-supervisors

Prof. Dr. Teresa M. Seccia

Dr. Nordin M.J. Hanssen

\section{Assessment committee}

Prof. Dr. AA Kroon

Prof. Dr. G. Albertin

Prof. Dr. AHJ Danser

Prof. Dr. G Haenen

Dr. S. Foulquier

Dr. O. Brouwers 


\section{CONTENTS}

Chapter 1 General introduction

Part 1

Chapter 2

Chapter 3

Chapter 4

Chapter 5

Chapter 6

Part 2

Chapter 7

Chapter 8

Chapter 9

Chapter 10

\section{Aldosterone}

The key role of Epithelial to Mesenchymal

Transition (EMT) in hypertensive kidney disease

The angiotensin type 2 receptor in the human adrenocortical zona glomerulosa and in aldosteroneproducing adenoma: low expression and no functional role

Macrolides blunt aldosterone Biosynthesis

A Proof-of-Concept Study in KCNJ5 Mutated Adenoma Cells Ex Vivo

Aldosterone Stimulates its Biosynthesis Via A Novel

83 GPER Mediated Mechanism

AT1AA (Angiotensin II Type-1 Receptor Autoantibodies)

101 Cause or Consequence of Human Primary Aldosteronism?

\section{Glycation}

Serum levels of autoantibodies against the angiotensin II type I receptor are not associated with serum dicarbonyl or AGE levels in patients with aldosterone producing adenoma.

Irbesartan treatment does not influence plasma levels of the dicarbonyls methylglyoxal, glyoxal and 3deoxyglucosone in patients with type 2 diabetes and microalbuminuria. An IRMA2 substudy

Angiotensin II infusion decreases glyoxalase I expression and activity in kidney and liver of C57BL/6J mice

Summary and General Discussion

Research Impact

Acknowledgements (Dankwoord)

Curriculum Vitae 



\section{Chapter 1}

General introduction 


\section{Renin angiotensin-aldosterone system}

The renin-angiotensin-aldosterone system (RAAS) plays an important role in the regulation of blood pressure, body fluid volume and sodium-potassium balance. It has been demonstrated that dysregulation of RAAS, including increased circulating angiotensin II (Ang II) and aldosterone, may contribute to the development of hypertension, atherosclerosis, left ventricular hypertrophy, stroke, myocardial infarction, heart failure and/or renovascular disorders ${ }^{1}$.

The conventional RAAS begins with the biosynthesis of the glycoprotein hormone renin, by the juxtaglomerular cells in the kidneys, in response to reduced renal perfusion pressure, low levels of intratubular sodium, sympathetic activation and lack of negative feedback by Ang II 1 (Figure 1.1). Renin converts angiotensinogen into angiotensin I (Ang I), which is subsequently hydrolyzed by angiotensin-converting enzymes (ACEs) to form Ang II 2,3. Ang II mediates its effects via Ang II type 1 (AT1R) and Ang II type 2 (AT2R) receptors.

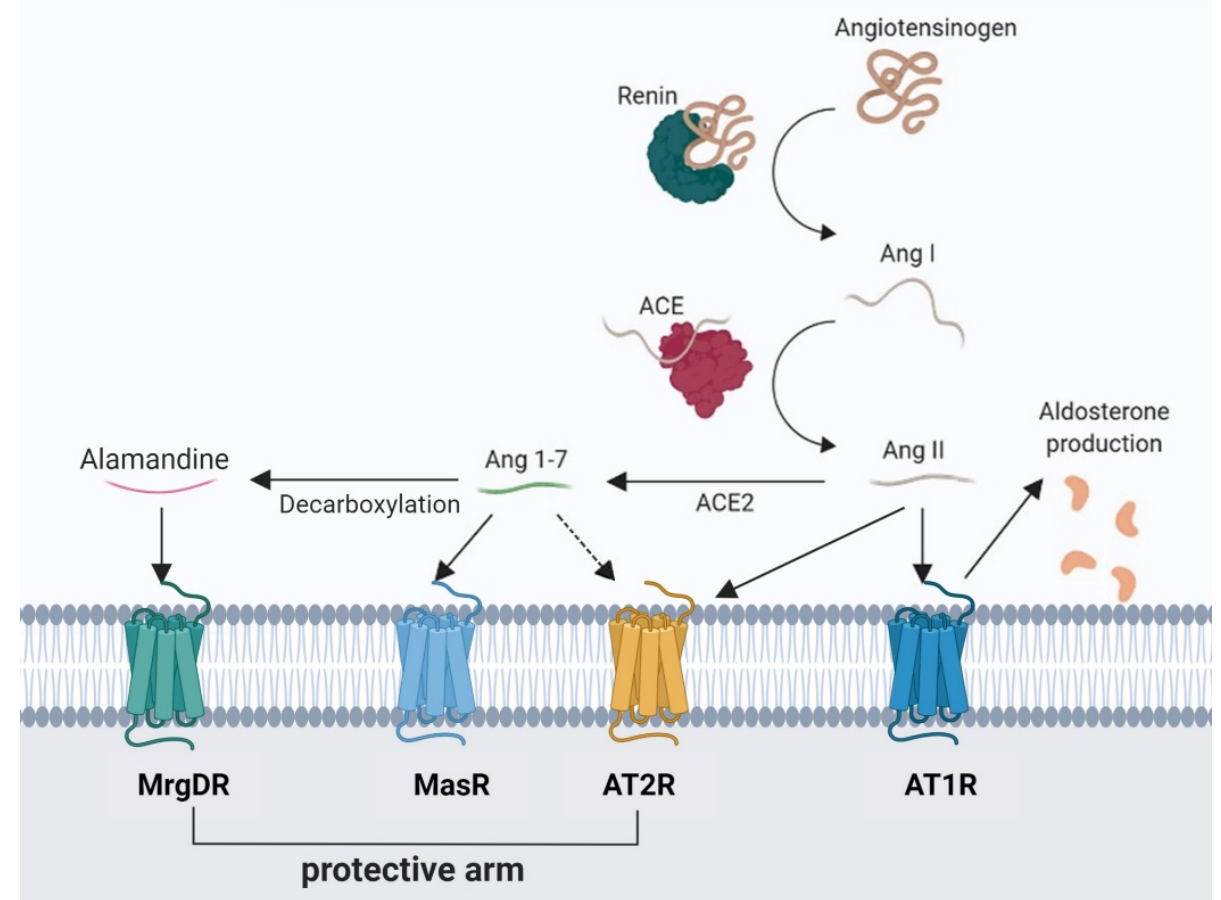

Figure 1.1. Overview of the RAAS. The diagram depicts the cell membrane bound angiotensin type 1 receptor (AT1R), angiotensin type 2 receptor (AT2R), Mas receptor (MasR), alamandine receptor (MrgDR) ACE, angiotensin-converting enzyme; ACE2, angiotensin-converting enzyme 2; Ang I, angiotensin I; Ang II angiotensin II; Ang1-7, angiotensin 1-7.Figure adapted from Wilkinson-Berka et al. 4 
Ang II has been regarded as a major peptide of the RAAS. AT1R activation by Ang II elicits vasoconstriction, water intake, and $\mathrm{Na}^{+}$retention. However, pathophysiological activation of the ACE/ANG II/AT1R axis is associated with oxidative stress, hypertrophy, inflammation and fibrosis. High levels of Ang II can promote tubulointerstitial damage by inducing epithelial mesenchymal transition (EMT) ${ }^{5}$. The key role of EMT in hypertensive kidney disease is discussed in detail in Chapter 2. The RAAS also possesses a 'protective arm', mediated through the AT2R, Mas receptor (MasR) and alamandine receptor (MrgDR). The activation of AT2R seems to counterbalance some of the actions of the AT1 receptor ${ }^{6,7}$. Furthermore, the cleavage of Ang II by ACE2 produces angiotensin 1-7 (Ang1-7) which also acts on the AT2R and MasR to partially antagonize the effects of AT1R ${ }^{8}$. One of the major effects of Ang II is the regulation of aldosterone synthesis, mediated via the AT1 receptor in the zona glomerulosa of the adrenal cortex ${ }^{9}$.

\subsection{Aldosterone}

Aldosterone is a steroid hormone that is produced in the adrenal cortex. The human adrenal cortex can be divided into three functionally distinct area; the zona glomerulosa (ZG), the zona fasciculata (ZF), and the zona reticularis (ZR). Each zone secretes different types of adrenocortical steroid hormones. The zona glomerulosa is the site of aldosterone synthesis. The zona fasciculata, corresponding to $75 \%$ of the cortex, is the site of cortisol synthesis. The inner cortex corresponds to the zona reticularis and is the site where androgens are synthesized.

Biosynthesis of aldosterone involves multiple enzymes common to all the zonas and is exerted at two rate-limiting steps in the steroidogenic pathway. The first step common to the cortisol synthesis is the transport of cholesterol into the mitochondria by StAR protein, where it is converted to pregnenolone ${ }^{10}$. Pregnenolone in the endoplasmic reticulum is converted to progesterone by $3 \beta-$ hydroxysteroid dehydrogenase (3ß-HSD). 21-hydroxalase (CYP21A2) then converts progesterone to 11-deoxycorticosterone and is transported back into the mitochondria in which the second rate-limiting step occurs, i.e. the sequential hydroxylation by aldosterone synthase (CYP11B2) leading to the synthesis of aldosterone. CYP11B2 is only expressed in the ZG, while expression of $11 \beta$ hydroxylase (CYP11B1), which is required for the final step in the biosynthesis of cortisol, is limited to the ZF and ZR ${ }^{11}$ (Figure 1.2). 


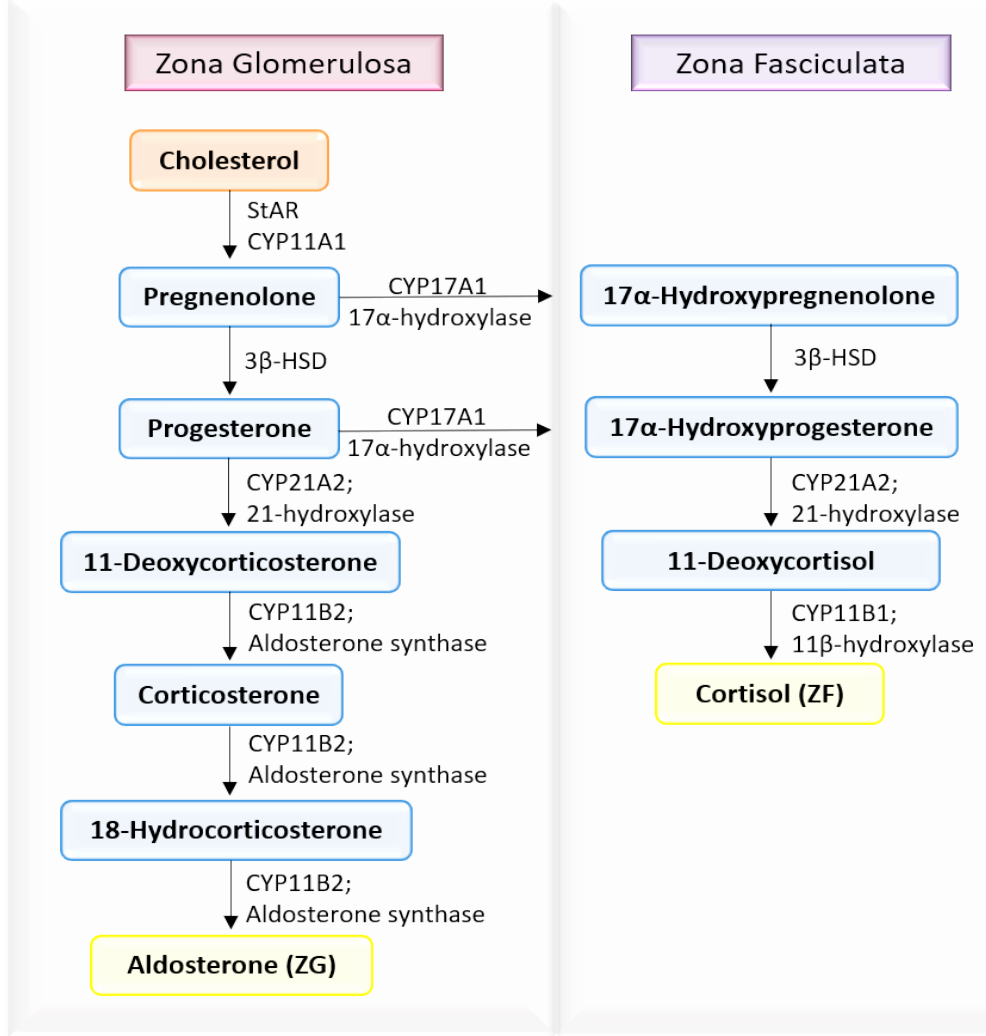

Figure 1.2. Steroidogenic pathway for the production of aldosterone and cortisol

The production of aldosterone is controlled by multiple factors including Ang II, potassium $\left(\mathrm{K}^{+}\right)$, endothelin-1, vasopressin, urotensin II, and circulating adrenocorticotrophic hormone (ACTH) ${ }^{12,13}$.

In the classic pathway aldosterone binds to the intracellular mineralocorticoid receptor (MR) in the epithelial cells of the distal convoluted tubule and the collecting duct of the nephrons ${ }^{14}$. By up-regulating the epithelial sodium channel $(\mathrm{ENaC})$ and the basolateral $\mathrm{Na}^{+} / \mathrm{K}^{+}$-ATPase, aldosterone promotes reabsorption of sodium and water which contributes directly to increased blood pressure. Aldosterone regulates the transcription of genes coding for these channels and the exchange pump via its receptor. Besides this genomic effect, non-genomic effects of aldosterone are described and they are mediated either via MR dependent - or MR independent pathways (Figure 1.3). Aldosterone via MR dependent pathways can promote the activation of second messenger responses such as the biosynthesis of cAMP, as well as the activation of extracellular signal-regulated kinase (ERK1/2) and mitogen-activated protein kinase (MAPK) cascades through the transactivation of the epidermal growth factor receptor (EGFR) ${ }^{15}$. 


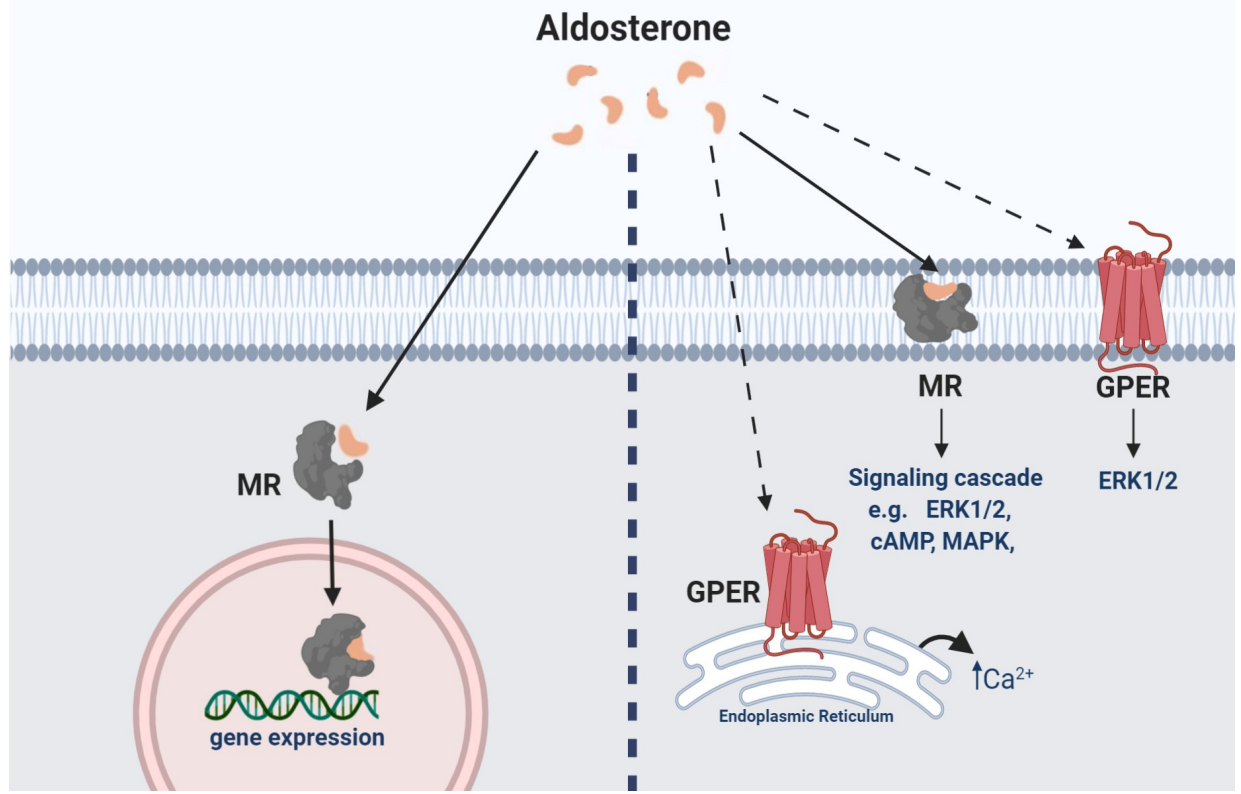

Figure 1.3. Genomic and non-genomic actions of aldosterone. In the genomic pathway, aldosterone diffuses across the cytoplasmic membrane and binds to mineralocorticoid receptor (MR) in the cytosol inducing receptor translocation to the nucleus and expression of genes. In contrast, the non-genomic effects of aldosterone are not dependent on transcription. Non-genomic pathways are MR dependent or independent and act via second messenger systems. Abbreviations: G-protein coupled estrogen receptor (GPER). Figure created with BioRender.com

Recently, several studies have shown rapid, non-genomic effects of aldosterone in the renal tubule, but also several other tissues, such as vascular tissue, and heart 16-19. Of note, MR is also distributed across a range of extraepithelial tissues such as endothelial cells, vascular smooth muscle cells, and kidney mesangial cells and podocytes, suggesting that the physiological effects of aldosterone are not limited to the MR on the renal epithelial cells ${ }^{20}$. Moreover, the non-genomic effect of aldosterone can involve other receptors such as G-protein coupled estrogen receptor (GPER) ${ }^{21}$. Although GPER was first characterized as an orphan G-protein coupled receptor (aka GPR30), later it was demonstrated to mediate rapid intracellular signaling of estrogens ${ }^{22}$. The expression of GPER is ubiquitous, and in the last decade it has been reported that aldosterone can activate GPER mediated pathways in both in-vitro and in-vivo models ${ }^{23}$. These include the rapid activation of ERK1/2 and apoptosis in vascular smooth muscle cells (VSMCs) of rat aorta via activation of both GPER and MR ${ }^{24}$, while activation of ERK1/2 in endothelial cells 25 and an increase in cytosolic $\mathrm{Ca}^{2+}$ concentration and depolarization in cardiac vagal neurons through GPER activation ${ }^{26}$. 
Although the RAAS in general and aldosterone in particular, has an important physiological role in blood pressure regulation, chronic activation of RAAS is a key factor in the pathophysiology of cardiovascular diseases, including hypertension and heart failure. Elevated aldosterone levels not only contribute to the development of hypertension but also induce a proinflammatory condition which ultimately leads to end-organ damage, such as cardiac and vascular fibrosis ${ }^{4}$.

\subsection{Hypertension}

Hypertension is one of the most important risk factors for stroke, heart and kidney disease, and hardening of the arteries.

According to the European guidelines, hypertension is defined as a blood pressure (BP) $\geq 140 / 90 \mathrm{mmHg}{ }^{27}$, but more recently the American guidelines recommends lower threshold of $B P \geq 130 / 80 \mathrm{mmHg}^{28}$.

In industrialised countries, the risk of becoming hypertensive during a lifetime exceeds $90 \%$. Globally, over 1 billion people are afflicted by hypertension and it is estimated that the number of people with hypertension will increase by 2025 , approaching a prevalence of 1.5 billion ${ }^{27,29}$. The increase in the prevalence of hypertension is a consequence of population growth, ageing and lifestyle, such as physical inactivity, use of alcohol, and the consumption of diets rich in fat, sugar and calories. (World Health Organisation, 2013; Das et al. 2005). Hypertension usually converges with other cardiovascular risk factors such as dyslipidaemia and glucose intolerance ${ }^{30,31}$.

Arterial hypertension can be classified into primary or secondary forms. About $80-$ $95 \%$ of arterial hypertension is primary or essential hypertension and does not have a precise, identifiable cause. The remaining $5-10 \%$ of cases is secondary hypertension and is the consequence of hormonal disorders or congenital or acquired diseases that affect the kidneys, adrenals, arterial vessels or the heart. In secondary hypertension, the identification and removal of the causes, that is, the effective treatment of the underlying disease, is accompanied by the normalization of the blood pressure. Essential hypertension classically affects the adult population and its prevalence increases with age, whereas secondary hypertension also affects younger subjects and is often characterized by higher pressure values that are more difficult to control with drug therapy.

\subsection{Primary Aldosteronism}

Primary aldosteronism (PA), first described by Jerome Conn in the 1950s, is the most common cause of secondary hypertension characterized by excessive secretion of the hormone aldosterone from the adrenal glands ${ }^{32}$ and thus an endogenous continuous exposure to elevated aldosterone levels. 
Large variations of the prevalence of PA have been reported, ranging from $<1 \%$ to $30 \%$. This variations can be explained by differences in the selection of the patient's cohorts and heterogeneous diagnostic criteria used in the various studies 33. However, the PA Prevalence in Hypertensives (PAPY) study, referred to specialized hypertension centres, represents the most realistic estimate on the prevalence of primary aldosteronism in the hypertensive patients. Based on a predefined protocol and standardized diagnostic criteria to diagnose PA, the PAPY study provided solid evidence that among referred hypertensive patients the prevalence of PA is $11.2 \%{ }^{34}$. Patients with PA have a higher risk of cardiovascular events and target organ damage than age-, sex- and BP-matched patients with essential hypertension ${ }^{35}$.

Therefore, early identification and specific treatment of PA is essential to minimize the adverse effects of aldosterone excess. However, PA remains largely unrecognized by medical professionals and currently available diagnostic tests for PA are complex, require long times are relatively expensive and cannot be applied to all hypertensive patients.

\subsubsection{Subtypes of Primary Aldosteronism}

The mechanisms that regulate aldosterone production are severely altered in PA. This disorder comprises both sporadic and familial forms.

There are two major subtypes of sporadic PA: the unilateral aldosterone-producing adenoma (APA). APA can be optimally treated with unilateral laparoscopic adrenalectomy. Bilateral adrenal hyperplasia (BAH, also known as idiopathic hyperaldosteronism, IHA) is usually treated with a lifelong treatment with mineralocorticoid receptor antagonists. Hence, the distinction between APA and IHA is crucial for appropriate treatment ${ }^{36,37}$.

Four familial forms of primary aldosteronism have been identified ( $\mathrm{FH}-\mathrm{I}$ to $\mathrm{FH}-\mathrm{IV}$ ) together with the PASNA (PA, seizures, neurologic abnormalities) syndrome, which is a genetic disease, but not a familial form of $P A{ }^{38}$.

Familial hyperaldosteronism type I (FH-I), also known as glucocorticoid-remediable aldosteronism (GRA), was first described in $1966{ }^{39}$. It is an autosomal dominant disease generated by an unequal crossing over during meiosis between the genes CYP11B1 (which encodes steroid 11ß-hydroxylase) and CYP11B2 (which encodes aldosterone synthase). The resulting hybrid gene encodes an enzyme chimera with aldosterone synthase activity that is expressed in the adrenal zona fasciculata under control of adrenocorticotropic hormone instead of angiotensin II. The majority of affected individuals develop early and severe hypertension, often associated with hypokalemia. GRA has a presumed prevalence of $0.7-1.0 \%$ of all PA 38,40 . Familial hyperaldosteronism type II (FH-II) is a non-glucocorticoid-remediable form of PA, present in patients with a familial history of PA caused by adrenal adenoma 
or hyperplasia. The prevalence of $\mathrm{FH}-\mathrm{Il}$ is $1.2-6 \%$ of adult patients with PA. With exome sequencing, de novo mutations in the CLCN2 gene coding for the CLC-2 chloride channel in patients with $\mathrm{FH}-\mathrm{II}$ and early-onset PA has been identified and the implication of a chloride channel in the regulation of aldosterone production has been described ${ }^{41,42}$.

Familial hyperaldosteronism type III (FH-III) was first described in a family with hyperaldosteronism, profound hypokalemia and severe hypertension that was resistant to medical therapy 43 .

The genetic cause of $\mathrm{FH}-\mathrm{III}$ has been identified as a germline mutation in the KCNJ5 gene encoding the potassium channel Kir3.4 which is expressed in adrenal zona glomerulosa ${ }^{44}$.

Familial hyperaldosteronism type IV (FH-IV) is a non-glucocorticoid-remediable form of $\mathrm{FH}$, which has been attributed to germline CACNA1H mutations. CACNA1H codes for the pore-forming a1 subunit of the voltage-gated T-type calcium channel Cav3.2. Patients with FH-IV showed hyperaldosteronism with low plasma renin activity but no evidence of a mass or hyperplasia on adrenal imaging 45 .

PASNA (primary aldosteronism with seizures and neurologic abnormalities) is a genetic disease in patients with primary aldosteronism and neurological symptoms characterized by germline CACNA1D mutations ${ }^{38}$.

\subsubsection{Aldosterone Producing Adenoma}

Aldosterone-producing adenomas are responsible for about half of PA.

Patients with APA are characterized by an increase in circulating aldosterone independent of plasma renin, and is a major cause of endocrine secondary hypertension.

Currently, the only reliable procedure allowing differentiation of the unilateral from bilateral PA and identification of APA side preoperatively is adrenal venous sampling (AVS) ${ }^{46}$. In AVS, aldosterone and cortisol levels are measured in blood collected from both adrenal veins to assess whether aldosterone is unilaterally overproduced. The development of specific antibodies against CYP11B2 now allows an accurate localization of the cells producing aldosterone and provides a conclusive diagnosis of the PA subtype. The diagnosis of APA is usually established when the following 'Five Corners Criteria' are fulfilled: 1) Biochemical evidence of PA (e.g., an inappropriately high aldosterone/renin ratio), 2) aldosterone secretion is lateralized at AVS, 3) an adenoma is detected at pathology of a nodule by imaging (CT or MRI), 4) PA is biochemically corrected by adrenalectomy, 5) a CYP11B2-positive adenoma at pathology is detected ${ }^{47}$.

However, the pathophysiological and molecular mechanisms that lead to the development of APA and which determine the hypersecretion of aldosterone are 
still unknown. Numerous recurrent somatic mutations have been identified in APA. Pathogenetic somatic mutations in the KCNJ5 potassium channel were first reported in $2011^{44}$ and involves up to $70 \%$ of cases of APA, usually the most florid PA phenotypes ${ }^{48}$. This finding was soon followed by the discovery of mutations in other genes affecting ion channel function: in the sodium/potassium ATPase ATP1A1, the calcium ATPase ATP2B3 genes, and in the CACNA1D gene ${ }^{49,50}$. All these mutations induce an increase in intracellular calcium levels, followed by an activation of calcium signaling and therefore increase the biosynthesis of aldosterone. Recent findings have shown that some macrolide antibiotics and their derivatives specifically inhibit in vitro the altered function of mutated KCNJ5 channels and blunted in dose-dependent manner aldosterone secretion, opening a new horizons for the diagnosis and treatment of APA with KCNJ5 mutations ${ }^{51}$. Autoimmune mechanisms have also been suggested as an important cause of human PA. Autoantibodies against type-1 angiotensin II receptor (AT1AAs) were found in the plasma of patients with PA at levels comparable to those found in preeclamptic women ${ }^{52}$. Moreover, circulating AT1AA levels discriminated between APAs and IHA, suggesting that they might be useful not only for diagnosing PA but also for differentiating APA from non-APA conditions ${ }^{52}$. 


\section{The glycation pathway and the formation of AGEs}

In addition to Ang II, a lot of studies have demonstrated the involvement of advanced glycation endproducts (AGEs) in the development of vascular dysfunction ${ }^{53}$, hypertension and chronic kidney disease and cardiovascular disease 54,55 . Thus, in addition to the activation of the renin-angiotensin system, the accumulation of AGEs is recognized as a key driver of macro- and microvascular complications. However, if, and if so, how these two mechanisms interact has been relatively underexplored.

\subsection{Formation of Advanced Glycation Endproducts (AGEs)}

Glycation is a non-enzymatic reaction of reducing sugars with proteins, lipids and nucleic acids. This process was first described by Louis-Camille Maillard in 191256 . The formation of AGEs via the Maillard reaction starts with condensation of the carbonyl group of reducing sugars and the amino group of proteins resulting in the rapid formation of unstable Schiff base intermediate. This Schiff base intermediate then slowly rearranged to more stable Amadori products (Figure 1.3). Only a small part of these Amadori products will be further, and irreversibly, modified to AGEs. At body temperature, AGE formation in vivo is a slow process and mainly affects long-lived proteins, such as collagen and elastin ${ }^{57}$. Besides the endogenous formation of AGEs, the accumulation of AGEs in our body can also originate from exogenous sources such as tobacco smoke and diet ${ }^{58,59}$, and this exogenous AGE formation in food is highly dependent on cooking methods. AGEs can be present in both the free (modified amino acid) and protein-bound (modified amino acid as part of a protein) form.

In addition to the classical pathway of AGE formation in the Maillard reaction, as described above, a rapid AGE formation on short-lived proteins and intracellular AGE formation have attracted attention. It should be realized that glucose has a very slow glycation rate. In contrast, glucose-derived glycolytic intermediates form not only much more glycated proteins than equimolar amounts of glucose, but also more rapidly. The glucose-derived glycolytic intermediates glyoxal (GO), methylglyoxal (MGO) and 3-deoxyglucosone (3-DG) play an important role in the fast intracellular Maillard reaction and are much more reactive than glucose or other reducing sugars ${ }^{60-62}$. Besides reducing sugars, other sources contribute to the formation of these reactive dicarbonyl compounds, including lipid peroxidation. Dicarbonyls derived from lipid peroxidation, create so-called advanced lipoxidation endproducts (ALEs). The mechanism of formation of ALEs is comparable as those formed from glucose-derived glycolytic intermediates. Thus, there is a strong interplay between the formation of AGEs and ALEs as their formation is through identical reactive dicarbonyls. 
The accumulation of reactive dicarbonyl compounds is known as "dicarbonyl stress" and leads to increased AGEs formation. including $\mathrm{N}^{\varepsilon}-(1-$ carboxymethyl)lysine (CML), $\mathrm{N}^{\varepsilon}$-(1-carboxyethyl)lysine (CEL), and $\mathrm{N}^{\delta}$-(5- hydro-5methyl-4-imidazolon-2-yl)-ornithine (MG-H1).

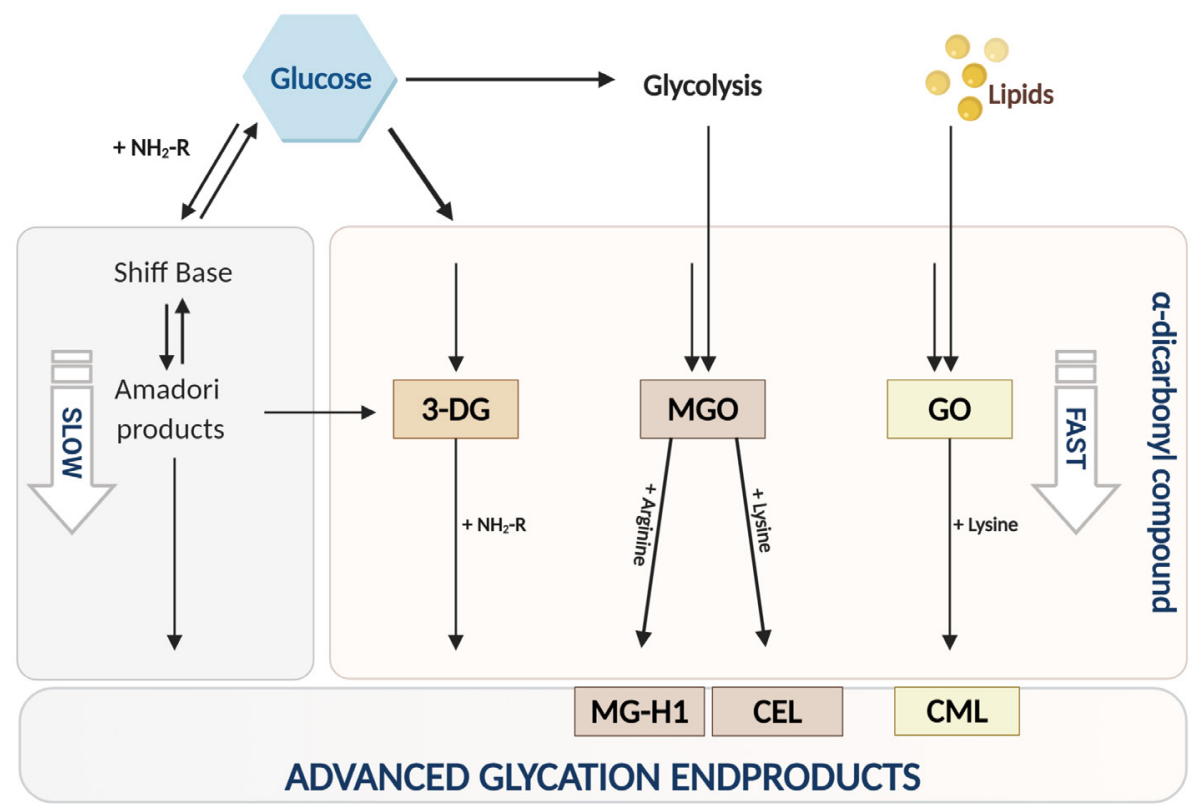

Figure 1.3. Main steps of endogenous AGE formation. Abbreviations: 3DG, 3-deoxyglucosone; CEL, $\mathrm{N} \varepsilon$-carboxyethyl-lysine; CML, Ne-carboxymethyl-lysine; GO, glyoxal; MG-H1, methylglyoxal-derived hydroimidazolone 1; MGO, methylglyoxal; 


\subsection{Mechanisms of vascular harm by glycation}

AGEs adverse effects on cellular and tissue function through direct modification of extracellular matrix proteins, leading to collagen cross-links and, subsequently, to an increase of vascular stiffness, or through binding to cell surface receptors such as RAGE, triggering multiple signaling cascades and the production of reactive oxygen species, resulting in proinflammatory cellular responses ${ }^{63}$.

\subsubsection{RAGE}

AGEs mediate some of their pathological effects by activating different signaling pathways upon binding to different cell surface receptors. Research has identified a number of AGE-binding proteins, including macrophage scavenger receptors (MRS) type I and II, oligosaccharyltransferase-48 (AGE-R1), 80K-H phosphoprotein (AGE-R2), galectin-3, CD36, LOX-1 and RAGE ${ }^{63,64}$. RAGE is the best characterized and the most-studied receptor so far. RAGE is a multi-ligand transmembrane receptor of the immunoglobulin superfamily and is expressed on several cell types, including endothelial cells, monocytes, macrophages, fibroblasts, and smooth muscle cells. The ligand-binding domain of RAGE resides in the V-domain and recognizes a large variety of ligands of different origin including AGEs, amyloid $\beta$ peptide, S100/calgranulin protein and HMGB1 ${ }^{65}$.

Under physiological conditions, the expression of RAGE is low while under pathogenic conditions like inflammation and diabetes, RAGE expression is upregulated. Interestingly, also at sites of increased levels of AGEs RAGE is upregulated, such as in podocytes in diabetic nephropathy ${ }^{66}$. Altered plasma or tissue level of RAGE has been identified in patients with diabetic complications and in chronic inflammation ${ }^{65}$.

Binding of AGEs to RAGE is linked to the activation of multiple cellular signal pathways including activation of a cascade of mitogen-activated protein kinases (MAPK), such as ERK1/2 (p44/p42) ${ }^{67}$. Activation of these MAPK results in activation of nuclear transcription factor- $\kappa B(N F-\kappa B)$, and subsequently to transcription of target genes, including numerous adhesion molecules and proinflammatory cytokines which are involved in vascular inflammation and endothelial dysfunction. The AGE-RAGE axis also represents an important mediator of oxidative stress as induced by increased NADPH oxidase gene expression, mitochondrial oxidase activity and downregulation of endogenous antioxidant mediator of oxidative stress 68,69 . This interaction of AGEs with RAGE on endothelial cells results also in a decrease of endothelial barrier function and hence an increase in the permeability of an endothelial cell monolayer ${ }^{70}$. 


\subsubsection{Intracellular glycation by methylglyoxal}

Based on the current literature, the predominant mechanism by which AGEs damage tissues is by intracellular glycation of proteins leading to impaired cell function. MGO is the major precursor in the formation of intracellular AGEs in endothelial cells ${ }^{63}$. MGO mainly reacts with arginine to generate methylglyoxalderived hydroimidazolone (MG-H1) and with lysine to $\mathrm{N}^{\varepsilon}$-(carboxyethyl)lysine (CEL). In addition to amino acids, specific nucleotides are also susceptible to modification by MGO ${ }^{60}$. Under physiological conditions, the concentration of MGO is maintained in the range of $100-300 \mathrm{nM}$ in human plasma and MGO levels increase under conditions of conditions of hyperglycaemia, inflammation and hypoxia ${ }^{71,72}$.

Several studies have reported MGO-induced changes in particular proteins including hemoglobin ${ }^{73}$, mitochondrial proteins ${ }^{74}$, and antioxidant enzyme such as GAPDH ${ }^{75}$, besides changes in DNA methylation ${ }^{76}$, and histone modifications ${ }^{76}$. Thus, intracellular glycation by MGO may lead to a range of molecular pathways that disrupt cellular function or even lead to cell-death ${ }^{60}$. The accumulation of MGO may cause hemodynamic, inflammatory, metabolic, and structural changes in the kidneys ${ }^{60}$ that may contribute to the manifestation of diabetic chronic kidney disease $^{77}$ and cardiovascular disease ${ }^{54,55}$. Furthermore, plasma MGO levels are increased in diabetes ${ }^{71}$ and are associated with cardiovascular disease in type 1 and type 2 diabetes ${ }^{54,55}$.

\subsubsection{Glyoxalase pathway}

MGO can be detoxified by the cytoplasmic glyoxalase system. The glyoxalase system consists of 2 enzymes, glyoxalase 1 (Glo1) and glyoxalase 2 (Glo2), and a catalytic amount of reduced glutathione (GSH). First, MGO is converted to SLactoylglutathione by Glo1, which uses $\mathrm{GSH}$ as a cofactor (Figure 1.4). Subsequent, S-Lactoylglutathione is metabolized to D-lactate by Glo2. GSH is recycled during this last step in the process, making it available for new detoxification of MGO. The conversion of MGO by Glo1 is important because this is the rate-limiting step and S- Lactoylglutathione is not as toxic to cells as MGO.

The formation of AGEs is suppressed by enzymatic metabolism of MGO by Glo1, indicating that $\mathrm{MGO}$ is the major precursor in the formation of AGEs ${ }^{60}$. Indeed, in endothelial cells, overexpression of Glo1 prevents hyperglycaemia-induced formation of the major AGEs CML and CEL ${ }^{78}$ as well as impaired angiogenesis ${ }^{79}$. In line with these in vitro experiments, overexpression of Glo1 in diabetic animal models reduces hyperglycaemia-induced formation of MGO ${ }^{80}$, improves diabetesinduced impairment of vasodilatation 81,82 and prevents endothelial dysfunction by 
reduction of expression of the adhesion molecules vascular cell adhesion molecule 1 (VCAM-1) and intracellular adhesion molecule 1 (ICAM-1) ${ }^{82}$.

Furthermore, overexpression of Glo1 attenuated diabetes-induced loss of podocytes in the glomerulus ${ }^{82}$, one of the early hallmarks of diabetic nephropathy 83. Glo1 is essential for normal kidney function in protecting cells from MGO stress as showed in nondiabetic mice, in which knockdown of Glo1 increases MG-H1 residues in proteins of renal glomeruli and tubules and oxidative stress with subsequent alterations in kidney morphology identical to those caused by diabetes 84. In accordance, knockdown of Glo1 in human aortic endothelial cells increases MGO and promote endothelial inflammation and apoptosis 85 .

The importance of Glo1 has also been demonstrated in human studies. In longstanding T1D, Glo1 expression was lower in kidneys affected by CKD ${ }^{86}$. Similar observations were made for carotid atherosclerotic plaques, in which Glo1 expression was lower in ruptured in comparison with stable plaque segments ${ }^{87}$. Furthermore, a very large genomic study revealed that Glo1 is a major driver of coronary artery disease ${ }^{88}$.

Interestingly, Miller and coworkers ${ }^{89}$ found a downregulation of Glo1 by Ang II in retinal vascular cells, and the downregulation of Glo1 was blocked by the angiotensin type 1 receptor blocker candesartan. This was one of the first indications that the RAAS and the AGE pathway are interconnected.

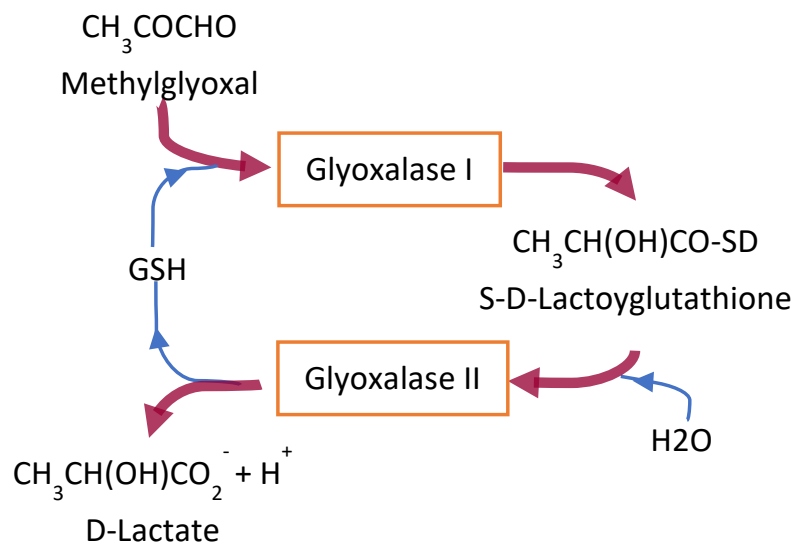

Figure 1.4. Metabolism of MGO by glyoxalase system 


\section{The interaction of RAAS and AGEs}

The RAAS, which is upregulated in diabetes ${ }^{90}$, plays a central role in the development of renal and cardiovascular diseases ${ }^{90}$. Blockade of the RAAS with the use of angiotensin receptor blockers (ARBs) is one of the most successful interventions to combat diabetic complications, as evidenced by the seminal publications of the IRMA-2 study ${ }^{91}$. In the IRMA-2 study irbesartan lowered albuminuria in individuals with type 2 diabetes mellitus (T2DM), and this effect occurred independently of blood pressure ${ }^{91}$.

Although an effect of the RAAS on AGE levels is largely unknown, Miller and coworkers have shown that Ang II increased the formation of AGEs, most likely caused by a Ang II-induced downregulation of Glo1 ${ }^{89}$, indicated an interaction of the RAAS with the AGE pathway. However, data about the effects of Ang II and ARBs on MGO levels is lacking. We have studied this in more detail and described the results in Chapter 7-9.

Accumulation of AGEs and activation of the RAAS are both implicated in diabetic vascular complications ${ }^{77,90}$. An interaction between the AGE/RAGE axis and the RAAS has been described in several in vitro systems. For example, in vascular smooth muscle cells, S100B-RAGE interaction augmented both Ang II-induced tyrosine phosphorylation of JAK2 and proliferation of vascular smooth muscle cell ${ }^{92}$. Several other in vitro studies have shown that the in vitro production of AGEs and dicarbonyl compounds and the AGE-induced activation of RAGE were attenuated by RAAS blockade ${ }^{92-94}$.

In accordance with in vitro studies, a study in rats demonstrated that Ang IIdependent renal injury was ameliorated by inhibition of AGE formation by ALT-946 and aminoguanidine (AG) ${ }^{95}$.

Ang II is an important vasoconstrictor and exerts multiple functional effects on endothelial cells, including excessive oxidative stress and vascular inflammation ${ }^{96}$. In diabetic retinopathy, Ang II mediates increases in RAGE and AGE-induced apoptosis of retinal pericytes ${ }^{97}$. Although the biological action of Ang II is mainly mediated by the AT1R, some studies have suggested a link between AT1R and RAGE receptor as an important signaling pathway in vascular smooth muscle cells and podocytes ${ }^{98,99}$. Recently, a direct crosstalk between the AT1R and RAGE has been shown ${ }^{100}$. Using a variety of mouse models, assay systems, and different RAGE domains the authors showed that RAGE and the AT1R form a heteromeric complex at the plasma membrane, which upon Ang II activation, induces NF-KB expression and the subsequent proinflammatory signaling events of RAAS. Thus, RAGE deletion prevented proinflammatory signaling events induced by AT1R activation. At the same time, RAGE deletion or inhibition did not affect blood pressure, natriuresis, or other homeostatic functions of the systemic RAAS ${ }^{100}$. 
The interactions between the AGE/RAGE pathway and RAAS may have important clinical implications and may provide further therapeutic targets. The possibility to develop novel therapeutics that are able to specifically target the adverse effects of RAGE transactivation by AT1R can be an effective mean to control diabetic vascular complications, atherosclerosis and other important inflammatory conditions in which RAGE is involved. 


\section{Outline of the thesis}

In the first part of the thesis, we investigated several aspects that regulate the biosynthesis of aldosterone in primary aldosteronism.

In chapter 2, we first assessed the role of epithelial mesenchymal transition in hypertensive kidney disease. In chapter 3 , we investigated the functional role of the AT2R in aldosterone producing adenomas and APA-adjacent tissues. In chapter 4, we investigated the effect of a macrolide antibiotic, clarithromycin on aldosterone synthesis in cells isolated ex-vivo from KCNJ5 mutated aldosterone producing adenomas. In chapter $\mathbf{5}$, we addressed the question whether GPERmediated mechanisms are involved in biosynthesis of aldosterone. In chapter $\mathbf{6}$, we investigated biological effects of AT1AA as derived from patients with aldosterone producing adenoma and studied whether the concentration of these AT1AA can be normalized after adrenalectomy.

In the second part, we studied the interactions between the AGE/RAGE pathway and RAAS.

Patients with APA are characterized by high titers agonistic autoantibodies against AT1AA. In chapter 7 , we made use of the study described in chapter 6 and assessed plasma levels of free and protein-bound AGEs and of MGO in patients with primary aldosteronism before and 1 month after adrenalectomy. In chapter 8, we studied the direct effect of Ang II on Glo1 in endothelial cells and in mice. Although previous studies have found that ARBs attenuate in vitro the production of AGEs and dicarbonyl compounds, it is unknown whether ARBs may reduce plasma levels of dicarbonyls in patients with type 2 diabetes. Therefore, we investigated in chapter 9 in a cohort of patients with type 2 diabetes the effects of the ARB irbesartan on circulating levels of dicarbonyls including MGO.

Finally, in chapter $\mathbf{1 0}$ we summarized the results and discussed all findings of this thesis and the implications of our findings for the field of endocrinology and cardiovascular disease. 


\section{References}

1. Ferrario CM, Strawn WB. Role of the Renin-Angiotensin-Aldosterone System and Proinflammatory Mediators in Cardiovascular Disease. Am J Cardiol. 2006;98(1):121-128. doi:10.1016/j.amjcard.2006.01.059

2. Busjahn A, Knoblauch $H$, Knoblauch $M$, et al. Angiotensin-Converting Enzyme and Angiotensinogen Gene Polymorphisms, Plasma Levels, Cardiac Dimensions: A Twin Study. Hypertension. 1997;29(1):165-170. doi:10.1161/01.HYP.29.1.165

3. Hackenthal E, Paul M, Ganten D, Taugner R. Morphology, physiology, and molecular biology of renin secretion. Physiol Rev. 1990;70(4):1067-1116. doi:10.1152/physrev.1990.70.4.1067

4. Wilkinson-Berka JL, Suphapimol V, Jerome JR, Deliyanti D, Allingham MJ. Angiotensin II and aldosterone in retinal vasculopathy and inflammation. Exp Eye Res. 2019;187:107766. doi:10.1016/j.exer.2019.107766

5. Seccia TM, Maniero C, Belloni AS, et al. Role of angiotensin II, endothelin-1 and L-type calcium channel in the development of glomerular, tubulointerstitial and perivascular fibrosis. J Hypertens. 2008;26(10):2022-2029. doi:10.1097/HJH.0b013e328309f00a

6. Bader M, Santos RA, Unger T, Steckelings UM. New therapeutic pathways in the RAS. JRAAS - $J$ Renin-Angiotensin-Aldosterone Syst. 2012;13(4):505-508. doi:10.1177/1470320312466519

7. Rompe F, Artuc M, Hallberg A, et al. Direct angiotensin II type 2 receptor stimulation acts antiinflammatory through epoxyeicosatrienoic acid and inhibition of nuclear factor kb. Hypertension. 2010;55(4):924-931. doi:10.1161/HYPERTENSIONAHA.109.147843

8. Patel VB, Zhong JC, Grant MB, Oudit GY. Role of the ACE2/angiotensin 1-7 axis of the reninangiotensin system in heart failure. Circ Res. 2016;118(8):1313-1326. doi:10.1161/CIRCRESAHA.116.307708

9. Nehme A, Zouein FA, Zayeri ZD, Zibara K. An Update on the Tissue Renin Angiotensin System and Its Role in Physiology and Pathology. J Cardiovasc Dev Dis. 2019;6(2):14. doi:10.3390/jcdd6020014

10. Gomez-Sanchez CE, Gomez-Sanchez EP. Immunohistochemistry of the adrenal in primary aldosteronism. Curr Opin Endocrinol Diabetes Obes. 2016;23(3):242-248. doi:10.1097/MED.0000000000000248

11. Nanba K, Vaidya A, Rainey WE. Aging and adrenal aldosterone production. Hypertension. 2018;71(2):218-223. doi:10.1161/HYPERTENSIONAHA.117.10391

12. Bollag WB. Regulation of aldosterone synthesis and secretion. Compr Physiol. 2014;4(3):10171055. doi:10.1002/cphy.c130037

13. Gordon H.Williams. Aldosterone Biosynthesis, Regulation, and Classical Mechanism of Action Gordon. Heart Fail Rev. 2005;10(1):7-13. doi:10.1007/s10741-005-2343-3

14. Briet M, Schiffrin EL. Vascular actions of aldosterone. J Vasc Res. 2013;50(2):89-99. doi:10.1159/000345243

15. Thomas W, Harvey B. Aldosterone Regulation of Protein Kinase Signaling Pathways and Renal $\mathrm{Na}+$ Transport by Non-genomic Mechanisms. In: Aldosterone-Mineralocorticoid Receptor - Cell Biology to Translational Medicine. IntechOpen; 2019. doi:10.5772/intechopen.87238

16. Good DW, George T, Watts III BA. Nongenomic regulation by aldosterone of the epithelial NHE3 $\mathrm{Na} / \mathrm{H}$ exchanger Downloaded from. Am J Physiol Cell Physiol. 2006;290:757-763. doi:10.1152/ajpcell.00391.2005.-The

17. Schmidt BMW, Sammer U, Fleischmann I, Schlaich M, Delles C, Schmieder RE. Rapid nongenomic effects of aldosterone on the renal vasculature in humans. Hypertension. 2006;47(4):650-655. doi:10.1161/01.HYP.0000205224.58715.cc

18. Lösel R, Schultz A, Boldyreff $B$, Wehling M. Rapid effects of aldosterone on vascular cells: clinical implications. Steroids. 2004;69(8-9):575-578. doi:10.1016/j.steroids.2004.05.005

19. Chai W, Garrelds IM, De Vries R, Batenburg WW, Van Kats JP, Danser AHJ. Nongenomic effects of aldosterone in the human heart: Interaction with Angiotensin II. Hypertension. 2005;46(4):701- 
706. doi:10.1161/01.HYP.0000182661.98259.4f

20. Briet M, Schiffrin EL. The role of aldosterone in the metabolic syndrome. Curr Hypertens Rep. 2011;13(2):163-172. doi:10.1007/s11906-011-0182-2

21. Rossi GP, Caroccia B, Seccia TM. Role of estrogen receptors in modulating aldosterone biosynthesis and blood pressure. Steroids. 2019;152:108486. doi:10.1016/j.steroids.2019.108486

22. Barton M. Position paper: The membrane estrogen receptor GPER - Clues and questions. Steroids. 2012;77(10):935-942. doi:10.1016/j.steroids.2012.04.001

23. Feldman RD, Limbird LE. Copernicus Revisited: Overturning Ptolemy's View of the GPER Universe. Trends Endocrinol Metab. 2015;26(11):592-594. doi:10.1016/j.tem.2015.09.002

24. Gros R, Ding Q, Sklar LA, et al. GPR30 expression is required for the mineralocorticoid receptorindependent rapid vascular effects of aldosterone. Hypertens . 2011;57(3):442-451. doi:10.1161/HYPERTENSIONAHA.110.161653

25. Gros R, Ding Q, Liu B, Chorazyczewski J, Feldman RD. Aldosterone mediates its rapid effects in vascular endothelial cells through GPER activation. Am J Physiol - Cell Physiol. 2013;304(6):C532-C540. doi:10.1152/ajpcell.00203.2012

26. Brailoiu GC, Benamar K, Arterburn JB, et al. Aldosterone increases cardiac vagal tone via G protein-coupled oestrogen receptor activation. $J$ Physiol. 2013;591(17):4223-4235. doi:10.1113/jphysiol.2013.257204

27. Williams B, Mancia G, Spiering W, et al. 2018 ESC/ESH Guidelines for the management of arterial hypertension. Eur Heart J. 2018;39(33):3021-3104. doi:10.1093/eurheartj/ehy339

28. Whelton PK, Carey RM, Aronow WS, et al. 2017 ACC/AHA/AAPA/ABC/ACPM/AGS/APhA/ ASH/ASPC/NMA/PCNA guideline for the prevention, detection, evaluation, and management of high blood pressure in adults a report of the American College of Cardiology/American Heart Association Task Force on Clinical practice guidelines. Hypertension. 2018;71(6):E13-E115. doi:10.1161/HYP.0000000000000065

29. Kearney MT, Whelton M, Reynolds K, Muntner P, He J. Global burden of hypertension WW data. Lancet. 2005;365:217-223. doi:10.1016/S0140-6736(05)17741-1

30. Bhatt DL, Gabriel Steg P, Magnus Ohman E, et al. International prevalence, recognition, and treatment of cardiovascular risk factors in outpatients with atherothrombosis. J Am Med Assoc. 2006;295(2):180-189. doi:10.1001/jama.295.2.180

31. Mancia G, Facchetti R, Bombelli M, et al. Relationship of office, home, and ambulatory blood pressure to blood glucose and lipid variables in the PAMELA population. Hypertens (Dallas, Tex 1979). 2005;45(6):1072-1077. doi:10.1161/01.HYP.0000165672.69176.ed

32. Syndrome CS, Conn J, Arbor A. Conn's Syndrome. Lancet. 1955;265(6875):1167. doi:10.1016/S0140-6736(55)90663-2

33. Rossi GP, Seccia TM, Pessina AC. Primary aldosteronism - Part I: Prevalence, screening, and selection of cases for adrenal vein sampling. J Nephrol. 2008;21(4):447-454.

34. Rossi GP, Bernini G, Caliumi C, et al. A prospective study of the prevalence of primary aldosteronism in 1,125 hypertensive patients. J Am Coll Cardiol. 2006;48(11):2293-2300. doi:10.1016/j.jacc.2006.07.059

35. Milliez P, Girerd X, Plouin PF, Blacher J, Safar ME, Mourad JJ. Evidence for an increased rate of cardiovascular events in patients with primary aldosteronism. J Am Coll Cardiol. 2005;45(8):12431248. doi:10.1016/j.jacc.2005.01.015

36. Funder JW, Carey RM, Mantero F, et al. The management of primary aldosteronism: Case detection, diagnosis, and treatment: An endocrine society clinical practice guideline. J Clin Endocrinol Metab. 2016;101(5):1889-1916. doi:10.1210/jc.2015-4061

37. Rossi GP, Auchus RJ, Brown M, et al. An expert consensus statement on use of adrenal vein sampling for the subtyping of primary aldosteronism. Hypertension. 2014;63(1):151-160. doi:10.1161/HYPERTENSIONAHA.113.02097

38. Lenzini L, Prisco S, Caroccia B, Rossi GP. Saga of familial hyperaldosteronism yet a new channel. Hypertension. 2018;71(6):1010-1014. doi:10.1161/HYPERTENSIONAHA.118.11150 
39. Sutherland DJ, Ruse JL, Laidlaw JC. Hypertension, increased aldosterone secretion and low plasma renin activity relieved by dexamethasone. Can Med Assoc J. 1966;95(22):1109-1119.

40. De Sousa K, Abdellatif A, El Zein R, Zennaro M-C. Molecular mechanisms in primary aldosteronism. J Mol Endocrinol. 2019;242(3):R67-R79. doi:10.1530/JOE-19-0193

41. Mulatero P, Monticone S, Rainey WE, Veglio F, Williams TA. Role of KCNJ5 in familial and sporadic primary aldosteronism. Nat Rev Endocrinol. 2013;9(2):104-112. doi:10.1038/nrendo.2012.230

42. Fernandes-Rosa FL, Daniil G, Orozco IJ, et al. A gain-of-function mutation in the CLCN2 chloride channel gene causes primary aldosteronism. Nat Genet. 2018;50(3):355-361. doi:10.1038/s41588-018-0053-8

43. Geller DS, Zhang J, Wisgerhof M V., Shackleton C, Kashgarian M, Lifton RP. A novel form of human mendelian hypertension featuring nonglucocorticoid- remediable aldosteronism. J Clin Endocrinol Metab. 2008;93(8):3117-3123. doi:10.1210/jc.2008-0594

44. Choi M, Scholl UI, Yue P, et al. K+ channel mutations in adrenal aldosterone-producing adenomas and hereditary hypertension. Science (80- ). 2011;331(6018):768-772. doi:10.1126/science. 1198785

45. Scholl UI, Stölting G, Nelson-Williams C, et al. Recurrent gain of function mutation in calcium channel CACNA1H causes early-onset hypertension with primary aldosteronism. Elife. 2015;4:e06315. doi:10.7554/eLife.06315

46. Rossi GP. Update in adrenal venous sampling for primary aldosteronism. Curr Opin Endocrinol Diabetes Obes. 2018;25(3):160-171. doi:10.1097/MED.0000000000000407

47. Seccia TM, Caroccia B, Gomez-Sanchez EP, Gomez-Sanchez CE, Rossi GP. The Biology of Normal Zona Glomerulosa and Aldosterone-Producing Adenoma: Pathological Implications. Endocr Rev. 2018;39(6):1029-1056. doi:10.1210/er.2018-00060

48. Lenzini L, Rossitto G, Maiolino G, Letizia C, Funder JW, Rossi GP. A meta-analysis of somatic KCNJ5 K+ channel mutations in 1636 patients with an aldosterone-producing adenoma. $J$ Clin Endocrinol Metab. 2015;100(8):E1089-E1095. doi:10.1210/jc.2015-2149

49. Beuschlein F, Boulkroun S, Osswald A, et al. Somatic mutations in ATP1A1 and ATP2B3 lead to aldosterone-producing adenomas and secondary hypertension. Nat Genet. 2013;45(4):440-444. doi:10.1038/ng.2550

50. Scholl UI, Goh G, Stölting G, et al. Somatic and germline CACNA1D calcium channel mutations in aldosterone-producing adenomas and primary aldosteronism. Nat Genet. 2013;45(9):1050-1054. doi:10.1038/ng.2695

51. Scholl UI, Abriola L, Zhang C, et al. Macrolides selectively inhibit mutant KCNJ5 potassium channels that cause aldosterone-producing adenoma. J Clin Invest. 2017;127(7):2739-2750. doi:10.1172/JCI91733

52. Rossitto G, Regolisti G, Rossi E, et al. Elevation of angiotensin-Il type-1-receptor autoantibodies titer in primary aldosteronism as a result of aldosterone-producing adenoma. Hypertension. 2013;61(2):526-533. doi:10.1161/HYPERTENSIONAHA.112.202945

53. Stirban A, Gawlowski T, Roden M. Vascular effects of advanced glycation endproducts: Clinical effects and molecular mechanisms. Mol Metab. 2014;3(2):94-108. doi:10.1016/j.molmet.2013.11.006

54. Hanssen NMJ, Scheijen JLJM, Jorsal A, et al. Higher Plasma Methylglyoxal Levels Are Associated With Incident Cardiovascular Disease in Individuals With Type 1 Diabetes: A 12-Year Follow-up Study. Diabetes. 2017;66(8):2278-2283. doi:10.2337/db16-1578

55. Hanssen NMJ, Westerink J, Scheijen JLJM, Van Der Graaf Y, Stehouwer CDA, Schalkwijk CG. Higher plasma methylglyoxal levels are associated with incident cardiovascular disease and mortality in individuals with type 2 diabetes. Diabetes Care. 2018;41(8):1689-1695. doi:10.2337/dc18-0159

56. Maillard LC. Action des acides aminés sur les sucres: Formation des mélanoidines par voie méthodique. Réaction de Maillard. C R Acad Sci. 1912;154:66-68. 
57. Zeng C, Li Y, Ma J, Niu L, Tay FR. Clinical/Translational Aspects of Advanced Glycation EndProducts. Trends Endocrinol Metab. 2019;30(12):959-973. doi:10.1016/j.tem.2019.08.005

58. Cerami C, Founds $\mathrm{H}$, Nicholl $\mathrm{I}$, et al. Tobacco smoke is a source of toxic reactive glycation products. Proc Natl Acad Sci U S A. 1997;94(25):13915-13920. doi:10.1073/pnas.94.25.13915

59. Scheijen JLJM, Hanssen NMJ, van Greevenbroek MM, et al. Dietary intake of advanced glycation endproducts is associated with higher levels of advanced glycation endproducts in plasma and urine: The CODAM study. Clin Nutr. 2018;37(3):919-925. doi:10.1016/j.clnu.2017.03.019

60. Schalkwijk C, Stehouwer CD. Methylglyoxal, a highly reactive dicarbonyl compound, in diabetes, its vascular complications and other age-related diseases. Physiol Rev. 2020;100(1):407-461. doi:10.1152/physrev.00001.2019

61. Thornalley PJ. Dicarbonyl Intermediates in the Maillard Reaction. Ann N Y Acad Sci. 2005;1043(1):111-117. doi:10.1196/annals.1333.014

62. Thornalley PJ, Langborg A, Minhas HS. Formation of glyoxal, methylglyoxal and 8deoxyglucosone in the glycation of proteins by glucose. Biochem J. 1999;344(1):109-116. doi:10.1042/0264-6021:3440109

63. Schalkwijk CG, Miyata T. Early- and advanced non-enzymatic glycation in diabetic vascular complications: the search for therapeutics. Amino Acids. 2012;42(4):1193-1204. doi:10.1007/s00726-010-0779-9

64. Goldin A, Beckman JA, Schmidt AM, Creager MA. Advanced glycation end products: Sparking the development of diabetic vascular injury. Circulation. 2006;114(6):597-605. doi:10.1161/CIRCULATIONAHA.106.621854

65. Kierdorf K, Fritz G. RAGE regulation and signaling in inflammation and beyond. $J$ Leukoc Biol. 2013;94(1):55-68. doi:10.1189/jlb.1012519

66. Tanji N, Markowitz GS, Fu C, et al. Expression of Advanced Glycation End Products and Their Cellular Receptor RAGE in Diabetic Nephropathy and Nondiabetic Renal Disease. J Am Soc Nephrol. 2000;11(9):1656-1666.

67. Yeh $\mathrm{CH}$, Sturgis $\mathrm{L}$, Haidacher J, et al. Requirement for $\mathrm{p} 38$ and $\mathrm{p} 44 / \mathrm{p} 42$ mitogen-activated protein kinases in RAGE-mediated nuclear factor-KB transcriptional activation and cytokine secretion. Diabetes. 2001;50(6):1495-1504. doi:10.2337/diabetes.50.6.1495

68. Yan SF, Ramasamy R, Naka Y, Schmidt AM. Glycation, inflammation, and RAGE: a scaffold for the macrovascular complications of diabetes and beyond. Circ Res. 2003;93(12):1159-1169. doi:10.1161/01.RES.0000103862.26506.3D

69. Wautier J-L, Schmidt AM. Protein glycation: a firm link to endothelial cell dysfunction. Circ Res. 2004;95(3):233-238. doi:10.1161/01.RES.0000137876.28454.64

70. Prasad K, Mishra M. AGE-RAGE Stress, Stressors, and Antistressors in Health and Disease. Int J Angiol. 2018;27(1):1-12. doi:10.1055/s-0037-1613678

71. Maessen DEM, Stehouwer CDA, Schalkwijk CG. The role of methylglyoxal and the glyoxalase system in diabetes and other age-related diseases. Clin Sci. 2015;128(12):839-861. doi:10.1042/CS20140683

72. Hanssen NMJ, Stehouwer CDA, Schalkwijk CG. Methylglyoxal and glyoxalase I in atherosclerosis. Biochem Soc Trans. 2014;42(2):443-449. doi:10.1042/BST20140001

73. Bose $T$, Bhattacherjee A, Banerjee S, Chakraborti AS. Methylglyoxal-induced modifications of hemoglobin: Structural and functional characteristics. Arch Biochem Biophys. 2013;529(2):99104. doi:10.1016/j.abb.2012.12.001

74. Morcos M, Du X, Pfisterer F, et al. Glyoxalase-1 prevents mitochondrial protein modification and enhances lifespan in Caenorhabditis elegans. Aging Cell. 2008;7(2):260-269. doi:10.1111/j.14749726.2008.00371.x

75. LEE HJ, HOWELL SK, SANFORD RJ, BEISSWENGER PJ. Methylglyoxal Can Modify GAPDH Activity and Structure. Ann N Y Acad Sci. 2005;1043(1):135-145. doi:10.1196/annals.1333.017

76. Galligan JJ, Wepy JA, Streeter MD, et al. Methylglyoxal-derived posttranslational arginine modifications are abundant histone marks. Proc Natl Acad Sci U S A. 2018;115(37):9228-9233. 
doi:10.1073/pnas.1802901115

77. Hanssen NMJ, Stehouwer CDA, Schalkwijk CG. Methylglyoxal stress, the glyoxalase system, and diabetic chronic kidney disease. Curr Opin Nephrol Hypertens. 2019;28(1):26-33. doi:10.1097/MNH.0000000000000465

78. Shinohara M, Thornalley PJ, Giardino I, et al. Overexpression of glyoxalase-I in bovine endothelial cells inhibits intracellular advanced glycation endproduct formation and prevents hyperglycemiainduced increases in macromolecular endocytosis. J Clin Invest. 1998;101(5):1142-1147. doi:10.1172/JCl119885

79. Ahmed U, Dobler D, Larkin SJ, Rabbani N, Thornalley PJ. Reversal of hyperglycemia-induced angiogenesis deficit of human endothelial cells by overexpression of glyoxalase 1 in vitro. In: Annals of the New York Academy of Sciences. Vol 1126. Blackwell Publishing Inc.; 2008:262-264. doi:10.1196/annals.1433.035

80. Brouwers O, Niessen PM, Ferreira I, et al. Overexpression of glyoxalase-I reduces hyperglycemiainduced levels of advanced glycation end products and oxidative stress in diabetic rats. J Biol Chem. 2011;286(2):1374-1380. doi:10.1074/jbc.M110.144097

81. Brouwers O, Niessen PM, Haenen G, et al. Hyperglycaemia-induced impairment of endotheliumdependent vasorelaxation in rat mesenteric arteries is mediated by intracellular methylglyoxal levels in a pathway dependent on oxidative stress. Diabetologia. 2010;53(5):989-1000. doi:10.1007/s00125-010-1677-0

82. Brouwers $\mathrm{O}$, Niessen PMG, Miyata $\mathrm{T}$, et al. Glyoxalase-1 overexpression reduces endothelial dysfunction and attenuates early renal impairment in a rat model of diabetes. Diabetologia. 2014;57(1):224-235. doi:10.1007/s00125-013-3088-5

83. Pagtalunan ME, Miller PL, Jumping-Eagle S, et al. Podocyte loss and progressive glomerular injury in type II diabetes. J Clin Invest. 1997;99(2):342-348. doi:10.1172/JCI119163

84. Giacco F, Du X, D'Agati VD, et al. Knockdown of glyoxalase 1 mimics diabetic nephropathy in nondiabetic mice. Diabetes. 2014;63(1):291-299. doi:10.2337/db13-0316

85. Stratmann B, Engelbrecht B, Espelage BC, et al. Glyoxalase 1-knockdown in human aortic endothelial cells - Effect on the proteome and endothelial function estimates. Sci Rep. 2016;6(1):1-16. doi:10.1038/srep37737

86. Gordin D, Shah H, Shinjo T, et al. Characterization of Glycolytic Enzymes and Pyruvate Kinase M2 in Type 1 and 2 Diabetic Nephropathy. Diabetes Care. 2019;42:1263-1273. doi:10.2337/dc182585

87. Hanssen NMJ, Wouters K, Huijberts MS, et al. Higher levels of advanced glycation endproducts in human carotid atherosclerotic plaques are associated with a rupture-prone phenotype. Eur Heart J. 2014;35(17):1137-1146. doi:10.1093/eurheartj/eht402

88. Mäkinen V-P, Civelek M, Meng Q, et al. Integrative Genomics Reveals Novel Molecular Pathways and Gene Networks for Coronary Artery Disease. Attie A, ed. PLoS Genet. 2014;10(7):e1004502. doi:10.1371/journal.pgen.1004502

89. Miller AG, Tan G, Binger KJ, et al. Candesartan attenuates diabetic retinal vascular pathology by restoring glyoxalase-I function. Diabetes. 2010;59(12):3208-3215. doi:10.2337/db10-0552

90. Volpe M. The Renin-Angiotensin System as a Risk Factor and Therapeutic Target for Cardiovascular and Renal Disease. J Am Soc Nephrol. 2002;13(Suppl 3):S173-S178. doi:10.1097/01.ASN.0000032549.36050.78

91. Parving HH, Lehnert $\mathrm{H}$, Bröchner-Mortensen J, et al. The effect of irbesartan on the development of diabetic nephropathy in patients with type 2 diabetes. N Engl J Med. 2001;345(12):870-878. doi:10.1056/NEJMoa011489

92. Huang J-S, Guh J-Y, Chen H-C, Hung W-C, Lai Y-H, Chuang L-Y. Role of receptor for advanced glycation end-product (RAGE) and the JAK/STAT-signaling pathway in AGE-induced collagen production in NRK-49F cells. J Cell Biochem. 2001;81(1):102-113. doi:10.1002/10974644(20010401)81:1<102::AID-JCB1027>3.0.CO;2-Y

93. Kamioka M, Ishibashi $\mathrm{T}$, Sugimoto $\mathrm{K}$, et al. Blockade of renin-angiotensin system attenuates 
advanced glycation end products-mediated signaling pathways. $J$ Atheroscler Thromb. 2010;17(6):590-600. doi:10.5551/jat.3624

94. Miyata T, Van Ypersele De Strihou C, Ueda Y, et al. Angiotensin II receptor antagonists and angiotensin-converting enzyme inhibitors lower in vitro the formation of advanced glycation end products: Biochemical mechanisms. J Am Soc Nephrol. 2002;13(10):2478-2487. doi:10.1097/01.ASN.0000032418.67267.F2

95. Wilkinson-Berka JL, Kelly DJ, Koerner SM, et al. ALT-946 and aminoguanidine, inhibitors of advanced glycation, improve severe nephropathy in the diabetic transgenic (mREN-2)27 rat. Diabetes. 2002;51(11):3283-3289. doi:10.2337/diabetes.51.11.3283

96. Mehta PK, Griendling KK. Angiotensin II cell signaling: Physiological and pathological effects in the cardiovascular system. Am J Physiol - Cell Physiol. 2007;292(1). doi:10.1152/ajpcell.00287.2006

97. Yamagishi SI, Takeuchi M, Matsui T, Nakamura K, Imaizumi T, Inoue H. Angiotensin II augments advanced glycation end product-induced pericyte apoptosis through RAGE overexpression. FEBS Lett. 2005;579(20):4265-4270. doi:10.1016/j.febslet.2005.06.058

98. Cheng $\mathrm{CL}$, Tang $\mathrm{Y}$, Zheng ZD, et al. Advanced glycation end-products activate the reninangiotensin system through the RAGE/PI3-K signaling pathway in podocytes. Clin Investig Med. 2012;35(5):E282-E293. doi:10.25011/cim.v35i5.18701

99. Ihara Y, Egashira K, Nakano K, et al. Upregulation of the ligand-RAGE pathway via the angiotensin II type I receptor is essential in the pathogenesis of diabetic atherosclerosis. $\mathrm{J} \mathrm{Mol}$ Cell Cardiol. 2007;43(4):455-464. doi:10.1016/j.yjmcc.2007.07.044

100. Pickering RJ, Tikellis C, Rosado CJ, et al. Transactivation of RAGE mediates angiotensin-induced inflammation and atherogenesis. J Clin Invest. 2019;129(1):406-421. doi:10.1172/JCI99987 
Chapter 1 
Part 1

ALDOSTERONE 



\section{Chapter 2}

The key role of epithelial to mesenchymal transition (EMT) in hypertensive kidney

disease

T.M. Seccia, B. Caroccia, M. Piazza and G.P. Rossi

Int. J. Mol. Sci. 2019,20, 356 


\begin{abstract}
Accumulating evidence indicates that epithelial to mesenchymal transition (EMT), originally described as a key process for organ development and metastasis budding in cancer, plays a key role in the development of renal fibrosis in several diseases, including hypertensive nephroangiosclerosis.

We herein reviewed the concept of EMT and its role in renal diseases, with particular focus on hypertensive kidney disease, the second leading cause of endstage renal disease after diabetes mellitus. After discussing the pathophysiology of hypertensive nephropathy, the 'classic' view of hypertensive nephrosclerosis entailing hyalinization and sclerosis of interlobular and afferent arterioles, we examined the changes occurring in the glomerulus and tubulo-interstitium and then the studies that investigated the role of EMT and its molecular mechanisms in the hypertensive kidney disease. Finally, we examined the reasons why some studies failed to provide solid evidences for renal EMT in hypertension.
\end{abstract}




\section{Introduction}

More than 20 million people have chronic kidney disease (CKD) in the US, with 3\% of them developing end-stage renal disease (ESRD) (https://www.usrds.org/adr.aspx), which accounts for $7 \%$ of the Medicare expenditures. In the EU, the last annual report of the European Renal Association - European Dialysis and Transplant Association (ERA-EDTA) Registry indicated that about 500 thousand people were on renal replacement therapy in $2018^{1}$. Moreover, the medical spending is held to be much greater, because ESRD patients are at high risk for cardio- and cerebrovascular vascular disease, and is projected to rise even more owing to population ageing in the next decades 2 . Arterial hypertension (HT), with a prevalence of $30-45 \%$ in the adult population, is the major cardiovascular risk factor and the second cause of ESRD after diabetes mellitus ${ }^{3,4}$. However, the relationship between the kidney and HT is doublethreaded in that nephropathies usually cause HT and high blood pressure damages the kidney 5 .

Even though classically described as nephroangiosclerosis and hyalinosis of the glomerular tuft 6,7 , hypertensive nephropathy has been more recently found to involve not only the glomerular and vascular compartments, but also the interstitium because of the development of tubular-interstitial fibrosis (TIF) and ultimately ESRD 8,9.

Depending on underlying pathophysiology and/or severity of $H T$, multiple mechanisms can concur to induce TIF, among which epithelial-to-mesenchymal transition (EMT), a process originally described in organ development and metastasis budding in cancer, and later observed in several diseases 10,11. Although potentially capable of affecting any injured epithelial tissue, whether and to what extent EMT plays role of in the kidney in hypertensive nephropathy remains unclear ${ }^{12-14}$.

Hence, we shall herein focus on the EMT process and its involvement in hypertensive nephropathy by exploiting a methodology to systematically review the English-written literature by means of a PICO search strategy (Table 2.1) with selection of the articles based on their relevance, rigorousness of study design and methodology, and appropriateness of data interpretation. 
Table 2.1. PICO strategy used for the literature search

\begin{tabular}{lcccc}
\hline Kew word & Operator & Kew word & Operator & Kew word \\
\hline Hypertension & OR & $\begin{array}{c}\text { High blood } \\
\text { pressure }\end{array}$ & \\
\hline Nephropathy & OR & AND & Tubular damage & OR \\
\hline $\begin{array}{l}\text { Epithelial-to- } \\
\text { mesenchymal } \\
\text { transition }\end{array}$ & OR & AND & & $\begin{array}{c}\text { Epithelial-to- } \\
\text { fibrosis }\end{array}$ \\
\hline
\end{tabular}

\section{Tubulointerstitial damage in hypertension}

In 1993 an involvement of tubule-interstitium in the hypertensive disease was postulated for the first time by Fine ${ }^{15}$, who put forward the 'chronic hypoxia hypothesis'. According to this contention, glomerular injury primarily determined by HT would induce hypoxia and endothelial damage of peritubular capillaries 15,16, thus stimulating tubular inflammation and fibrosis. Although appealing, this hypothesis remained unproven until one study showed peritubular capillaries rarefaction and tubulointerstitial scarring in human biopsies of CKD hypertensive patients ${ }^{17}$ and models of hypertensive disease documented an involvement of the interstitium in $\mathrm{HT}$ 8,9,18,19.

Fibroblasts are strategically posed in the interstitium to sense circulating toxins or factors and environmental changes and can be activated by local tissue injury to differentiate into myofibroblasts that synthesize extracellular matrix deposition and collagens. However, fibroblasts can act also as inflammatory effector cells: they express immune receptors as Toll-like receptors (TLRs) and activate NF-kB signaling with ensuing release of cytokines and chemokines that amplify kidney damage. In the hypertensive nephropathy, TIF usually associates with glomerular damage, loss of nephrons and decline in renal function. Nephrons are then focally replaced by fibrotic tissue along a scarring process finally leading to ESRD 20 . Thus, chronic and progressive tubular damage invariably leads to TIF.

Several factors can induce TIF. One of them is angiotensin II (Ang II), a major effector of the renin angiotensin aldosterone system (RAAS), which acts as a potent vasoconstricting and pro-inflammatory factor. Using a transgenic renindependent model of severe HT and cardiovascular and renal damage created with insertion of the mouse renin gene into the rat genome, the TG(mRen2)27 rat, we found that blockade of the Ang II type 1 (AT1) receptor with irbesartan, prevented TIF, thus supporting a fibrogenic role of Ang II ${ }^{8}$. Interestingly, in this model TIF was also prevented by bosentan, a mixed $E T_{A}-E T_{B}$ endothelin receptor antagonist, but worsened by BMS-182874, a selective $E T_{A}$ receptor antagonist, suggesting a key role of endothelin-1 (ET-1) acting via $E T_{B}$ receptor subtype in triggering renal fibrosis ${ }^{8}$. 
Of note, dual inhibition of ACE and of neutral endopeptidase also prevented TIF; moreover, this favorable effect was abolished by the bradykinin B2 receptor antagonist icatibant, thus implicating also the B2 subtype receptor in counterbalancing the deleterious effects of Ang II in the tubule-interstitium ${ }^{9}$.

Ang II can promote TIF not only by activating resident fibroblasts, but also by inducing proteinuria or EMT (see later "EMT in Hypertensive Nephropathy"). When hypertensive nephropathy is associated with proteinuria, filtered proteins are held to exert a further toxic effect on proximal tubular cells, which can amplify inflammation ${ }^{21}$. Pro-inflammatory factors as Monocyte Chemoattractant Protein-1 (MCP-1/CCL2), Regulated upon Activation Normal T-cell Expressed and Secreted (RANTES/CCL5), and fractalkine/CX3CL1, are chemoattractant for monocytes/macrophages and $T$ lymphocytes, which stimulate synthesis of transforming growth factor $\beta 1$ (TGF $\beta 1$ ), a potent fibroblast activator ${ }^{14}$.

\section{Epithelial to mesenchymal transition (EMT)}

Renal epithelial cells arise during embryogenesis by mesenchymal-to-epithelial transition (MET) ${ }^{22,23}$. For decades the dogma was that epithelial cells maintain its phenotype until death, but, after the seminal study by Gros in $2014{ }^{24}$, the concept that epithelial cells can switch back to a mesenchymal phenotype via epithelial-tomesenchymal transition (EMT) was promptly accepted ${ }^{25,26}$. First described in embryogenesis ${ }^{24}$, EMT was then observed in inflammation ${ }^{27}$, fibrosis ${ }^{28-30}$, wound healing ${ }^{31}$, and cancer progression ${ }^{32-34}$. Epithelia are characterized by apical-basal polarity and tight cell-cell junctions between neighboring cells, accounting for cell integrity and stability, whereas mesenchymal and interstitial tissues are formed by elongated and spindle-shaped cells, known as fibroblast-like cells, which have loose cell-cell interactions. Because of their mobility, these cells can migrate and create an anchorage distantly. The cells undergoing EMT progressively lose epithelial markers, such as E-cadherin, which is the main component of adherent junctions, and acquire markers of mesenchymal phenotype, such as a smooth muscle actin ( $(\mathrm{SSMA}){ }^{35}$. Loss of cell junctions allows epithelial cells to translate into loss of adhesion, change morphology, and loss apical-basal polarity. After synthesis of matrix metalloproteinases (MMPs), cells cleave and invade the basal lamina to move towards the interstitial space. Migration is driven by newly formed matrix of fibronectin and type I collagen. Upon completion of the epithelial-tomesenchymal phenotype switch, the cells acquire a myofibroblast phenotype synthesizing aSMA and matrix proteins, the major constituents of TIF ${ }^{35}$. A number of epithelial and mesenchymal markers have been used to track EMT, and a lot of factors have been identified as drivers of EMT. Not unexpectedly, most factors were also found to be involved in embryogenesis, tissue repair, and cancer, suggesting parallels between normal development and malignant growth. TGF $\beta$, a driver of EMT in cancer, is also the most potent factor triggering EMT in the renal 
cells. After the binding of TGF- $\beta$ to receptor II T $\beta R$-II, TGF- $\beta$-bound T $\beta R$-II phosphorylates type I receptor (T $\beta R-I)$ leads to the activation of Smad 2 and 3. Activated Smad2/3 can form a complex with Smad4, which translocates into the nucleus, where it interacts with transcriptional factors and transcriptional coactivators, ultimately inducing synthesis of mesenchymal proteins ${ }^{36-38}$.

\section{Markers of EMT}

In 1995, Strutz et al. detected S100A4 in tubular cells with persistent inflammation. Since S100A4 was considered a typical protein of mesenchymal cells and only seldom found in tubular cells of healthy kidneys, S100A4 was renamed fibroblastspecific protein-1 (FSP-1) and proposed to be a marker of cells undergoing EMT 39. However, other investigators were not able to localize FSP-1/S100A4 in activated fibroblasts, and found this protein in immune cells and occasionally in the endothelial cells. Hence, the specificity of FSP-1/S100A4 as a marker of EMT was challenged ${ }^{40,41}$.

Other markers of EMT have been later proposed. Vimentin is expressed in mesenchymal cells, but also in injured tubular cells and/or regenerating cells ${ }^{42-44}$, which led some investigators to consider it as a marker of EMT and other to propose it as a marker of tubular regenerating activity.

aSMA is characteristically expressed in mesenchymal cells, as vascular smooth muscle cells, pericytes, and interstitial cells around injured tubules and myofibroblasts ${ }^{45,46}$. In contrast, proximal tubular cells contain F-actin, a different isoform that constitutes cytoskeleton microfilaments and that cannot bind antibodies against aSMA. However, detection of aSMA cannot be used as a marker specific of EMT, because it cannot discriminate between mesenchymal cells physiologically present in the kidney or myofibroblasts.

The decrease or loss of markers of epithelial cells, as E-cadherin or ZO-1, is strongly suggestive of EMT, but could also denote tubular cell damage with no transition into mesenchymal cells.

Collagens and proteins that participate to collagen synthesis, as the collagenspecific molecular chaperone HSP 47 and prolyl-4-hydroxylase, have been also used as markers ${ }^{47}$.

Invasion of the basal membrane and cell migration are markers of fully completed EMT. Hence, different markers of EMT have been suggested, with some (loss of Ecadherin and ZO-1, synthesis of $\alpha$ SMA and vimentin) indicating the early phenotypic cell switch and others (collagens, matrix invasion) full transformation of epithelial cells into mesenchymal cells. However, because of the lack of specific markers of transforming cells, per se no marker can provide unambiguous demonstration of EMT. As discussed below, EMT is a dynamic and transient process difficult to be visualized. Only an integrated approach evaluating early and late steps can allow identification of EMT. 


\section{EMT as mediator of TIF}

Using a mouse model of severe renal fibrosis, i.e., unilateral ureteral obstruction, Yang and Liu first described EMT in the kidney as an orchestrated process consisting of the classical four steps, i.e., loss of epithelial cell adhesion, de novo synthesis of aSMA, disruption of tubular basement membrane, and cell migration and invasion ${ }^{48}$. In the same model, Iwano et al. found that up to $36 \%$ of interstitial matrix-producing cells derived from tubular cells through EMT ${ }^{35}$. However, using models characterized by less pronounced TIF, such as overload proteinuria ${ }^{48}$, other investigators found that the contribution of EMT was very scant, and, Humphreys et al. ${ }^{49}$, using the model of unilateral ureteral obstruction, were unable to reproduce data from Iwano ${ }^{35}$, suggesting that, although renal epithelial cells can acquire mesenchymal markers in vitro, they do not contribute to interstitial myofibroblast cells in vivo. Thus, whether EMT actually contributes to TIF in vivo in all types of nephropathies remains controversial ${ }^{50,51}$. According to a popular view, EMT would be a process by which epithelial cells under stress conditions escape from the unfriendly microenvironment ${ }^{52}$. After an injury, tubular epithelial cells express genes, such as Wnt, Notch, and Hedgehog, which confer resistance to apoptosis and are involved in normal development ${ }^{52}$. However, during physiologic development differentiated epithelial cells proliferate and in an injured kidney epithelial cells acquire partial or full mesenchymal characteristics, thereby preventing proliferation and replacement of damaged cells. Hence, tubular epithelial cells are not locked in a differentiated state, but are 'plastic cells' that transform into a different phenotype, but are unable to reach terminal differentiation 52. Two mechanisms have been proposed: (1) Differentiation of epithelial cells needs "turning off" of Wnt and Notch genes, a process that does not happen in damaged cells; (2) the over-expression of transcription factors, such as Twist, Zeb1, Zeb2, Snai1, and Snai2 favors, mesenchymal reprogramming, preventing terminal differentiation. Elegant studies by Kalluri's and Nieto's groups support such contentions: mice over-expressing Snai1 exhibited epithelial plasticity, myofibroblast accumulation, and inflammation, whereas an ablation of Twist and Snai1 induced expression of markers of differentiated cells, such as aquaporins and solute transporters ${ }^{29,30}$. In contrast to other strategies used by epithelial cells to avoid threatening conditions, such as apoptosis or necrosis, EMT is hardly identifiable because of the difficulty of catching exactly the time-point when cells transform into mesenchymal cells and pass the basement membrane ${ }^{51}$. Whether EMT is too rapid to be detected or visualization of EMT needs an integrated methodological approach remains a matter of debate.

\section{EMT in hypertensive nephropathy}

Several in vitro studies showed that some factors that induce HT, fibrosis, or both can also drive EMT, suggesting that EMT is a common mechanism underlying TIF 
13,53-55. However, only a few studies provided evidences of EMT in vivo in hypertensive nephropathy ${ }^{12,56,57}$. Ang II was found to induce EMT in cell culture models ${ }^{13,53-55,58}$. In the rat proximal tubular cell line (NRK52-E), EMT was identified as a morphological change of the epithelial cells from the typical cobblestone pattern to elongated, spindle-shaped mesenchymal cells, and also as a reduction in E-cadherin and synthesis of aSMA protein expression ${ }^{54}$. In a rat model of accelerated ESRD induced by a 14-day infusion of Ang II after preinjury by injection of Habu venom, Falkner et al. observed a progressive increase in aSMA staining, starting from $48 \mathrm{~h}$. However, peritubular interstitial myofibroblasts were also detected after 7 days of Ang II alone infusion, confirming capability of Ang II of inducing EMT ${ }^{50}$. It is important to note that a blockade of the AT1 receptor prevented EMT in models of $\mathrm{HT}$, caused by partial nephrectomy ${ }^{56}$ or unilateral ureteral obstruction ${ }^{57}$, supporting a role of Ang II in EMT. As mentioned above, we recently provided evidence that ET-1 can also induce EMT in the kidney ${ }^{12}$ : In the same kidney sections of TG(mRen2)27 rats, where we observed TIF, we found a decrease in the epithelial marker E-cadherin along with an increase in the mesenchymal markers aSMA and S100A4, i.e., phenotypic changes that indicated the occurrence of EMT. We also demonstrated co-expression of the epithelial with mesenchymal markers, thus strongly supporting EMT as the mechanism underlying fibrosis in this Ang-Il-dependent model of severe hypertension 12. Moreover, in vitro experiments confirmed that ET-1 can drive EMT in the proximal tubular cells ${ }^{12}$. Exposure of HK2 cells to ET-1 caused disruption of cell junctions and synthesis of aSMA, causing blunting of E-cadherin along with the increase of mesenchymal markers, synthesis of MMP-9, and cell migration ${ }^{12}$. All steps of EMT, such as TIF involved the ETB receptor subtype, which is the predominant receptor subtype in the kidney tubular cells (Figure 2.1) ${ }^{12}$. 


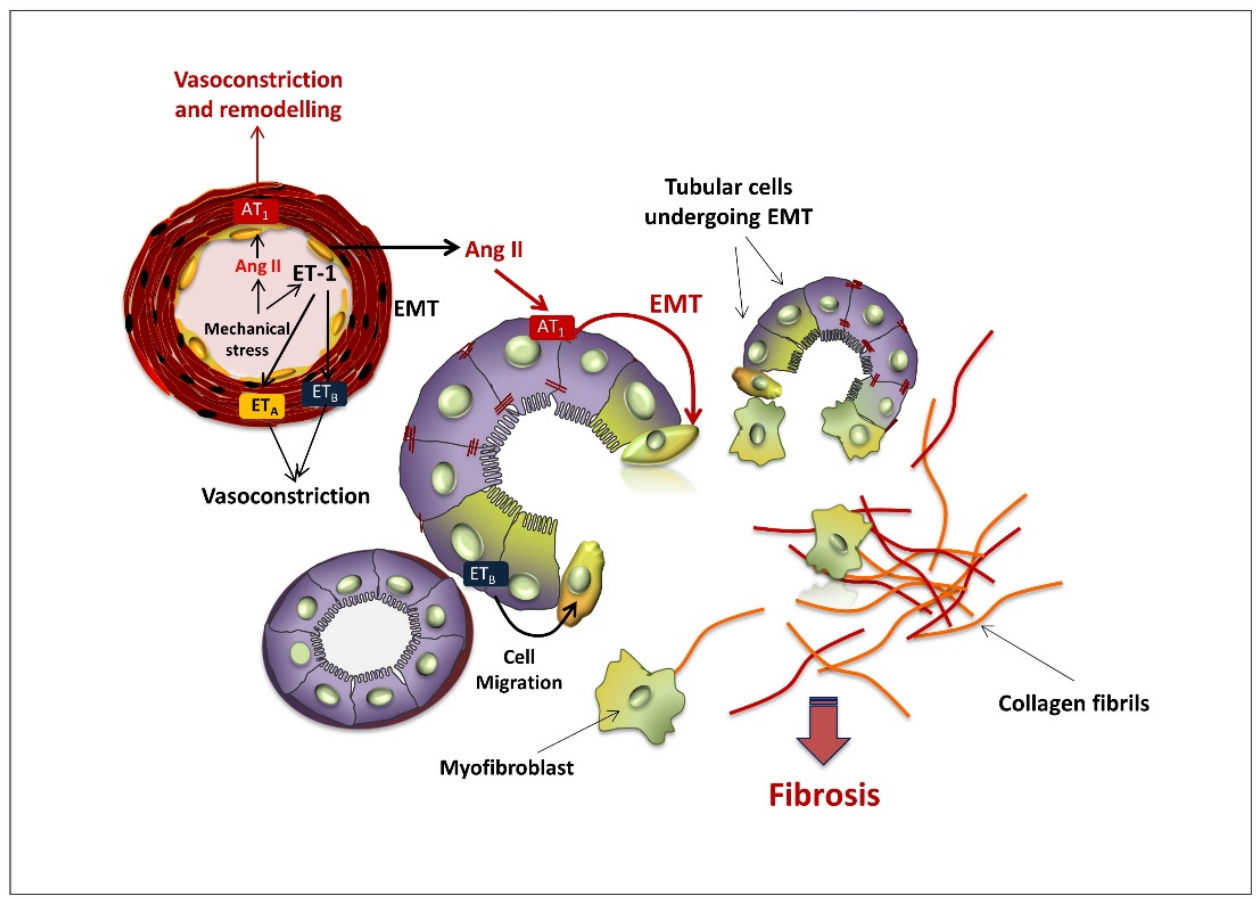

Figure 2.1. Development of tubule-interstitial damage in the hypertensive disease. When angiotensin II and/or endothelin-1 are abnormally produced, such as under conditions characterized by excess mechanical or oxidative stress, epithelial-to-mesenchymal transition (EMT) is triggered, leading to transformation of tubular cells into myofibroblasts that produce collagens. The final event is tubulointerstitial fibrosis. Angiotensin II (Ang II), by binding Ang II type 1 (AT1) receptors in the vascular smooth muscle cells, also favors vasoconstriction and vascular remodeling, worsening kidney damage. Vasoconstriction is also mediated by endothelin-1 via ETA and ETB receptors, located at the vascular smooth muscle cells.

\section{Conclusions}

In summary, EMT entails a dynamic sequential process characterized by progressive loss of epithelial markers and acquirement of a mesenchymal phenotype marker that is key to several physiological and pathological processes that need cell plasticity. Although evidences obtained in model of severe Ang IIdependent hypertension strongly support the contention that EMT contributes to TIF, which is the major determinant of ESRD, likely via the activation of the AT1 and ETB receptors, it remains debated if EMT contributes to TIF in other forms of nephropathy, which are characterized by less prominent TIF. 


\section{References}

1. Kramer A, Pippias M, Noordzij M, et al. The European Renal Association - European Dialysis and Transplant Association (ERA-EDTA) Registry Annual Report 2015: A summary. Clinical Kidney Journal. 2018;11(1):108-122. doi:10.1093/ckj/sfx149

2. Levey AS, Coresh J. Chronic kidney disease. Lancet (London, England). 2012;379(9811):165180. doi:10.1016/S0140-6736(11)60178-5

3. Williams B, Mancia G, Spiering W, et al. 2018 Practice Guidelines for the management of arterial hypertension of the European Society of Cardiology and the European Society of Hypertension. Journal of Hypertension. 2018;36(12):2284-2309. doi:10.1097/HJH.0000000000001961

4. Udani S, Lazich I, Bakris GL. Epidemiology of hypertensive kidney disease. Nature reviews Nephrology. 2011;7(1):11-21. doi:10.1038/nrneph.2010.154

5. Ritz E. The Kidney: both culprit and victim. Hypertension. 2009;54(1):25-26. doi:10.1161/HYPERTENSIONAHA.109.131607

6. Hill GS, Heudes D, Bariéty J. Morphometric study of arterioles and glomeruli in the aging kidney suggests focal loss of autoregulation. Kidney international. 2003;63(3):1027-1036. doi:10.1046/j.1523-1755.2003.00831.x

7. Hill GS. Hypertensive nephrosclerosis. Current opinion in nephrology and hypertension. 2008;17(3):266-270. doi:10.1097/MNH.0b013e3282f88a1f

8. Seccia TM, Maniero C, Belloni AS, et al. Role of angiotensin II, endothelin-1 and L-type calcium channel in the development of glomerular, tubulointerstitial and perivascular fibrosis. Journal of Hypertension. 2008;26(10):2022-2029. doi:10.1097/HJH.0b013e328309f00a

9. Seccia TM, Belloni AS, Guidolin D, et al. The renal antifibrotic effects of angiotensin-converting enzyme inhibition involve bradykinin B2 receptor activation in angiotensin II-dependent hypertension. Journal of Hypertension. 2006;24(7):1419-1427. doi:10.1097/01.hjh.0000234124.94013.ac

10. Ribatti D. Epithelial-mesenchymal transition in morphogenesis, cancer progression and angiogenesis. Experimental Cell Research. 2017;353(1):1-5. doi:10.1016/j.yexcr.2017.02.041

11. Piera-Velazquez S, Li Z, Jimenez SA. Role of endothelial-mesenchymal transition (EndoMT) in the pathogenesis of fibrotic disorders. American Journal of Pathology. 2011;179(3):1074-1080. doi:10.1016/j.ajpath.2011.06.001

12. Seccia TM, Caroccia B, Gioco F, et al. Endothelin-1 Drives Epithelial-Mesenchymal Transition in Hypertensive Nephroangiosclerosis. Journal of the American Heart Association. 2016;5(7). doi:10.1161/JAHA.116.003888

13. Carvajal G, Rodríguez-Vita J, Rodrigues-Díez R, et al. Angiotensin II activates the Smad pathway during epithelial mesenchymal transdifferentiation. Kidney International. 2008;74(5):585-595. doi:10.1038/ki.2008.213

14. Macconi D, Remuzzi G, Benigni A. Key fibrogenic mediators: Old players. Renin-angiotensin system. Kidney International Supplements. 2014;4(1):58-64. doi:10.1038/kisup.2014.11

15. Fine LG, Ong ACM. Mechanisms of tubulo-interstitial injury in progressive renal diseases. 1993;23(1993):259-265.

16. Fine LG, Norman JT. Chronic hypoxia as a mechanism of progression of chronic kidney diseases: from hypothesis to novel therapeutics. Kidney international. 2008;74(7):867-872. doi:10.1038/ki.2008.350

17. Choi YJ, Chakraborty S, Nguyen V, et al. Peritubular capillary loss is associated with chronic tubulointerstitial injury in human kidney: altered expression of vascular endothelial growth factor. Human pathology. 2000;31(12):1491-1497. doi:10.1053/hupa.2000.20373 
18. Gross O, Schulze-Lohoff E, Koepe ML, et al. Antifibrotic, nephroprotective potential of ACE inhibitors vs AT1 antagonist in a murine model of renal fibrosis. Nephrology Dialysis Transplantation. 2004;19(7):1716-1723. doi:10.1093/ndt/gfh219

19. Hartner A, Porst M, Klanke B, Cordasic N, Hilgers KF, Veelken R. Angiotensin II formation in the kidney and nephrosclerosis in Ren-2 hypertensive rats. Nephrology Dialysis Transplantation. 2006;21(7):1778-1785. doi:10.1093/ndt/gfl065

20. Kriz W, Kaissiing B, Le Hir M. Epithelial-mesenchymal transition (EMT) in kidney fibrosis : fact or fantasy? Journal of Clinical Investigation. 2011;121(2):468-474. doi:10.1172/JC144S95.468

21. Liu BC, Tang TT, Lv LL, Lan HY. Renal tubule injury: a driving force toward chronic kidney disease. Kidney International. 2018;93(3):568-579. doi:10.1016/j.kint.2017.09.033

22. Galichon P, Finianos S, Hertig A. EMT-MET in renal disease: Should we curb our enthusiasm? Cancer Letters. 2013;341(1):24-29. doi:10.1016/j.canlet.2013.04.018

23. Hay ED, Zuk A. Transformations between epithelium and mesenchyme: Normal, pathological, and experimentally induced. American Journal of Kidney Diseases. 1995;26(4):678-690. doi:10.1016/0272-6386(95)90610-X

24. Gros J, Tabin CJ. Vertebrate limb bud formation is initiated by localized epithelial-to-mesenchymal transition. Science (New York, NY). 2014;343(6176):1253-1256. doi:10.1126/science.1248228

25. Stark K, Vainio S, Vassileva G, McMahon AP. Epithelial transformation of metanephric mesenchyme in the developing kidney regulated by Wnt-4. Nature. 1994;372(6507):679-683. doi:10.1038/372679a0

26. Thiery JP, Acloque H, Huang RYJ, Nieto MA. Epithelial-mesenchymal transitions in development and disease. Cell. 2009;139(5):871-890. doi:10.1016/j.cell.2009.11.007

27. Neilson EG. Mechanisms of disease: Fibroblasts - A new look at an old problem. Nature Clinical Practice Nephrology. 2006;2(2):101-108. doi:10.1038/ncpneph0093

28. Strutz F, Neilson EG. New insights into mechanisms of fibrosis in immune renal injury. Springer Seminars in Immunopathology. 2003;24(4):459-476. doi:10.1007/s00281-003-0123-5

29. Lovisa S, LeBleu VS, Tampe B, et al. Epithelial-to-mesenchymal transition induces cell cycle arrest and parenchymal damage in renal fibrosis. Nature medicine. 2015;21(9):998-1009. doi:10.1038/nm.3902

30. Grande MT, Sánchez-Laorden B, López-Blau C, et al. Snail1-induced partial epithelial-tomesenchymal transition drives renal fibrosis in mice and can be targeted to reverse established disease. Nature medicine. 2015;21(9):989-997. doi:10.1038/nm.3901

31. Banerjee P, Venkatachalam S, Mamidi MK, Bhonde R, Shankar K, Pal R. Vitiligo patient-derived keratinocytes exhibit characteristics of normal wound healing via epithelial to mesenchymal transition. Experimental dermatology. 2015;24(5):391-393. doi:10.1111/exd.12671

32. Wei SC, Fattet L, Tsai JH, et al. Matrix stiffness drives epithelial-mesenchymal transition and tumour metastasis through a TWIST1-G3BP2 mechanotransduction pathway. Nature cell biology. 2015;17(5):678-688. doi:10.1038/ncb3157

33. Ruscetti M, Quach B, Dadashian EL, Mulholland DJ, Wu H. Tracking and Functional Characterization of Epithelial-Mesenchymal Transition and Mesenchymal Tumor Cells during Prostate Cancer Metastasis. Cancer research. 2015;75(13):2749-2759. doi:10.1158/00085472.CAN-14-3476

34. Chen T, You Y, Jiang H, Wang ZZ. Epithelial-mesenchymal transition (EMT): A biological process in the development, stem cell differentiation, and tumorigenesis. Journal of Cellular Physiology. 2017;232(12):3261-3272. doi:10.1002/jcp.25797

35. Iwano M, Plieth D, Danoff TM, Xue C, Okada H, Neilson EG. Evidence that fibroblasts derive from epithelium during tissue fibrosis. The Journal of clinical investigation. 2002;110(3):341-350. 
doi:10.1172/JCl15518

36. Saitoh M, Miyazawa K. Transcriptional and Post-transcriptional Regulation in TGF- -mediated epithelial-mesenchymal transition. Journal of Biochemistry. 2012;151(6):563-571. doi: $10.1093 / \mathrm{jb} / \mathrm{mvs} 040$

37. Griggs LA, Hassan NT, Malik RS, et al. Fibronectin fibrils regulate TGF- $\beta 1$-induced EpithelialMesenchymal Transition. Matrix Biology. 2017;60-61:157-175. doi:10.1016/j.matbio.2017.01.001

38. Hewitson TD, Holt SG, Tan S-J, Wigg B, Samuel CS, Smith ER. Epigenetic Modifications to H3K9 in Renal Tubulointerstitial Cells after Unilateral Ureteric Obstruction and TGF- $\beta 1$ Stimulation. Frontiers in Pharmacology. 2017;8(MAY):307. doi:10.3389/fphar.2017.00307

39. Strutz F, Okada H, Lo CW, et al. Identification and characterization of a fibroblast marker: FSP1. The Journal of cell biology. 1995;130(2):393-405.

40. Inoue $\mathrm{T}$, Plieth $\mathrm{D}$, Venkov $\mathrm{CD}, \mathrm{Xu} \mathrm{C}$, Neilson EG. Antibodies against macrophages that overlap in specificity with fibroblasts. Kidney international. 2005;67(6):2488-2493. doi:10.1111/j.15231755.2005.00358.x

41. Le Hir M, Hegyi I, Cueni-Loffing D, Loffing J, Kaissling B. Characterization of renal interstitial fibroblast-specific protein 1/S100A4-positive cells in healthy and inflamed rodent kidneys. Histochemistry and cell biology. 2005;123(4-5):335-346. doi:10.1007/s00418-005-0788-z

42. Zhu MQ, De Broe ME, Nouwen EJ. Vimentin expression and distal tubular damage in the rat kidney. Experimental nephrology. 4(3):172-183.

43. Witzgall R, Brown D, Schwarz C, Bonventre J V. Localization of proliferating cell nuclear antigen, vimentin, c-Fos, and clusterin in the postischemic kidney. Evidence for a heterogenous genetic response among nephron segments, and a large pool of mitotically active and dedifferentiated cells. The Journal of clinical investigation. 1994;93(5):2175-2788. doi:10.1172/JCl117214

44. Gröne HJ, Weber K, Gröne E, Helmchen U, Osborn M. Coexpression of keratin and vimentin in damaged and regenerating tubular epithelia of the kidney. The American journal of pathology. 1987;129(1):1-8.

45. Skalli O, Pelte MF, Peclet MC, et al. Alpha-smooth muscle actin, a differentiation marker of smooth muscle cells, is present in microfilamentous bundles of pericytes. The journal of histochemistry and cytochemistry : official journal of the Histochemistry Society. 1989;37(3):315321. doi:10.1177/37.3.2918221

46. Gabbiani G, Schmid E, Winter S, et al. Vascular smooth muscle cells differ from other smooth muscle cells: predominance of vimentin filaments and a specific alpha-type actin. Proceedings of the National Academy of Sciences of the United States of America. 1981;78(1):298-302.

47. Cheng S, Pollock AS, Mahimkar R, Olson JL, Lovett DH. Matrix metalloproteinase 2 and basement membrane integrity: a unifying mechanism for progressive renal injury. FASEB journal : official publication of the Federation of American Societies for Experimental Biology. 2006;20(11):1898-1900. doi:10.1096/fj.06-5898fje

48. Yang J, Liu Y. Dissection of Key Events in Tubular Epithelial to Myofibroblast Transition and Its Implications in Renal Interstitial Fibrosis. The American Journal of Pathology. 2001;159(4):14651475. doi:10.1016/S0002-9440(10)62533-3

49. Humphreys BD, Lin S-L, Kobayashi A, et al. Fate tracing reveals the pericyte and not epithelial origin of myofibroblasts in kidney fibrosis. The American journal of pathology. 2010;176(1):85-97. doi:10.2353/ajpath.2010.090517

50. Faulkner JL, Szcykalski LM, Springer F, Barnes JL. Origin of interstitial fibroblasts in an accelerated model of angiotensin II-induced renal fibrosis. The American journal of pathology. 2005;167(5):1193-1205. doi:10.1016/S0002-9440(10)61208-4

51. Zhu C, Mertens PR. Epithelial-mesenchymal transition to be or not to be? Is the answer yes and 
no at the same time? International Urology and Nephrology. 2010;42(3):843-846. doi:10.1007/s11255-010-9730-y

52. Huang S, Susztak K. Epithelial Plasticity versus EMT in Kidney Fibrosis. Trends in Molecular Medicine. 2016;22(1):4-6. doi:10.1016/j.molmed.2015.11.009

53. Chen L, Liu B-C, Zhang X-L, Zhang J-D, Liu H, Li M-X. Influence of connective tissue growth factor antisense oligonucleotide on angiotensin II-induced epithelial mesenchymal transition in HK2 cells. Acta pharmacologica Sinica. 2006;27(8):1029-1036. doi:10.1111/j.17457254.2006.00344.x

54. Burns WC, Thomas MC. Angiotensin II and its role in tubular epithelial to mesenchymal transition associated with chronic kidney disease. Cells Tissues Organs. 2010;193(1-2):74-84. doi:10.1159/000320359

55. Rodrigues-Díez R, Carvajal-González G, Sánchez-López E, et al. Pharmacological modulation of epithelial mesenchymal transition caused by angiotensin II. Role of ROCK and MAPK pathways. Pharmaceutical research. 2008;25(10):2447-2461. doi:10.1007/s11095-008-9636-x

56. Yang F, Huang XR, Chung AC, Hou C-C, Lai KN, Lan HY. Essential role for Smad3 in angiotensin II-induced tubular epithelial-mesenchymal transition. The Journal of Pathology. 2010;221(4):n/an/a. doi:10.1002/path.2721

57. Kellner D, Chen J, Richardson I, et al. Angiotensin Receptor Blockade Decreases Fibrosis and Fibroblast Expression in a Rat Model of Unilateral Ureteral Obstruction. Journal of Urology. 2006;176(2):806-812. doi:10.1016/j.juro.2006.03.076

58. Hu H, Hu S, Xu S, Gao Y, Zeng F, Shui H. MiR-29b regulates Ang II-induced EMT of rat renal tubular epithelial cells via targeting PI3K/AKT signaling pathway. International Journal of Molecular Medicine. 2018;42(1):453-460. doi:10.3892/ijmm.2018.3579 
Chapter 2 


\section{Chapter 3}

The angiotensin type 2 receptor in the human adrenocortical zona glomerulosa and in aldosterone-producing adenoma: low expression and no functional role

P.E. Vanderriele, B. Caroccia, T.M. Seccia, M. Piazza, L. Lenzini,

F. Torresan, M. lacobone, T. Unger and G.P Rossi

Clinical Science 2018, 132 627-640 


\section{Abstract}

The angiotensin II (Ang II) type 2 receptor (AT2R) and the angiotensin-(1-7) (Ang(1-7)) receptor (MasR) play a cardiovascular protective role by counter-regulating Ang II type 1 receptor (AT1R)-mediated effects, but whether this involves blunting of adrenocortical hormone secretion is unknown. We investigated the presence of AT1R, AT2R, and MasR in aldosterone-producing adenoma (APA), a condition featuring hyperaldosteronism, and in APA-adjacent tissue. The effect of Compound 21 (C21), an AT2R agonist, on CYP11B1 (cortisol synthase) and CYP11B2 (aldosterone synthase) gene expression in $\mathrm{NCl}-\mathrm{H} 295 \mathrm{R}$ and $\mathrm{HAC} 15$ cell lines, and in APA and APA-adjacent tissue, was also assessed using the AT1R antagonist irbesartan to ascertain the specificity of C21 effect. We found that the AT1R, AT2R, and MasR were expressed in APA and APA-adjacent tissue, albeit heterogeneously.

The gene expression of AT1R and AT2R was lower, and that of the MasR higher in APAs than in APA-adjacent tissue. In steroid-producing NCl-H295R and HAC15 cell lines, and in APA and APA-adjacent tissue, C21 was ineffective at nanomolar concentrations, but increased CYP11B1 and CYP11B2 gene expression at micromolar concentrations through AT1R, as this effect was blunted by irbesartan. The scant expression of the AT2R, along with the lack of any effect of C21 at low concentrations on CYP11B2, do not support the contention that the protective arm of renin-angiotensin system (RAS) blunts aldosterone synthase in the normal adrenal cortex and primary aldosteronism 


\section{Introduction}

The biosynthesis of aldosterone, the main mineralocorticoid hormone in the adrenocortical zonaglomerulosa ${ }^{1,2}$ is tightly controlled by multiple factors, as angiotensin II (Ang II) ${ }^{3}$, potassium $\left(\mathrm{K}+\right.$ ), endothelin-1 ${ }^{4,5}$, vasopressin ${ }^{6,7}$, urotensin II 8,9 , and circulating adrenocorticotrophic hormone (ACTH) ${ }^{3}$. Inappropriate aldosterone production results in several pathological conditions featuring $\mathrm{Na}^{+}$and water retention, as heart failure, high renin forms of arterial hypertension and primary aldosteronism ${ }^{10,11}$, the most common form of secondary hypertension.

Amongst the aldosterone regulators, Ang II is held to act through the Ang II type 1 receptor (AT1R) ${ }^{12,13}$; a role of the Ang II type 2 receptor (AT2R) is suggested by some data in animals 14,15 , but is unknown in humans. The AT2R expression is high in the fetus ${ }^{16,17}$, but falls markedly after birth, being restricted to few organs and tissues in adults ${ }^{18}$; moreover, its role remained undefined, until the first nonpeptide AT2R agonist Compound 21 (C21) was developed ${ }^{19}$. In animal models $\mathrm{C} 21$ induced vasodilatation, inhibition of cell proliferation, inflammation and fibrosis. It also caused axonal regeneration and prevention of cancer ${ }^{20-22}$, suggesting that AT2R activation can be useful for treatment of hypertension, cardiovascular diseases and other conditions.

The existence of a 'protective arm' of the renin-angiotensin system (RAS) has also been supported by identification of the angiotensin-(1-7) (Ang-(1-7)), itsMas receptor (Ang-(1-7) receptor (MasR)) ${ }^{23,24}$, the alamandine receptor (Mas-related G-coupled receptor type $D(M r g D))$, and the Ang-(1-7) generating enzyme angiotensin-converting enzyme (ACE)-2 (ACE2) ${ }^{25,26}$. By binding to MasR, Ang-(17) was shown to exert beneficial actions in experimental heart failure and in AT1Rmediated inflammation, to improve endothelial function in atherosclerosis, and to inhibit lung cancer growth in vitro (for review ${ }^{27,28}$ ). Even less known is the role of alamandine, a furtherMasR, although studies in spontaneously hypertensive rats suggested that it might also play a protective role ${ }^{29}$ in that a single dose of the alamandine/ $\beta$-hydroxypropylcyclodextrin compound induced a long-lasting blood pressure lowering effect ${ }^{30}$.

Thus, accumulating evidence indicates that the so-called 'protective pathway' of the RAS may act by counteracting the effects to the canonical RAS, composed of ACE, AT1R, and Ang II. Notwithstanding this, little is known about its presence and role in the human adrenal cortex. Thus, given the key role of aldosterone in cardiovascular disease, we sought to ascertain the expression of AT1R, AT2R, MasR, and MrgD and the functional role of $A T 2 R$ in aldosterone-producing adenoma (APA) and APA-adjacent tissue. 


\section{Materials and methods}

\section{Cells}

The polyclonal $\mathrm{NCl}-\mathrm{H} 295 \mathrm{R}$ and clonalHAC15 cell lines, the latter derived fromH295R, were used as in vitro models for steroid synthesis ${ }^{31}$. NCl-H295Rwere grown in Roswell Park Memorial Institute (RPMI)medium supplemented with $10 \%$ FBS, $1 \%$ glutamine, and $1 \%$ antibiotic/antimycotic mixture. HAC15 were grown in Dulbecco's modified Eagle's medium F12 supplemented with $10 \%$ cosmic calf serum, $1 \%$ glutamine, and $1 \%$ antibiotic/antimycotic mixture.

Cells were seeded in 12-well plates at $2 \times 105$ cells per well and grown to subconfluence $(80 \%)$. Before treatment, cells were starved for $24 \mathrm{~h}$ with RPMI/Dulbecco's modified Eagle's medium F12 medium supplemented with $0.5 \%$ FBS/cosmic calf serum, $1 \%$ glutamine, and $1 \%$ antibiotic/antimycotic. This medium was also used for cell stimulation. After starvation, the cells were treated with a stimulus alone and/or with selective antagonists for $12 \mathrm{~h}$. Experiments were also performed by adding receptor antagonists in fresh medium 30 min before stimulation. C21 (kindly provided by Vicore Pharma) and irbesartan (from SigmaAldrich) were used as AT2R agonist and AT1R antagonist, respectively.

\section{Tissues}

APA ( $n=14)$ tissue and APA-adjacent tissue $(n=7)$, used as control, were obtained from our own tumor bank from patients with a conclusive diagnosis of APA following the four corner criteria ${ }^{32-34}$. All tissues were collected under sterile conditions in the operating room immediately after excision. Small pieces were frozen and stored in liquid nitrogen. The creation of the biobank of human adrenal tissues was approved by the Ethics Committee; informed consent was obtained from each patient.

For in vitro studies, adrenocortical specimens were cut into 20-mg strips which were put in 24-well plates, starved with Dulbecco's modified Eagle's medium F12 supplemented with $0.5 \%$ FBS for $6 \mathrm{~h}$, and then treated with C21 alone and/or with selective antagonists for $12 \mathrm{~h}$.

\section{Immunomagnetic isolation of $\mathrm{CD}^{2} 6^{+}$cells}

APA cells were obtained by sequential enzymatic digestion and mechanical disaggregation of tissues from three patients. We used immunoseparation of $\mathrm{CD} 6^{+}$cells on magnetic beads precoated with an antibody specific for neural cell adhesion molecule (NCAM-CD56) to obtain a pure population of aldosteronesecreting cells from the APA-adjacent tissue human zona glomerulosa, as previously reported in detail ${ }^{35}$. 


\section{RNA extraction and quantitative real-time PCR}

RNA from cells was extracted with the Roche RNeasy kit (Roche), and RNA from tissue with Qiagen RNA extraction kit (Qiagen) following the manufacturer's protocol. The integrity and quality of total RNA, extracted with the RNeasy Mini kit (Qiagen), was systematically checked with a laboratory-on-chip technology in an Agilent Bioanalyzer 2100 with the RNA 6000 Nano Assay (Agilent Technologies). One microgram total RNA from cells, and $300 \mathrm{ng}$ total RNA from tissues, were reverse transcribed with Iscript (Bio-Rad) in a final volume of $20 \mu \mathrm{l}$ and following the manufacturer's recommendations. The RT-PCR reactions were performed in Delphi 1000TM Thermal Cycler (Oracle Biosystems).

For quantitation of the angiotensin receptor genes, the gene expression of AT1R, AT2R, MasR, MrgD were measured in APA-adjacent tissue, APA, and CD56 ${ }^{+}$cells by real-time RT-PCR with Universal ProbeLibrary Probes (Roche) in the LightCycler 480 Instrument (Roche). For quantitation of the angiotensin receptors' genes, the ratio of target gene $(A T 1 R, A T 2 R, M a s R)$ and the housekeeping gene porphobilinogen-deaminase $(P B G D), C t$ was used by applying the Advance Relative Quantification Analysis by the LightCycler 480 software.

In NCl-H295R and HAC15 cells, the relative expression levels of aldosterone synthase (CYP11B2), cortisol synthase (CYP11B1) mRNA were measured with real time RT-PCR. Primers and probes (Universal ProbeLibrary, Roche) for the amplification of the genes of interest were designed using ProbeFinder Software (Roche). Sequences are shown in Supplementary Table S3.1. After treatment, CYP11B2 and CYP11B1 gene expression were calculated by the comparative $C t$ $\left(2^{-\Delta \Delta C t}\right)$ method ${ }^{36}$ : each sample was quantitated against PBGD and normalized to the control group. Each experiment was repeated at least three times in duplicate, and the results are presented as mean percentage fold increase \pm S.D. Standard curves were generated for all the primers by serial dilutions of RT products spanning four orders of magnitude, yielding a PCR efficiency close to two for each reaction.

\section{Immunoblotting}

Immunoblotting for AT1R, AT2R, and MasR was performed following a standard protocol. In brief, cells were homogenized in lysis buffer (Thermo Scientific) and protein concentration was determined in the soluble supernatant with BCA assay (Thermo Scientific). Lysate fraction $(50 \mu \mathrm{g})$ was separated in a polyacrylamide gel and then electro blotted on to nitrocellulose or PVDF membrane (Hybond ECLAmersham Biosciences, Europe). The membranes were blocked for $30 \mathrm{~min}$ at room temperature in 5\% non-fat dry blocking milk or with 5\% BSA and thereafter incubated overnight at $4 \circ \mathrm{C}$ with a primary rabbit monoclonal antibody against human AT1R (diluted 1:1000, Abgent), 
AT2R (diluted 1:500, Novus Biologicals), MasR (diluted 1:1000, Novus Biologicals). After washing, the membrane was incubated for $1 \mathrm{~h}$ with an anti-rabbit secondary antibody. Then, band intensity was measured with VersaDoc Imaging System (Bio-Rad).

Protein samples were obtained from APA tissues $(n=6)$ and the APA-adjacent tissue $(n=6)$. Images were analyzed by Image Processing and Analysis in Java (ImageJ, NIH). Bands for AT1R, AT2R, and MasR were normalized to glyceraldehyde 3-phosphate dehydrogenase (GAPDH).

\section{Immunohistochemistry}

Paraffin-embedded adrenal glands were cut at $5 \mu \mathrm{m}$, and the sections dried and then melted at $56{ }^{\circ} \mathrm{C}$ for at least $3 \mathrm{~h}$. After deparaffination through alcohols, antigen retrieval was performed for $15 \mathrm{~min}$ at $121^{\circ} \mathrm{C}$ in autoclave followed by treatment with $0.5 \% \mathrm{H} 2 \mathrm{O} 2$ for $20 \mathrm{~min}$ to inhibit endogenous peroxidases. Slides were blocked with PBS, $0.3 \%$ Tween, and $5 \%$ goat serum for $1 \mathrm{~h}$ and then incubated overnight at $4 \circ \mathrm{C}$ with antibodies against angiotensin receptors (1:200 AT1R and 1:150MasR). Antigen was detected by incubation with a secondary antibody labeled with horseradish peroxidase and diaminobenzidine; sections were counterstained with Hematoxylin, dehydrated, cleared, and mounted. The negative control was immunostained only with secondary antibody.

\section{Statistical analysis}

Values are reported as mean and S.D., or median and minimum and maximum of data, as appropriate. Quantitative data were analyzed after verification of normal distribution. Non-parametric Mann-Whitney test or one-way ANOVA test were used, as appropriate. Statistical analysis was performed with GraphPad SoftwareTM (version 6 for Mac OS X, La Jolla, CA).

\section{Results}

\section{Angiotensin receptors in human adrenal tissue}

The relative amounts of $A T 1 R, A T 2 R, M a s R$, and $M r g D$ mRNA were investigated by real-time RT-PCR in APA and the APA-adjacent tissue, and in $\mathrm{CD} 56^{+}$cells, i.e. a pure population of aldosterone-producing cells obtained from APA. In the APAadjacent tissue and in APA, AT1R was the most expressed angiotensin receptor subtype, whereas $A T 2 R$ and MasR were expressed at low levels (Figure 3.1A). Both $A T 1 R$ and $A T 2 R$ mRNA were more abundant in APA-adjacent tissue than in APA (Figure 3.1B). At variance, MasR showed the highest expression levels in the APA tissue (Figure 3.1B). All angiotensin receptors were expressed in APA CD56 ${ }^{+}$ cells $(n=3)$, albeit in varying amounts. RT-PCR showed high expression of AT1R in APA CD56 cells and very low levels of AT2R and MasR (ratio of PBGD to AT1R: 
$1.158 \pm 0.25$, AT2R: $0.0036 \pm 0.0007$, MasR: $0.0047 \pm 0.0001)$. The MrgD was detected in both APA-adjacent tissue and APA, even though at low levels $(\sim 200-$ times lower than AT1R levels), but not in $\mathrm{CD}^{+} 6^{+} \mathrm{APA}$ cells.

A

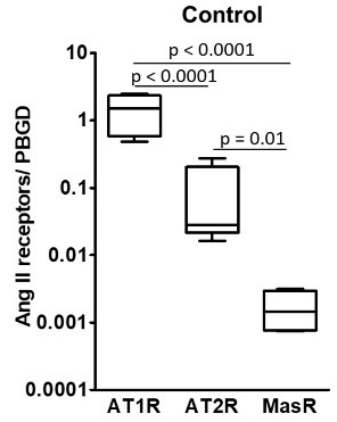

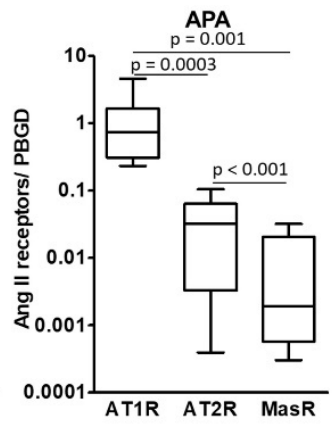

B

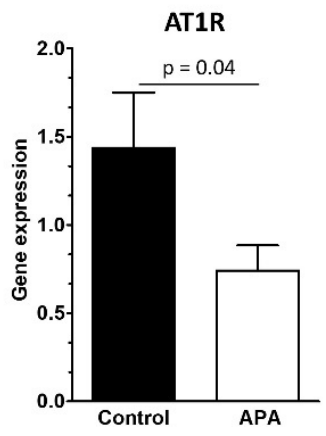

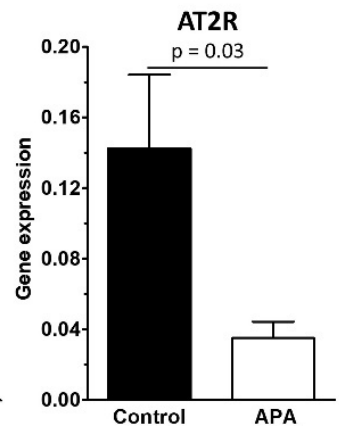

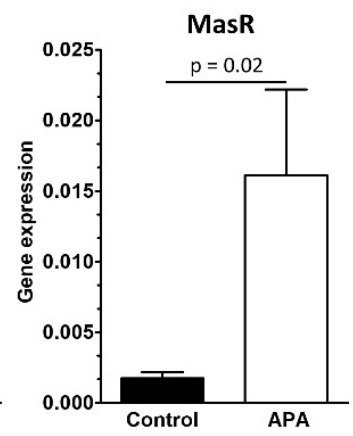

Figure 3.1. Gene expression of angiotensin receptors in human adrenal tissue.

(A) Relative amount of the different angiotensin receptors (AT1R, AT2R, MasR) in APA $(n=14)$ and in control $(n=7)$. Control: APA-adjacent tissues. (B) AT1R, AT2R, and MasR expression levels between APA samples and control. Expression is measured as the ratio of $\mathrm{Ct}$ of target gene (angiotensin receptors) and housekeeping gene (PBGD) Ct (median and minimum and maximum of data). Control: APA-adjacent tissues.

Immunoblotting confirmed that AT1R was the predominant subtype angiotensin receptor subtype in APA-adjacent tissue and APA tissues, whereas MasR protein expression was detectable at low levels in both tissues (Figure 3.2A). Immunohistochemistry was used to localize AT1R and MasR receptors in APAadjacent tissue and APA. This showed that AT1R staining was much stronger in zona glomerulosa layer than in zona fasciculata of the APA-adjacent tissue (Figure 3.2B), mostly in the cytoplasm and occasionally in the cell membrane. In contrast, a diffused immunostaining for MasR was observed in the APA-adjacent tissue without differences between the adrenal layers. In the APAs, the immunostaining signal pertaining to AT1R was stronger than that for MasR (Figure 3.2B). We cannot provide any information on AT2R because all tested antibodies failed to specifically recognize AT2R (at immunoblotting, the antibody detected a band with 
molecular weight different fromthat predicted, and at immunohistochemistry it provided staining of the nuclei also).

A
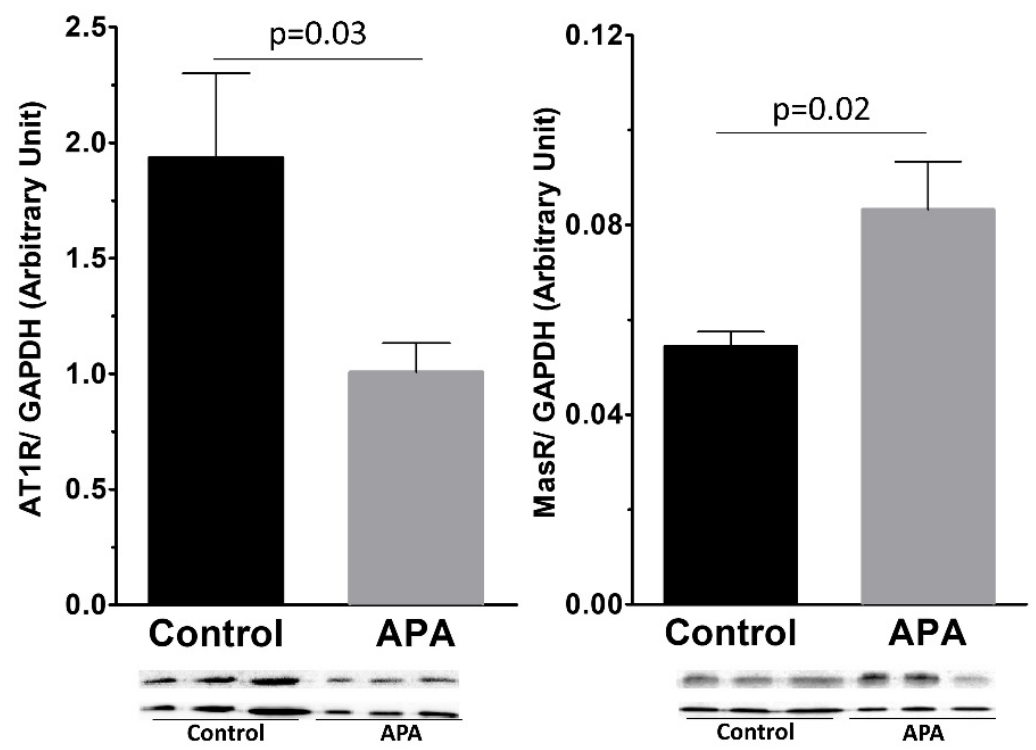

B

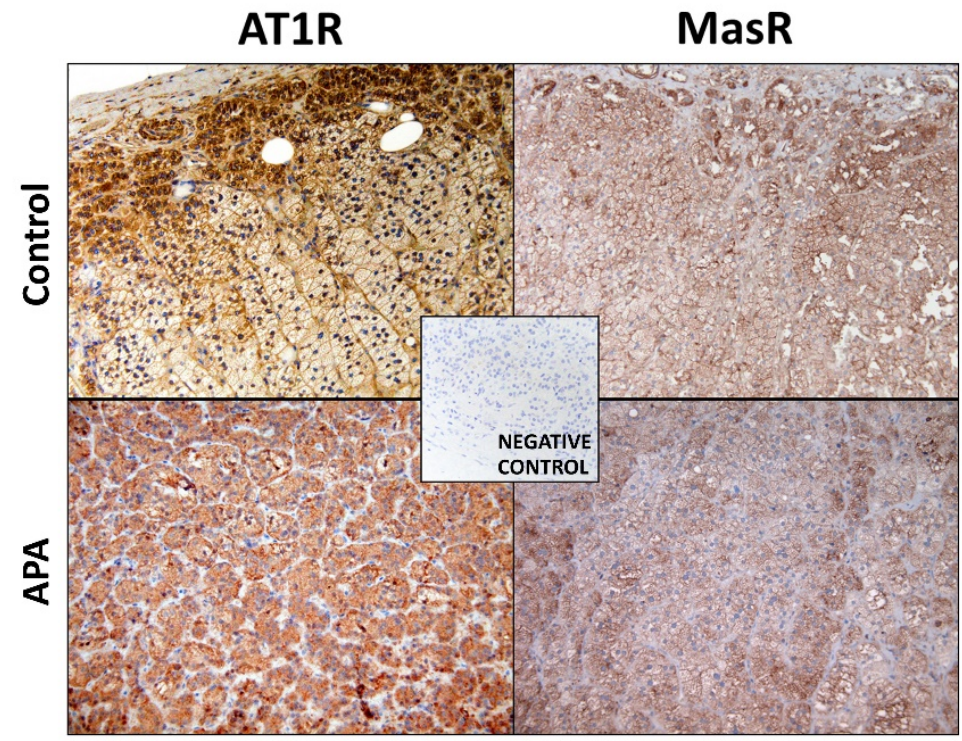

Figure 3.2. AT1R and MasR protein expression in human adrenal tissue.

(A) Immunoblotting of AT1R and MasR proteins in APA $(n=6)$ and in the control $(n=6)$. Relative quantitation is shown in the bar plots. (B) Representative results of immunostaining for AT1R and MasR in the APA $(n=3)$ and control $(n=3)$. Middle panel: negative control. Control: APA-adjacent tissues. 


\section{Effects of C21}

C21 at concentrations (ranging from $10^{-8}$ to $10^{-5} \mathrm{M}$ ) previously used ${ }^{37}$ allowed us to investigate the role of selective AT2R activation in CYP11B1 (cortisol synthase) and CYP11B2 (aldosterone synthase) gene expression. At low concentrations (ranging from $10^{-8}$ to $10^{-6} \mathrm{M}$ ), C21 did not affect CYP11B1 and CYP11B2 gene expression in HAC15 and $\mathrm{H} 295$ cell lines. However, it markedly increased CYP11B1 and CYP11B2 gene expression at $10^{-5} \mathrm{M}$ (Figure 3.3). Moreover, to determine if AT2R activation could blunt CYP11B2 expression only when aldosterone secretion is enhanced, e.g. in hyperaldosteronism, we stimulated both cell lines with $10^{-7} \mathrm{M}$ Ang II and exposed them to increasing concentrations of C21. We found that at low concentration C21 was ineffective, while at high concentration $\left(10^{-5} \mathrm{M}\right)$ it enhanced the effect of Ang II on CYP11B1 and CYP11B2 gene expression in HAC15 cell line (Figure 3.4). Pretreatment of $\mathrm{H} 295$ and HAC15 cells with the AT1R antagonist irbesartan abolished the effect of Ang II as well as high concentrations of C21 at high concentrations on CYP1B1 and CYP11B2 gene expression (Figure 3.5).

The effect of $\mathrm{C} 21$ on aldosterone and cortisol production was also investigated in APA-adjacent tissue and in APA strips. These experiments showed that both in APA-adjacent tissue and in APA, C21 was ineffective at low concentrations, but augmented CYP11B2 gene expression at $10^{-5} \mathrm{M}$ (Figures 3.6A and 3.7A). In both tissues, C21 had no effects on Ang II-stimulated CYP11B1 and CYP11B2 gene expression (Figures 3.6B and 3.7B).

\section{Effects of C21 on K+-induced aldosterone synthase gene expression}

As physiologically multiple stimuli drive aldosterone secretion, we sought to determine the effect of $C 21$ on CYP11B1 or CYP11B2 gene expression driven by $\mathrm{K}^{+}$. H295R cells, which unlike HAC15 are known to be sensitive to $\mathrm{K}^{+}{ }^{32-34}$, were stimulated with $10^{-2} \mathrm{M}$ and $2 \times 10^{-2} \mathrm{M} \mathrm{K}+$. As for Ang II, C21 did not blunt $\mathrm{K}+$ induced CYP11B1 or CYP11B2 gene expression (Figure 3.8). 
A

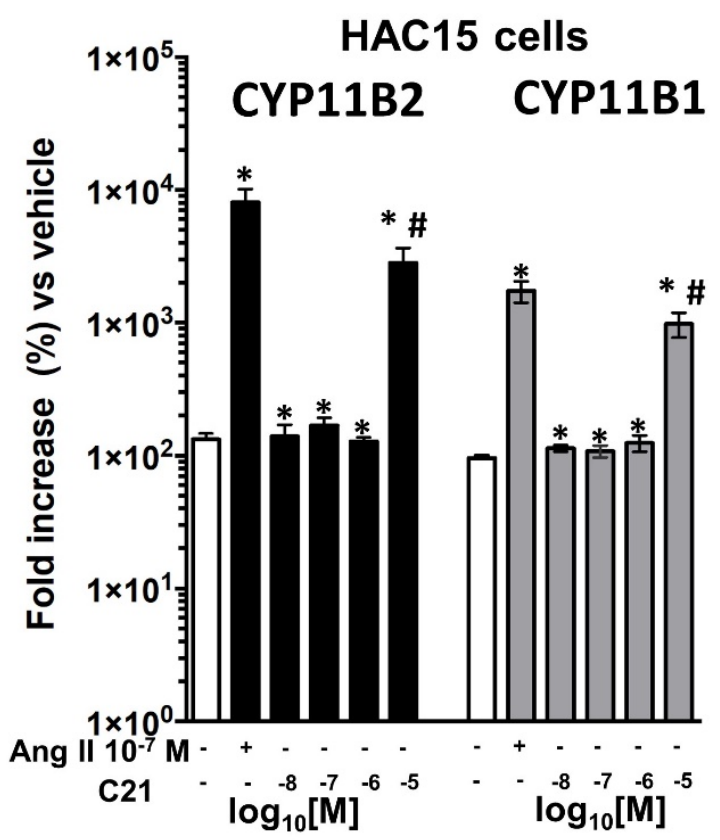

B

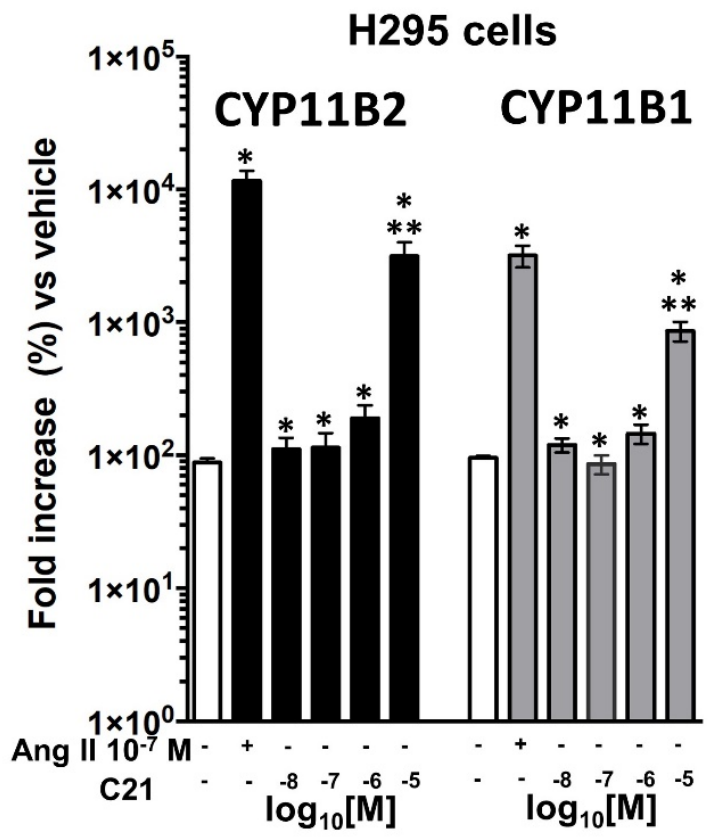

Figure 3.3. Effects of C21 on CYP11B2 and CYP11B1 gene expression in human adrenocortical cell lines

CYP11B2 and CYP11B1 gene expression after stimulation of HAC15 cells (A) and H295R cells (B) with $10^{-7} \mathrm{M}$ Ang II or $\mathrm{C} 21$ at $10^{-8}, 10^{-7}, 10^{-6}$, and $10^{-5} \mathrm{M}$ concentrations, (mean \pm S.D.; $n=3$ in triplicate). ${ }^{*} P<0.001$ compared with vehicle; ${ }^{* \star} P<0.001$ compared with Ang II; \#P=0.04 compared with Ang I 
A

HAC15 cells

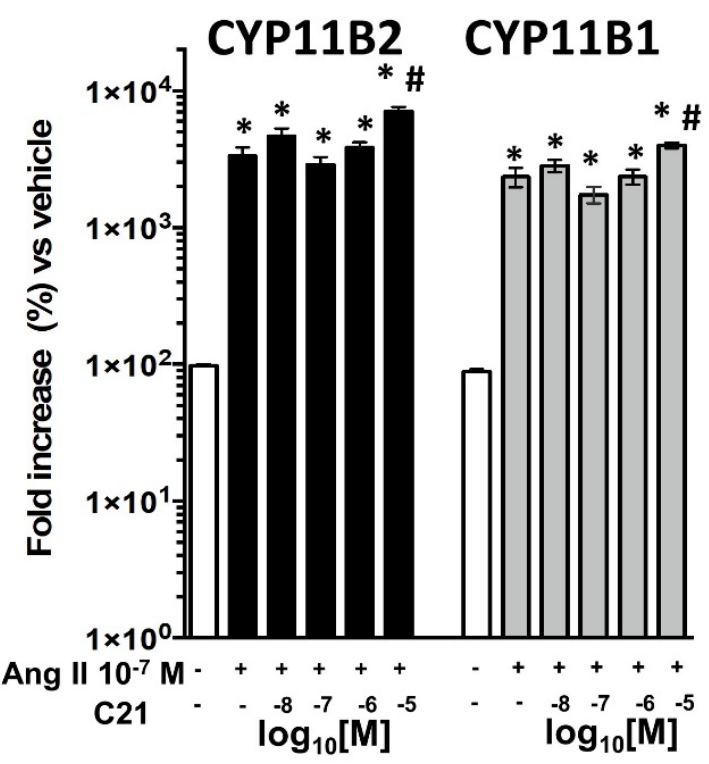

B

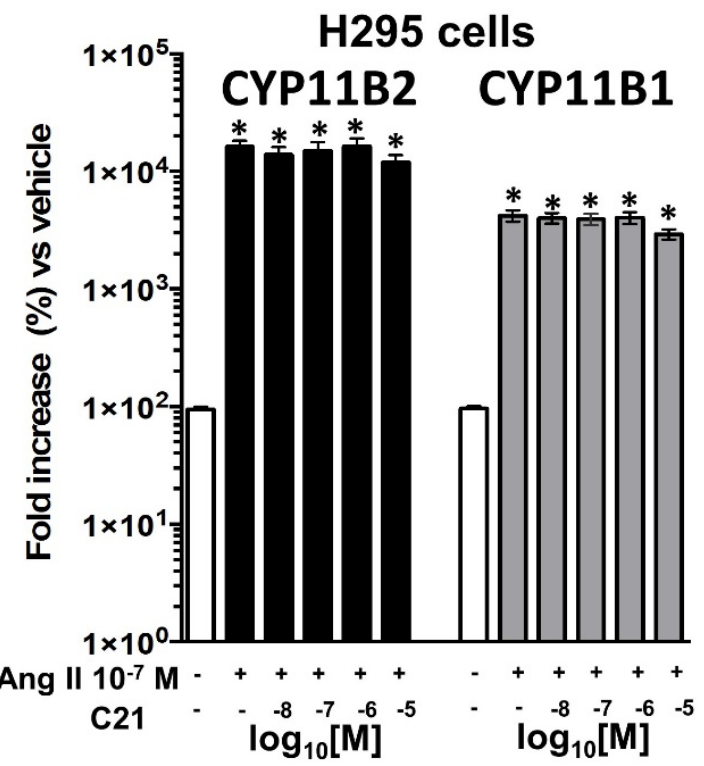

Figure 3.4. Effects of Ang II and C21 on CYP11B2 and CYP11B1 gene expression in human adrenocortical cell lines.

CYP11B2 and CYP11B1 gene expression after treatment of HAC15 cells (A) and H295R cells (B) with $10^{-7} \mathrm{M}$ Ang II alone or in the presence of increasing concentrations of $\mathrm{C} 21\left(10^{-8}, 10^{-7}, 10^{-6}\right.$, and $\left.10^{-5} \mathrm{M}\right)$ (mean \pm S.D.; $n=3$ in triplicate). ${ }^{*} P<0.0001$ compared with vehicle; $\# P<0.01$ compared with Ang II. 


\section{Discussion}

Given the emerging protective role of the non-canonical pathway of the RAS, which is being explored as a target for pharmacological intervention, we investigated this pathway in the regulation of the human adrenocortical hormones that are keys for $\mathrm{Na}^{+}$and water balance and, therefore, for blood pressure. Inappropriate aldosterone secretion contributes substantively to arterial hypertension and heart failure, and thereby to cardiovascular damage and events ${ }^{38-42}$.

Seeking for the components of the protective RAS in the human adrenal cortex, we could detect the mRNAs of AT1R, AT2R, MasR, and MrgD in both APA and APAadjacent tissue, but we found that $A T 2 R$ was expressed at lower levels than the AT1R, keeping with previous reports ${ }^{43-45}$. While AT1R and AT2R expression in APA and APA-adjacent tissue were already reported ${ }^{46-49}$, Mas $R$ expression has only recently been demonstrated in rats ${ }^{50}$. Thus, the presence of MasR and MrgD receptors in the human adrenal gland is a novel finding of this study.

We investigated the effects of the receptors/pathways involved in the protective armof the RAS on aldosterone and cortisol synthesis using a pharmacological approach and found no appreciable effect of C21, an AT2R agonist, on CYP11B1 or CYP11B2 gene expression at concentration ranging from $10^{-8}$ to $10^{-6} \mathrm{M}$. At these concentrations, $\mathrm{C} 21$ had no effect on aldosterone production even when the latter was up-regulated by Ang II, as it occurs clinically in secondary aldosteronism, indicating that the cardiovascular protective effects of $\mathrm{C} 21$ do not seem to involve a blunted aldosterone production. Despite being ineffective at low concentrations, at 10-5 M concentration C21 markedly increased CYP11B1 and CYP11B2 gene expression (Figure 3.3) and enhanced the effect of Ang II on expression of these genes in HAC15 cells (Figure 3.4). Moreover, pretreatment with the AT1R antagonist irbesartan abolished the effect of Ang II and of high C21 concentrations of CYP11B1 and CYP11B2 gene expression (Figure 3.5), suggesting that at $10^{-5}$ $M$ and higher concentrations $\mathrm{C} 21$ likely acts as an AT1R agonist. In H295 cells, another model commonly used for investigating aldosterone synthesis ${ }^{31}$, results were similar, indicating that at $10^{-5} \mathrm{M}$ and higher concentrations C21 likely acts as an AT1R agonist. Thus, these results support the following conclusions: at concentrations ranging between $10^{-8}$ and $10^{-6} \mathrm{M}, \mathrm{C} 21$ does not lower basal aldosterone or cortisol production, and does not counter-regulate the secretagogue effect of Ang II and potassium in the human adrenal cortex.

We used human adrenocortical strips ex vivo to further challenge the findings obtained in the cell lines. We found that at concentrations from $10^{-8}$ to $10^{-6} \mathrm{M} \mathrm{C} 21$ does not affect CYP11B2 expression. Thus, together with the low levels of AT2R found in the adrenal, these findings suggest that a major protective role of AT2R stimulation is unlikely in the human adrenal cortex and in primary aldosteronism due to APA. 


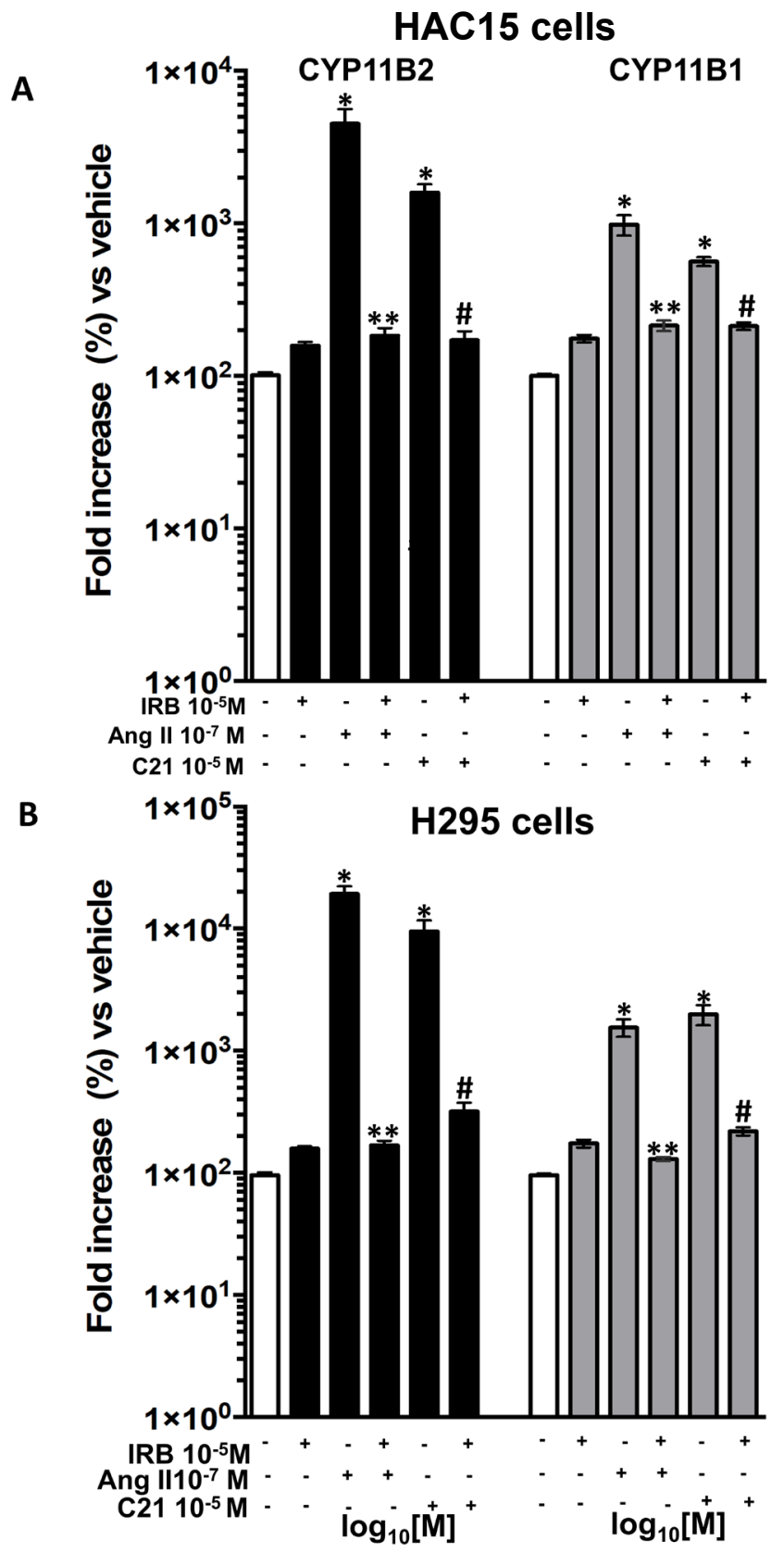

Figure 3.5. Effects of $\mathrm{C} 21$ on top of the AT1R antagonist irbesartan on CYP11B2 and CYP11B1 gene expression in human adrenocortical cell lines

CYP11B2 and CYP11B1 gene expression after stimulation of HAC15 cells (A) and H295R cells (B) with $\mathrm{C} 21$ at $10^{-5} \mathrm{M}$ on top of irbesartan at $10^{-5} \mathrm{M}$ (mean+-S.D.; $n=3$ in triplicate). ${ }^{*} P<0.001$ compared with vehicle; ${ }^{* *} P<0.001$ compared with Ang II; $\# P<0.001$ compared with $\mathrm{C} 21$. 
A

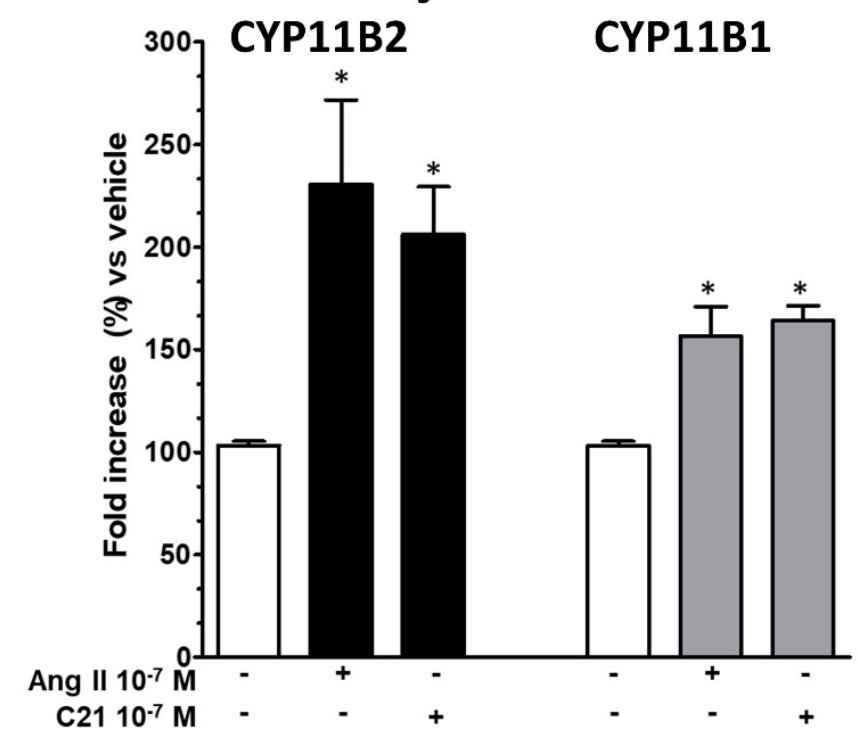

B

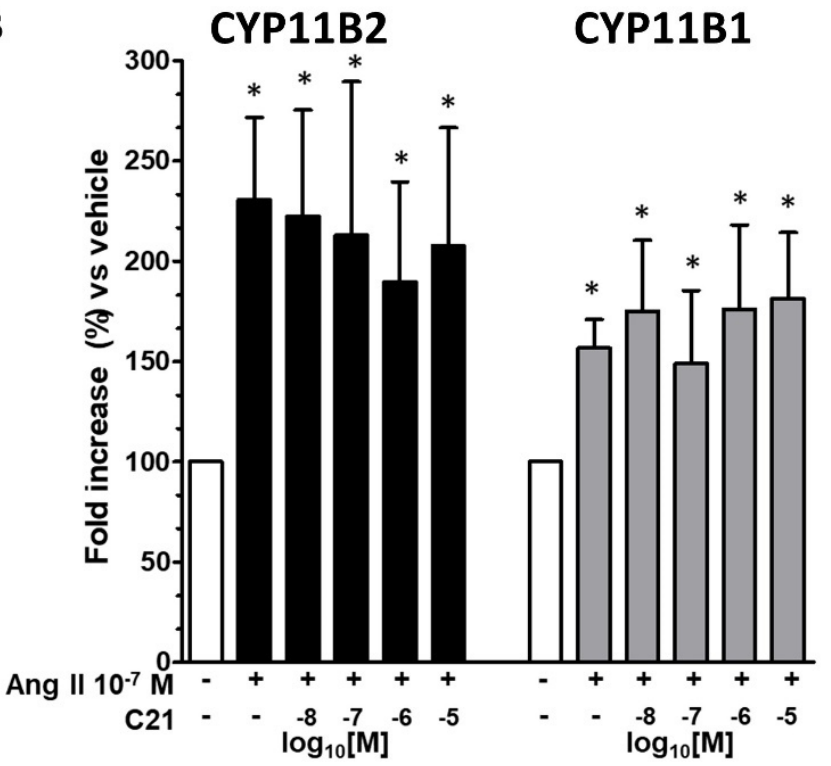

Figure 3.6. Effects of C21 on CYP11B2 and CYP11B1 gene expression in human adrenocortical tissue

CYP11B2 and CYP11B1 gene expression after treatment with $\mathrm{C} 21$ at $10^{-5} \mathrm{M}(\mathbf{A})$. CYP11B2 and CYP11B1 gene expression after stimulation of human adrenocortical tissues with $\mathrm{C} 21$ at $10^{-8}, 10^{-7}$, $10^{-6}$, and $10^{-5} \mathrm{M}$ on top of $10^{-7} \mathrm{M}$ Ang II (B) (mean \pm S.D.; $n=4$ in duplicate). ${ }^{*} P<0.001$ compared with vehicle 
A

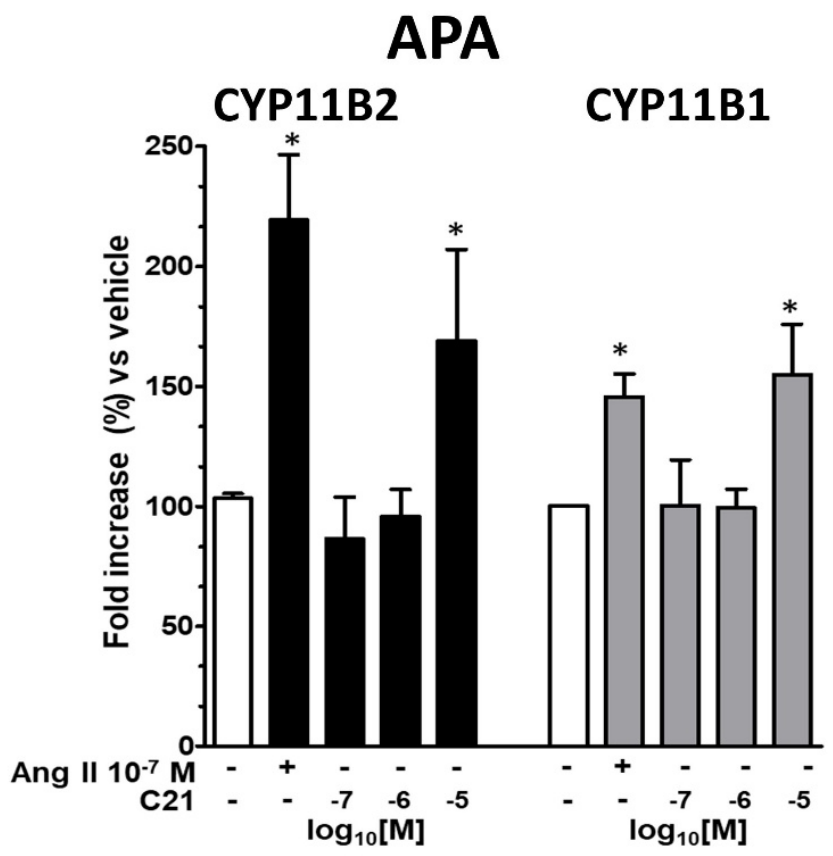

B

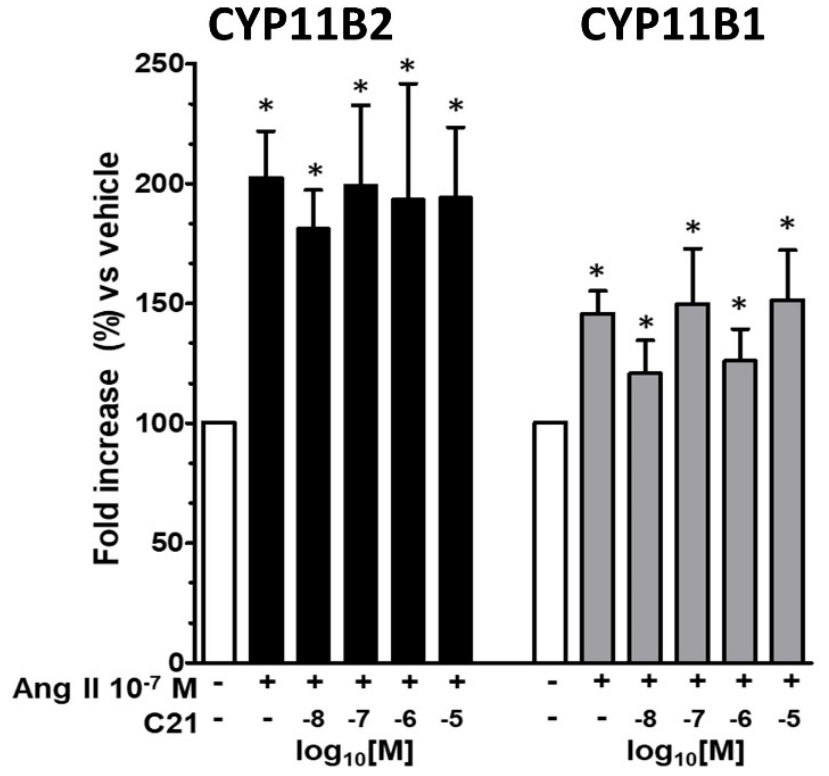

Figure 3.7. Effects of C21 on CYP11B2 and CYP11B1 gene expression in APA tissue CYP11B2 and CYP11B1 gene expression after treatment with $C 21$ at $10^{-7}, 10^{-6}$, and $10^{-5} \mathrm{M}$ concentrations (A). CYP11B2 and CYP11B1 gene expression after stimulation of APA with C21 at 10-8, $10^{-7}, 10^{-6}$, and $10^{-5} \mathrm{M}$ on top of $10^{-7} \mathrm{M}$ Ang II (B) (mean \pm S.D.; $n=4$ in duplicate). ${ }^{*} P<0.01$ compared with vehicle. 
Our results may seem to be in contrast with those of Yatabe et al. ${ }^{51}$, who found that the selective AT2R agonist CGP42112 increased aldosterone secretion in rat adrenal zona glomerulosa cells, and that the AT2R antagonist PD123319 abolished this effect. Moreover, when they combined candesartan with PD123319, the latter seemed to blunt but not abolish Ang II-mediated aldosterone secretion ${ }^{51}$. However, while in that study no quantitation of AT1R and AT2R was performed, it should be acknowledged that the agonistic or antagonistic activity of both CGP42112 and PD123319 for AT2R depends on their concentrations, in that these agents lose their specificity at high concentrations ${ }^{52}$. Of note, the blunting effect of PD123319 on Ang II-stimulated aldosterone secretion was significantly weaker than that of candesartan. Moreover, both candesartan and PD123319 were able to abolish the Ang-II secretagogue effect on aldosterone only when used together at $10^{-7} \mathrm{M}$ concentrations, and no experiments with CGP42112 stimulation on top of AT1R blockade were performed, not allowing to confirm the specificity of both CGP42112 and PD123319 for the AT2R at these concentrations. Thus, besides the species-related differences, our results in humans are by no means challenged by the studies previously done in rats. Lack of specific antibodies binding to the AT2R and non-feasibility of radioactive-based techniques limited our investigation, but the functional studies using the antagonists provide compelling evidence for a predominant role of the AT1R, although a larger number of experiments in APAs can be necessary to conclusively confirm our present findings.

In conclusion, all the main components of the protective RAS are scantly expressed in APA and APA-adjacent tissue. C21, a putative novel therapeutic tool for conditions featuring hyperaldosteronism, as heart failure, does not affect CYP11B1 or CYP11B2 gene expression at concentrations at which it acts as an AT2R agonist. By contrast, it significantly increased CYP11B2 gene expression at high concentrations by acting via AT1R. Whether an enhanced expression of ACE2, which leads to generation of the MasR agonist Ang-(1-7), plays a role in the human adrenal cortex, and whether pharmacological stimulation of this enzyme with diminazene aceturate regulates CYP11B2 gene expression are being investigated in our laboratory. 

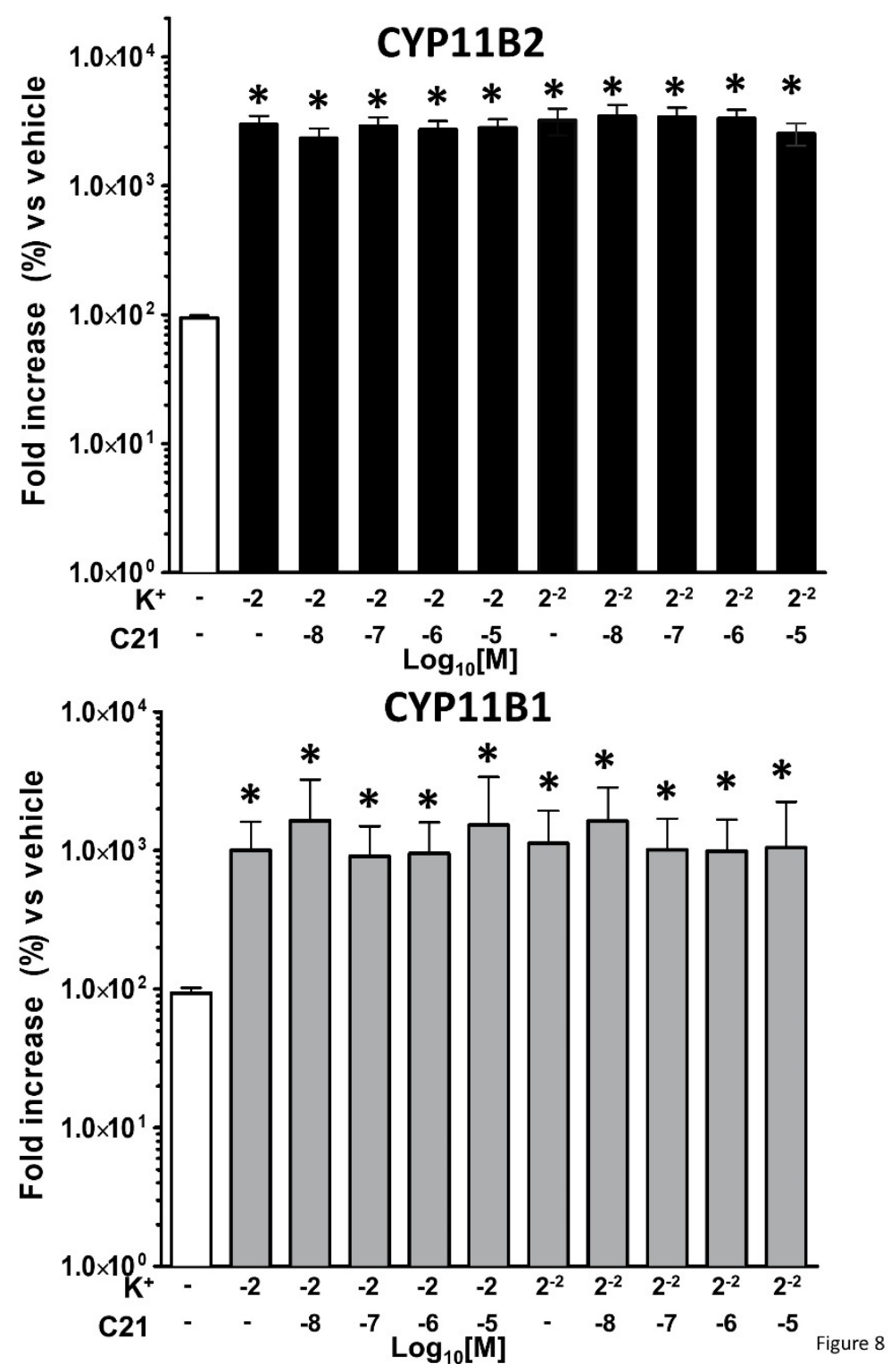

Figure 3.8. Effects of $\mathrm{C} 21$ on $\mathrm{K}+$ induced $C Y P 11 B 2$ and CYP11B1 gene expression in H295R cell line

CYP11B2 and CYP11B1 gene expression after treatment of H295R cells with C 21 at $10^{-8}, 10^{-7}, 10^{-6}$, and $10^{-5} \mathrm{M}$, on top of $\mathrm{K}^{+}\left(10^{-2}\right.$ or $2 \times 10^{-2} \mathrm{M}$ concentration) (mean +-S.D.; $n=4$ in duplicate). ${ }^{*} P<0.001$ compared with Vehicle. 
Chapter 3

\section{Clinical perspectives}

- The AT2R and MasR play a cardiovascular protective role by counter-regulating AT1R-mediated effects in various tissues, but whether they mediate blunting of adrenocortical hormone secretion is unknown.

- Angiotensin receptors AT1R, AT2R, and MasR are expressed in the human adrenal cortex and in APA. The AT2 agonist C21 did not affect aldosterone or cortisol secretion at low concentrations, but it significantly increased aldosterone secretion at high concentrations, likely by acting via the angiotensin AT1R.

- The cardiovascular protective effects of $\mathrm{C} 21$ are unlikely to involve a blunted production of adrenocortical hormones. 


\section{References}

1. Miller, W.L. and Auchus, R.J. (2011) The molecular biology, biochemistry, and physiology of human steroidogenesis and its disorders. Endocr. Rev. 32, 81-151, https://doi.org/10.1210/er.2010-0013

2. Hattangady, N.G., Olala, L.O., Bollag, W.B. and Rainey, W.E. (2012) Acute and chronic regulation of aldosterone production. Mol. Cell. Endocrinol. 350, 151-162, https://doi.org/10.1016/j.mce.2011.07.034

3. Guagliardo, N.A., Yao, J., Hu, C. and Barrett, P.Q. (2012) Minireview: Aldosterone byosynthesis: electrically gated for our protection. Endocrinology 153, 3579-3586, https://doi.org/10.1210/en.2012-1339

4. Rossi, G.P., Albertin, G., Neri, G., Andreis, P.G., Hofmann, S., Pessina, A.C. et al. (1997) Endothelin-1 stimulates steroid secretion of human adrenocortical cells ex vivo via both ETA and ETB receptor subtypes. J. Clin. Endocrinol. Metab. 82, 3445-3449, https://doi.org/10.1210/jcem.82.10.4279

5. Rossi, G.P., Ganzaroli, C., Cesari, M., Maresca, A., Plebani, M., Nussdorfer, G.G. et al. (2003) Endothelin receptor blockade lowers plasma aldosterone levels via different mechanisms in primary aldosteronism and high-to-normal renin hypertension. Cardiovasc. Res. 57, 277-283, https://doi.org/10.1016/S0008-6363(02)00658-2

6. Perraudin, V., Delarue, C., Lefebvre, H., Contesse, V., Kuhn, J.M. and Vaudry, H. (1993) Vasopressin stimulates cortisol secretion from human adrenocortical tissue through activation of V1 receptors. J. Clin. Endocrinol. Metab. 76, 1522-1528

7. Gallo-Payet, N. and Guillon, G. (1998) Regulation of adrenocortical function by vasopressin. Horm. Metab. Res. 30, 360-367, https://doi.org/10.1055/s-2007-978899

8. Caroccia, B., Menegolo, M., Seccia, T.M., Petrelli, L., Antonello, M., Limena, A. et al. (2017) Urotensin II exerts pressor effects by stimulating renin and aldosterone synthase gene expression. Sci. Rep. 7, 13876, https://doi.org/10.1038/s41598-017-12613-y

9. Giuliani, L., Lenzini, L., Antonello, M., Aldighieri, E., Belloni, A.S., Fassina, A. et al. (2009) Expression and functional role of urotensin-II and its receptor in the adrenal cortex and medulla: novel insights for the pathophysiology of primary aldosteronism. J. Clin. Endocrinol. Metab. 94, 684-690, https://doi.org/10.1210/jc.2008-1131

10. Rossi, G.P., Bernini, G., Caliumi, C., Desideri, G., Fabris, B., Ferri, C. et al. (2006) A prospective study of the prevalence of primary aldosteronism in 1,125 hypertensive patients. J. Am. Coll. Cardiol. 48, 2293-2300, https://doi.org/10.1016/j.jacc.2006.07.059

11. Nakamura, Y., Yamazaki, Y., Konosu-Fukaya, S., Ise, K., Satoh, F. and Sasano, H. (2015) Aldosterone biosynthesis in the human adrenal cortex andnassociated disorders. J. Steroid Biochem. Mol. Biol. 153, 57-62, https://doi.org/10.1016/j.jsbmb.2015.05.008

12. Timmermans, P.B., Wong, P.C., Chiu, A.T., Herblin, W.F., Benfield, P., Carini, D.J. et al. (1993) Angiotensin II receptors and angiotensin II receptor antagonists. Pharmacol. Rev. 45, 205-251

13. Kaschina, E. and Unger, T. (2003) Angiotensin AT1/AT2 receptors: regulation, signalling and function. Blood Press. 12, 70-88, https://doi.org/10.1080/08037050310001057

14. Wintour, E.M ., Moritz, K., Butkus, A., Baird, R., Albiston, , A. and Tenis, , N. (1999) Ontogeny and regulation of AT1 and AT2 receptors in the ovine fetal adrenal gland. Mol. Cell. Endocrinol. 157 , 161-170, https://doi.org/10.1016/S0303-7207(99)00149-5

15. Moritz, K.M., Boon, W.C. and Wintour, E.M. (1999) Aldosterone secretion by the mid-gestation ovine fetus: role of the AT2 receptor. Mol. Cell. Endocrinol. 157, 153-160, https://doi.org/10.1016/S0303-7207(99)00148-3

16. Chamoux, E., Breault, L., Lehoux, J.G. and Gallo-Payet, N. (1999) Involvement of the angiotensin II type 2 receptor in apoptosis during human fetal adrenal gland development. J. Clin. Endocrinol. Metab. 84, 4722-4730

17. Moritz, K.M., Boon, W.C. and Wintour, E.M. (1999) Aldosterone secretion by the mid-gestation ovine fetus: role of the AT2 receptor. Mol. Cell. Endocrinol. 157, 153-160, https://doi.org/10.1016/S0303-7207(99)00148-3 
18. Yu, L., Zheng, M., Wang, W., Rozanski, G.J., Zucker, I.H. and Gao, L. (2010) Developmental changes in AT1 and AT2 receptor-protein expression in rats. J. Renin. Angiotensin Aldosterone Syst. 11, 214-221, https://doi.org/10.1177/1470320310379065

19. Wan, Y., Wallinder, C., Plouffe, B., Beaudry, H., Mahalingam, A.K., Wu, X. et al. (2004) Design, synthesis, and biological evaluation of the first selective nonpeptide AT2 receptor agonist. J. Med. Chem. 47, 5995-6008, https://doi.org/10.1021/jm049715t

20. Lucius, R., Gallinat, S., Rosenstiel, P., Herdegen, T., Sievers, J. and Unger, T. (1998) The angiotensin II type 2 (AT2) receptor promotes axonal regeneration in the optic nerve of adult rats. J. Exp. Med. 188, 661-670, https://doi.org/10.1084/jem.188.4.661

21. Kaschina, E., Namsolleck, P. and Unger, T. (2017) AT2 receptors in cardiovascular and renal diseases. Pharmacol. Res. 125, 39-47, https://doi.org/10.1016/j.phrs.2017.07.008

22. Zhao, Y., Lu" tzen, U., Fritsch, J., Zuhayra, M., Schu“ tze, S., Steckelings, U.M. et al. (2015) Activation of intracellular angiotensin AT 2 receptors induces rapid cell death in human uterine leiomyosarcoma cells. Clin. Sci. 128, 567-578, https://doi.org/10.1042/CS20140627

23. Santos, R. A.S., Simoes e Silva, A.C., Maric, C., Silva, D. M.R., Machado, R.P., de Buhr, I. et al. (2003) Angiotensin-(1-7) is an endogenous ligand for the G protein-coupled receptor Mas. Proc. Natl. Acad. Sci. U.S.A. 100, 8258-8263, https://doi.org/10.1073/pnas.1432869100

24. Bader, M., Alenina, N., Andrade-Navarro, M.A. and Santos, R.A. (2014) MAS and its related G protein-coupled receptors, Mrgprs. Pharmacol. Rev. 66, 1080-1105, https://doi.org/10.1124/pr.113.008136

25. Donoghue, M., Hsieh, F., Baronas, E., Godbout, K., Gosselin, M., Stagliano, N. et al. (2000) A novel angiotensin-converting enzyme-related carboxypeptidase (ACE2) converts angiotensin I to angiotensin 1-9. Circ. Res. 87, E1-E9, https://doi.org/10.1161/01.RES.87.5.e1

26. Lautner, R.Q., Villela, D.C., Fraga-Silva, R.A., Silva, N., Verano-Braga, T., Costa-Fraga, F. et al. (2013) Discovery and characterization of alamandine: a novel component of the renin-angiotensin system. Circ. Res. 112, 1104-1111, https://doi.org/10.1161/CIRCRESAHA.113.301077

27. Patel, V.B., Zhong, J.C., Grant, M.B. and Oudit, G.Y. (2016) Role of the ACE2/angiotensin 1-7 axis of the renin-angiotensin system in heart failure. Circ. Res. 118, 1313-1326, https://doi.org/10.1161/CIRCRESAHA.116.307708

28. Passos-Silva, D.G., Verano-Braga, T. and Santos, R. A.S. (2013) Angiotensin-(1-7): beyond the cardio-renal actions. Clin. Sci. (Lond.) 124, 443-456, https://doi.org/10.1042/CS20120461

29. Mendoza-Torres, E., Oyarzun, A., Mondaca-Ruff, D., Azocar, A., Castro, P.F., Jalil, J.E. et al. (2015) ACE2 and vasoactive peptides: novel players in cardiovascular/renal remodeling and $\begin{array}{lllll}\text { hypertension. Ther. Adv. Cardiovasc. Dis. } & \text { 9, }\end{array}$ https://doi.org/10.1177/1753944715597623

30. Donoghue, M., Hsieh, F., Baronas, E., Godbout, K., Gosselin, M., Stagliano, N. et al. (2000) A novel angiotensin-converting enzyme-related carboxypeptidase (ACE2) converts angiotensin I to angiotensin 1-9. Circ. Res. 87, E1-E9, https://doi.org/10.1161/01.RES.87.5.e1

31. Wang, T., Rowland, J.G., Parmar, J., Nesterova, M., Seki, T. and Rainey, W.E. (2012) Comparison of aldosterone production among human adrenocortical cell lines. Horm. Metab. Res. 44, 245-250, https://doi.org/10.1055/s-0031-1298019

32. Funder, J.W., Carey, R.M., Mantero, F., Murad, M.H., Reincke, M., Shibata, H. et al. (2016) The management of primary aldosteronism: case detection, diagnosis, and treatment: an Endocrine Society Clinical Practice Guideline. J. Clin. Endocrinol. Metab. 101, 1889-1916, https://doi.org/10.1210/jc.2015-4061

33. Rossi, G.P., Seccia, T.M. and Pessina, A.C. (2007) Clinical use of laboratory tests for the identification of secondary forms of arterial hypertension. Crit.Rev. Clin. Lab. Sci. 44, 1-85, https://doi.org/10.1080/10408360600931831

34. Rossi, G.P., Pitter, G., Bernante, P., Motta, R., Feltrin, G. and Miotto, D. (2008) Adrenal vein sampling for primary aldosteronism: the assessment of selectivity and lateralization of aldosterone excess baseline and after adrenocorticotropic hormone (ACTH) stimulation. J. Hypertens. 26, 989-997, https://doi.org/10.1097/HJH.0b013e3282f9e66a 
35. Caroccia, B., Fassina, A., Seccia, T.M., Recarti, C., Petrelli, L., Belloni, A.S. et al. (2010) Isolation of human adrenocortical aldosterone-producing cells by a novel immunomagnetic beads method. Endocrinology 151, 1375-1380, https://doi.org/10.1210/en.2009-1243

36. Livak, K.J. and Schmittgen, T.D. (2001) Analysis of relative gene expression data using real-time quantitative PCR and the 2(-Delta Delta C(T)) method. Methods 25, 402-408, https://doi.org/10.1006/meth.2001.1262

37. Menk, M., Graw, J.A., von Haefen, C., Sifringer, M., Schwaiberger, D., Unger, T. et al. (2015) Stimulation of the angiotensin II AT2 receptor is anti-inflammatory in human lipopolysaccharideactivated monocytic cells. Inflammation 38, 1690-1699, https://doi.org/10.1007/s10753-015-01469

38. Ponikowski, P., Voors, A.A., Anker, S.D., Bueno, H., Cleland, J. G.F., Coats, A. J.S. et al. (2016) 2016 ESC Guidelines for the diagnosis and treatment of acute and chronic heart failure: the Task Force for the diagnosis and treatment of acute and chronic heart failure of the European Society of Cardiology (ESC)Developed with the special contribution of the Heart Failure Association (HFA) of the ESC. Eur. Heart J. 37, 2129-2200, https://doi.org/10.1093/eurheartj/ehw128

39. Pitt, B., Zannad, F., Remme, W.J., Cody, R., Castaigne, A., Perez, A. et al. (1999) The effect of spironolactone on morbidity and mortality in patients with severe heart failure. Randomized Aldactone Evaluation Study Investigators. N. Engl. J. Med. 341, 709-717, https://doi.org/10.1056/NEJM199909023411001

40. Pitt, B., Remme, W., Zannad, F., Neaton, J., Martinez, F., Roniker, B. et al. (2003) Eplerenone, a selective aldosterone blocker, in patients with left ventricular dysfunction after myocardial infarction. N. Engl. J. Med. 348, 1309-1321, https://doi.org/10.1056/NEJMoa030207

41. Pfeffer, M.A., Claggett, B., Assmann, S.F., Boineau, R., Anand, I.S., Clausell, N. et al. (2015) Regional variation in patients and outcomes in the Treatment of Preserved Cardiac Function Heart Failure With an Aldosterone Antagonist (TOPCAT) trial. Circulation 131, 34-42, https://doi.org/10.1161/CIRCULATIONAHA.114.013255

42. Zannad, F., McMurray, J.J.V., Krum, H., van Veldhuisen, D.J., Swedberg, K., Shi, H. et al. (2011) Eplerenone in patients with systolic heart failure and mild symptoms. N. Engl. J. Med. 364, 11-21, https://doi.org/10.1056/NEJMoa1009492

43. Pawlikowski, M., Winczyk, K. and Sledz, B. (2008) Immunohistochemical detection of angiotensin receptors AT1 and AT2 in adrenal tumors. Folia Histochem. Cytobiol. 46, 51-55, https://doi.org/10.2478/v10042-008-0006-7

44. Harada, K., Matsuoka, H., Fujimoto, N., Endo, Y., Hasegawa, Y., Matsuo, A. et al. (2010) Localization of type-2 angiotensin II receptor in adrenal gland. J. Histochem. Cytochem. 58, 585593, https://doi.org/10.1369/jhc.2010.955575

45. Wu, Z., Ni, D., Yan, Y., Li, J., Wang, B., Ouyang, J. et al. (2010) Expression of angiotensin II receptors in aldosterone-producing adenoma of the adrenal gland and their clinical significance. $J$. Huazhong Univ. Sci. Technolog. Med. Sci. 30, 486-489, https://doi.org/10.1007/s11596-0100454-0

46. Tanabe, A., Naruse, M., Arai, K., Naruse, K., Yoshimoto, T., Seki, T. et al. (1998) Gene expression and roles of angiotensin II type 1 and type 2 receptors in human adrenals. Horm. Metab. Res. 30, 490-495, https://doi.org/10.1055/s-2007-978918

47. Allen, A.M., Zhuo, J. and Mendelsohn, F.A. (2000) Localization and function of angiotensin AT1 receptors. Am. J. Hypertens. 13, 31S-38S, https://doi.org/10.1016/S0895-7061(99)00249-6

48. Pawlikowski, M., Winczyk, K. and Sledz, B. (2008) Immunohistochemical detection of angiotensin receptors AT1 and AT2 in adrenal tumors. Folia Histochem. Cytobiol. 46, 51-55, https://doi.org/10.2478/v10042-008-0006-7

49. Wu, Z., Ni, D., Yan, Y., Li, J., Wang, B., Ouyang, J. et al. (2010) Expression of angiotensin II receptors in aldosterone-producing adenoma of the adrenal gland and their clinical significance. $J$. Huazhong Univ. Sci. Technolog. Med. Sci. 30, 486-489, https://doi.org/10.1007/s11596-0100454-0 
Chapter 3

50. Shefer, G., Marcus, Y., Knoll, E., Dolkart, O., Foichtwanger, S., Nevo, N. et al. (2016) Angiotensin 1-7 is a negative modulator of aldosterone secretion in vitro and in vivo. Hypertension 68, 378384, https://doi.org/10.1161/HYPERTENSIONAHA.116.07088

51. Yatabe, J., Yoneda, M., Yatabe, M.S., Watanabe, T., Felder, R.A., Jose, P.A. et al. (2011) Angiotensin III stimulates aldosterone secretion from adrenal gland partially via angiotensin II type 2 receptor but not angiotensin II type 1 receptor. Endocrinology 152, 1582-1588, https://doi.org/10.1210/en.2010-1070

52. de Gasparo, M., Whitebread, S., Criscione, L., Buehlmayer, P. and Furet, P. (2017) The AT2 receptor: historical perspective. The Protective Arm of the Renin Angiotensin System (RAS): Functional Aspects and Therapeutic Implications, pp. 11-16, Elsevier Inc., 978-0-12-801364-9 


\title{
Supplemental Table S3.1.
}

\author{
Gene \\ Sequences \\ AT1R \\ NM_000685.4 \\ For : 5'-atgattccagcgcctgac- 3' \\ Rev : 5'- ggtccagacgtcctgtcact- 3' \\ AT2R \\ NM_000686.4 \\ For: 5'- ggtttctagcatatacatcttcaacct- 3' \\ Rev: 5'- ttgcccatagaggaagagtagc- 3' \\ MasR \\ For: 5'- ttcgctatgcccatgagact- 3' \\ NM_002377.2 \\ Rev: 5'- tggtgtaggttcccaaaggt- 3' \\ $\mathrm{MrgD}$ \\ NM_198923.2 \\ For: 5'- cgtggaccttgtcagtggta- 3' \\ Rev: 5'- ttcctcttcagcatggcttc- 3' \\ CYP11B2 \\ For: 5'-gtgaccgcaggttgcttt-3' \\ NM_000498.3 \\ Rev: 5'-cccttattcctttcccatgc-3' \\ CYP11B1 \\ NM_000497.3 \\ For: 5'- ttcagccgccctcaaca- 3' \\ Rev: 5'- ggatgttcactgatgctgg- 3' \\ PBGD \\ NM_000190.3 \\ For: 5'-tgccctggagaagaatgaag-3' \\ Rev: 5'- agatggctccgatggtga -3
}


Chapter 3 


\section{Chapter 4}

\section{Macrolides blunt aldosterone biosynthesis}

a proof-of-concept study in KCNJ5 mutated adenoma cells ex vivo

B. Caroccia, S. Prisco, T. M. Seccia, M. Piazza, G. Maiolino, G.P. Rossi

Hypertension 2017;70:1238-1242. 


\begin{abstract}
Aldosterone-producing adenoma, a major subtype of primary hyperaldosteronism, the main curable cause of human endocrine hypertension, involves somatic mutations in the potassium channel Kir3.4 (KCNJ5) in $30-70 \%$ of cases, typically the more florid phenotypes. Since KCNJ5 mutated channels were reported to be specifically sensitive to inhibition by macrolide antibiotics, which concentrationdependently blunt aldosterone production in HAC15 transfected with the G151R and L168R mutated channel, we herein tested the effect of clarithromycin on aldosterone synthesis and secretion in a pure population of aldosterone-secreting cells obtained by immunoseparation $\left(\mathrm{CD} 6^{+}\right.$cells) from aldosterone-producing adenoma tissues with/without the two most common KCNJ5 mutations. From a large cohort of patients with an unambiguous aldosterone-producing adenoma diagnosis we recruited those who were wild-type $(n=3)$, or had G151R $(n=2)$ and L168R ( $n=2)$ mutations. We found that clarithromycin concentration-dependently lowered CYP11B2 gene expression (by 60\%) and aldosterone secretion (by 70\%) $\left(p<0.001\right.$ for both) in $\mathrm{CD}^{+} 6^{+}$cells isolated ex vivo from KCNJ5-mutated aldosterone-producing adenomas, while it was ineffective in $\mathrm{CD}^{+} 6^{+}$cells from wildtype aldosterone-producing adenomas. By proving the principle that the over secretion of aldosterone can be specifically blunted in aldosterone-producing adenoma cells ex vivo with G151R and L168R mutations, these results provide compelling evidence of the possibility of specifically correcting aldosterone excess in patients with aldosterone-producing adenoma carrying the two most common KCNJ5 somatic mutations.
\end{abstract}




\section{Introduction}

In 2011 Choi et al. ${ }^{1}$ identified mutations in the Kir 3.4 (KCNJ5) $\mathrm{K}^{+}$channel in about one third of 24 aldosterone-producing adenoma (APA), which were shown to lead to a loss of selectivity for $\mathrm{Na}^{+}$and thus to $\mathrm{Ca}^{2+}$ influx, via opening of T-type calcium channel and activation of the $\mathrm{Na}^{+} / \mathrm{Ca}^{2+}$ exchange ${ }^{2,3}$, and thus increased aldosterone production. Of note, these mutations were found to involve from $30 \%$ to $70 \%$ of all APA in a very large meta-analysis, albeit with marked geographic variations ${ }^{4}$.

Some macrolide antibiotics and their derivatives were recently shown to correct the altered electrophysiology of HEK293T cells transfected with the L168R and G151R KCNJ5 mutated Kir3.4 channel, and to concentration-dependently lower aldosterone synthesis in HAC15, an adrenocortical carcinoma cell line transfected to overexpress these mutated channels ${ }^{5}$. Notably, these effects were suggested to be specific in that they were not seen in the same cells carrying the wild type Kir 3.4 channel ${ }^{5}$. These seminal discoveries might open the way to personalized diagnosis and treatment of primary aldosteronism, the most common, albeit often overlooked, form of secondary arterial hypertension ${ }^{6}$, which carries an excess cardiovascular damage, as well as a worse outcome ${ }^{7,8}$. In fact, if these in vitro findings could be confirmed in vivo, the fall of plasma aldosterone concentration (PAC) after administration of a macrolide antibiotic might represent a proxy for the presence of an APA carrying a KCNJ5 mutation. Likewise, if associated with a blood pressure lowering, this PAC fall would suggest the feasibility of controlling the aldosteronism and arterial hypertension with a macrolide or derivatives devoid of antibiotic activity.

As APA are known to be highly heterogeneous at the molecular level ${ }^{9}$, and therefore could respond differently to stimuli and drugs, a first inevitable step toward these clinical applications is to prove that the effects seen in these two models of genetically engineered cell lines, which are far from APA cells, do occur also in the APA cells taken ex vivo from APA patients. Therefore, by taking advantage of the availability of primary culture of aldosterone-producing cells isolated ex vivo from wild-type APA and from G151R and L168R mutated APA, we conducted a pilot study to test the effect on aldosterone synthase (CYP11B2) gene expression and aldosterone production of clarithromycin, one of the macrolides that effectively corrected the altered electrophysiology of G151R and L168R overexpressing HEK293T cells ${ }^{5}$.

\section{Methods}

\section{Patients}

From a large databank of cells from APA patients we selected for this study a total of 7 patients. These patients received an unambiguous diagnosis of APA by the 
"four corners criteria" 6 . Approval for this study was obtained from the Ethics Committee of the University of Padova and all participants gave informed written consent to the study and to the use of their adrenocortical specimen; all procedures followed the Helsinki Declaration Principles.

\begin{tabular}{|c|c|c|c|c|c|c|}
\hline \multirow[b]{2}{*}{ Variable } & \multicolumn{2}{|c|}{ Wild-Type APA } & \multicolumn{2}{|c|}{ G151R Mutated APA } & \multicolumn{2}{|c|}{ L168R Mutated APA } \\
\hline & Baseline & Post-Adrenalectomy & Baseline & Post-Adrenalectomy & Baseline & Post-Adrenalectomy \\
\hline Age, y & $52 \pm 4$ & N.A. & $49 \pm 3$ & N.A. & $49 \pm 7$ & N.A. \\
\hline Systolic BP, mm Hg & $139 \pm 4$ & $124 \pm 5$ & $168 \pm 32$ & $128 \pm 4$ & $154 \pm 20$ & $130 \pm 0$ \\
\hline Diastolic BP, mm Hg & $91 \pm 15$ & $73 \pm 6$ & $96 \pm 8$ & $80 \pm 7$ & $90 \pm 14$ & $77 \pm 4$ \\
\hline Serum $\mathrm{K}^{+}$, mmol/L & $3.3 \pm 0.1$ & $4.2 \pm 0.3$ & $3.0 \pm 0.5$ & $4.0 \pm 0.4$ & $3.4 \pm 0.3$ & $4.0 \pm 0.1$ \\
\hline U-Na+ excretion, mEq/24 h & $150 \pm 164$ & $113 \pm 60$ & $100 \pm 14$ & $127 \pm 84$ & $174 \pm 26$ & $100 \pm 24$ \\
\hline $\mathrm{DRC}, \mathrm{mUI} / \mathrm{L}$ & $4.0(2.0-8.0)$ & $15.4(2.0-34.0)$ & $2.5(2.1-2.8)$ & $5.0(3.0-7.0)$ & $2.4(2.0-2.9)$ & $6.7(2.8-11.0)$ \\
\hline PAC, ng/dL & $69.7(27.1-152.4)$ & $9.0(2.6-12.3)$ & $48.9(44.7-52.1)$ & $4.0(3.0-5.1)$ & $35.8(15.0-56.6)$ & $3.0(1.4-4.5)$ \\
\hline ARR, (ng/dL)/(mUI/L) & $60.3(10.8-93.9)$ & $1.0(0.4-1.3)$ & $143.6(21.3-265.9)$ & $0.9(1.0-0.8)$ & $84.7(28.3-141.1)$ & $0.6(0.4-0.7)$ \\
\hline APA diameter, mm* & \multicolumn{2}{|c|}{$12 \pm 11$} & \multicolumn{2}{|c|}{$12 \pm 2$} & \multicolumn{2}{|c|}{$19 \pm 16$} \\
\hline $\begin{array}{l}\text { Histopathology (\%), ZF like/ } \\
\text { ZG like/mixed }\end{array}$ & \multicolumn{2}{|c|}{$33 / 0 / 66$} & \multicolumn{2}{|c|}{$50 / 0 / 50$} & \multicolumn{2}{|c|}{$50 / 0 / 50$} \\
\hline
\end{tabular}

Table 4.1 Demographic and Clinical Features of the APA Patients and Diagnostic Indexes

Data presented as mean \pm SD or median (IQR), as appropriate. Normal values: $\mathrm{SK}^{+}: 3.5-4.5 \mathrm{mmoL} / \mathrm{L}$; on a $\mathrm{Na}^{+}$intake 200-300 mmoL/d: DRC: 2.5-32 mUL/L; PAC: $<15.0 \mathrm{ng} / \mathrm{dL} ;$ ARR $<2.06$ $(\mathrm{ng} / \mathrm{dL}) /(\mathrm{mUI} / \mathrm{L}){ }^{12}$ The predominant pattern at histopathology (\% ZF like/ZG like/mixed) is also indicated. Statistical significance was not calculated because of the small number of cases. APA indicates aldosterone-producing adenoma; ARR, aldosterone-renin ratio; $\mathrm{BP}$, blood pressure; $\mathrm{DRC}$, direct renin concentration; N.A., not applicable; PAC, plasma aldosterone concentration; serum $\mathrm{K}^{+}$, serum potassium levels; $\mathrm{U}-\mathrm{Na}^{+}$, urinary $\mathrm{Na}^{+}$; ZF, zona fasciculata; and ZG, zona glomerulosa.

${ }^{*}$ At pathology.

\section{Detection of KCNJ5 mutations}

DNA was extracted from APAs removed from the consecutive APA patients referred to our specialized hypertension center with a standard procedure as reported ${ }^{10}$. PCR was performed on $250 \mathrm{ng}$ DNA in a final volume of $50 \mu \mathrm{l}$ containing $300 \mathrm{nM} \mathrm{MgCl}$, $400 \mathrm{nM}$ of each primer, $200 \mu \mathrm{M}$ deoxynucleotide triphosphate, and 2.6 U expand high-fidelity enzyme mix (Roche Applied Science, Milan, Italy). Purified PCR products underwent direct Sanger sequencing using the ABI Prism Big Dye Terminator version 3.1 cycle sequencing kit (Applied Biosystems, Foster City, CA) on an ABI Prism 3700 DNA analyzer (Applied Biosystems, Foster City, CA).

\section{Isolation of aldosterone producing cells}

Dispersed APA cells were obtained by sequential enzymatic digestion, mechanical disaggregation and incubation in $5 \mathrm{~mL}$ of Krebs Ringer solution supplemented with $2 \mathrm{mg} / \mathrm{mL}$ collagenase-I, $0.1 \mathrm{mg} / \mathrm{mL}$ deoxyribonuclease-I, $4 \%$ bovine serum albumin at $37^{\circ} \mathrm{C}$ for $40 \mathrm{~min}$ with gentle shaking. Single-cell suspension obtained was 
washed with PBS containing $0.1 \%$ BSA and then incubated with CD56 pre-coated magnetic beads by gentle shaking for 1 hour at $4^{\circ} \mathrm{C}$. Beads were used at a ratio of 5 beads per cell ${ }^{11}$. After separating the bead-bound CD56-positive $\left(\mathrm{CD} 56^{+}\right)$cells with a magnet, the $\mathrm{CD}_{56}{ }^{+}$cells were seeded at a density of 104 cells $/ \mathrm{cm} 2$ into 24well plates and treated with $5 \mathrm{umol} / \mathrm{L}, 20 \mathrm{umol} / \mathrm{L}$ or $50 \mathrm{umol} / \mathrm{L}$ of clarithromycin.

\section{Electron microscopy}

Freshly immunoseparated CD56 ${ }^{+}$APA cells were fixed in 3\% phosphate-buffered glutaraldehyde and processed following a standard protocol, as described. ${ }^{12}$

\section{CYP11B2 gene expression quantification}

CYP11B2 mRNAs were measured in duplicate in CD56 ${ }^{+}$APA cells after incubation for 18 hours in DMEM-F-12 medium with $5 \%$ FBS added with increasing concentrations of clarithromycin.

After treatment, the cells were lysed and mRNA was isolated using the high-pure RNA isolation kit (Roche Applied Science, Milan, Italy). Gene expression was quantified by real-time RT-PCR with universal probe library probes in the LightCycler 480 instrument (Roche Applied Science, Milan, Italy) using the comparative cycle threshold $\left(2^{-\Delta \Delta c t}\right)$ method and the porphobilinogendeaminase (PBGD) as reference gene.

\section{Aldosterone measurement}

Aldosterone levels were quantified by an aldosterone ELISA kit (Alpha Diagnostic International, San Antonio, Texas). A total of $50 \mu \mathrm{L}$ of cell medium was added to aldosterone-coated wells following the manufacturer's instructions; the signal was detected in an ELISA Reader (Berthold Technologies, Milan, Italy). Aldosterone levels were normalized to the amount of cell RNA content.

\section{Statistical analysis}

Data are expressed as mean and SD. One-way ANOVA followed by Bonferroni's post hoc test and repeated measure ANOVA were used to test the effect of clarithromycin and its increasing concentration amongst APA groups. The nonparametric Mann Whitney test was used to compare CD56 ${ }^{+}$and CD56- cells for quantitative variables. Significance was set at $p<0.05$. The GraphPad for Mac (vers. 6.0 GraphPad Software, Inc., San Diego, CA) and SPSS (version 24 for Mac, IBM, USA) softwares were used for statistical analysis. 


\section{Results}

\section{Characteristics of the APA patients.}

We selected seven PA patients, who were unambiguously diagnosed with APA by the "four corners criteria" 6 ; of them 3 were found to be wild-type, 2 had G151R and 2 had L168R mutations at sequencing. All showed the florid PA phenotype expected in APA patients, with no clear-cut differences among genotypes from the clinical standpoint (Table 4.1). By definition all were biochemically cured of PA and became normotensive without treatment after unilateral adrenalectomy.
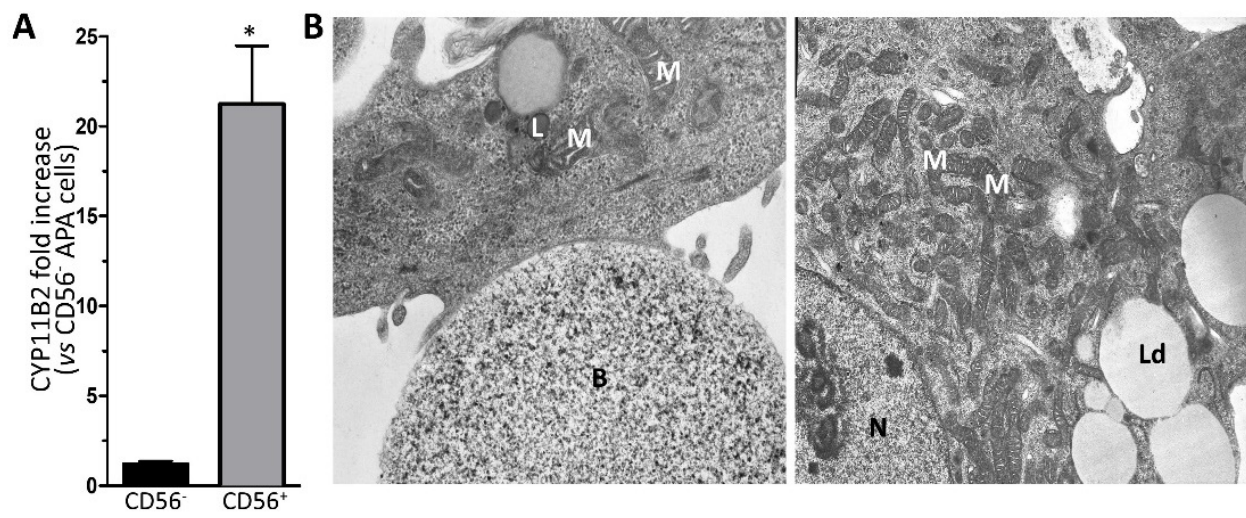

Figure 4.1. Characterization of aldosterone-producing adenoma (APA) CD56+ cells. A,The bar graph shows that the relative expression of CYP11B2 gene expression was significantly higher in $\mathrm{CD}_{56}{ }^{+}$than in $\mathrm{CD}^{-} 6^{-}$cells isolated from APA. Data represent mean $\pm \mathrm{SD}, \mathrm{n}=7,{ }^{*} \mathrm{P}=0.01$ by Mann-Whitney test. B, Representative electron microscopy pictures of CD56 ${ }^{+}$APA wild-type cells showing binding to CD56 precoated beads. CD56 + APA cells are characterized by the presence of mitochondria with tubule-vesicular cristae, abundant lipid droplets, some liposome, all of which are the typical features of steroidogenic aldosterone-producing cells $(B, n=3)$. Magnification: $\times 20000$. B indicates bead; L, lysosomes; Ld, lipid droplets; $M$, mitochondria; and N, nucleus.

\section{Characterization of APA CD56 ${ }^{+}$cells}

Real-time PCR showed that expression of CYP11B2 was $21.23 \pm 9.15$-fold $(p=0.01)$ higher in $\mathrm{CD}^{+} 6^{+}$cells than in $\mathrm{CD}^{-} 6^{-}$cells isolated from APA cells (Figure 4.1, panel $A, n=7)$. Electron microscopy demonstrated that dispersed $\mathrm{CD}^{+} 6^{+} \mathrm{APA}$ cells were selectively bound to CD56-precoated beads. These cells showed the classical features of steroidogenic aldosterone-producing APA cells 13, e.g. abundant mitochondria with tubule-vesicular cristae, abundant lipid droplets, some liposomes, and smooth endoplasmic reticulum (SER) profiles (Figure 4.1, panel B). 
Effect of clarithromycin on CYP11B2 gene expression and aldosterone release

Compared to the $\mathrm{CD}^{+} 6^{+}$cells isolated from the wild-type APA, the G151R and L168R mutated APA showed a significantly higher in vitro production of aldosterone (Figure 4.2, panels $B$ and $D$ ). When $C D 56^{+}$cells isolated from G151R mutated (Figure 4.2 panel A, circle symbols) and L168R APAs (Figure 4.2 panel A, square symbols) were exposed to increasing concentrations [5 to $50 \mathrm{umol} / \mathrm{L}$ ] of clarithromycin, we found a consistent concentration-dependent blunting effect of clarithromycin on both CYP11B2 gene expression (Figure 4.2, panel A) and aldosterone release (Figure 4.2, panel B), which did not occur in wild-type APA cells (Figure 4.2 panel A and B, triangle symbol). No differences in CYP11B2 gene expression changes and the aldosterone production lowering between the G151R and the L168R mutated APA cells were seen at post hoc Bonferroni's test. Therefore, the results obtained in the mutated APA cells were examined jointly and compared to the wild-type APA cells (Figure 4.2, panels $C$ and D). This showed a highly significant $(p<0.001)$ effect of clarithromycin concentration and group at repeated measures ANOVA. 
A

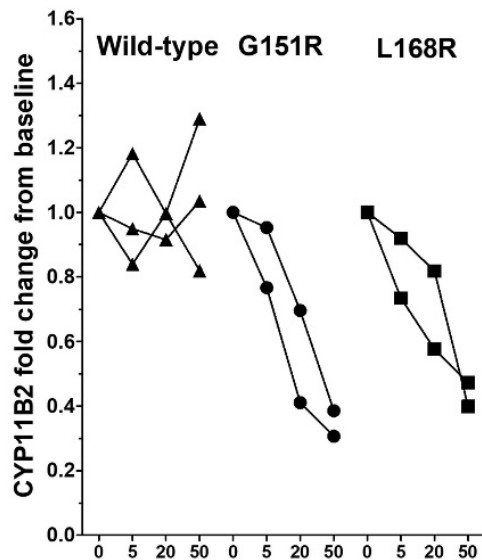

[Clarithromycin $\mu \mathrm{mol} / \mathrm{L}$ ]

B

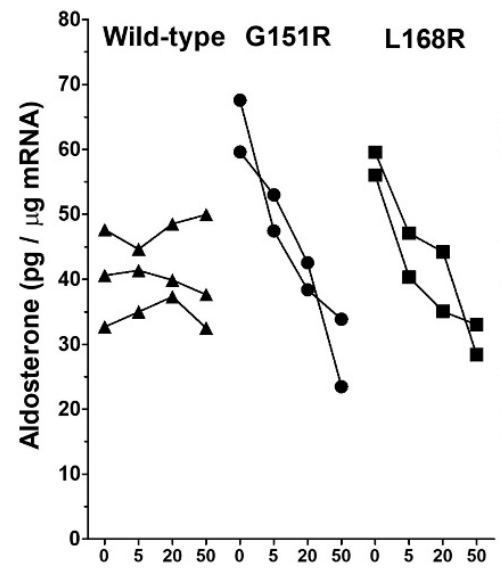

[Clarithromycin $\mu \mathrm{mol} / \mathrm{L}]$

\section{C}

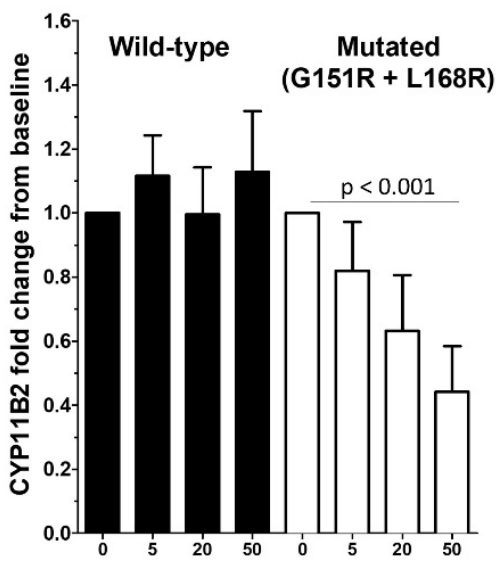

[Clarithromycin $\mu \mathrm{mol} / \mathrm{L}$ ]

\section{D}

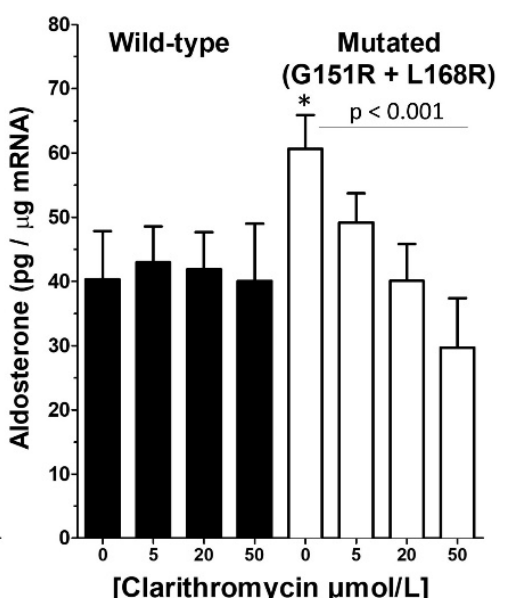

[Clarithromycin $\mu \mathrm{mol} / \mathrm{L}]$

Figure 4.2. Effects of clarithromycin on aldosterone in wild-type and mutated KCNJ5 aldosterone-producing adenoma (APA). A and B, Average values of CYP11B2 gene expression (A) and aldosterone production (B) obtained from the CD56 ${ }^{+}$APA cells. Clarithromycin concentration dependently blunts CYP11B2 gene expression and aldosterone release in $\mathrm{CD}_{56}{ }^{+}$cells isolated from G151R mutated (circle symbols, $n=2$ ) and L168R APAs (square symbols, $n=2$ ) but not in those wild-type APAs (triangle symbols, $n=3$ ). Each experiment was performed in duplicate: please note the consistency of the findings. Aldosterone production was significantly higher at baseline in the KCNJ5 mutated than in wild-type APA ( $\left.{ }^{*} \mathrm{P}<0.01\right)$. Given the similar response to clarithromycin of $\mathrm{G} 151 \mathrm{R}$ and L168R APA cells, the downstream analysiswas performed by cumulating these 4 APA together (C and $D)$. At repeated measures ANOVA, there was a highly significant $(P<0.001)$ lowering of both CYP11B2 mRNA and aldosterone production in the mutated group and a highly significant $(P<0.001)$ difference of the change when compared with wild- type APA cells. 0 denotes exposure to vehicle. Data represent mean $\pm S D$. 


\section{Discussion}

In this proof-of-principle study we selected seven patients, who were unambiguously diagnosed with APA by the "four corners criteria", as confirmed by biochemical cure of PA and normotension without treatment after unilateral adrenalectomy ${ }^{6}$. They showed the florid PA phenotype expected in APA patients, but no clear-cut differences among genotypes from the clinical standpoint. Of them, 3 were found to be wild-type, 2 had G151R and 2 had L168R mutations at sequencing. The APA tissue obtained at adrenalectomy was used to obtain dispersed APA cells from which a pure population of aldosterone-secreting cells could be immunoseparated using CD56 pre-coated magnetic beads, as described in detail ${ }^{11}$.

When exposed to increasing concentrations of clarithromycin the $\mathrm{CD}^{2} 6^{+}$cells obtained from wild-type APAs showed no change of CYP11B2 gene expression and aldosterone secretion in response to the macrolide (Figure 4.2). By contrast, both G151R or L168R APA cells exposed to clarithromycin showed a concentration-dependent consistent blunted expression of the aldosterone synthase gene (CYP11B2), the step-limiting enzyme, which in a 3-step process converts deoxycorticosterone to aldosterone in the mitochondria. Moreover, both G151R and L168R mutated CD56+ APA cells, which exhibited a higher in vitro production of aldosterone than wild-type APA cells at baseline in keeping with the literature 4,14 , showed a concentration-dependent consistent brisk fall also of aldosterone release (Figure 4.2, panels B and D). Therefore, these experiments extend the finding obtained in vitro in the HAC15 cell line engineered to over express the mutated G151R and L168R Kir3.4 channel ${ }^{5}$, to APA cells obtained ex vivo, which had these two common somatic mutations.

\section{Perspectives}

These results, albeit obtained in a small dataset, provide compelling evidence of the feasibility of blunting aldosterone synthesis specifically in aldosteroneproducing cells from tumors carrying two most common KCNJ5 mutations.

Whether these effects occur in all KCNJ5 mutated APA cells and whether they can happen in vivo in patients with KCNJ5 mutated APA, and whether the lowering of PAC and blood pressure after acute administration of a macrolide can be a proxy for pinpointing the PA patients harboring a mutated APA is the currently under investigation at our center. If proven, this principle will open the way to personalized diagnosis and treatment of the PA patients, who show the most florid forms of the disease, e.g. those with APA carrying KCNJ5 mutations. 


\section{What Is New?}

This study extends to aldosterone-producing cells obtained ex vivo from tumors carrying two most common KCNJ5 mutations and to clarithromycin the observation that roxithromycin, another macrolide, blunts aldosterone synthesis specifically in genetically engineered HAC15 cells.

\section{What Is Relevant?}

Macrolides and their derivatives devoid of antibiotic activity may be a novel diagnostic and therapeutic tool for blunting aldosterone synthesis specifically in aldosterone-producing cells from tumors carrying two most common KCNJ5 mutations.

\section{Summary}

In a pure population of aldosterone-producing cells isolated ex vivo from KCNJ5mutated APAs, clarithromycin specifically blunted aldosterone secretion, while it was ineffective in $\mathrm{CD}_{56}{ }^{+}$cells from wild-type APAs. This discovery opens new horizons for the diagnosis and treatment of APA with KCNJ5 mutations, which entail the most common and severe cases of PA. 


\section{References}

1. Choi M, Scholl UI, Yue $\mathrm{P}$, et al. $\mathrm{K}+$ channel mutations in adrenal aldosterone-producing adenomas and hereditary hypertension. Science. 2011;331:768-772. doi: 10.1126/science.1198785.

2. Kuppusamy M, Caroccia B, Stindl J, Bandulik S, Lenzini L, Gioco F, Fishman V, Zanotti G, Gomez-Sanchez C, Bader M, Warth R, Rossi GP. A novel KCNJ5-insT149 somatic mutation close to, but outside, the selectivity filter causes resistant hypertension by loss of selectivity for potassium. J Clin Endocrinol Metab. 2014;99:E1765-E1773. doi: 10.1210/jc.2014-1927.

3. Lenzini L, Rossi GP. The molecular basis of primary aldosteronism: from chimeric gene to channelopathy. Curr Opin Pharmacol. 2015;21:35-42.doi: 10.1016/j.coph.2014.12.005.

4. Lenzini L, Rossitto G, Maiolino G, Letizia C, Funder JW, Rossi GP. A meta-analysis of somatic $\mathrm{KCNJ} 5 \mathrm{~K}(+)$ channel mutations in 1636 patients with an aldosterone-producing adenoma. J Clin Endocrinol Metab.2015;100:E1089-E1095. doi: 10.1210/jc.2015-2149.

5. Scholl UI, Abriola L, Zhang C, Reimer EN, Plummer M, Kazmierczak BI, Zhang J, Hoyer D, Merkel JS, Wang W, Lifton RP. Macrolides selectively inhibit mutant KCNJ5 potassium channels that cause aldosterone-producing adenoma. J Clin Invest. 2017;127:2739-2750. doi: 10.1172/JCI91733.

6. Rossi GP, Bernini G, Caliumi C, et al; PAPY Study Investigators. A prospective study of the prevalence of primary aldosteronism in 1,125 hypertensive patients. J Am Coll Cardiol. 2006;48:2293-2300. doi: 10.1016/j.jacc.2006.07.059.

7. Schirpenbach C, Segmiller F, Diederich S, Hahner S, Lorenz R, Rump LC, Seufert J, Quinkler M, Bidlingmaier $M$, Beuschlein $F$, Endres S,Reincke $M$. The diagnosis and treatment of primary hyperaldosteronism in Germany: results on 555 patients from the German Conn Registry. Dtsch Arztebl Int. 2009;106:305-311. doi: 10.3238/arztebl.2009.0305.

8. Milliez P, Girerd X, Plouin PF, Blacher J, Safar ME, Mourad JJ. Evidence for an increased rate of cardiovascular events in patients with primary aldosteronism. J Am Coll Cardiol. 2005;45:12431248. doi: 10.1016/j. jacc.2005.01.015.

9. Lenzini L, Seccia TM, Aldighieri E, Belloni AS, Bernante P, Giuliani L, Nussdorfer GG, Pessina AC, Rossi GP. Heterogeneity of aldosterone-producing adenomas revealed by a whole transcriptome analysis. Hypertension. 2007;50:1106-1113. doi: 10.1161/HYPERTENSIONAHA.107.100438.

10. Seccia TM, Mantero F, Letizia C, Kuppusamy M, Caroccia B, Barisa M,Cicala MV, Miotto D, Rossi GP. Somatic mutations in the KCNJ5 gene raise the lateralization index: implications for the diagnosis of primary aldosteronism by adrenal vein sampling. $\mathrm{J}$ Clin Endocrinol Metab.2012;97:E2307-E2313. doi: 10.1210/jc.2012-2342.

11. Caroccia B, Fassina A, Seccia TM, Recarti C, Petrelli L, Belloni AS, Pelizzo MR, Rossi GP. Isolation of human adrenocortical aldosterone-producing cells by a novel immunomagnetic beads method. Endocrinology.2010;151:1375-1380. doi: 10.1210/en.2009-1243.

12. Spinazzi R, Petrelli L, Guidolin D, Carraro G, Casale V, Tortorella C, Neri G, Albertin G, Andreis PG, Nussdorfer GG. In vitro culture on Matrigel favors the long-term maintenance of rat zona glomerulosa-cell differentiated phenotype. Int J Mol Med. 2006;17:1101-1110.

13. Bornstein SR, Brown JW, Carballeira A, Goodman J, Scherbaum WA, Fishman LM. Ultrastructural dynamics of mitochondrial morphology in varying functional forms of human adrenal cortical adenoma. HormMetab Res. 1996;28:177-182. doi: 10.1055/s-2007-979155.

14. Boulkroun S, Beuschlein F, Rossi GP, et al. Prevalence, clinical, and molecular correlates of KCNJ5 mutations in primary aldosteronism. Hypertension. 2012;59:592-598. doi: 10.1161/HYPERTENSIONAHA.111.186478. 
Chapter 4 


\section{Chapter 5}

\section{Aldosterone stimulates its biosynthesis via a novel GPER mediated mechanism}

B. Caroccia, T. M. Seccia, M. Piazza, Prisco, S. Zanin, M. lacobone, L. Lenzini, G. Pallafacchina, O. Domening, M. Poglitsch, R. Rizzuto and G.P. Rossi

JCEM 2019 


\begin{abstract}
Context: The G protein-coupled estrogen receptor (GPER) mediates an aldosterone secretagogue effect of 17b-estradiol in human HAC15 adrenocortical cells after estrogen receptor $b$ blockade. Because GPER mediates mineralocorticoid receptor-independent aldosterone effects in other cell types, we hypothesized that aldosterone could modulate its own synthesis via GPER activation.
\end{abstract}

Methods: HAC15 cells were exposed to aldosterone in the presence or absence of canrenone, a mineralocorticoid receptor antagonist, and/or of the selective GPER antagonist G36. Aldosterone synthase (CYP11B2) mRNA and protein levels changes were the study end points. Similar experiments were repeated in strips obtained ex vivo from aldosterone-producing adenoma (APA) and in GPERsilenced HAC15 cells.

Results: Aldosterone markedly increased CYP11B2 mRNA and protein expression (vs untreated samples, $P<0.001$ ) in both models by acting via GPER, because these effects were abolished by $G 36(P<0.01)$ and not by canrenone. GPERsilencing $(P<0.01)$ abolished the aldosterone-induced increase of CYP11B2, thus proving that aldosterone acts via GPER to augment the step-limiting mitochondrial enzyme (CYP11B2) of its synthesis. Angiotensin II potentiated the GPER-mediated effect of aldosterone on CYP11B2. Coimmunoprecipitation studies provided evidence for GPER- angiotensin type-1 receptor heterodimerization.

Conclusion: We propose that this autocrine-paracrine mechanism could enhance aldosterone biosynthesis under conditions of immediate physiological need in which the renin-angiotensin- aldosterone system is stimulated as, for example, hypovolemia. Moreover, as APA overexpresses GPER this mechanism could contribute to the aldosterone excess that occurs in primary aldosteronism in a seemingly autonomous fashion from angiotensin II. 


\section{Introduction}

The mechanisms regulating aldosterone biosynthesis remain incompletely known despite several decades of investigation (for review ${ }^{1}$ ). For example, what causes the inappropriate over-secretion of aldosterone in primary aldosteronism (PA), the most common cause of endocrine hypertension where the renin-angiotensin system is shut off ${ }^{2}$,remained unknown until agonistic autoantibodies against the angiotensin type 1 receptor ${ }^{3,4}$, elevated serum levels of PTH ${ }^{5}$ that stimulates aldosterone secretion ${ }^{6}$, downregulation of TWIK-related acid-sensitive K1 channel $2{ }^{7}$, and somatic and germline loss- and gain-of-function mutations in both cations and anions channels ${ }^{8-13}$ were discovered (for review ${ }^{1,14,15}$ ).

Multiple observations have also suggested a role for estrogens in the regulation of aldosterone under physiological and pathophysiological conditions 16-19. Accordingly, GPER, a G-protein coupled receptor initially described as an estrogen-specific receptor ${ }^{20-22}$, but subsequently discovered to promiscuously bind other steroids ${ }^{23}$, and to mediate mineralocorticoid receptor (MR)-independent aldosterone effects in different cell types ${ }^{24-28}$, was found to be overexpressed in aldosterone-producing adenoma (APA), a main subtype of human $\mathrm{PA}^{29}$. In human adrenocortical cells we previously observed that GPER mediates a potent secretagogue effect of $17 \beta$-estradiol (E2) on aldosterone when the estrogen $\beta$ receptor $(E R \beta)$ is pharmacologically blocked or molecularly silenced ${ }^{29}$. Based on evidences suggesting the possibility of promiscuous activation of GPER by steroids other than E2, we hypothesized that aldosterone could activate GPER and act as its own secretagogue. If proven, this mechanism could be relevant for rapidly and potently enhancing the biosynthesis of aldosterone when the renin-angiotensinaldosterone system is stimulated. It could be also important for understanding the autonomous aldosterone production in human PA 2,30 . Hence, by acting in an autocrine-paracrine fashion in GPER-overexpressing APA ${ }^{29,31}$, that generate high local concentrations of the hormone, aldosterone could self-perpetuate the hyperaldosteronism despite a blunted renin-angiotensin system. This study was, therefore, set up to test in vitro this hypothesis using two different models that are characterized by sizable differences of aldosterone production, i.e. a human adrenocortical carcinoma cell line that produces relatively small amounts of aldosterone, and strips obtained ex vivo from APA that produce substantial amounts of aldosterone.

\section{Methods}

\section{Adrenocortical cell line HAC15}

Adrenocortical cell line HAC15, a gift of William E. Rainey (University of Michigan at Ann Arbor, USA), was grown in Dulbecco's Modified Eagle Medium (DMEM F12) supplemented with $10 \%$ Cosmic Calf serum (CCS), $1 \%$ glutamine, and $1 \%$ 
antibiotic/antimycotic mixture. For the experiments, the cells were seeded in 12well plates at $2 * 10^{5}$ cells per well and grown to sub-confluence $(80 \%)$. Prior to experiment, they were synchronized by incubation for 24 hours with DMEM/F12 medium supplemented with $0.5 \%$ dextran-coated charcoal-stripped CCS, $1 \%$ glutamine, and $1 \%$ antibiotic/antimycotic. Cells were treated with increasing concentrations of aldosterone (from $10^{-11}$ to $10^{-7} \mathrm{M}$; Sigma-Aldrich, Milan, Italy) for 12 hours. The treatment with $10^{-7} \mathrm{M}$ aldosterone was then performed at different time points $(2,8,12,24,48$ hours). To establish if aldosterone effect was mediated by mineralocorticoid receptor, glucocorticoid receptor or GPER receptor, the selective MR antagonist, canrenone $\left(10^{-5} \mathrm{M}\right.$; Sigma-Aldrich, Milan, Italy), or the selective GR antagonist RU486 $\left(10^{-6} \mathrm{M}\right.$ or $10^{-5} \mathrm{M}$; generous gift of Prof. Massimiliano Caprio), or the selective GPER antagonist G36 ${ }^{32}\left(10^{-5} \mathrm{M}\right.$; Tocris Bioscience, Bristol, UK), were added to fresh media 1 hour before aldosterone treatment.

To establish if angiotensin type-1 receptor (AT1R) and GPER activation interacted in altering CYP11B2 expression and if these two receptors formed heterodimers, HAC15 cells were treated for 12 hours with aldosterone $10^{-7} \mathrm{M}$ on top of angiotensin II (Ang II) $10^{-7} \mathrm{M}$, in the absence or presence of the selective AT1R antagonist irbesartan, $\mathrm{G} 36$, and of both antagonists.

\section{Tissues}

APA tissues were obtained from consenting patients with a conclusive diagnosis of APA, as established by the five corner criteria, which include i) biochemical evidence of PA; ii) lateralized aldosterone secretion by adrenal vein sampling; iii) detection of an adenoma by imaging (TC or MR) and at pathology; iv) biochemical correction of PA after adrenalectomy; v) detection of a CYP11B2-positive adenoma in the resected adrenal cortex at immunohistochemistry with a monoclonal antibody for human CYP11B2 1,2.

Briefly, tissues were obtained under sterile conditions in the operating room immediately after excision. For the functional studies, APA tissues were cut into 2 to 3-mm strips, which were transferred into 48-well plates containing $500 \mathrm{uL}$ of serum-free DMEM/F12 culture medium. After 6 hours of starvation, the strips were treated with $10^{-7}$ and $10^{-8} \mathrm{M}$ aldosterone alone or in presence of $10^{-5} \mathrm{M}$ G36. All procedures were approved by the local Ethics Committee and informed written consent was obtained from each individual patient.

\section{RNA extraction and quantitative real-time PCR}

RNA from cells was extracted after treatments with the Roche RNeasy kit (Roche, Monza, Italy) and RNA from tissues with Qiagen RNA extraction kit (Qiagen, Hilden, Germany) following the manufacturer's protocol. The quantity and quality were also determined by spectrophotometric readings at 260/280/230 $\mathrm{nm}$. 
One $\mu \mathrm{g}$ total RNA from cells and from tissues was reverse transcribed in a final volume of $20 \mu \mathrm{L}$ using the iScript ${ }^{\mathrm{TM}} \mathrm{cDNA}$ Synthesis kit (Bio-Rad, Milan, Italy) following the manufacturer's recommendations. The RT-PCR reactions were performed in Delphi 1000 ${ }^{\mathrm{TM}}$ Thermal Cycler (Oracle Biosystems ${ }^{\mathrm{TM}}$ Watertown, MA, USA). We measured the levels of aldosterone synthase (CYP11B2) mRNA with a real time RT-PCR by the comparative Ct $\left(2^{-\Delta \Delta C t}\right)$ method: each sample was quantified $v s$ its housekeeping gene transcript, porphobilinogen deaminase $(P B G D)$, and normalized to the control group. Each experiment was repeated at least 5 times in duplicate, and the results are presented as fold increase \pm SD. Primers used in real time RT-PCR are reported in are reported in an online repository ${ }^{33}$.

\section{Immunoblotting}

Immunoblotting for CYP11B2, GPER and AT1R was performed following a standard protocol. In brief, after treatment, cells were homogenized in lysis buffer (Thermo Scientific, Milan, Italy) and protein concentration was determined in the soluble supernatant with BCA (Thermo Scientific, Milan, Italy). Lysate fraction (50 $\mu \mathrm{g}$ ) was separated in a polyacrylamide gel and then electro-blotted onto nitrocellulose or polyvinyldene fluoride (PVDF) membrane (Amersham-Hybond EC, GE Healthcare Life Sciences, Milan, Italy). The membranes were blocked for 30 minutes at room temperature in $5 \%$ non-fat dry blocking milk and thereafter incubated overnight at $4^{\circ} \mathrm{C}$ with a primary mouse monoclonal antibody CYP11B2 ${ }^{34}$ (diluted 1/500) or GPER or AT1R. After washing, membranes were incubated 1 hour with an anti-mouse secondary antibody. After that, the band intensity was measured in a VersaDoc Imaging System (Bio-Rad, Milan, Italy). Images were analyzed by Image Processing and Analysis in Java (Image J- NIH). Bands for CYP11B2 were normalized to glyceraldehyde 3-phosphate dehydrogenase (GAPDH).

\section{Small interfering RNA (siRNA)}

The expression of GPER was silenced in HAC15 cells by RNA interference using the Nucleofector technology (Amaxa Biosystems, Thermo Scientific, Milan, Italy) following the manufacturer's protocol. To silence GPER, HAC15 were transfected with $50 \mathrm{nM}$ ON-TARGET plus GPER siRNA (GPER siRNA; Dharmacon, Carlo Erba Reagents, Milan, Italy). An ON-TARGET plus Non-targeting Pool (Dharmacon, Carlo Erba Reagents, Milan, Italy) transfection in mock-transfected cells was used as control. Cells were seeded in 6 -well culture plates at the density of $1 \times 10^{6}$ cells per well. After 24 hours of transfection, mock-transfected and silenced cells were treated with aldosterone. Protein extraction was performed after 24 hours of treatment and followed by immunoblotting analysis for GPER and CYP11B2. 


\section{Cytosolic $\mathrm{Ca}^{2+}$ measurements in $\mathrm{CD}^{2} 6^{+}$cells}

A pure population of aldosterone-secreting cells from APA was obtained by sequential enzymatic digestion and immune-separation of $\mathrm{CD}^{2} 6^{+}$cells on magnetic beads pre-coated with an antibody specific for neural cell adhesion molecule tissues from 3 patients, as previously reported ${ }^{35}$. At electron microscopy we showed that these $\mathrm{CD}_{56}{ }^{+}$cells had a high content in mitochondria and lipid droplets, thus entailing the ultrastructural features of aldosterone-producing cell. Moreover, they also showed aldosterone production in vitro ${ }^{35,36}$. CD56 ${ }^{+}$cells were plated on L-polylysine pre-coated coverslips two day before the experiments. Cells were loaded with $2 \mu \mathrm{M}$ Fura-2-AM (Life Technologies, Milan, Italy) diluted in KrebsRinger modified buffer containing $0.02 \%$ pluronic acid and $250 \mu \mathrm{M}$ sulfinpyrazone for $20 \mathrm{~min}$ at $37^{\circ} \mathrm{C}$ and then washed two times for $10 \mathrm{~min}$ with Krebs-Ringer modified buffer. Images were acquired every $2 \mathrm{~s}$ with a Nikon Ti-E microscope equipped with a Nikon 20x air objective (Nikon, Tokyo, Japan) and the software used for the acquisition was NIS Element AR (Nikon). Exposure time was set to $100 \mathrm{~ms}$. Excitation was performed with a Cairn OptoScan equipped with a $150 \mathrm{~W}$ Xenon arc lamp. Changes in Fura-2 fluorescence (340/380 $\mathrm{nm}$ ratio) were expressed as $R / R 0$, where $R$ is the ratio at time $t$ and $R 0$ is the ratio at the beginning of the experiment. $\mathrm{CD}^{+} 6^{+}$cells from APA tissues were treated with aldosterone, Ang II and $17 \beta$-estradiol (E2), the two latter used as control.

\section{Aldosterone measurement in human adrenocortical tissues}

We measured aldosterone levels in APA-adjacent tissue and in APA to determine how the concentration of aldosterone that increased CYP11B2 expression in our in vitro experiments compared with those occurring in vivo in these tissues. To this end, adrenal tissue samples (10-20 mg wet weight per sample) were grinded under liquid nitrogen. The obtained frozen tissue powder was then rapidly dissolved in ice-cold guanidine hydrochloride (6 mol/L) supplemented with $1 \%(\mathrm{v} / \mathrm{v})$ TFA at a $100 \mathrm{mg}$ tissue/mL concentration. Resulting homogenates were spiked with $500 \mathrm{pg}$ of deuterated aldosterone (D4) for internal standardization. Following C18-based solid phase extraction, samples were analyzed by UPLC-MS/MS using a reversed phase analytical column operating in line with a Xevo TQ-S mass spectrometer (Waters, Milford, MA). The tissue concentration of aldosterone was calculated considering the corresponding response factors determined in calibration curves in tissue extract matrix, under condition in which the integrated signals exceeded a signal to-noise ratio of 10 .

\section{Coimmunoprecipitation studies}

Interaction between AT1R and GPER was investigated in HAC15 cells using Pierce Co-Immunoprecipitation Kit (Thermofisher, Milan, Italy) and following the manufacturer's protocol, as described in detail in an online repository ${ }^{33}$. HAC15 
cells harvested from four $15 \mathrm{~cm}$ culture dishes were centrifuged and pelleted. Cell pellet was dissolved into the solution for protein isolation. For coimmunoprecipitation studies, protein complexes were immunoprecipitated with antiAT1R (Cusabio, Paris, France) or anti-GPER antibody (Novus biologicals, Milan, Italy). The presence of GPER in AT1R immunoprecipitated protein was investigated with immunoblot; the presence of AT1R in GPER immunoprecipitated protein was also verified with immunoblot.

\section{Statistical analysis}

Statistical analysis was performed with GraphPad Software ${ }^{\mathrm{TM}}$ (vers. 8.02 for Mac OS X, La Jolla, CA). Non-parametric Mann Whitney test or one-way ANOVA test and repeated-measures ANOVA were used, as appropriate.

\section{Results}

\section{Aldosterone treatment enhances CYP11B2}

In concentration-response and time-course experiments for up to 48 hours in HAC15 cells, we found that aldosterone enhanced CYP11B2 gene expression at $10^{-8}$ and $10^{-7} \mathrm{M}$ and that this effect was clearly evident after 12 hours (Figure 5.1 panel $\mathrm{A}$ and $\mathrm{B}$ ). The latter concentration and time point were therefore used to analyze the changes of CYP11B2 mRNA and protein in the further experiments in HAC15 cells.

To investigate the role of the MR in mediating CYP11B2 gene expression changes we preincubated HAC15 cells with either the MR antagonist canrenone, or the GPER antagonist G36. At concentration between $10^{-6}-10^{-4} \mathrm{M}$ canrenone alone slightly, but significantly, increased CYP11B2 mRNA (Figure 5.1, panel D) ${ }^{33}$, but blunted CYP11B2 expression at $10^{-3} \mathrm{M}^{33}$.

Cell viability studies carried out in parallel in HAC15 cells showed a cytotoxic effect of canrenone at the latter concentration ${ }^{33}$. Importantly, at $10^{-5} \mathrm{M}$, i.e. a concentration 100-fold higher than that of aldosterone, but not cytotoxic, canrenone did not blunt aldosterone-induced CYP11B2 mRNA increase. By contrast, 1-hour pretreatment with $10^{-5} \mathrm{M} \mathrm{G}-36$ abolished the CYP11B2 gene expression enhanced by aldosterone (Figure 5.1, panel D).

To rule out the possibility that at $10^{-8} \mathrm{M}-10^{-7} \mathrm{M}$ aldosterone could activate the glucocorticoid receptor $(\mathrm{GR})^{37}$, we treated HAC15 cells with the $\mathrm{GR}$ antagonist RU486 at two different concentrations $\left(10^{-6} \mathrm{M}-10^{-5} \mathrm{M}\right)$, alone or in the presence of aldosterone. RU486 neither affected by itself CYP11B2 gene expression, nor did it alter aldosterone-induced CYP11B2 gene expression ${ }^{33}$.

The stimulatory effect of aldosterone on CYP11B2 was confirmed at protein levels: HAC15 cell exposure to aldosterone for 24 hours increased CYP11B2 protein 
expression, while G-36 abolished this increase, and canrenone left it unaffected (Figure 5.1, panel E).

Practically identical results were found in strips obtained ex vivo from two female and two male APA patients upon exposure to $10^{-7}$ and $10^{-8} \mathrm{M}$ aldosterone concentrations: the hormone augmented CYP11B2 gene expression; this effect was prevented by G-36 but not by canrenone, that per se elicited no effects (Figure 5.1, panel C).

Importantly, in parallel experiments the changes in CYP11B2 gene expression were found to be consistently associated with aldosterone release in the medium 33.

\section{GPER silencing blunted aldosterone-induced CYP11B2 protein expression}

We used siRNA technology to confirm the finding that GPER modulates aldosterone synthase expression after aldosterone treatment. After 48 hours transfection GPER-silenced HAC15 cells showed a 50\% significant reduction of GPER protein expression, as compared to control HAC15 cells mock-transfected with non-targeting siRNA (Figure 5.2, panel A). In the GPER silenced cells $10^{-7} \mathrm{M}$ aldosterone induced no increase of CYP11B2 protein expression after 24-hour, thus confirming that the aldosterone-activated CYP11B2 expression was GPERmediated (Figure 5.2, panel B).

\section{Cytosolic $\mathrm{Ca}^{2+}$ measurements}

We measured cytosolic $\mathrm{Ca}^{2+}$ levels after exposure to $10^{-7} \mathrm{M}$ aldosterone to gain insight into the pathways downstream GPER activation, using the ratiometric Fura$2 \mathrm{Ca}^{2+}$ indicator and $\mathrm{E} 2$ and $\mathrm{Ang} \mathrm{Il}$, as controls, in $\mathrm{CD}_{56}{ }^{+}$cells freshly isolated from APA. We found that, although exposure to $10^{-8} \mathrm{M}$ Ang II caused a significant increase of cytosolic $\mathrm{Ca}^{2+}$ that was followed by prominent $\mathrm{Ca}^{2+}$ oscillations (Figure 5.2, panel C), cytosolic $\mathrm{Ca}^{2+}$ was not affected by E2 or by aldosterone, indicating that the GPER-mediated stimulatory effect of these steroids on CYP11B2 gene expression does not involve detectable increases of cytosolic $\mathrm{Ca}^{2+}$ (Figure 5.2, panel C).

\section{Aldosterone concentration in human adrenocortical tissues ex vivo}

To investigate how the concentrations of aldosterone that elicited a clear-cut effect on CYP11B2 mRNA levels and aldosterone synthase protein expression compared with those present in the APA tissue, we measured tissue concentrations of aldosterone by using a state-of-the-art UPLC-MS/MS spectrometry after C18based solid phase extraction. We found $3.9^{*} 10^{4} \mathrm{fmol} / \mathrm{g}\left(1.8^{*} 10^{4}-9.1^{*} 10^{4} \mathrm{fmol} / \mathrm{g}\right.$, median, $95 \% \mathrm{Cl}$ ) and $1.8^{*} 10^{6} \mathrm{fmol} / \mathrm{g}\left(7.0^{*} 10^{5}-3.8^{*} 10^{6} \mathrm{fmol} / \mathrm{g}\right.$, median, $\left.95 \% \mathrm{Cl}\right)$ of aldosterone in the APA-adjacent tissue and in APA obtained ex vivo, respectively 
(Figure 5.2, panel D). By assuming $1 \mathrm{~g}$ of adrenal tissue to correspond approximatively $1 \mathrm{ml}$ of tissue, we estimated that $1.8^{*} 10^{6} \mathrm{fmol} / \mathrm{g}$ is equivalent to $1.8^{*} 10^{6} \mathrm{M}$, i.e. about 18 -fold higher than the highest concentration $\left(10^{-7} \mathrm{M}\right)$ of aldosterone used in our in vitro and ex vivo experiments in HAC15 cells and APA strips.

\section{Cross-talk between G protein-coupled receptors AT1 and GPER-1}

Because functional interactions between GPCRs have been reported, we investigated whether cross-talk between AT1R and GPER could help understanding of the mechanism(s) by which aldosterone-induced GPER activation promoted CYP11B2 gene expression. We quantified GPER and AT1R gene and protein expression in APA and APA adjacent tissues by digital droplet PCR, a technique held to furnish absolute copies number of gene transcripts. We found that GPER and AT1R showed comparable mRNA levels; however, immunoblotting studies showed that only GPER was more abundant in APA than in APA adjacent tissue at the protein level ${ }^{33}$. Both aldosterone and Ang II increased CYP11B2 gene expression in APA strips (Figure 5.3, panel A); when given on top of Ang II, aldosterone potentiated the secretagogue effect of the peptide. Moreover, the additive effect of aldosterone and Ang II was inhibited by either irbesartan or G36 (Figure 5.3, panel B). Similarly, in HAC15 cells aldosterone potentiated the effect of Ang II, whilst pre-treatment with irbesartan and/or G36 blunted this augmentation (Figure 5.3, panels C, D).

To investigate if the interaction between GPER and AT1R activation could be sustained by heterodimer formation, we performed co-immunoprecipitation experiments in HAC15 cells. GPER protein expression was detected by immunoblot after AT1R immunoprecipitation and vice versa, thus confirming the presence of heterodimers (Figure 5.3, panel E). 
A

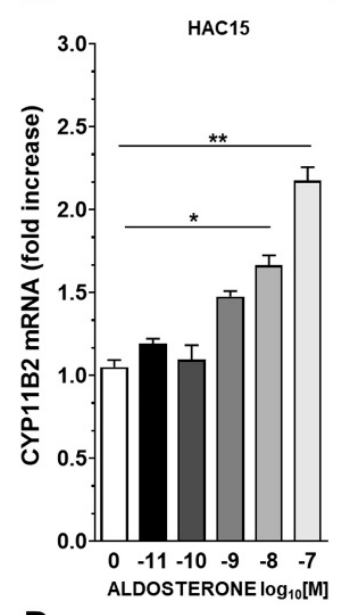

D
B

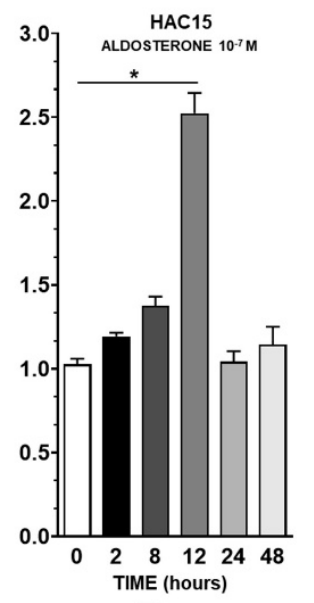

$\mathbf{E}$
C

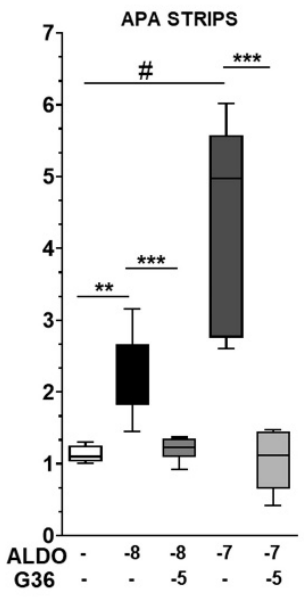

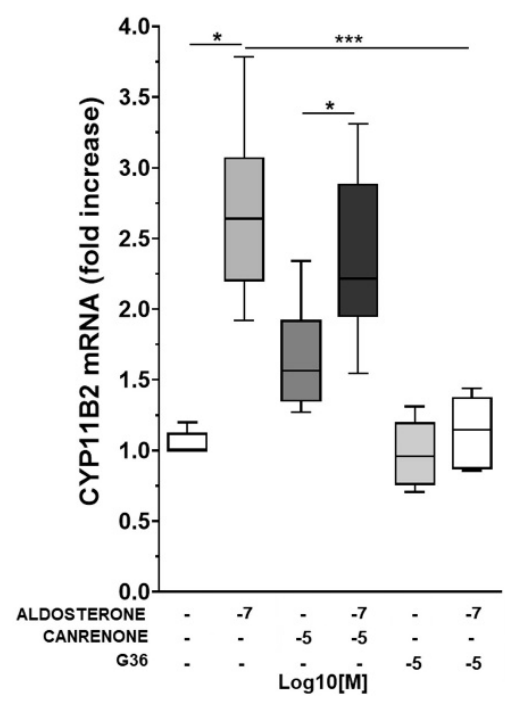

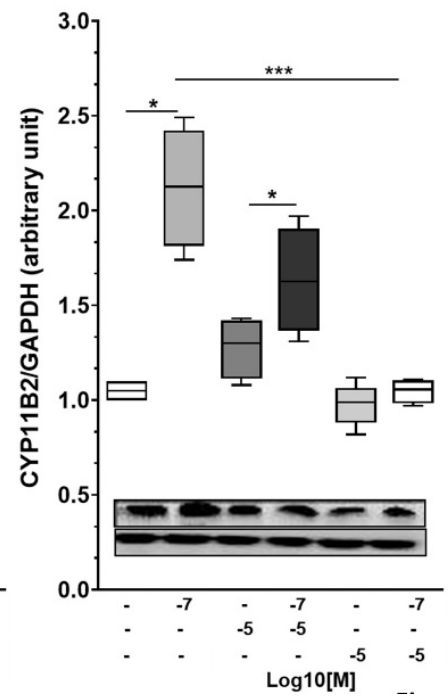

Figure 5.1: Aldosterone treatment enhances CYP11B2 via GPER activation.

Panel A: CYP11B2 gene expression after exposure of HAC15 cells to increasing concentration of aldosterone. Data represent mean \pm SD $(n=5)$. Panel B: CYP11B2 expression levels in HAC15 cell exposed for 2, 8, 12, 24 and 48 hours to aldosterone $10^{-7} \mathrm{M}$. Data represent mean $\pm S D(n=5)$. Panel C: Aldosterone-induced CYP11B2 mRNA expression in APA strips obtained from 4 different patients. APA strips were treated with aldosterone $10^{-8} \mathrm{M}$ and $10^{-7} \mathrm{M}$ alone or on top of G36 $10^{-6} \mathrm{M}$ or $10^{-5} \mathrm{M}$, respectively. Data represent median and $95 \% \mathrm{Cl}$ of 4 different experiments performed in triplicate. Panel D: CYP11B2 gene expression after treatment of HAC15 cells with aldosterone $10^{-7} \mathrm{M}$ on top of canrenone $10^{-5} \mathrm{M}$ or $\mathrm{G} 3610^{-5} \mathrm{M}$. Data represent median and $95 \% \mathrm{Cl}$ of 7 different experiments performed in duplicate. Panel E: CYP11B2 protein expression after treatment with aldosterone $10^{-7} \mathrm{M}$ alone or on top of canrenone $10^{-5} \mathrm{M}$ or G36 $10^{-5} \mathrm{M}$ for 24 hours. Data represent median and $95 \% \mathrm{Cl}$ of 5 different experiments performed in duplicate. ALDO: Aldosterone; ${ }^{*} \mathrm{P}<0.01$; ${ }^{* \star} \mathrm{P}<0.001$, $^{* \star *} \mathrm{P}<$ $0.0001 ; \# \mathrm{P}=0.002$ 
A

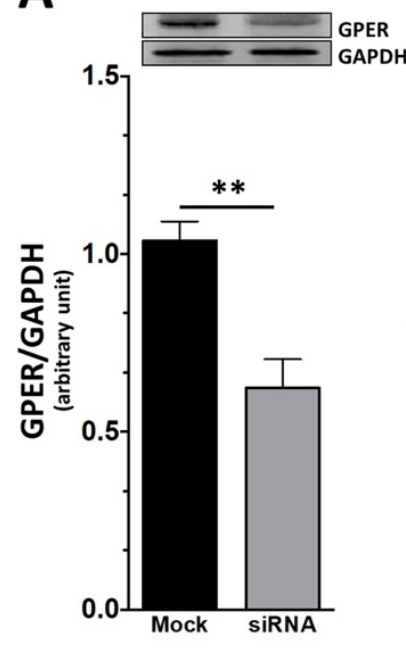

C

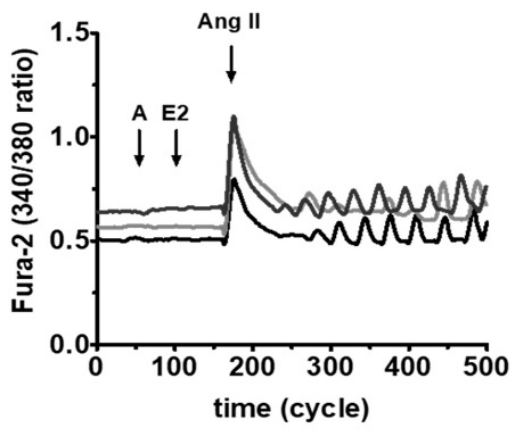

B

D
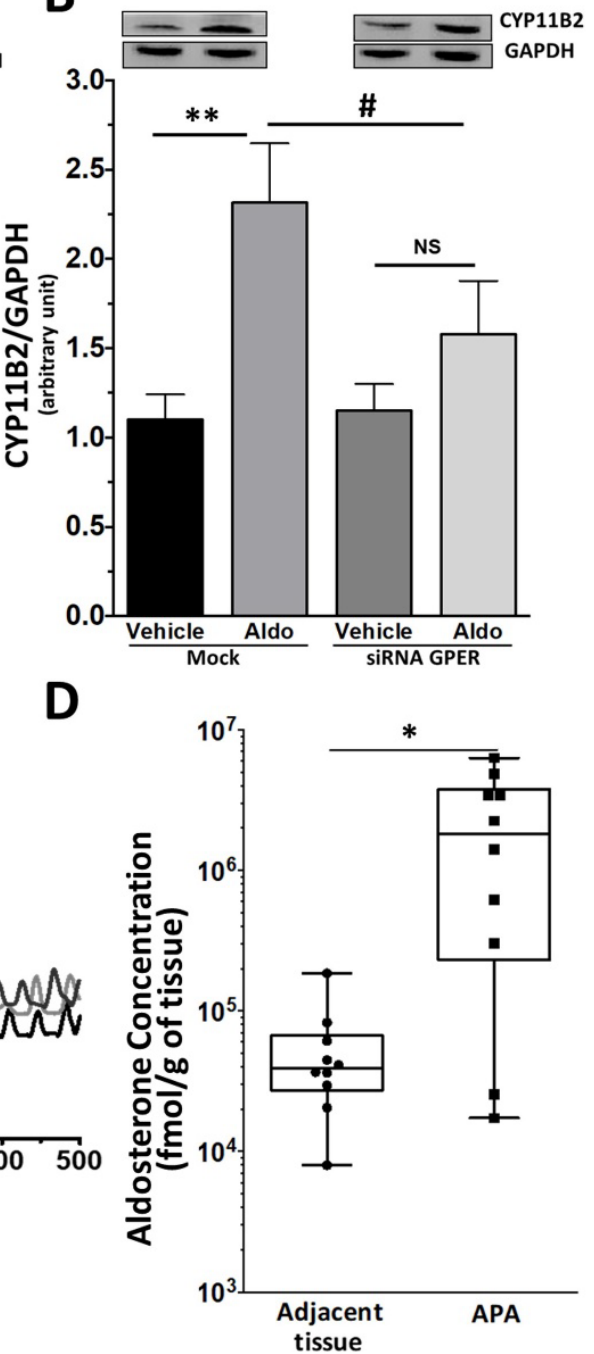

Figure 5.2: GPER silencing blunted aldosterone-induced CYP11B2 protein expression.

Panel A: GPER-1 protein levels in HAC15 cells after transfection with GPER siRNA compared with mock-transfected cells. Data represent mean \pm SD of 4 different experiments performed in duplicate. Panel B: CYP11B2 protein expression after exposure of mock transfected HAC15 cells and of silenced GPER-1 cells to aldosterone $10-7$ M. Data represent mean \pm SD $(n=4)$. Panel C: Representative traces of cytosolic $\mathrm{Ca}^{2+}$ measurement in CD56 + cells obtained from APA performed with the $\mathrm{Ca}^{2+}$ sensitive fluorescent dye Fura-2 after treatment with $10^{-7} \mathrm{M}$ aldosterone $(\mathrm{A}), 10^{-8} \mathrm{M} 17 \beta$-estradiol (E2) and $10^{-8} \mathrm{M}$ angiotensin II (Ang II). Experiments were performed in $\mathrm{CD}^{2} 6^{+}$cells obtained from 3 different APAs. Panel D: Tissue concentration of aldosterone in APA and in APA-adjacent tissue. Data represent median and $95 \% \mathrm{Cl}, \mathrm{n}=10 .{ }^{*} \mathrm{P}=0.01 ;{ }^{* *} \mathrm{P}<0.01$; $\mathrm{P}<0.001$ 
A

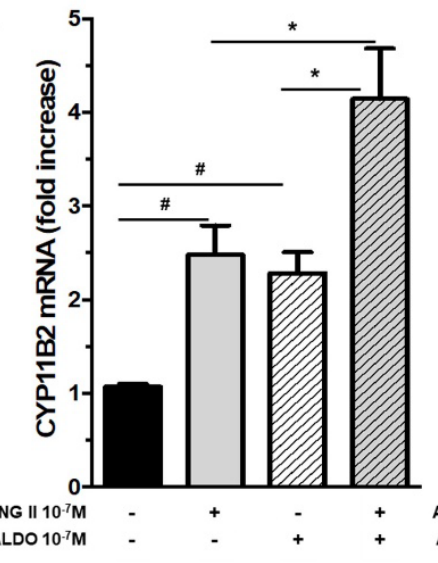

B

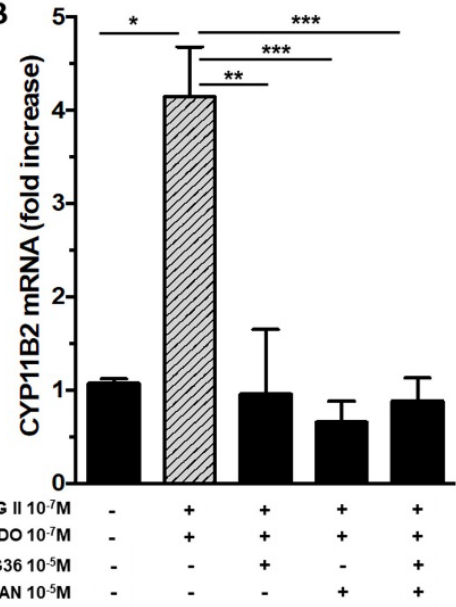

C
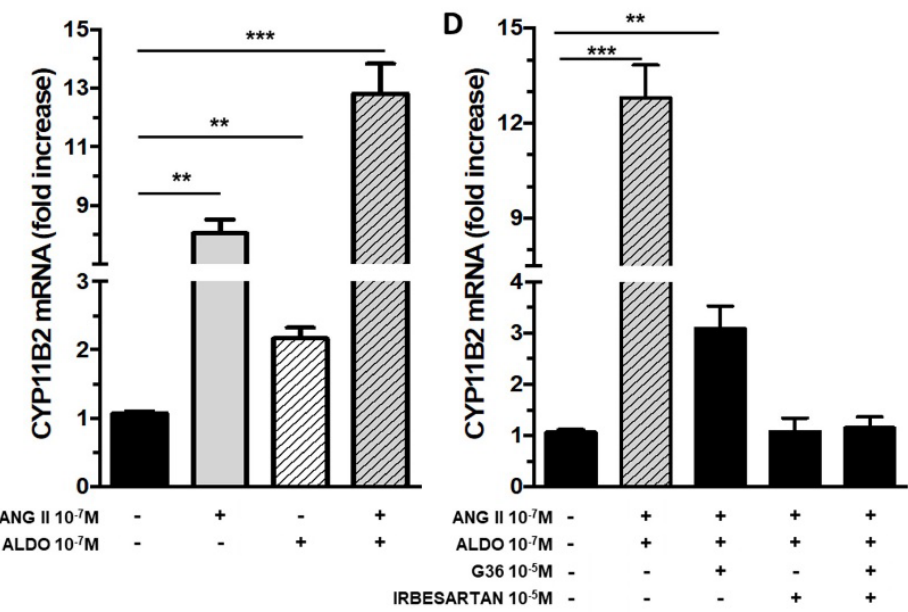

E

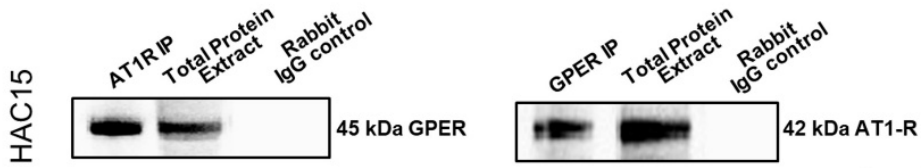

Figure 5.3: Cross talk between $G$ protein-coupled receptors AT1 and GPER-1.

Panel A:Aldosterone on top of Ang II increased the expression of CYP11B2 gene in APA strips. Panel B: CYP11B2 gene expression in APA strips after pretreatment with aldosterone and Ang II on top of irbesartan or G36, or both. Panel C: Aldosterone on top of Ang II increased the expression of CYP11B2 gene in HAC15 cells. Panel D: CYP11B2 gene expression in HAC15 cells after pretreatment with aldosterone and Ang II on top of irbesartan or G36, or both. For panels A-D data represent mean \pm SD of 4 different experiments performed in duplicate. Panel E: Representative results of coimmunoprecipitation experiments performed in HAC15 cells; after AT1R immunoprecipitation, GPER protein expression was detected by immunoblot; the presence of heterodimers in GPERimmunoprecipitated protein was also confirmed $(n=3)$. Rabbit IgG control: negative control. ALDO: Aldosterone; $\# \mathrm{P}=0.04 ;{ }^{*} \mathrm{P}=0.03 ;{ }^{* *} \mathrm{P}<0.01$; ${ }^{* *} \mathrm{P}<0.001$ 


\section{Discussion}

In this study we found that aldosterone stimulated the expression of CYP11B2, the mitochondrial $\mathrm{Ca}^{2+}$ - and $\mathrm{NADH}$-dependent step-limiting enzyme of its biosynthesis. This effect occurred both in a female-derived adrenocortical carcinoma cell line (HAC15), and in strips obtained ex vivo at adrenalectomy from a mixed-gender cohort of primary aldosteronism patients with aldosterone-producing adenoma (Figure 5.1). These are novel important pieces of information on the regulation of aldosterone secretion under physiological and pathophysiological conditions, as several parallel studies ${ }^{33}$ showed that increased levels of CYP11B2 mRNA and protein are proxies of enhanced aldosterone release ${ }^{29}$. They could also improve understanding of what happens in primary aldosteronism, the most common, albeit often overlooked, cause of endocrine hypertension ${ }^{2,30}$.

By using pharmacological tools to specifically block the MR or the GPER, and also by means of molecular silencing, we could identify GPER as the main mediator of CYP11B2 activation in response to aldosterone (Figures 5.1 and 5.2). The selective MR antagonist canrenone was chosen because it is an active metabolite of spironolactone, which, at variance with spironolactone, does not require cytochrome P450 activation ${ }^{38}$. In accordance with the notion that MR antagonists are not very potent drugs and require a high molar antagonist/agonist ratio to display their antagonistic effects ${ }^{39}$ we used canrenone at concentrations 100 -fold higher than those of aldosterone and we found that canrenone did not blunt the effect of aldosterone.

The effect of canrenone on CYP11B2 expression was further investigated in a concentration-dependent experiment that showed a dual action: at $10^{-6}$ and up to $10^{-4} \mathrm{M}$ canrenone stimulated CYP11B2 gene expression, while at $10^{-3} \mathrm{M}$ it blunted it ${ }^{33}$. We contend that the stimulatory effect seen at lower concentrations might involve an off-target antagonist effect on the ER $\beta{ }^{33}$, because previous studies showed that ER $\beta$ blockade unmasks the GPER-mediated stimulatory effect on CYP11B2 expression of steroids as E2 ${ }^{29}$. Moreover, the fall of CYP11B2 seen at the highest concentrations of the MR antagonist likely occurred because of a cytotoxic effect as shown by our cell viability ex- periments based on the 3-(4,5Dimethylthiazol-2-yl)-2,5- diphenyltetrazolium bromide for dye (MTT assay).

Of further note, the effect of aldosterone on CYP11B2 did not involve the glucocorticoid receptor (GR), as it was be unaffected by the GR antagonist RU486 33,37. As the adrenocortical carcinoma cells HAC15 might not reflect what occurs in vivo in human PA, which is usually caused by an aldosterone-producing adenoma, we wished to corroborate the findings by using strips of these tumours obtained ex vivo at adrenalectomy from a mixed gender cohort of patients presenting with florid clinical PA phenotypes. These results provided additional proof that aldosterone increased CYP11B2 gene expression (Figure 5.1, panel C) via GPER, and not the 
MR or GR, as its effect was abolished by G36 and unaffected by canrenone and $\mathrm{RU} 486^{33}$.

As regards signaling pathways, we herein found no detectable changes of cytosolic $\mathrm{Ca}^{2+}$ levels in response to aldosterone (Figure 5.2, panel C), consistently with the previous finding that E2-induced GPER-mediated expression of CYP11B2 and aldosterone secretion does not involve the protein kinase A-CAMP signaling pathway but not cytosolic $\mathrm{Ca}^{2+}$ mobilization ${ }^{29}$.

Some limitations are, however, to be acknowledged: first, experiments with mitochondria-specific $\mathrm{Ca}^{2+}$ sensitive probes are necessary to investigate the possibility that GPER activation of CYP11B2 can involve $\mathrm{Ca}^{2+}$ influx into the mitochondria. Second, although strips from APA represent the experimental model that is closest to the in vivo conditions, caution is advised before extrapolating our findings to what occurs clinically in PA patients. Finally, it might be argued that we have merely identified a pharmacologic effect of aldosterone, because we used high concentrations of the hormone, possibly higher than those in plasma or in adrenocortical tissue of patients with PA. However,because aldosterone is locally produced in the zona glomerulosa and in APA cells, and then released in the interstitial fluid, it might attain local concentrations greater than in the bloodstream. To address the lack of information on aldosterone concentrations in APA tissue, we measured aldosterone concentrations in APA by a state-of-the art tandem mass spectrometry technique. We found that the local tissue concentrations of aldosterone in APA tissue were about 18-fold higher than those enhancing CYP11B2 expression in vitro (Figure 5.2, panel D). As we used exogenous aldosterone as a secretagogue, we could not measure aldosterone release in the medium of our cell and strip preparations, because of the impossibility of discriminating between endogenously made and exogenously added aldosterone, without using radiolabeled precursors, which are no longer allowed in our laboratory. However, in multiple parallel experiments with angiotensin II and E2, as secretagogue, we found that changes in CYP11B2 mRNA were consistently followed by aldosterone secretion ${ }^{33}$, finding consistent with the view that aldosterone is not stored but constitutively secreted.

One additional point deserves a comment: aldosterone-mediated GPER activation did not require prior ER $\beta$ receptor blockade at variance with results with E2 ${ }^{29}$. Because data on relative affinity of aldosterone and E2 for human adrenocortical cells lack, at present we could only speculate that this might be due to a higher affinity of aldosterone for GPER and/or to lower binding affinity of E2 for GPER than for $E R \beta^{41}$.

A further novel and intriguing observation in this study was the finding that aldosterone potentiated in an additive fashion the secretagogue effect of angiotensin II in adrenocortical cells, which suggested a functional interaction 
between the angiotensin II type 1 receptor (AT1R) and GPER. This could be due to functional heterodimer formation between GPER and AT1R as shown in HAC15 cells (Figure 5.3), which were found to be stable at coimmunoprecipitation studies with proper controls in spite of no prior cross-linking (Figure 5.3, panel E).

Based on these in vitro and ex vivo studies, we would like to propose an autocrineparacrine mechanism whereby aldosterone, acting via GPER, can swiftly increase its own biosynthesis and release, under conditions when the renin-angiotensinaldosterone system needs to be rapidly activated to preserve vital organ perfusion as, for example, during acute hypovolemia and dehydration. This mechanism can play a pathophysiological role also in maintaining an inappropriately high secretion of aldosterone in PA patients, where the high blood pressure and volume expansion would also be expected to blunt renin and angiotensin II synthesis and to diminish aldosterone biosynthesis. Finally, we suggest that this autocrineparacrine mechanism could explain the occurrence of aldosterone-producing cell clusters (APCCs), which can coexist with APA, and possibly represent an early stage of the latter tumor ${ }^{41}$.

Whether this mechanism could be implicated in idiopathic hyperaldosteronism that might be sustained by APCCs ${ }^{42}$, and whether this mechanism can be further amplified by angiotensin II remains to be investigated. 


\section{References}

1. Seccia TM, Caroccia B, Gomez-Sanchez EP, Gomez-Sanchez CE, Rossi GP. The Biology of Normal Zona Glomerulosa And Aldosterone-Producing Adenoma: Pathological Implications. Endocr. Rev. 2018;39(6):1029-1056.

2. Rossi GP, Bernini G, Caliumi C, Desideri G, Fabris B, Ferri C, Ganzaroli C, Giacchetti G, Letizia C, Maccario M, Mallamaci F, Mannelli M, Mattarello MJ, Moretti A, Palumbo G, Parenti G, Porteri E, Semplicini A, Rizzoni D, Rossi E, Boscaro M, Pessina AC, Mantero F, Investigators PS. A prospective study of the prevalence of primary aldosteronism in 1,125 hypertensive patients. $J$. Am. Coll. Cardiol. 2006;48(11):2293-2300.

3. Rossitto G, Regolisti G, Rossi E, Negro A, Nicoli D, Casali B, Toniato A, Caroccia B, Seccia TM, Walther T, Rossi GP. Elevation of angiotensin-II type-1-receptor autoantibodies titer in primary aldosteronism as a result of aldosterone-producing adenoma. Hypertension 2013;61(2):526-533.

4. Kem DC, Li H, Velarde-Miranda C, Liles C, Vanderlinde-Wood M, Galloway A, Khan M, Zillner C, Benbrook A, Rao V, Gomez-Sanchez CE, Cunningham MW, Yu X. Autoimmune mechanisms activating the angiotensin AT1 receptor in "primary" aldosteronism. J. Clin. Endocrinol. Metab. 2014;99(5):1790-1797.

5. Maniero C, Fassina A, Seccia TM, Toniato A, lacobone M, Plebani M, De Caro R, Calò LA, Pessina AC, Rossi GP, Caro R De, Calo LA, Pessina AC, Rossi GP. Mild hyperparathyroidism: a novel surgically correctable feature of primary aldosteronism. J. Hypertens. 2012;30(2):390-395.

6. Mazzocchi G, Aragona F, Malendowicz LK, Nussdorfer GG. PTH and PTH-related peptide enhance steroid secretion from human adrenocortical cells. Am. J. Physiol. Metab. 2001;280(2):E209-13.

7. Lenzini L, Caroccia B, Campos AG, Fassina A, Belloni AS, Seccia TM, Kuppusamy M, Ferraro S, Skander G, Bader M, Rainey WE, Rossi GP. Lower expression of the TWIK-related acid-sensitive $\mathrm{K}+$ channel 2 (TASK-2) gene is a hallmark of aldosterone-producing adenoma causing human primary aldosteronism. J. Clin. Endocrinol. Metab. 2014;99(4):1-9.

8. Choi M, Scholl UI, Yue P, Bjorklund P, Zhao B, Nelson-Williams C, Ji W, Cho Y, Patel A, Men CJ, Lolis E, Wisgerhof M V, Geller DS, Mane S, Hellman P, Westin G, Akerstrom G, Wang W, Carling $\mathrm{T}$, Lifton RP. K+ channel mutations in adrenal aldosterone-producing adenomas and hereditary hypertension. Science 2011;331(6018):768-772.

9. Scholl UI, Goh G, Stölting G, de Oliveira RC, Choi M, Overton JD, Fonseca AL, Korah R, Starker LF, Kunstman JW, Prasad ML, Hartung EA, Mauras N, Benson MR, Brady T, Shapiro JR, Loring E, Nelson-Williams C, Libutti SK, Mane S, Hellman P, Westin G, Åkerström G, Björklund P, Carling T, Fahlke C, Hidalgo P, Lifton RP. Somatic and germline CACNA1D calcium channel mutations in aldosterone-producing adenomas and primary aldosteronism. Nat. Genet. 2013;45(9):1050-1054.

10. Fernandes-Rosa FL, Daniil G, Orozco IJ, Göppner C, El Zein R, Jain V, Boulkroun S, Jeunemaitre X, Amar L, Lefebvre H, Schwarzmayr T, Strom TM, Jentsch TJ, Zennaro MC. A gain-of-function mutation in the CLCN2 chloride channel gene causes primary aldosteronism. Nat. Genet. 2018;50(3):355-361.

11. Beuschlein F, Boulkroun S, Osswald A, Wieland T, Nielsen HN, Lichtenauer UD, Penton D, Schack VR, Amar L, Fischer E, Walther A, Tauber P, Schwarzmayr T, Diener S, Graf E, Allolio B, Samson-Couterie B, Benecke A, Quinkler M, Fallo F, Plouin PF, Mantero F, Meitinger T, Mulatero $P$, Jeunemaitre $X$, Warth R, Vilsen B, Zennaro MC, Strom TM, Reincke M. Somatic mutations in ATP1A1 and ATP2B3 lead to aldosterone-producing adenomas and secondary hypertension. Nat. Genet. 2013;45(4):440-4, 444-2.

12. Azizan EA, Poulsen H, Tuluc P, Zhou J, Clausen M V, Lieb A, Maniero C, Garg S, Bochukova EG, Zhao W, Shaikh LH, Brighton CA, Teo AED, Davenport AP, Dekkers T, Tops B, Kusters B, Ceral J, Yeo GSH, Neogi SG, McFarlane I, Rosenfeld N, Marass F, Hadfield J, Margas W, Chaggar K, 
Solar M, Deinum J, Dolphin AC, Farooqi IS, Striessnig J, Nissen P, Brown MJ. Somatic mutations in ATP1A1 and CACNA1D underlie a common subtype of adrenal hypertension. Nat. Genet. 2013;45(9):1055-1060.

13. Scholl UI, Stölting G, Schewe J, Thiel A, Tan H, Nelson-Williams C, Vichot AA, Jin SC, Loring E, Untiet V, Yoo T, Choi J, Xu S, Wu A, Kirchner M, Mertins P, Rump LC, Onder AM, Gamble C, McKenney D, Lash RW, Jones DP, Chune G, Gagliardi P, Choi M, Gordon R, Stowasser M, Fahlke C, Lifton RP. CLCN2 chloride channel mutations in familial hyperaldosteronism type II. Nat. Genet. 2018;50(3):349-354.

14. Lenzini L, Prisco S, Caroccia B, Rossi GP. Saga of Familial Hyperaldosteronism. Hypertension 2018;71(6):1010-1014.

15. Gioco F, Seccia TM, Gomez-Sanchez EP, Rossi GP, Gomez-Sanchez CE. Adrenal histopathology in primary aldosteronism: Is it time for a change? Hypertension 2015;66(4):724730.

16. Ahmed AH, Gordon RD, Ward G, Wolley M, Kogovsek C, Stowasser M. Should aldosterone suppression tests be conducted during a particular phase of the menstrual cycle, and, if so, which phase? Results of a preliminary study. Clin. Endocrinol. (Oxf). 2015;83(3):303-307.

17. Boulkroun S, Beuschlein F, Rossi GP, Golib-Dzib JF, Fischer E, Amar L, Mulatero P, SamsonCouterie B, Hahner S, Quinkler M, Fallo F, Letizia C, Allolio B, Ceolotto G, Cicala MV, Lang K, Lefebvre H, Lenzini L, Maniero C, Monticone S, Perrocheau M, Pilon C, Plouin PF, Rayes N, Seccia TM, Veglio F, Williams TA, Zinnamosca L, Mantero F, Benecke A, Jeunemaitre X, Reincke $\mathrm{M}$, Zennaro MC. Prevalence, clinical, and molecular correlates of KCNJ5 mutations in primary aldosteronism. Hypertension 2012;59(3):592-598.

18. Lenzini L, Rossitto G, Maiolino G, Letizia C, Funder JW, Rossi GP. A Meta-Analysis of Somatic KCNJ5 K(+) Channel Mutations In 1636 Patients With an Aldosterone-Producing Adenoma. 2015;100(8):E1089-E1095.

19. Fommei E, Ghione S, Ripoli A, Maffei S, Di Cecco P, lervasi A, Turchi S. The ovarian cycle as a factor of variability in the laboratory screening for primary aldosteronism in women. J. Hum. Hypertens. 2009;23(2):130-135.

20. Carmeci C, Thompson DA, Ring HZ, Francke U, Weigel RJ. Identification of a gene (GPR30) with homology to the G-protein-coupled receptor superfamily associated with estrogen receptor expression in breast cancer. Genomics 1997;45(3):607-17.

21. Revankar CM, Cimino DF, Sklar LA, Arterburn JB, Prossnitz ER, Revenkar CM, Cimino DF, Sklar LA, Arterburn JB, Prossnitz ER. A Transmembrane Intracellular Estrogen Receptor Mediates Rapid Cell Signaling. Science 2005;307(5715):1625-1630.

22. Filardo EJ, Quinn JA, Frackelton AR, Bland KI. Estrogen action via the G protein-coupled receptor, GPR30: stimulation of adenylyl cyclase and cAMP-mediated attenuation of the epidermal growth factor receptor-to-MAPK signaling axis. Mol. Endocrinol. 2002;16(1):70-84.

23. Prossnitz ER, Arterburn JB. International Union of Basic and Clinical Pharmacology. XCVII. G Protein-Coupled Estrogen Receptor and Its Pharmacologic Modulators. Pharmacol. Rev. 2015;67(3):505-540.

24. Brailoiu GC, Benamar K, Arterburn JB, Gao E, Rabinowitz JE, Koch WJ, Brailoiu E. Aldosterone increases cardiac vagal tone via $G$ protein-coupled oestrogen receptor activation. J. Physiol. 2013;591(17):4223-4235.

25. Gros R, Ding Q, Liu B, Chorazyczewski J, Feldman RD. Aldosterone mediates its rapid effects in vascular endothelial cells through GPER activation. Am. J. Physiol. Physiol. 2013;304(6):C532-40.

26. Feldman RD, Ding Q, Hussain Y, Limbird LE, Pickering JG, Gros R. Aldosterone mediates metastatic spread of renal cancer via the $G$ protein-coupled estrogen receptor (GPER). FASEB J. 2016;30(6):2086-2096.

27. Gros R, Ding Q, Sklar LA, Prossnitz EE, Arterburn JB, Chorazyczewski J, Feldman RD. GPR30 Expression Is Required for the Mineralocorticoid Receptor-Independent Rapid Vascular Effects of Aldosterone. Hypertension 2011;57(3):442-451. 
28. Rigiracciolo DC, Scarpelli A, Lappano R, Pisano A, Santolla MF, Avino S, Marco P De, Bussolati $B$, Maggiolini M, Francesco EM De. GPER is involved in the stimulatory effects of aldosterone in breast cancer cells and breast tumor-derived endothelial cells. Oncotarget 2016;7(1):94-111.

29. Caroccia B, Seccia TM, Campos AG, Gioco F, Kuppusamy M, Ceolotto G, Guerzoni E, Simonato $F$, Mareso S, Lenzini L, Fassina A, Rossi GP. GPER-1 and estrogen receptor- $\beta$ ligands modulate aldosterone synthesis. Endocrinology 2014;155(11):4296-4304.

30. Monticone S, Burrello J, Tizzani D, Bertello C, Viola A, Buffolo F, Gabetti L, Mengozzi G, Williams TA, Rabbia F, Veglio F, Mulatero P. Prevalence and Clinical Manifestations of Primary Aldosteronism Encountered in Primary Care Practice. J. Am. Coll. Cardiol. 2017;69(14):18111820.

31. Caroccia B, Seccia TM, Barton M, Rossi GP. Estrogen Signaling in the Adrenal Cortex: Implications for Blood Pressure Sex Differences. Hypertension 2016;68(4):840-848.

32. Dennis MK, Field AS, Burai R, Ramesh C, Petrie WK, Bologa CG, Oprea TI, Yamaguchi Y, Hayashi S-I, Sklar LA, Hathaway HJ, Arterburn JB, Prossnitz ER. Identification of a GPER/GPR30 antagonist with improved estrogen receptor counterselectivity. J. Steroid Biochem. Mol. Biol. 2011;127(3-5):358-66.

33. Caroccia B, Seccia TM, Piazza M, Prisco S, Zanin S, lacobone M, Lenzini L, Pallafacchina G, Domening O, Poglitsch M, Rizzuto R, Rossi GP. Supplemental Data from: Aldosterone Stimulates Its Biosynthesis Via A Novel GPER Mediated Mechanism. Res. Data Unipd 2019. doi:10.25430/researchdata.cab.unipd.it.00000112.

34. Gomez-Sanchez CE, Qi X, Velarde-Miranda C, Plonczynski MW, Parker CR, Rainey W, Satoh F, Maekawa T, Nakamura Y, Sasano H, Gomez-Sanchez EP. Development of monoclonal antibodies against human CYP11B1 and CYP11B2. Mol. Cell. Endocrinol. 2014;383(1-2):111117.

35. Caroccia B, Fassina A, Seccia TM, Recarti C, Petrelli L, Belloni AS, Pelizzo MR, Rossi GP. Isolation of human adrenocortical aldosterone-producing cells by a novel immunomagnetic beads method. Endocrinology 2010;151(3):1375-1380.

36. Caroccia B, Prisco S, Seccia TM, Piazza M, Maiolino G, Rossi GP. Macrolides Blunt Aldosterone Biosynthesis: A Proof-of-Concept Study in KCNJ5 Mutated Adenoma Cells Ex Vivo. Hypertension 2017;70(6):1238-1242.

37. Bousquet E, Zhao M, Ly A, Leroux les Jardins G, Goldenberg B, Naud MC, Jonet L, BessonLescure B, Jaisser F, Farman N, de Kozak Y, Behar-Cohen F. The Aldosterone-Mineralocorticoid Receptor Pathway Exerts Anti-Inflammatory Effects in Endotoxin-Induced Uveitis. PLoS One 2012;7(11):1-10.

38. Kolkhof $\mathrm{P}$, Bärfacker L. 30 years of the mineralocorticoid receptor: Mineralocorticoid receptor antagonists : 60 years of research and development. 2017;234:T125-T140.

39. Corvol P, Claire M, Oblin ME, Geering K, Rossier B. Mechanism of the antimineralocorticoid effects of spironolactones. Kidney Int. 1981;20(1):1-6.

40. Filardo EJ, Thomas P. Minireview: G protein-coupled estrogen receptor-1, GPER-1: its mechanism of action and role in female reproductive cancer, renal and vascular physiology. Endocrinology 2012;153(7):2953-62.

41. Sugiura Y, Takeo E, Shimma S, Yokota M, Higashi T, Seki T, Mizuno Y, Oya M, Kosaka T, Omura M, Nishikawa T, Suematsu M, Nishimoto K. Aldosterone and 18-oxocortisol coaccumulation in aldosterone-producing lesions. Hypertension 2018;72(6):1345-1354.

42. Omata K, Satoh F, Morimoto R, Ito S, Yamazaki Y, Nakamura Y, Anand SK, Guo Z, Stowasser M, Sasano H, Tomlins SA, Rainey WE. Cellular and Genetic Causes of Idiopathic Hyperaldosteronism. Hypertension 2018;72(4):874-880. 


\section{Chapter 6}

\section{AT1AA \\ (angiotensin II type-1 receptor autoantibodies)}

Cause or consequence of human primary aldosteronism?

M. Piazza, T.M. Seccia, B. Caroccia, B. Caroccia, G. Rossitto, R. Scarpa,P. Persichitti, D. Basso, G. P. Rossi

Hypertension 2019;74:793-799 


\begin{abstract}
AT1AA (Angiotensin II type-1 receptor autoantibodies) were first detected in patients with primary aldosteronism (PA) because of aldosterone-producing adenoma (APA) with an in-house developed assay, but it remained unclear if they can be ascertained also with commercially available assays and if they have a functional role. Aims of our study were to investigate if (1) commercially available kits allow detection of raised AT1AA titer in APA; (2) this titer is normalized by adrenalectomy; and (3) AT1AA display any biological roles in vitro. We measured with 2 ELISA kits the AT1AA titer in serum of APA patients and its changes after adrenalectomy. We also investigated AT1AA bioactivity by using AT1-R (angiotensin type-1 receptor)-transfected Chinese hamster ovary and human adrenocortical carcinoma cells, and by measuring aldosterone synthase (CYP11B2) expression in human adrenocortical carcinoma cells after incubation with IgG. Both kits allowed detection of higher AT1AA levels in APA patients than in healthy subjects; surgical cure of PA did not decrease this titer at 1-month follow-up. Human adrenocortical carcinoma cells stimulation with IgG purified from sera of APA patients increased both CYP11B2 expression and aldosterone release $(+40 \%$ and $+76 \%$, respectively, versus healthy subjects). However, no detectable effect of IgG was seen in Chinese hamster ovary cells expressing AT1-R. These findings support the contentions that (1) the raised AT1AA titer does not seem to be a consequence of hyperaldosteronism as it did not normalize after its cure; (2) AT1AA act as weak stimulators of aldosterone biosynthesis, but this effect can be identified only by using a sensitive in vitro technique.
\end{abstract}




\section{Introduction}

Primary Aldosteronism (PA) is the most common endocrine form of arterial hypertension. The distinction between its major subtypes, i.e. unilateral aldosterone-producing adenoma (APA) and bilateral adrenocortical hyperplasia (BAH), is key for optimal clinical management inasmuch as the former is best treated surgically, while the latter requires life-long medical treatment with mineralocorticoid receptor (MR) antagonists, alone or combined with other agents 1,2 .

Immunohistochemical studies using monoclonal antibodies specific for human aldosterone synthase (CYP11B2) developed in Gomez-Sanchez's laboratory highlighted that the pathology underlying $\mathrm{PA}$ is far more complex than simply $\mathrm{BAH}$ and APA, as a single APA usually coexists with clusters of aldosterone-producing cells (APCC) ${ }^{3-5}$, which seem to accumulate with aging in humans ${ }^{6}$, and might be an early stage of APA formation ${ }^{7}$. Along with the concept of asymmetrical aldosterone excess in PA (Celso Gomez-Sanchez, personal communication), these findings suggested that a systemic stimulus can lead to APCC and eventually to APA formation, which could account for the existence of a continuum between APA and BAH.

In 2013 using an in-house made ELISA kit, we described elevated titers of autoantibodies against type-I angiotensin II receptor (AT1AA) in serum of patients with APA at levels comparable to those seen in women with preeclampsia, a prototype disease of raised AT1AA ${ }^{8}$. This finding was thereafter confirmed by others ${ }^{9}{ }^{10}$, and particularly by Kem et al. ${ }^{9}$, who proposed that these AT1AA could have agonistic properties based on their finding of an AT1AA-activated $\beta$-arrestindependent chemiluminescent signal in $\mathrm{CHO}$ cells engineered to express the angiotensin type-1 receptor (AT1-R) and enhanced aldosterone production in a human adrenocortical carcinoma cell-line (HAC15).

It remained, however, altogether unknown if this titer could be corrected by cure of PA by means of adrenalectomy and/or medical treatment targeting the MR, thus leaving uncertain if the raised titer of AT1AA was a cause or a consequence of hyperaldosteronism. Hence, we set out this prospective study to answer the following questions: 1) does treatment with adrenalectomy normalize the titers of AT1AA? 2) Can the reported agonist effect of AT1AA be confirmed in genetically engineered cells by using purified IgG from APA patients with high AT1AA titers?

\section{Methods}

The authors declare that all supporting data are available within the article and its online supplementary file. Further data supporting the findings of this study are available from the authors upon request. 


\section{Patients}

We recruited for this study patients who had an APA confirmed by the "five corners" criteria ${ }^{2}$ (Table 6.1). At variance with recently proposed criteria ${ }^{11}$, to assess clinical and biochemical success, recognizing the long known fact that normalization of renin can lack even in patients who were unambiguously cured after surgery ${ }^{12}$, we defined as 'biochemically cured' the patients who showed normalized PAC, serum $\mathrm{K}^{+}$and $24-\mathrm{h} \mathrm{K}^{+}$excretion, besides a clearcut lowering of blood pressure, enailing cure or improvement by the aforementioned criteria. ${ }^{11}$ Serum for measurement of AT1AA was obtained before and 1 month after adrenalectomy. Patients furnished written consent to the study, which was approved by the Institutional Review Board.

\section{Table 6.1. "Five corners" criteria for the diagnosis of APA. ${ }^{2}$}

1. Biochemical evidence of PA (e.g., an inappropriately high aldosterone/renin ratio)

2. Lateralized aldosterone secretion by AVS

3. Detection of a nodule by imaging (CT or MRI) or an adenoma at pathology

4. Biochemical correction of PA after adrenalectomy

5. Detection of a CYP11B2-positive adenoma in the resected adrenal cortex at immunohistochemistry with a monoclonal antibody for human CYP11B2

\section{Enzyme-linked immunosorbent assays (ELISA)}

On the day of the assay serum samples for AT1AA stored at $-80^{\circ} \mathrm{C}$ were thawed at room temperature. AT1AA were detected with two commercially available sandwich ELISA kits. The first exploits use of horseradish peroxidase labeled-antihuman IgG and TMB substrate solution for AT1AA detection (CellTrend kit, Luckenwalde, Germany)(See also Supplementary Data). The second uses biotinconjugate in addition to horseradish peroxidase labeled-anti-human IgG and TMB (Cusabio, Wuhan, China). Intra- and inter-assay CV found in our laboratory were $5 \%$ and $6 \%$ for the first kit, and $4 \%$ and $7 \%$ for the second. Both kits are currently used to measure AT1AA in kidney transplant recipients to identify those at high risk of allograft rejection ${ }^{13-16}$.

In both assays, standard and diluted samples were added to the wells of a microtiter plate pre-coated with AT1-R and incubated for $2 \mathrm{~h}$. Optical density was read at $450 \mathrm{~nm}$ and then AT1AA concentration in the samples was obtained with a standard curve. 


\section{IgG purification}

IgG were purified from APA or control patients' sera using the NAb ${ }^{T M}$ Protein A/G spin kit following the manufacturer's recommendations (Pierce Biotechnology Rockford, Illinois) and quantified using the Nanodrop $® 2000 \mathrm{c}$ spectrophotometer.

\section{CYP11B2 gene expression}

The HAC15 human adrenocortical carcinoma cells (a gift of Doctor W. E. Rainey, University of Michigan, Ann Arbor, Michigan) were cultured in DMEM-F12 supplemented with $10 \%$ Cosmic Calf serum at $37^{\circ} \mathrm{C}$ under an atmosphere of $5 \%$ $\mathrm{CO}_{2}{ }^{17}$. They were stimulated for 12 hours with angiotensin $I I\left(10^{-7} \mathrm{M}\right)$ or $\lg \mathrm{G}(0.3$ or $0.6 \mathrm{mg} / \mathrm{mL}$ ). Irbesartan, or candesartan (both $10^{-5} \mathrm{M}$ ), were used as AT1-R antagonists at concentrations chosen to be 100 -fold higher than those of angiotensin II based on previous studies that showed abolishment of angiotensin II effects. ${ }^{18}$ After treatment, cells were lysed and mRNA was isolated with high-pure RNA isolation kit (Roche Applied Science, Penzberg, Germany). CYP11B2 gene expression was quantified by real-time RT-PCR with universal probe library probes in the LightCycler 480 software (Roche Applied Science, Penzberg, Germany) using the comparative cycle threshold $\left(2^{-\Delta \Delta \mathrm{Ct}}\right)$ method: each sample was quantified against its PBGD transcript content and normalized to the control group.

\section{Measurement of aldosterone production}

Aldosterone levels were quantified by an aldosterone ELISA kit (Alpha Diagnostic International, San Antonio, TX). A total of $50 \mu \mathrm{L}$ of cell medium was added to aldosterone-coated wells following the manufacturer's instructions; the signal was detected in an ELISA reader (Berthold Technologies, Milan, Italy). Aldosterone levels were normalized to the amount of cell RNA content ${ }^{19}$.

\section{$\beta$-arrestin recruitment assay}

The bioactivity of AT1AA was measured in AT1R-transfected $\mathrm{CHO}$ cells engineered to express both the AT1 receptor and an intracellular $\beta$-arrestin signaling pathway that, when activated by agonist binding AT1-R, develops a luminescent signal (DiscoveRx, Fremont, Canada). Briefly, CHO cells $\left(n=10^{4}\right)$ were dispensed into each well of a 96-well culture plate and incubated for $48 \mathrm{hrs}$. Ten $\mu$ l serum or purified IgG were then added and incubated for $90 \mathrm{~min}$.

Each assay also comprised proper negative (buffer) and positive (angiotensin II) controls following manufacturer's recommendation. Detection reagents were then added and chemiluminescent signal was read on a luminometer (LB960 Berthold, Bad Wildbad, Germany). A standard curve with angiotensin II was obtained (Supplementary Figure S6.1), and $\beta$-arrestin recruitment by sera or IgG was expressed as bioactivity of angiotensin II (pM/L). 


\section{Statistical Analysis}

DRC, PRA, PAC, and ARR values, which showed a skewed distribution, were analyzed after log transformation. Distribution of categorical variables was investigated by $\mathrm{x} 2$ analysis. Bland-Altman plot was used to detect systematic and proportional errors, and magnitude-dependent bias between AT1AA titers measured with the two assays ${ }^{20}$. Deming regression was also used to look for systematic differences between methods. Paired t-test was used to compare quantitative variables between baseline and follow-up, and between bufferstimulated and IgG-stimulated cells. The significance was set at $p<0.05$. Analyses were performed with Prism (vers. 8.1.2, GraphPad, San Diego, CA) and SPSS $^{\mathrm{TM}}$ (vers. 25.0, IBM, Armonk, NY) for Mac.

\section{Results}

\section{Clinical features and AT1AA levels of the APA patients}

We recruited for this study 27 APA patients (48\% men, $52 \%$ women) aged $51 \pm 8$ years, whose main clinical features at baseline and after adrenalectomy are shown in Table 6.2.

In 12 such patients we measured AT1AA titer using both assays, and found that they showed significantly higher titers of AT1AA than healthy volunteers $(n=7)(p$ $<10^{-4}$ and $p=3^{*} 10^{-3}$ for assays 1 and 2, respectively) (Figure 6.1, Panels $A$ and $B$ ). A Bland-Altman plot of the results obtained with the two commercially available kits showed a good agreement, with no systematic or proportional errors, as all points fell within $2 \mathrm{SD}$; however, a funnel-like shape appearance suggested some magnitude-dependent bias (Figure 6.1, Panel C). Deming regression analysis confirmed that results obtained with the two assays did not differ by a constant amount or a proportional difference, thus supporting their interchangeability (Figure 6.1, Panel D). Hence, we used assay 1 in a larger cohort of APA patients $(n=27)$ to confirm that they had AT1AA titers higher than healthy donors, which was actually the case $\left(p=3^{*} 10^{-2}\right)$ (Figure 6.2, Panel A).

\begin{tabular}{lccc}
\hline & Pre-adrenalectomy & Post-adrenalectomy & P \\
\hline Patients $(\mathrm{n})$ & 27 & 27 & -- \\
SBP $(\mathrm{mmHg})$ & $153 \pm 16$ & $126 \pm 7$ & $10^{-4}$ \\
DBP $(\mathrm{mmHg})$ & $93 \pm 9$ & $80 \pm 6$ & $10^{-4}$ \\
$\mathrm{~K}^{+}(\mathrm{mmol} / \mathrm{L})$ & $3.2 \pm 0.4$ & $4.2 \pm 0.4$ & $3^{*} 10^{-3}$ \\
PAC $(\mathrm{ng} / \mathrm{dL})$ & $20.9(14.3-43.62)$ & $5.5(4.4-8.7)$ & $10^{-4}$ \\
DRC $(\mathrm{mlU} / \mathrm{L})$ & $2(2.0-3.1)$ & $7.1(2.5-16.9)$ & $10^{-4}$ \\
ARR $(\mathrm{ng} / \mathrm{mlU})$ & $90.5(57-214.2)$ & $7.3(3.8-16.9)$ & $10^{-4}$ \\
\hline
\end{tabular}

Table 6.2. Clinical profiles of APA patients before and after adrenalectomy. Data are presented as mean $\pm S D$, or median [interquartile range]. 
SBP: systolic blood pressure; DBP: diastolic blood pressure; PAC: plasma aldosterone concentration; DRC: direct renin concentration; ARR: aldosterone to renin ratio.

A

\section{Assay 1}

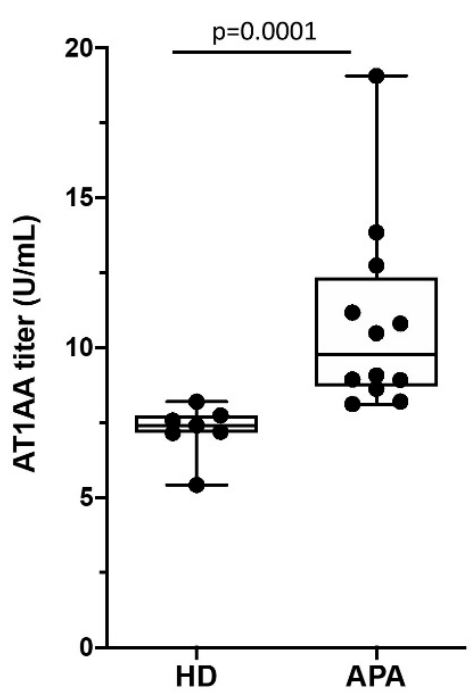

C

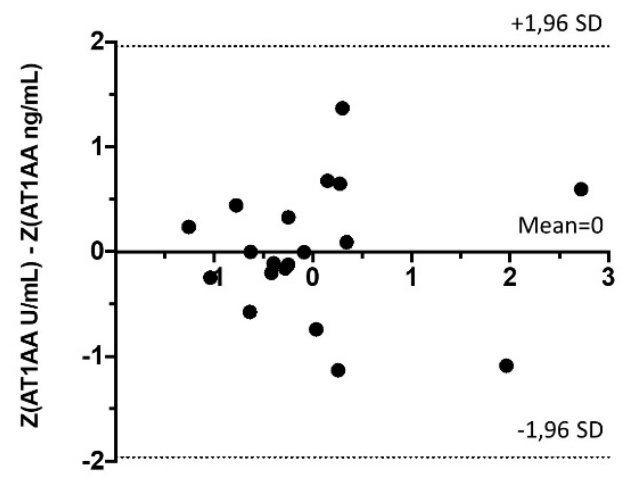

Average of Z(AT1AA U/mL) and Z(AT1AA $\mathrm{ng} / \mathrm{mL})$
B

Assay 2

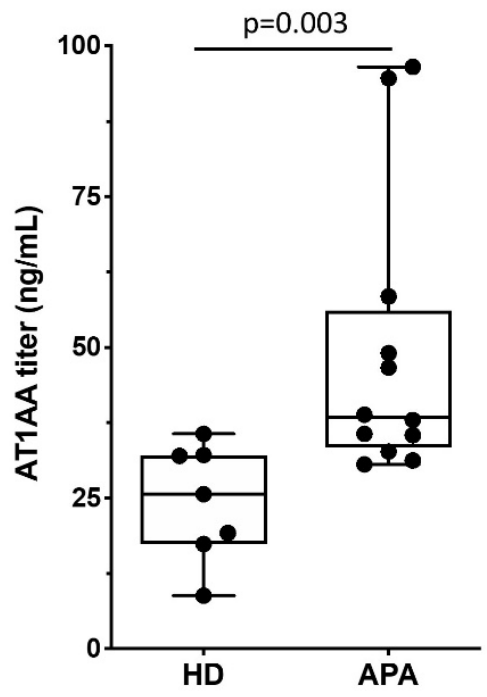

D

Deming regression: $Y=0.99 x+2.104 e-006$

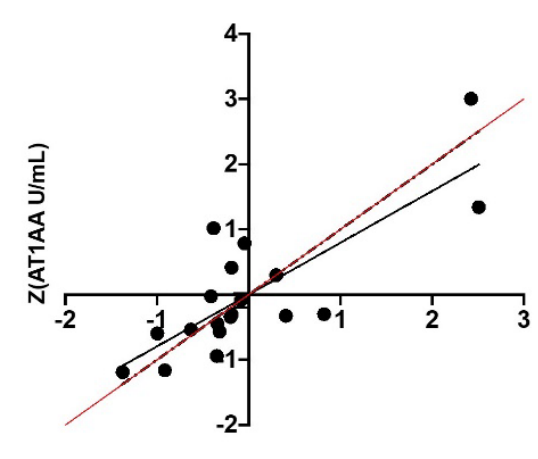

Z(AT1AA ng/ml)

Figure 6.1. Box and whisker plots showing show AT1AA titers measured with two commercially available ELISA kits in healthy normotensive subjects $(H D, n=7)$ and patients with aldosterone producing aldosterone (APA, $n=12$ ). Both assays showed higher AT1AA titers in APA patients than in healthy donors. The Bland Altman test shows no systematic or proportional errors (Panel C); the Deming regression analysis confirmed the lack of systematic differences between the assays (Panel D). 
See Supplementary Data for interpretation of the Deming regression line (dotted line). The grey and black lines represent the identity and linear regression, respectively. Because of the different units of measurement, $Z$ score values $(Z)$ were plotted instead of raw values in panels $C$ and $D$.

\section{Post-adrenalectomy results}

Of the 27 patients with APA submitted to adrenalectomy, 26 showed full biochemical cure of PA after surgery, as evidenced by normalization of plasma aldosterone concentration (PAC) and serum potassium levels; one patient showed persistent hyperaldosteronism.

As regards blood pressure outcome, all patients were cured or markedly improved. Serum was available at follow-up in 14 patients and therefore assessment of biochemical cure was not feasible in all. In those who showed biochemical cure and cure or a marked improvement of blood, we could not observe any evident decrease of AT1AA levels at one-month follow-up after removal of APA (Figure 6.2, Panel B).

A

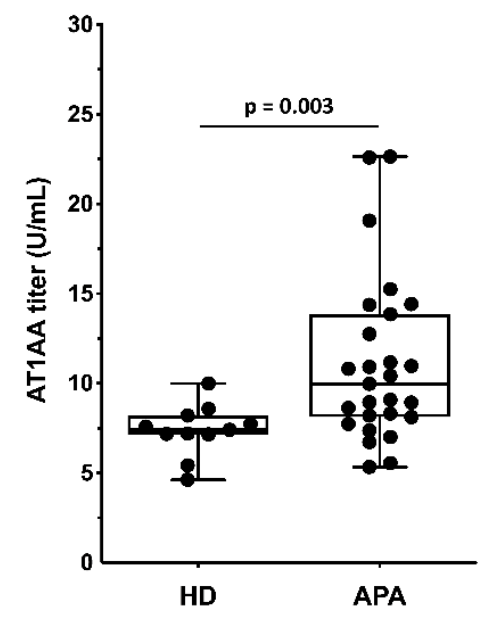

B

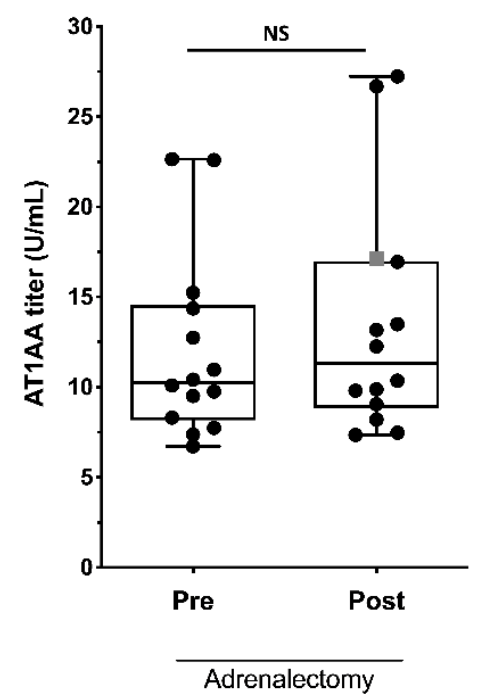

Figure 6.2. Panel A shows AT1AA titers in an expanded series of patients with aldosterone producing aldosterone (APA, $n=27)$ and in control donors (HD, n=11). No significant change in AT1AA titers of APA patients was seen before (Pre) and after (Post) adrenalectomy in either the patients who were cured (biochemically and hemodynamically) or in those who were not (both $n=14$ ) (Panel B). Grey squares represent patients not biochemically cured at follow-up.

\section{Bioactivity of AT1AA}

Two sets of experiments were undertaken to investigate if circulating AT1AA from APA patients could activate the AT1-R. In the first, Chinese hamster ovary cells 
engineered to express the AT1R were exposed to sera from APA patients using increasing concentrations of angiotensin $\mathrm{II}$, ranging from $10^{-10} \mathrm{M}$ to $10^{-5} \mathrm{M}$, as positive control. While angiotensin II elicited a clearcut concentration-dependent chemiluminescent response (Supplementary Figure S6.1, Panel A), the serum did not induce any detectable response as the readings were below the lowest detection threshold of the angiotensin II concentration response curve (Supplementary Figure S6.1, Panel B).

Several attempts to improve the sensitivity of this assay failed in that we could not detect a reproducible chemiluminescent signal. These results suggested that either the activity of AT1AA was below the detection threshold of this assay and/or that they were not biologically active.

To further investigate these hypotheses, in a second set of experiments, HAC15 cells were exposed to IgG purified from serum of APA patients $(n=10)$ with the highest AT1AA titer with both commercially available kits and CYP11B2 mRNA was measured as experimental endpoint (Figure 6.3). IgG induced a $40 \%$ increase in CYP11B2 gene expression (Figure 6.3, Panel B), which, albeit statistically significant, was much lower than that induced by angiotensin II (Figure 6.3, Panel A). However, the purified $\lg G(n=8)$ enhanced the release of aldosterone in the medium (Figure 6.4, Panels A and Panel B). Pre-treatment of HAC15 cells with irbesartan provided quite variable effects among patients; however, on average irbesartan blunted, albeit did not abolish, the increase in CYP11B2 mRNA induced by IgG from APA patients (Figure 6.3, Panel B). 
A

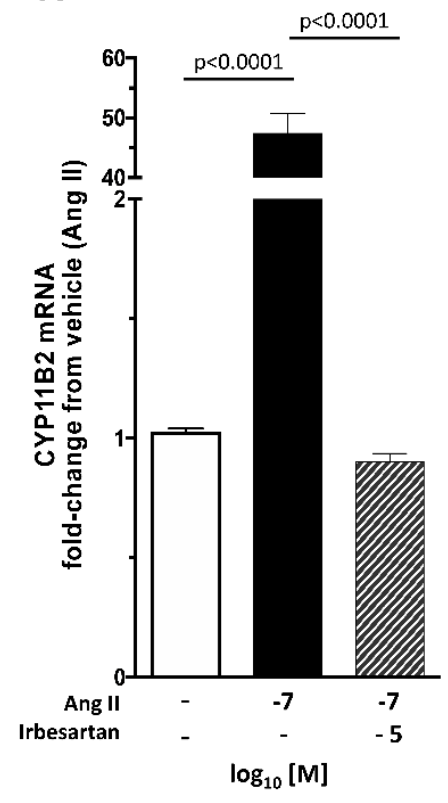

B

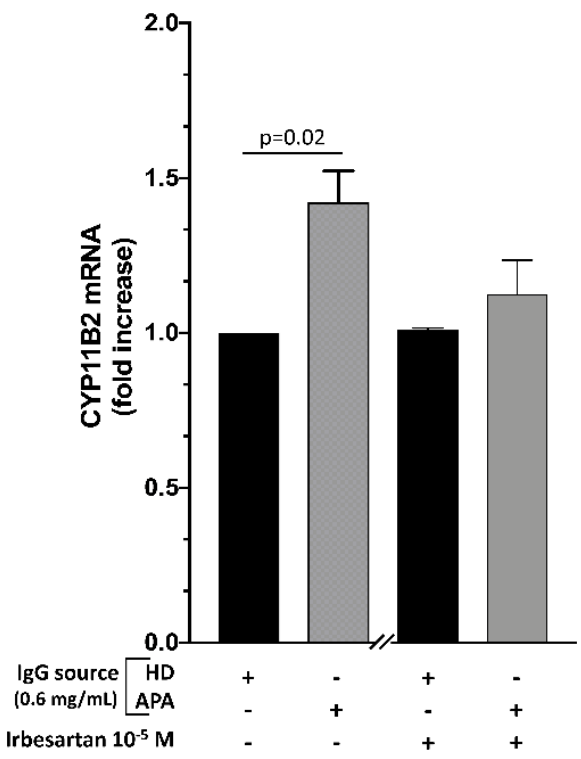

Figure 6.3. CYP11B2 gene expression increased after exposure of HAC15 cells to angiotensin II, used as positive control (Panel A), or to IgG purified from serum of the APA patients that showed the highest AT1AA titer $(n=10)$ (Panel B). While irbesartan prevented the response to angiotensin II (Panel A), it reduced, but did not abolish that induced by IgG from APA patients (Panel B). 


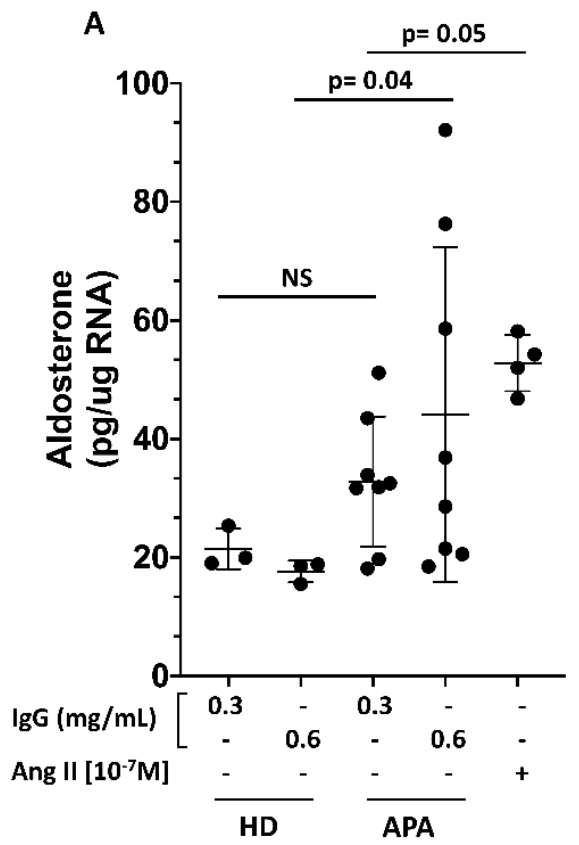

B

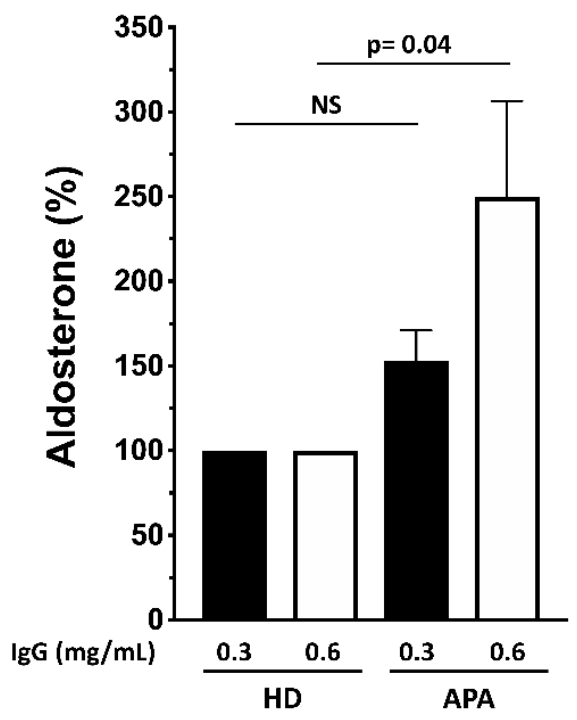

Figure 6.4. IgG purified from serum of the APA patients induced aldosterone release from HAC15 cells higher than IgG purified from serum of healthy subjects (HD). Panel A shows aldosterone levels normalized to the amount of cell RNA content, whereas Panel B shows the increase of aldosterone levels in APA patients normalized to those of healthy subjects. Data obtained from two experiments in triplicate

\section{Discussion}

The discovery that APA patients, who usually show the most florid clinical PA phenotypes, have an increased titer in serum of autoantibodies against the angiotensin type I receptor ${ }^{8}$, followed by the report that these autoantibodies could have an agonistic effect on AT1-R, opened a new line of investigation as to why excess aldosterone production occurs in PA, in a fashion seemingly autonomous from angiotensin II ${ }^{9}$.

The present results provided novel pieces of information in this area by showing that the increased AT1AA titer could be detected not just with an in-house developed method using a peptide corresponding to the second extracellular loop of the human AT1 receptor, as originally reported ${ }^{8}$, but also with two commercially available assays that uses microtiter plate pre-coated with recombinant AT1-R protein (Figure 6.1, Panels $A$ and $B$ ). These findings indicate that the recombinant AT1-R protein used in the microplate retains a conformation similar to that of cell membrane AT1-R, which renders it accessible to the AT1AA. Accordingly, they testify the possibility of expanding research in this field by means of commercially 
available kits to groups of investigators that do not have in-house generated assays.

The second important question to answer was if the elevated AT1AA titer is a cause or a consequence of PA. We addressed this issue at two levels: first, we investigated the effect of surgical cure of PA by unilateral laparoscopic adrenalectomy on AT1AA titers, and found no normalization of the raised autoantibodies titers, suggesting that PA by itself does not raise the titer of AT1AA. Accordingly, AT1AA might not simply represent a biomarker of the excess cardiovascular damage, which in PA has been well documented at the level of the heart, kidney and vasculature ${ }^{21}$. However, this contention needs, in our view, to be tempered by considering the following. First, serum was available at follow-up in only 14 patients, because some cured patients, who were from far away municipalities, after the initial follow-up visit one month after surgery could not to come back for further blood testing. Second, autoimmune diseases may need long time to resolve, which implies that the disappearance of circulating AT1AA levels could take a time longer than exploited in this study. Therefore, whether AT1AA production can be long-lasting and, moreover, if T memory cells involved in AT1AA production are harbored in the APA, are important issues that deserve further investigations.

As regards the biological role of AT1AA, when tested in vitro in AT1-R engineered $\mathrm{CHO}$ cells, under several experimental conditions and in a consistent manner, purified IgG from our APA patients with the highest antibodies titers did not elicit any detectable effect. These cells showed a clear-cut concentration-dependent response to angiotensin II even when tested in the presence patients' serum, which ruled out a matrix effect. Hence, we could not confirm the elegant results reported by Kem et al. using a similar cell system. The reasons for these discrepant results are currently unclear; however, we would like to suggest that engineered $\mathrm{CHO}$ cells might be not sensitive enough to allow detection of a weak biological activity of AT1AA, at least in our hands and at the titers found in our PA patients.

In line with this proposition, HAC15 cells exposed to purified IgG isolated from APA patients showed a $40 \%$ increase of CYP11B2 mRNA over IgG isolated from healthy subjects (Figure 6.3). This CYP11B2 mRNA increase was associated with a $76 \%$ increase in aldosterone levels in the medium. Hence, AT1AA from APA patients exerted a weak effect, which was detectable only using highly sensitive in vitro assays, on aldosterone biosynthesis and secretion. Finally, it should also be considered that the the proportion of AT1AA in the IgG fraction is currently unknown; therefore, differences between cohorts of APA patients could explain the different findings obtained in different cohorts of patients.

An involvement of AT1-R activation in the stimulation of CYP11B2 gene expression induced by the IgG fraction of APA patients was suggested by our experiments 112 
with irbesartan, which exerted a blunting effect, albeit in a variable fashion. Further research is, however, necessary to dissect the reasons for these variable effects in different patients.

\section{Conclusions}

In summary, our results confirmed that elevated titers of AT1-R autoantibodies can be detected in serum of APA patients with two commercially available kits. These AT1AA might represent a biomarker of florid forms of PA, but are unlikely to result from the excess cardiovascular damage documented in APA patients, as they remain elevated after biochemical cure of PA ${ }^{22}$. Moreover, the AT1AA act as weak stimulators of aldosterone biosynthesis, albeit their effect could only be shown under well-defined conditions with a sensitive assay.

\section{Perspectives}

We found AT1AA not only in APA, but also in some healthy donors, as similarly observed for other $G$ protein-coupled receptors (GPCR) autoantibodies ${ }^{23}$. A number of relevant questions remain, however, to be answered as, for example, which is the cut-off between normal subjects and APA patients, what proportion of purified IgG entails AT1AA, and even more importantly, if healthy normotensive subjects represent a preclinical phase of PA as recently suggested ${ }^{24}$.

The persistence of an elevated AT1AA titer at times longer than 1 month after unilateral PA curative adrenalectomy, as well as investigation of an involvement of $T$ memory cells as possible determinants in an autoimmune process leading to the development of APA seem important lines of future investigation at a stage when the mechanisms leading to APCCs and possible APA are being investigated with a great deal of success ${ }^{2}$. 


\section{Novelty and Significance}

\section{What Is New.}

- The titer of AT1AA is increased in primary aldosteronism (PA) patients and these autoantibodies are stimulators of aldosterone biosynthesis.

- This agonistic effect can be identified by using purified IgG and a sensitive in vitro technique.

- The raised AT1AA titer persisted one month after biochemical cure of PA and therefore does not seem to be a consequence of hyperaldosteronism.

\section{What Is Relevant?}

- The AT1AA titer can be a biomarker of PA and can be measured with commercially available assays.

\section{Summary}

The raised AT1AA titer in APA patients, which persisted after cure of hyperaldosteronism suggests a pathogenetic role of AT1AA in raising aldosterone biosynthesis in PA. 


\section{References}

1. lacobone M, Citton M, Viel G, Rossi GP, Nitti D. Approach to the surgical management of primary aldosteronism. Gland Surg. 2015;4:69-81.

2. Seccia TM, Caroccia B, Gomez-Sanchez EP, Gomez-Sanchez CE, Rossi GP. The Biology of Normal Zona Glomerulosa And Aldosterone-Producing Adenoma: Pathological Implications. Endocr Rev. 2018;39:1029-1056.

3. Omata K, Tomlins SA, Rainey WE. Aldosterone-Producing Cell Clusters in Normal and Pathological States. Horm Metab Res. 2017;49:951-956.

4. Gioco F, Seccia TM, Gomez-Sanchez EP, Rossi GP, Gomez-Sanchez CE. Adrenal histopathology in primary aldosteronism: Is it time for a change? Hypertension. 2015;66:724-730.

5. Omata K, Satoh F, Morimoto R, Ito S, Yamazaki Y, Nakamura Y, Anand SK, Guo Z, Stowasser M, Sasano H, Tomlins SA, Rainey WE. Cellular and Genetic Causes of Idiopathic Hyperaldosteronism. Hypertension. 2018;72:874-880.

6. Omata K, Anand SK, Hovelson DH, Liu C-J, Yamazaki Y, Nakamura Y, Ito S, Satoh F, Sasano H, Rainey WE, Tomlins SA. Aldosterone-Producing Cell Clusters Frequently Harbor Somatic Mutations and Accumulate With Age in Normal Adrenals. J Endocr Soc. 2017;1:787-799.

7. Gomez-Sanchez CE, Williams TA. Visualizing Adrenal Steroids in Primary Aldosteronism. Hypertension. 2018;72:1269-1271.

8. Rossitto G, Regolisti G, Rossi E, Negro A, Nicoli D, Casali B, Toniato A, Caroccia B, Seccia TM, Walther T, Rossi GP. Elevation of angiotensin-II type-1-receptor autoantibodies titer in primary aldosteronism as a result of aldosterone-producing adenoma. Hypertension. 2013;61:526-533.

9. Kem DC, Li H, Velarde-Miranda C, Liles C, Vanderlinde-Wood M, Galloway A, Khan M, Zillner C, Benbrook A, Rao V, Gomez-Sanchez CE, Cunningham MW, Yu X. Autoimmune mechanisms activating the angiotensin AT1 receptor in "primary" aldosteronism. J Clin Endocrinol Metab. 2014;99:1790-1797.

10. Sabbadin C, Ceccato F, Ragazzi E, Boscaro M, Betterle C, Armanini D. Evaluation of angiotensin II type-1 receptor antibodies in primary aldosteronism and further considerations about their possible pathogenetic role. J Clin Hypertens. 2018;20:1313-1318.

11. Williams TA, Lenders JWM, Mulatero P, Burrello J, Rottenkolber M, Adolf C, Satoh F, Amar L, Quinkler M, Deinum J, Beuschlein F, Kitamoto KK, Pham U, Morimoto R, Umakoshi H, Prejbisz A, Kocjan T, Naruse M, Stowasser M, Nishikawa T, Young WF, Gomez-Sanchez CE, Funder JW, Reincke M. Outcomes after adrenalectomy for unilateral primary aldosteronism: An international consensus on outcome measures and analysis of remission rates in an international cohort. Lancet Diabetes Endocrinol. 2017;8587:1-11.

12. Rutherford JC, Taylor WL, Stowasser M, Gordon RD. Success of surgery for primary aldosteronism judged by residual autonomous aldosterone production. World $\mathrm{J}$ Surg. 1998;22:1243-1245.

13. Lefaucheur C, Viglietti D, Bouatou Y, Philippe A, Pievani D, Aubert O, Duong Van Huyen J-P, Taupin J-L, Glotz D, Legendre C, Loupy A, Halloran PF, Dragun D. Non-HLA agonistic antiangiotensin II type 1 receptor antibodies induce a distinctive phenotype of antibody-mediated rejection in kidney transplant recipients. Kidney Int. 2019;96:189-201.

14. Hesemann LE, Subramanian V, Mohanakumar T, Dharnidharka VR. De novo development of antibodies to kidney-associated self-antigens angiotensin II receptor type I, collagen IV, and fibronectin occurs at early time points after kidney transplantation in children. Pediatr Transplant. 2015;19:499-503.

15. In JW, Park H, Rho EY, Shin S, Park KU, Park MH, Song EY. Anti-Angiotensin Type 1 Receptor Antibodies Associated With Antibody-Mediated Rejection in Patients Without Preformed HLADonor-Specific Antibody. Transplant Proc. 2014;46:3371-3374.

16. Lee J, Huh KH, Park Y, Park BG, Yang J, Jeong JC, Lee J, Park JB, Cho J-H, Lee S, Ro H, Han S-Y, Kim MS, Kim YS, Kim SJ, Kim C-D, Chung W, Park S-B, Ahn C, KNOW-KT Study Group. The clinicopathological relevance of pretransplant anti-angiotensin II type 1 receptor antibodies in 
Chapter 6

renal transplantation. Nephrol Dial Transplant. 2017;32:1244-1250.

17. Caroccia B, Seccia TM, Gonzalez-Campos A, Gioco F, Kuppusamy M, Ceolotto G, Guerzoni E, Simonato F, Mareso S, Lenzini L, Fassina A, Rossi GP. GPER-1 and estrogen receptor- $\beta$ ligands modulate aldosterone synthesis. Endocrinology. 2014;155:4296-4304.

18. Vanderriele P-E, Caroccia B, Seccia TM, Piazza M, Lenzini L, Torresan F, lacobone M, Unger T, Rossi GP. The angiotensin type 2 receptor in the human adrenocortical zona glomerulosa and in aldosterone-producing adenoma: low expression and no functional role. Clin Sci. 2018;132:627640.

19. Caroccia B, Prisco S, Seccia TM, Piazza M, Maiolino G, Rossi G. Macrolides Blunt Aldosterone Biosynthesis: A Proof-of-Concept Study in KCNJ5 Mutated Adenoma Cells Ex Vivo. Hypertension. 2017;70:1238-1242.

20. Bland JM, Altman DG. Measuring agreement in method comparison studies. Stat Methods Med Res. 1999;8:135-160.

21. Rossi GP, Sacchetto A, Pavan E, Palatini P, Graniero GR, Canali C, Pessina AC. Remodeling of the left ventricle in primary aldosteronism due to Conn's adenoma. Circulation. 1997;95:14711478.

22. Monticone S, D'Ascenzo F, Moretti C, Williams TA, Veglio F, Gaita F, Mulatero P. Cardiovascular events and target organ damage in primary aldosteronism compared with essential hypertension: a systematic review and meta-analysis. Lancet Diabetes Endocrinol. 2018;6:41-50.

23. Cabral-Marques O, Marques A, Giil LM, De Vito R, Rademacher J, Günther J, Lange T, Humrich JY, Klapa S, Schinke S, Schimke LF, Marschner G, Pitann S, Adler S, Dechend R, Müller DN, Braicu I, Sehouli J, Schulze-Forster K, Trippel T, Scheibenbogen C, Staff A, Mertens PR, Löbel M, Mastroianni J, Plattfaut C, Gieseler F, Dragun D, Engelhardt BE, Fernandez-Cabezudo MJ, Ochs HD, Al-Ramadi BK, Lamprecht P, Mueller A, Heidecke H, Riemekasten G. GPCR-specific autoantibody signatures are associated with physiological and pathological immune homeostasis. Nat Commun. 2018;9:5224.

24. Baudrand R, Guarda FJ, Fardella C, Hundemer G, Brown J, Williams G, Vaidya A, Commentary SE. Primary Aldosteronism Continuum of Renin-Independent Aldosteronism in Normotension. Hypertension. 2017;68:950-957. 


\section{SUPPLEMENTAL METHODS}

\section{Enzyme-linked immunosorbent assays (ELISA)}

Both kits employ the quantitative sandwich enzyme immunoassay technique with microtiter plates pre-coated with AT1-R. Standards and samples are pipetted into the wells and, after washing the wells to remove any unbound reagent, a substrate solution is added to the wells to develop color in proportion to the amount of AT1-R bound antibody. After stopping the color development, the intensity of the color is measured and the AT1AA concentration can be interpolated by the standard curve. The first kit (CellTrend kit, Luckenwalde, Germany) exploits use of horseradish peroxidase labeled-anti-human $\lg G$ and $T M B$ substrate solution for AT1AA detection. Intra- and inter-assay CV are $3.9 \%$ and $5.1 \%$. The second kit (Cusabio, Wuhan, China) uses biotin-conjugated AT1-R and avidin conjugated horseradish peroxidase (HRP). Intra- and inter-assay $\mathrm{CV}$ are $<8 \%$ and $10 \%$.

\section{Statistical Analysis}

Deming regression was used to look for systematic differences between methods.

The null hypothesis of identity (i.e. that $Y=X$ ) was tested by individual tests: the $95 \%$ confidence interval for the intercept to test the hypothesis that $A=0$. This hypothesis is accepted if the confidence interval for $A$ contains the value 0 , and rejected if $A$ is significantly different from 0 and both methods differ at least by a constant amount. The $95 \%$ confidence interval for the slope was used to test the hypothesis that $B=1$; this hypothesis is accepted if the confidence interval for $B$ contains the value 1 . If the hypothesis is rejected, then it is concluded that $B$ is significantly different from 1 and there is at least a proportional difference between the two methods.

A

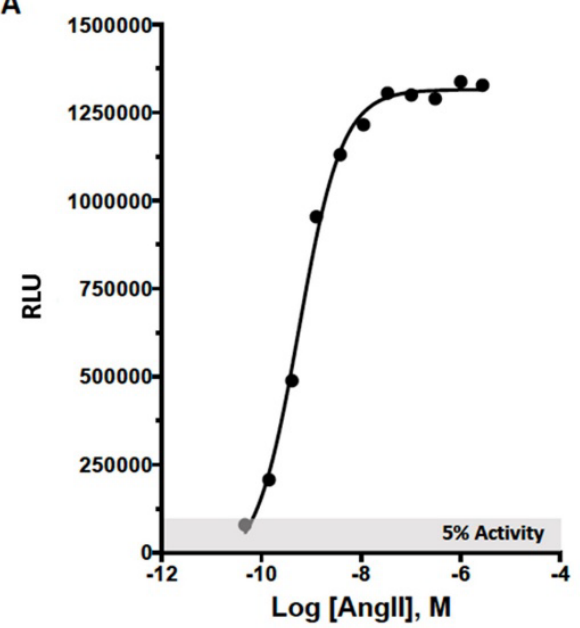

B

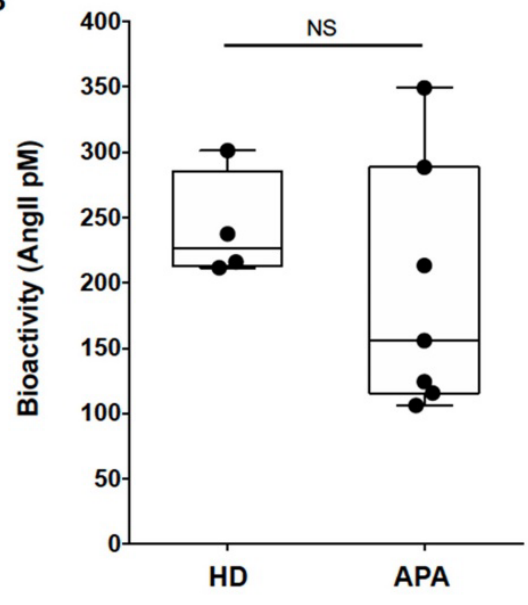

Supplemental Figure S6.1. Panel A. Dose-response curve of Angiotensin II $\left(10^{-10} \mathrm{M}\right.$ to $\left.10^{-5} \mathrm{M}\right)$ in engineered AT1R-transfected Chinese hamster ovary $(\mathrm{CHO})$ cells, assessed as chemiluminescent response. Chemiluminescence measured in $\mathrm{CHO}$ cells exposed to sera from APA patients was used to interpolate Angiotensin II (pM/L), which was considered as equivalent bioactivity. Engineered cells 


\section{Chapter 6}

exposed to such sera provided low chemiluminescent responses that fell in the shaded area, corresponding to $5 \%$ equivalent bioactivity of the maximal response elicited by Angiotensin II. Per cent activity was calculated as follows:

$\%$ Activity $=100 \%{ }^{*}[($ Mean RLU(test sample) - Mean RLU(vehicle control)) / (Mean RLU(control ligand, i.e. Angiotensin II) - Mean RLU(vehicle control))] Panel B. The plot shows that bioactivity (calculated as Angiotensin II equivalents, pM/L) measured in $\mathrm{CHO}$ cells exposed to sera from APA patients did not significantly differ from that of healthy normotensive subjects (HD). 
Part 2

GLYCATION 



\section{Chapter 7}

Serum levels of autoantibodies against the angiotensin II type I receptor are not associated with serum dicarbonyl or AGE levels in patients with aldosterone producing adenoma

M. Piazza, N.M.J Hanssen, J Scheijen, M.P.H. Waarenburg, B. Caroccia, T.M. Seccia, C.D.A. Stehouwer, G.P. Rossi, C.G. Schalkwijk

In Preparation 


\section{Abstract \\ Background}

Individuals with an aldosterone producing adenoma (APA) carry a disproportionately high cardiovascular risk relative to primary hypertension. Patients with APA have high levels of activating autoantibodies (AT1AA) against the angiotensin II type I receptor (AT1R). Activation of the AT1R is linked to an increase of the glucose metabolite methylglyoxal (MGO), a potential precursor of advanced glycation endproducts (AGEs) and a driver of cardiovascular disease. We investigated whether serum AT1AA levels in individuals with APA are associated with serum MGO and AGE levels.

\section{Methods}

In 26 patients with APA $(51 \pm 7.7 y)$ and in a subset of 14 of these patients before and 1 month after adrenalectomy, we measured serum levels of the dicarbonyls methylglyoxal (MGO), glyoxal (GO) and 3-deoxyglucosone (3-DG), as well as the major dicarbonyl-derived AGEs 5-hydro-5-methylimidazolone (MG-H1), $\mathrm{N}^{\varepsilon_{-}}$

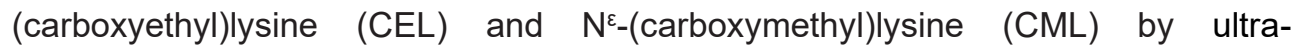
performance liquid chromatography tandem mass-spectrometry (UPLC-MS/MS). AT1AA were measured by ELISA.

\section{Results}

Baseline AT1AA levels were not associated with baseline serum MGO, GO and 3DG, or protein-bound and free MG-H1, CEL and CML levels. No changes were observed in any of the dicarbonyl and protein-bound AGE levels after adrenalectomy. Surprisingly, we found a significant increase of free CML, CEL and MG-H1 levels after adrenalectomy (CML from $86 \mathrm{nmol} / \mathrm{L}$ to $142 \mathrm{nmol} / \mathrm{L}$, CEL from $46 \mathrm{nmol} / \mathrm{L}$ to $63 \mathrm{nmol} / \mathrm{L}$ and MG-H1 from $110 \mathrm{nmol} / \mathrm{L}$ to $237 \mathrm{nmol} / \mathrm{L}$; all $\mathrm{p}<0.02)$ ).

\section{Conclusion and discussion}

In patients with APA, serum levels of AT1AA are not associated with serum dicarbonyls, or protein-bound and free AGE levels. Serum free AGEs level were higher after adrenalectomy, potentially due to changes in kidney function or the use of less co-medication after surgery. 


\section{Introduction}

Primary aldosteronism (PA) is the most common form of endocrine hypertension, with a prevalence of $11 \%$ of the patients referred to specialized centers for hypertension 1. Aldosterone producing adenoma (APA) and bilateral adrenal hyperplasia $(\mathrm{BAH})$ are the leading causes of PA. Individuals with PA have a severely increased risk of cardiovascular disease (CVD), even compared to individuals with primary hypertension ${ }^{2,3}$, for reasons that remain incompletely understood. We previously reported that patients with APA are characterized by high levels of activating autoantibodies against the angiotensin II type I receptor $(\text { AT1AA })^{4}$. AT1AA may have agonistic properties to the angiotensin II receptor type I (AT1R), similar to angiotensin II (Ang II) ${ }^{4,5}$. In turn, activation of the AT1R by Ang II has been linked to increased formation of methylglyoxal (MGO), a highly reactive glucose-metabolite that leads to the formation of advanced glycation endproducts (AGEs) ${ }^{6}$. MGO and its derived AGEs are key players in the development of CVD ${ }^{7,8}$. Glyoxalase 1 (Glo1) is the rate-limiting enzyme in the degradation of MGO to D-lactate and increased activation of AT1R by Ang II has been linked to decreased expression of Glo1 ${ }^{9}$. Therefore, we hypothesize that higher serum levels of AT1AA, as putative ligands for AT1R, are associated with higher MGO levels and MGO-derived AGEs in individuals with APA.

Therefore, we have analyzed the associations between serum AT1AA levels and serum levels of MGO and two other well-known dicarbonyls, glyoxal (GO) and 3deoxyglucosone (3-DG), and the major dicarbonyl-derived AGEs 5-hydro-5 methylimidazolone (MG-H1), $\quad \mathrm{N}^{\varepsilon_{-}}$(carboxyethyl)lysine (CEL) and $\mathrm{N}^{\varepsilon_{-}}$ (carboxymethyl)lysine (CML), in patients with APA before and after adrenalectomy. Furthermore, we investigated associations between serum AT1AA levels and serum D-lactate levels, as a reflection of MGO.

\section{Methods}

\section{Patients}

We recruited for this study 26 patients who had an APA confirmed by the "five corners" criteria ${ }^{10}$. The Primary Aldosteronism Surgical Outcome (PASO) criteria were used to assess complete or partial clinical and biochemical success ${ }^{11}$. Patients provided written consent to the study, which was approved by the Institutional Review Board.

A subset of 14 of these patients underwent adrenalectomy. To assess clinical and biochemical success, we defined as biochemically cured, the patients who showed normalized plasma aldosterone concentrations, serum $\mathrm{K}+$, and 24-hour $\mathrm{K}+$ excretion, and a clear-cut lowering of blood pressure, entailing cure, or improvement of the aforementioned criteria ${ }^{11}$.

The AT1AA titer in these patients has been reported previously ${ }^{4}$. Serum samples for the assessment of dicarbonyls and AGEs were stored at $-80^{\circ} \mathrm{C}$. MGO, GO and 
3-DG, the free and protein-bound AGEs CML, CEL and MG-H1 and D-lactate levels were analyzed at base-line and 1-month follow-up of adrenalectomy.

\section{Measurement of dicarbonyl, AGEs, D-lactate}

Serum levels of the dicarbonyls MGO, GO, and 3-DG, the protein-bound CML, CEL, MG-H1, and free CML, CEL and MG-H1 were analysed using ultraperformance liquid chromatography tandem mass-spectrometry (UPLC-MS/MS) as described in detail previously ${ }^{12-14}$.

\section{Measurement of endothelial dysfunction and low-grade inflammation markers}

Serum markers of endothelial dysfunction (soluble vascular adhesion molecule (sVCAM-1) and soluble intercellular adhesion molecule 1 (sICAM-1)) and of lowgrade inflammation (C-reactive protein (CRP), and serum amyloid A (SAA)) were measured with a commercially available 4-plex sandwich immunoassay kits with different standards and antibodies (Meso Scale Discovery, Rockville, Maryland). For this technique, the intra- and inter-assay coefficients of variation for these markers were below $10 \%$.

\section{Statistical analysis}

Direct renin concentrations, plasma renin activity, plasma aldosterone concentrations, aldosterone to renin ratio values, plasma creatinine and eGFR showed a skewed distribution, and were analyzed after log transformation. Distribution of categorical variables was investigated by $x 2$ analysis.

A paired $t$ test was used to compare quantitative variables between baseline and follow-up. Spearman correlation coefficients were calculated to study the correlation between the AT1AA and serum dicarbonyl, free and protein-bound AGEs levels. The significance was set at $P<0.05$. Analyses were performed with Prism (vers. 5.03, GraphPad, San Diego, CA).

\section{Results}

\section{Clinical Features of the APA Patients}

The clinical characteristics of the 26 APA patients in this study are shown in Table 7.1. In the subset of 14 individuals that underwent adrenalectomy, plasma aldosterone concentrations, blood pressure serum potassium levels, eGFR, but not AT1AA levels, were markedly improved at 1-month after removal of APA (Table 7.2). The use of antihypertensive drugs was strongly reduced after adrenalectomy. Markers of inflammation and endothelial function were not associated with AT1AA (data not shown) and did not change after surgery (Table 7.2). 
Table 7.1. Clinical characteristics of the APA patients.

$\begin{array}{lc}\text { Patients }(\mathrm{n}) & 26 \\ \text { Gender }(\mathrm{M} \%) & 46 \% \\ \text { Age }(\mathrm{Y}) & 51 \pm 7.7 \\ \text { Systolic blood pressure }(\mathrm{mmHg}) & 152 \pm 16 \\ \text { Diastolic blood pressure }(\mathrm{mmHg}) & 93 \pm 9 \\ \mathrm{~K}^{+}(\mathrm{mmol} / \mathrm{L}) & 3.2 \pm 0.4 \\ \text { Plasma aldosterone concentration } & 19.9(13.2-43.9) \\ \text { Direct renin concentration }(\mathrm{mlU} / \mathrm{L}) & 2(2.0-2.9) \\ \text { Aldosterone to renin ratio }(\mathrm{ng} / \mathrm{mlU}) & 90.6(57-214.2) \\ \text { Plasma creatinine }(\mu \mathrm{mol} / \mathrm{L}) & 75(59.3-84) \\ \text { eGFR } \mathrm{cDK}-\mathrm{EPI}\left(\mathrm{ml} / \mathrm{min} / 1,73 \mathrm{~m}^{2}\right) & 90(86-104) \\ \text { AT1AA }(\mathrm{U} / \mathrm{mL}) & 11.1 \pm 4.7 \\ \text { Protein-Bound AGEs } & \\ \text { CML }(\mathrm{nmol} / \mathrm{L}) & 3790(3107-4318) \\ \text { CEL }(\mathrm{nmol} / \mathrm{L}) & 569(443-728) \\ \text { MG-H1 }(\mathrm{nmol} / \mathrm{L}) & 1736(1452-2082) \\ \text { Free } A G E s & \\ \text { CML }(\mathrm{nmol} / \mathrm{L}) & 91.5(72-115.8) \\ \text { CEL }(\mathrm{nmol} / \mathrm{L}) & 47(34-61.5) \\ \text { MG-H1 }(\mathrm{nmol} / \mathrm{L}) & 119(80-176) \\ \text { Dicarbonyls } & \\ \text { MGO }(\mathrm{nM}) & 541(433-859) \\ \text { GO }(\mathrm{nM}) & 1589(929-2769) \\ \text { 3DG }(\mathrm{nM}) & 1683(1247-2007) \\ \text { D-Lactate }(\mu \mathrm{mol} / \mathrm{L}) & 6.3(4.4-10.6) \\ \text { L-Lactate }(\mu \mathrm{mol} / \mathrm{L}) & 2319(1652-3285) \\ \text { Endothelial markers } & \\ \text { sICAM-1 }(\mathrm{ug} / \mathrm{mL}) & 499(403-634) \\ \text { sVCAM-1 }(\mathrm{ug} / \mathrm{mL}) & 616(440-719) \\ \text { Inflammatory markers } & \\ \text { CRP }(\mathrm{ug} / \mathrm{mL}) & 2.1(0.5-5.1) \\ \text { SAA }(\mathrm{ug} / \mathrm{mL}) & 4.5(2.3-7.9) \\ & \\ & \end{array}$

Data are presented as mean $\pm S D$, or median [interquartile range] 
Table 7.2. Characteristics of APA patients before and after adrenalectomy

Pre-adrenalectomy Post-adrenalectomy P valu

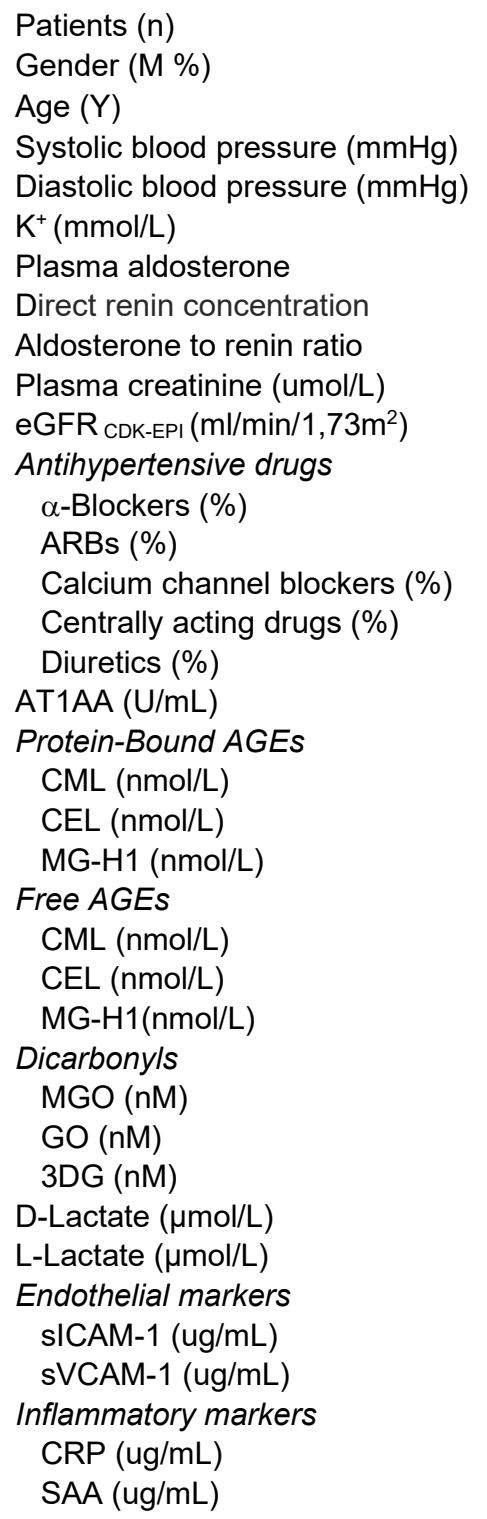

\begin{tabular}{|c|c|c|}
\hline 14 & 14 & -- \\
\hline $50 \%$ & $50 \%$ & -- \\
\hline $51 \pm 8.7$ & $51 \pm 8.9$ & -- \\
\hline $153 \pm 16$ & $124 \pm 7$ & 0.000 \\
\hline $92 \pm 7$ & $81 \pm 2.3$ & 0.002 \\
\hline $3.3 \pm 0.4$ & $4.3 \pm 0.4$ & 0.000 \\
\hline $19.3(12.3-38.5)$ & $5.8(4.3-8.4)$ & 0.000 \\
\hline $2(2.0-3.5)$ & $5.9(2.5-17.1)$ & 0.000 \\
\hline 82.5 (48.9-156.4) & $9.9(3.6-18.9)$ & 0.000 \\
\hline 75 (67.3-84.8) & 91.5 (77-99.5) & $0.00 \approx$ \\
\hline $89.5(85.7-99.5)$ & 75 (67-.3-88.3) & $0.00 \approx$ \\
\hline $43 \%$ & $7 \%$ & -- \\
\hline $7 \%$ & $0 \%$ & -- \\
\hline $86 \%$ & $29 \%$ & -- \\
\hline $7 \%$ & $0 \%$ & -- \\
\hline $14 \%$ & $0 \%$ & -- \\
\hline $11.9 \pm 5.2$ & $13.5 \pm 6.5$ & 0.07 \\
\hline 3481 (2965-4199) & $3718(3509-4154)$ & 0.09 \\
\hline $488(439-642)$ & 607 (484-897) & 0.17 \\
\hline 1659 (1270-2041) & $1561(1331-1819)$ & 0.29 \\
\hline $86.5(71.3-116.8)$ & 142 (104-182) & 0.01 \\
\hline $46(31.5-60.5)$ & $62.5(47.3-121)$ & 0.01 \\
\hline $110(74.3-241)$ & 237 (129-336) & 0.04 \\
\hline $448(368-698)$ & $470(425-630)$ & 0.43 \\
\hline $1162(837-2000)$ & $873(766-1622)$ & 0.27 \\
\hline 1654 (1247-2079) & $1510(1341-1876)$ & 0.63 \\
\hline $6.4(4.6-10.3)$ & $10.4(5.3-23.2)$ & 0.43 \\
\hline $1991(1360-2647)$ & 3199 (2046-3809) & 0.12 \\
\hline $442(392-540)$ & $492(413-613)$ & 0.13 \\
\hline 547 (434-697) & $657(548-750)$ & 0.06 \\
\hline $1.2(0.5-5.1)$ & $2.3(0.9-4.3)$ & 0.75 \\
\hline $3.8(2.2-7.2)$ & $4.1(2.5-9.9)$ & 0.17 \\
\hline
\end{tabular}

Data are presented as mean $\pm \mathrm{SD}$, or median [interquartile range]. 


\section{Association of serum AGEs, and dicarbonyls with AT1AA}

Serum levels of MGO, GO and 3-DG and free AGEs were not associated with AT1AA levels (Figure 7.1A and 7.1B). Furthermore, no association was observed between protein-bound AGEs and AT1AA (Figure 7.1C).

A

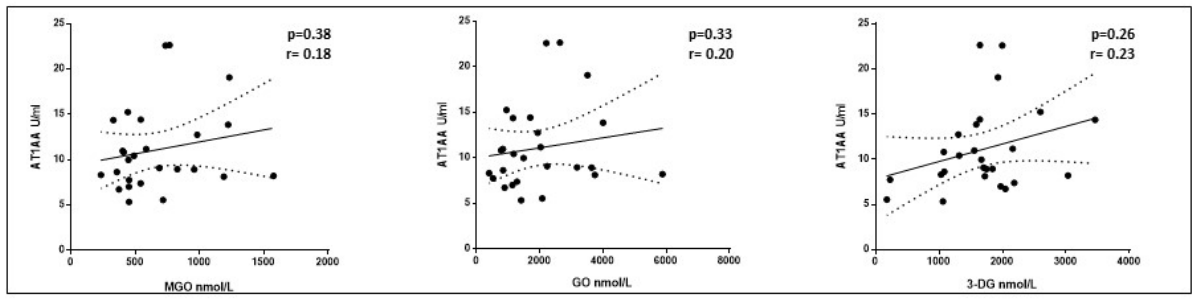

B

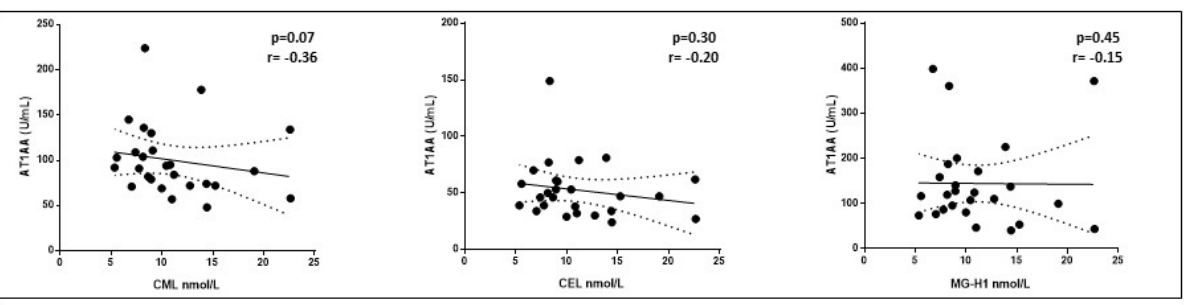

C

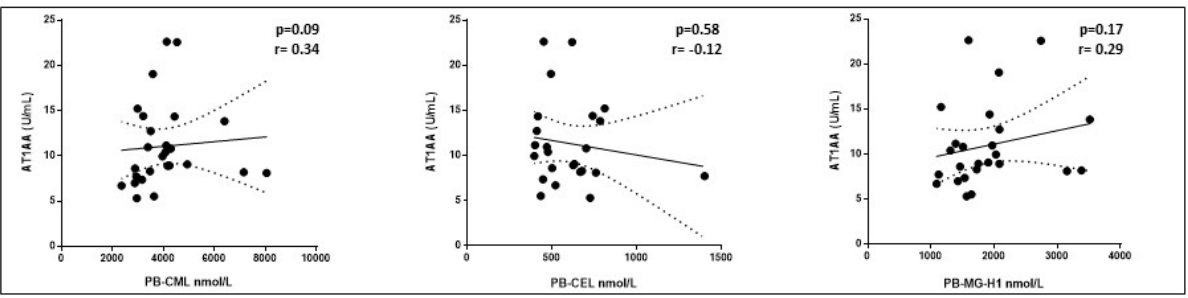

Figure 7.1. Scatter plot of correlation between serum levels of AT1AA and dicarbonyls MGO, GO and 3-DG at baseline (A); Scatter plot of correlation between serum levels of AT1AA and free and proteinbound (PB) AGEs CML, CEL and 3-DG at baseline (B-C); p-value of Spearman rank correlation test, and " $r$ " is the linear correlation coefficient.

Pre- and Post-adrenalectomy levels of AGEs, dicarbonyls and Dlactate

Serum levels of MGO, GO and 3-DG did not change significantly after adrenalectomy (Figure 7.2A). Furthermore, we observed no change after adrenalectomy of serum D-lactate levels (Table 7.2). Free plasma AGEs CML, CEL and MG-H1 (Figure 7.2B), but not protein-bound AGEs (Figure 7.2C), were significantly increased after adrenalectomy. 

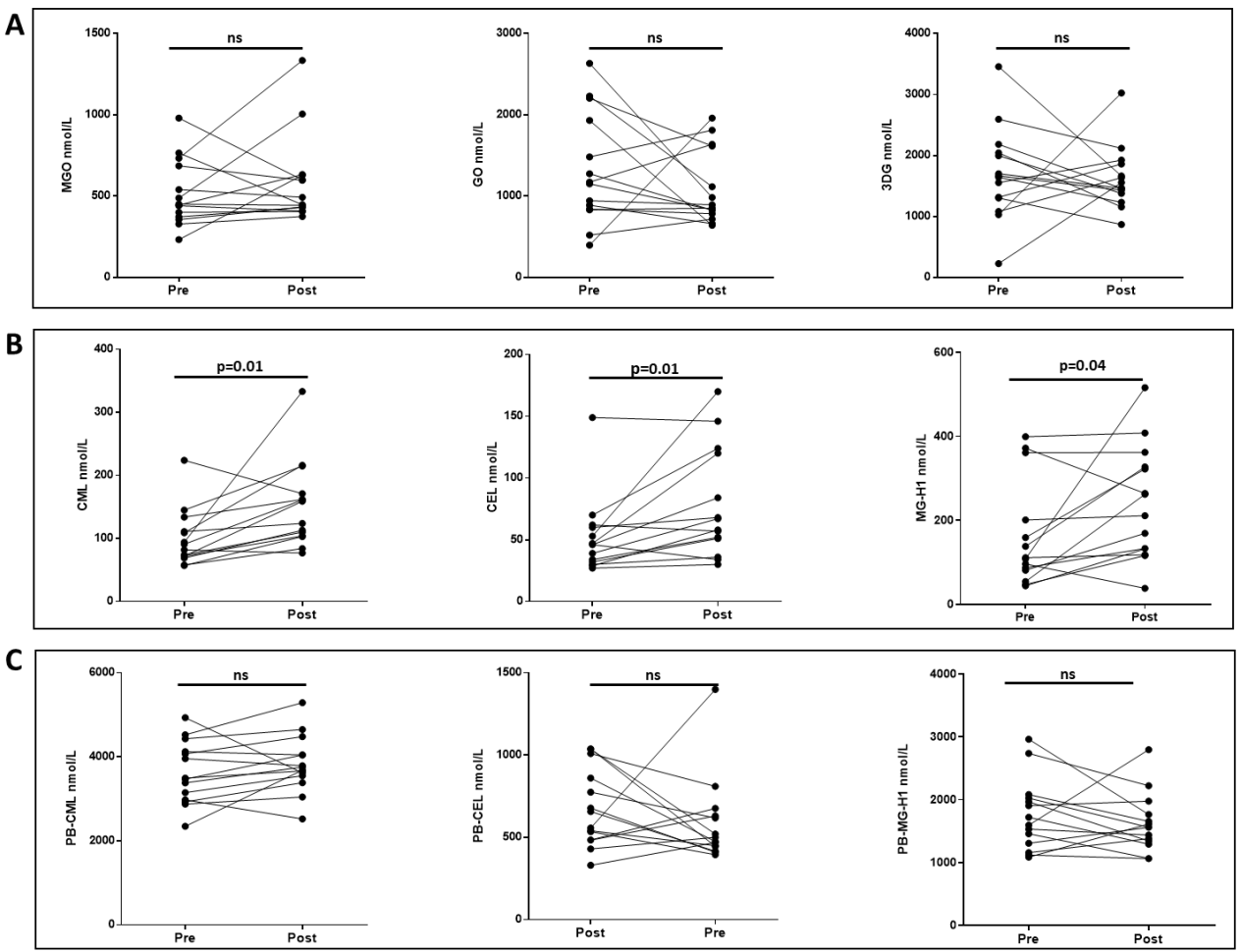

Figure 7.2. Serum levels of MGO, GO and 3-DG before (Pre) and 1-month after adrenalectomy (Post) (A); serum levels of free and protein-bound (PB) AGEs CML, CEL and 3-DG before (Pre) and 1-month after adrenalectomy (Post) (B-C)

\section{Discussion}

The main finding of this study was that serum AT1AA levels were not associated with serum levels of MGO or the other dicarbonyls GO and 3-DG, or the free and protein-bound AGEs CML, CEL and MG-H1, and the MGO metabolite D-lactate. In addition to these cross-sectional findings, we did not observe changes in dicarbonyls after adrenalectomy, albeit in the context of a AT1AA titer that did not change.

We focused on AT1AA and markers and glycation since it has been demonstrated that activation of the AT1R by Ang II leads to the decreased expression of Glo1 enzyme and subsequent increase formation of AGEs ${ }^{9}$. However, it is not fully established whether AT1AA are capable of stimulating AT1R. Although Kem at al. found that AT1AA have agonistic properties similar to Ang II on the AT1R ${ }^{5}$, we were not able to confirm a similar biological effects of AT1AA ${ }^{4}$ and we could only demonstrate a very weak biological activity of AT1AA on aldosterone biosynthesis and secretion in cultured adrenal cells ${ }^{4}$, suggesting a low affinity, if any, of AT1AA for AT1R. This is in line with the current study in which we did not find an 
association of the titers of AT1AA with markers of dicarbonyls stress and free AGEs.

Although there was no association between AT1AA and serum AGE levels, unexpectedly we found an increase of free CML, CEL and MG-H1 levels after adrenalectomy. This could be explained by the fact that adrenalectomy is associated with a small decrease in eGFR or a reduction of medication after surgery. Furthermore, some antihypertensive medications may decrease AGEs levels, such as angiotensin receptor blockers such as olmesartan ${ }^{15}$ valsartan ${ }^{16,17}$ or angiotensin-converting enzyme inhibitors (ACEi) 15,18. Because of the small sample size in the present study, we lacked the statistical power to address the question whether the increase of free CML, CEL and MG-H1 levels after adrenalectomy could be explained by eGFR or a reduction of medication use after surgery.

Emerging evidence indicates that aldosterone plays an important role in the development of endothelial dysfunction ${ }^{19}$. We investigated for the first time whether surgical cure of PA by unilateral laparoscopic adrenalectomy altered the levels of markers of inflammation (CRP, SAA) and endothelial dysfunction (sVCAM, sICAM-1). Although adrenalectomy decreased aldosterone levels in patients with APA in this study, changes in aldosterone did not correlate with systemic inflammation or endothelial dysfunction. In contrast, a prospective cohort study showed a significant decrease in CRP level in PA patients 1 year after initiation of therapy with mineralocorticoid receptor antagonists or adrenalectomy 20. It might be that in our current study the sample size of patients with APA was not large enough or follow-up times were too short to demonstrate the effect of adrenalectomy on systemic inflammation.

However, it should also be emphasized that several studies provided conflicting results concerning a pro-inflammatory profile in PA patients ${ }^{21,22}$. In line with our results, a very recent study reported no difference in circulating hsCRP and other markers of inflammation and endothelial dysfunction between PA patients and essential hypertension controls ${ }^{22}$.

The major strengths of the present study include its in-depth phenotyping of the APA who had an APA confirmed by the "five corners" criteria and the large state-ofthe-art equipment for estimating plasma dicarbonyl levels and of AGEs. However, there are also several limitations. A major limitation of this study includes a small sample size that may have led to a type I error, and limited our ability to do extensive multivariate analysis. Furthermore, the use of antihypertensive drugs may have affected the production of AGEs and dicarbonyl compounds. Larger studies with a long-term follow-up time are required to further clarify the importance of post-adrenalectomy levels on AGEs.

In conclusion, our study shows that in APA patients serum levels of AT1AA do not correlate with serum dicarbonyls, free and protein-bound AGEs levels. In this specific population, the increase of free AGEs CML, CEL and MG-H1 serum levels 
after-adrenalectomy are likely due to changes in kidney function or the use of less co-medication after surgery.

\section{References}

1. Rossi GP, Bernini G, Caliumi C, et al. A prospective study of the prevalence of primary aldosteronism in 1,125 hypertensive patients. Journal of the American College of Cardiology. 2006;48(11):2293-2300. doi:10.1016/j.jacc.2006.07.059

2. Milliez P, Girerd X, Plouin PF, Blacher J, Safar ME, Mourad JJ. Evidence for an increased rate of cardiovascular events in patients with primary aldosteronism. Journal of the American College of Cardiology. 2005;45(8):1243-1248. doi:10.1016/j.jacc.2005.01.015

3. Savard S, Amar L, Plouin PF, Steichen O. Cardiovascular complications associated with primary aldosteronism: A controlled cross-sectional study. Hypertension. 2013;62(2):331-336. doi:10.1161/HYPERTENSIONAHA.113.01060

4. Piazza M, Seccia TM, Caroccia B, et al. AT1AA (Angiotensin II Type-1 Receptor Autoantibodies) Cause or Consequence of Human Primary Aldosteronism? Hypertension. 2019;74(4):793-799. doi:https://doi.org/10.1161/HYPERTENSIONAHA.119.13388

5. Kem DC, Li H, Velarde-Miranda $\mathrm{C}$, et al. Autoimmune mechanisms activating the angiotensin AT1 receptor in "primary" aldosteronism. Journal of Clinical Endocrinology and Metabolism. 2014;99(5):1790-1797. doi:10.1210/jc.2013-3282

6. Sousa Silva M, Gomes RA, Ferreira AEN, Ponces Freire A, Cordeiro C. The glyoxalase pathway: The first hundred years... and beyond. Biochemical Journal. 2013;453(1):1-15. doi:10.1042/BJ20121743

7. Hanssen NMJ, Stehouwer CDA, Schalkwijk CG. Methylglyoxal and glyoxalase I in atherosclerosis. Biochemical Society Transactions. 2014;42(2):443-449. doi:10.1042/BST20140001

8. Maessen DEM, Stehouwer CDA, Schalkwijk CG. The role of methylglyoxal and the glyoxalase system in diabetes and other age-related diseases. Clinical Science. 2015;128(12):839-861. doi:10.1042/CS20140683

9. Miller AG, Tan G, Binger KJ, et al. Candesartan attenuates diabetic retinal vascular pathology by restoring glyoxalase-I function. Diabetes. 2010;59(12):3208-3215. doi:10.2337/db10-0552

10. Seccia TM, Caroccia B, Gomez-Sanchez EP, Gomez-Sanchez CE, Rossi GP. The Biology of Normal Zona Glomerulosa and Aldosterone-Producing Adenoma: Pathological Implications. Endocrine Reviews. 2018;39(6):1029-1056. doi:10.1210/er.2018-00060

11. Williams TA, Lenders JWM, Mulatero $P$, et al. Outcomes after adrenalectomy for unilateral primary aldosteronism: an international consensus on outcome measures and analysis of remission rates in an international cohort. The Lancet Diabetes and Endocrinology. 2017;5(9):689-699. doi:10.1016/S2213-8587(17)30135-3

12. Scheijen JLJM, Schalkwijk CG. Quantification of glyoxal, methylglyoxal and 3-deoxyglucosone in blood and plasma by ultra performance liquid chromatography tandem mass spectrometry: Evaluation of blood specimen. Clinical Chemistry and Laboratory Medicine. 2014;52(1):85-91. doi:10.1515/cclm-2012-0878

13. Scheijen JLJM, Hanssen NMJ, Van De Waarenburg MPH, Jonkers DMAE, Stehouwer CDA, Schalkwijk CG. $\mathrm{L}(+)$ and $\mathrm{D}(-)$ lactate are increased in plasma and urine samples of type 2 diabetes as measured by a simultaneous quantification of $L(+)$ and $D(-)$ lactate by reversedphase liquid chromatography tandem mass spectrometry. Experimental Diabetes Research. 2012;2012. doi:10.1155/2012/234812

14. Hanssen NMJ, Engelen L, Ferreira I, et al. Plasma Levels of Advanced Glycation Endproducts $N^{\epsilon}$-(carboxymethyl)lysine, $N^{\epsilon}$-(carboxyethyl)lysine, and Pentosidine Are not Independently Associated With Cardiovascular Disease in Individuals With or Without Type 2 Diabetes: The $\mathrm{H}$. The Journal of Clinical Endocrinology \& Metabolism. 2013;98(8):E1369-E1373. doi:10.1210/jc.2013-1068

15. Miyata T, Van Ypersele De Strihou C, Ueda Y, et al. Angiotensin II receptor antagonists and angiotensin-converting enzyme inhibitors lower in vitro the formation of advanced glycation end products: Biochemical mechanisms. Journal of the American Society of Nephrology. 2002;13(10):2478-2487. doi:10.1097/01.ASN.0000032418.67267.F2 
16. Monacelli F, Poggi A, Storace D, et al. Effects of valsartan therapy on protein glycoxidation. Metabolism: Clinical and 2006;55(12):1619-1624. doi:10.1016/j.metabol.2006.07.024

17. Forbes JM, Thomas MC, Thorpe SR, Alderson NL, Cooper ME. The effects of valsartan on the accumulation of circulating and renal advanced glycation end products in experimental diabetes. Kidney International, Supplement. 2004;66(92):S105-S107. doi:10.1111/j.15231755.2004.09225.x

18. Forbes JM, Cooper ME, Thallas V, et al. Reduction of the accumulation of advanced glycation end products by ACE inhibition in experimental diabetic nephropathy. Diabetes. 2002;51(11):3274-3282. doi:10.2337/diabetes.51.11.3274

19. Chen ZW, Tsai CH, Pan CT, et al. Endothelial dysfunction in primary aldosteronism. International Journal of Molecular Sciences. 2019;20(20). doi:10.3390/ijms20205214

20. Remde H, Dietz A, Emeny R, et al. The cardiovascularmarkers copeptin and highsensitive Creactive protein decrease following specific therapy for primary aldosteronism. Journal of Hypertension. 2016;34(10):2066-2073. doi:10.1097/HJH.0000000000001041

21. Šomlóová Z, Petrák O, Rosa J, et al. Inflammatory Markers in Primary Aldosteronism. Physiol Res. 2016;65:229-237. doi:10.33549/physiolres.932994

22. van der Heijden CDCC, Smeets EMM, Aarntzen EHJG, et al. Arterial Wall Inflammation and Increased Hematopoietic Activity in Patients With Primary Aldosteronism. The Journal of Clinical Endocrinology \& Metabolism. 2020;105(5). doi:10.1210/clinem/dgz306 
Chapter 7 


\section{Chapter 8}

\section{Irbesartan treatment does not influence plasma levels of the dicarbonyls methylglyoxal, glyoxal and 3-}

deoxyglucosone in participants with type 2 diabetes and microalbuminuria. An IRMA2 substudy

M. Piazza, N.M.J Hanssen, F. Persson, J Scheijen, M.P.H. Waarenburg, M.M.J. Greevenbroek, P. Rossing, P. Hovind, C.D.A. Stehouwer, H-H Parving, C.G. Schalkwijk

Diabetic Medicine 2020 Sep 22;e14405 


\section{Abstract \\ Background}

Angiotensin receptor blockers (ARBs) reduce vascular complications in diabetes independently of blood pressure. Experimental studies suggested that ARBs may restore the detoxifying enzyme glyoxalase 1, thereby lowering dicarbonyls such as methylglyoxal. Human data on the effects of ARBs on plasma dicarbonyl levels are lacking. We investigated in individuals with type 2 diabetes (T2D) whether irbesartan lowered plasma levels of the dicarbonyls methylglyoxal, glyoxal, 3deoxyglucosone, and their derived Advanced Glycation End products (AGEs), and increased D-lactate, reflecting greater methylglyoxal flux.

\section{Methods}

We analysed a subset of the Irbesartan in Patients with T2D and Microalbuminuria (IRMA2) study. We measured plasma dicarbonyls methylglyoxal, glyoxal and 3deoxyglucosone, free AGEs and D-lactate with ultra-performance liquid chromatography tandem mass-spectrometry (UPLC-MS/MS) in the treatment arm receiving $300 \mathrm{mg}$ irbesartan $(n=121)$ and placebo group $(n=101)$ at baseline and after 1 and 2 years. Effect of treatment was analyzed with repeated measurements ANOVA.

\section{Results}

There was a slight, but significant difference in baseline median methylglyoxal levels (placebo 1119 (907-1509) nmol/L versus irbesartan 300mg: 1053 (8201427) $\mathrm{nmol} / \mathrm{L}$ ), but no significant changes were observed in any of the plasma dicarbonyls over time in either group and there was no effect of irbesartan treatment on plasma free AGEs or D-lactate levels at either 1 or 2 years.

\section{Conclusion}

Irbesartan treatment does not change plasma levels of the dicarbonyls methylglyoxal, glyoxal and 3-deoxyglucosone, free AGEs or D-lactate in T2D. This indicates that increased dicarbonyls in T2D are not targetable by ARBs, and other approaches to lower systemic dicarbonyls are needed in T2D. 


\section{Introduction}

Type 2 diabetes (T2D) is associated with development of cardiovascular disease (CVD), chronic kidney disease (CKD), and is a main cause of end-stage kidney disease (ESKD). The Renin-Angiotensin-Aldosterone System (RAAS) plays an important role in the development of CVD and CKD in T2D 1,2. Inhibition of the RAAS with ARBs reduces the incidence of CKD and CVD in T2D ${ }^{3,4}$. However, the mechanisms through which ARBs attenuate renal and cardiovascular risk remains incompletely understood. This was highlighted by the seminal original Irbesartan in T2D With Microalbuminuria 2 (IRMA2) investigation, where the ARB irbesartan reduced progression of diabetic CKD, independently of blood pressure ${ }^{4}$. Therefore, research into the mechanisms of action of ARBs is still needed to maximize the benefit of this vital class of medications for the prevention of diabetic complications. This is highly relevant since the incidence of CVD and CKD in T2D remains high and many individuals still progress towards ESKD despite optimal treatment with ARBs ${ }^{5}$.

A potential underlying mechanism of the protective effects of ARBs is a reduction in the accumulation of methylglyoxal, a highly reactive glucose metabolite and the major precursor in the rapid formation of advanced glycation endproducts (AGEs) ${ }^{6}$. Methylglyoxal levels are increased in $\mathrm{T} 2 \mathrm{D}{ }^{7}$, and higher plasma methylglyoxal levels were associated with CVD, albuminuria and a decline in estimated glomerular filtration rate (eGFR) in T2D ${ }^{8-10}$. Methylglyoxal is detoxified by the glyoxalase system to D-lactate, with glyoxalase 1 (Glo1) as the rate-limiting enzyme ${ }^{11}$. Glo1 expression is lower in kidneys affected by CKD ${ }^{12}$. In line, Glo1 overexpression attenuated albuminuria in diabetic rats ${ }^{13}$, while Glo1 knockdown caused a CKD-like phenotype even in normoglycaemic mice ${ }^{14}$. These findings imply that Glo1 is a major protective factor against CKD. Interestingly, it has been shown in an experimental study that the ARB candesartan attenuates the formation of methylglyoxal levels through enhanced Glo1 expression ${ }^{15}$. These observations led to the hypothesis that health benefits of ARBs are due, at least in part, to increased expression of Glo1 and a decrease of methylglyoxal levels. However, human studies about the effect of ARBs on systemic methylglyoxal levels are lacking. To explore whether irbesartan lowers dicarbonyl stress, we have now investigated plasma levels of methylglyoxal and two other major dicarbonyls, glyoxal and 3-deoxyglucosone, as well as D-lactate and free levels of the major dicarbonyl derived AGEs $\mathrm{N}^{\varepsilon}$-carboxymethyllysine $(\mathrm{CML}), \mathrm{N}^{\varepsilon}$-carboxyethyllysine (CEL) and methylglyoxal-derived hydroimidazolone (MG-H1) in the IRMA2 substudy with a follow-up period of 2 years. 


\section{Methods}

\section{Study design and participants}

The IRMA 2 study was a 2-year multicenter, double-blind, parallel randomized controlled trial in individuals with T2D and microalbuminuria in which the main goal was to compare the effects of irbesartan (150 or $300 \mathrm{mg}$ once daily) versus placebo, in addition to conventional antihypertensive treatment, on the development of overt nephropathy ${ }^{4}$. Briefly, we enrolled individuals with T2D (diagnosed according to the World Health Organization criteria) and hypertension (defined as mean systolic blood pressure $>135 \mathrm{mmHg}$ and/or mean diastolic blood pressure $>85 \mathrm{mmHg}$ in two of three consecutive measurements 1 week apart) and persistent microalbuminuria (defined as an albumin excretion rate of 20-200 $\mathrm{mg} / \mathrm{min}$ in two of three consecutive overnight urine samples) and a serum creatinine concentration of $133 \mu \mathrm{mol} / \mathrm{L}$ for men and $97 \mu \mathrm{mol} / \mathrm{L}$ for women. A total of 590 (186 women) individuals, aged 30-70 years, were included and randomly assigned to receive $150 \mathrm{mg}$ irbesartan once daily ( $n=195), 300 \mathrm{mg}$ irbesartan once daily $(n=194)$ or matching placebo $(n=201)$ (Figure S8.1). Results regarding the primary end point, and other secondary end points such as markers of inflammation and endothelial dysfunction, have been reported previously ${ }^{4}$. The aim of the present study was to evaluate the effect of irbesartan treatment on glycation, using several state-of-the art panels to quantify plasma levels of the plasma dicarbonyls methylglyoxal, glyoxal and 3-deoxyglucosone, the free AGE levels of CML, CEL, MG-H1 and D-lactate. Samples for the assessment of these markers at baseline and at 1- and 2-year follow-up were still available from 121 participants in the treatment arm receiving $300 \mathrm{mg}$ irbesartan and from 101 participants receiving placebo. In the initial analyses of this study, no significant effects of $150 \mathrm{mg}$ irbesartan treatment versus placebo were found on the development of nephropathy, creatinine clearance or blood pressure. The $150 \mathrm{mg}$ irbesartan samples were not included in the current analyses because they are no longer available as they unfortunately have been discarded by mistake in the past. Individuals included in the current analyses had similar base-line characteristics as the original investigation (data not shown) ${ }^{4}$

\section{Biochemical measurements}

$\mathrm{HbA} \mathrm{A}_{1 \mathrm{c}}$ was measured by ion-exchange HPLC. Serum creatinine concentration was originally measured by the Jaffe reaction with the use of a Hoffmann LaRoche kit and creatinine clearance (in $\mathrm{mL} / \mathrm{min} / 1.73 \mathrm{~m}^{2}$ body surface area) was estimated with the Cockcroft-Gault equation. These variables were evaluated at the time of randomization, 2 and 4 weeks after randomization and at 3, 6, 12, 18 and 22-24 months. 


\section{Measurement of plasma dicarbonyls}

Plasma samples were stored at $-80 \mathrm{C}^{\circ}$ until analyses. Plasma dicarbonyls were measured with ultra-performance liquid chromatography tandem massspectrometry (UPLC-MS/MS) ${ }^{16}$. In brief, EDTA plasma samples $(25 \mu \mathrm{L})$ were mixed with $75 \mu \mathrm{L} \mathrm{d}_{8}$-O-phenylenediamine (oPD) $(10 \mathrm{mg}$ oPD in $10 \mathrm{~mL} 1.6 \mathrm{~mol} / \mathrm{L}$ perchloric acid) in an Eppendorf cup. After an overnight (20h) reaction, at room temperature and shielded from light, $10 \mu \mathrm{L}$ of internal standard solution was added. Samples were mixed and subsequently centrifuged for $20 \mathrm{~min}$ at $21,000 \mathrm{~g}$ at a temperature of $4^{\circ} \mathrm{C} ; 10 \mu \mathrm{L}$ was injected for UPLC/MSMS analysis. The inter-assay variations for methylglyoxal, glyoxal and 3-deoxyglucosone were 4.3, 5.1 and $2.2 \%$, respectively ${ }^{16}$.

Plasma D-lactate levels were measured with UPLC-MS/MS ${ }^{17} .25 \mu \mathrm{L}$ of plasma was derivatized with diacetyl-L-tartaric anhydride and separated on a C(18)-reversed phase column. D-lactate inter- and intra-assay variations were between $2 \%$ and $9 \%$.

Plasma free MG-H1 levels were measured with UPLC-MS/MS ${ }^{18} .50 \mu \mathrm{L}$ plasma was used, samples were derivatized with butanolic hydrochloric acid and subsequently detected in multiple reaction monitoring (MRM) mode using a Xevo TQ MS (Waters, Milford, USA). Quantification of free MG-H1 was performed by calculating the peak area ratio of each unlabeled peak area to the corresponding internal standard peak area. In plasma, the intra- and inter-assay variation of protein-bound CML, CEL and MG-H1 were between 4.8 and $18.8 \%$ and for free CML, CEL and MG-H1 between 2.8 and $7.1 \%$.

\section{Statistics}

Variables with skewed distribution (plasma dicarbonyls) were Ln-transformed prior to further analyses. Changes in plasma dicarbonyl levels over the 2-year follow-up time were examined according to the intention-to-treat principle and with the use of repeated measurement analysis of variance. As a sensitivity analysis, we stratified our dataset on the median baseline $\mathrm{HbA}_{1 c}$ value of the current dataset to investigate whether the effect of irbesartan differed by glycaemic control. For this analyses $n=19$ individuals were initially excluded because of missing baseline $\mathrm{HbA}_{1 \mathrm{c}}$ values. When we added these individuals to the above median $\mathrm{HbA}_{1 \mathrm{c}}$ group, reasoning that individuals with missing values on average have poorer control, the results did not change. All statistical analyses were performed using SPSS version 23.

\section{Results}

Baseline characteristics of the current subset of the IRMA2 trial are shown in Table 8.1. An in-depth description of the complete study has been provided elsewhere ${ }^{4}$. 
Chapter 8

\begin{tabular}{lcc}
\hline & Placebo $(\mathbf{n = 1 0 1})$ & 300mg Irbesartan $(\mathbf{n}=\mathbf{1 2 1})$ \\
\hline Sex $(\%$ women) & 32.1 & 30.8 \\
Age (years) & $57.7 \pm 9.3$ & $57.3 \pm 7.8$ \\
Known duration of diabetes (years) & $7.0(3.0-14.5)$ & $7.0(4.0-12.0)$ \\
$\mathrm{HbA}_{1 \mathrm{c}}(\%)$ & $7.0 \pm 1.6$ & $6.9 \pm 1.7$ \\
$\mathrm{HbA}_{1 \mathrm{c}}(\mathrm{mmol} / \mathrm{mol})$ & $53 \pm 18$ & $52 \pm 19$ \\
Body mass index $\left(\mathrm{kg} / \mathrm{m}^{2}\right)$ & $30.4 \pm 4.3$ & $29.9 \pm 4.3$ \\
Total cholesterol $(\mathrm{mmol} / \mathrm{L})$ & $5.7 \pm 1.1$ & $5.8 \pm 1.1$ \\
Current smoking $(\%)$ & 19.3 & 14.6 \\
Systolic blood pressure $(\mathrm{mmHg})$ & $153.1 \pm 14.3$ & $154.5 \pm 13.2$ \\
Diastolic blood pressure $(\mathrm{mmHg})$ & $89.8 \pm 8.4$ & $91.9 \pm 9.7$ \\
Creatinine clearance $\left(\mathrm{mL} / \mathrm{min} / 1.73 \mathrm{~m}^{2}\right)$ & $110.0(89.5-130.5)$ & $106.0(92.5-124.3)$ \\
Urinary albumin excretion $(\mathrm{mg} / 24 \mathrm{~h})$ & $51.0(33.0-82.0)$ & $51.0(35.0-87.0)$ \\
\hline
\end{tabular}

Table 8.1: Baseline characteristics of the study participants

Data are expressed as mean $\pm S D$, median (interquartile range) or percentages as appropriate and stratified according to treatment group (300 $\mathrm{mg}$ irbesartan or placebo).

\section{Effects of $300 \mathrm{mg}$ irbesartan treatment on plasma levels of methylglyoxal, glyoxal and 3-deoxyglucosone}

Plasma methylglyoxal levels were significantly lower at baseline in the group randomized to $300 \mathrm{mg}$ irbesartan (Table 8.2, Figure 8.1). Plasma levels of methylglyoxal, glyoxal and 3-deoxyglucosone did not change significantly over the 1 and 2 year follow-up time in either group and did not differ between groups (Table 8.2, Figure 8.1). These results did not change when we adjusted the repeated measurements in ANOVA for sex, age, $\mathrm{HbA}_{1 \mathrm{c}}$, duration of diabetes and BMI (data not shown).
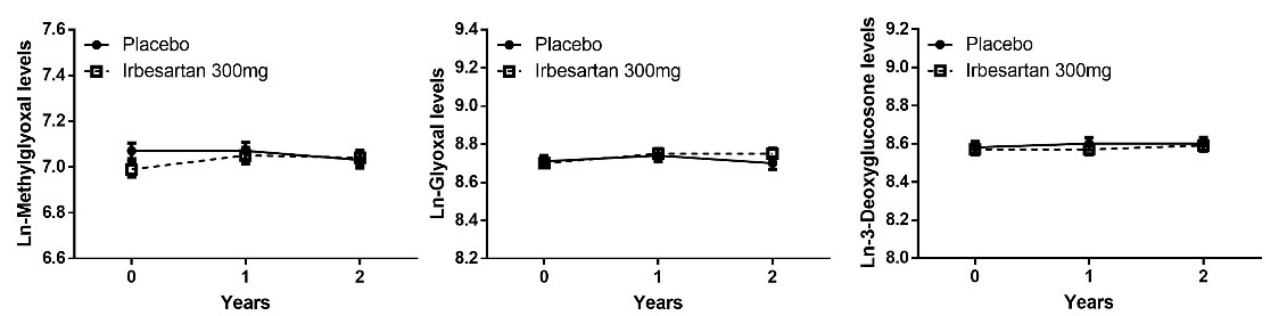

Figure 8.1. 2-way plots of plasma levels of Ln-transformed methylglyoxal, glyoxal and 3deoxyglucosone at baseline, 1-year and 2-year follow-up for the irbesartan (IRB) $300 \mathrm{mg}$ group and the placebo $(P L)$ group. Data are presented as mean \pm standard error. ${ }^{*}<P 0.05$ versus placebo. Differences between groups and over time were tested with repeated measures ANOVA, after Ln-transformation of the outcome variables. 


\section{Effects of $300 \mathrm{mg}$ irbesartan treatment on plasma levels of D-lactate}

Plasma levels of D-lactate did not change significantly in either group after 1 and 2year follow-up time and no difference was found between groups (Table 8.2, Figure 8.2).

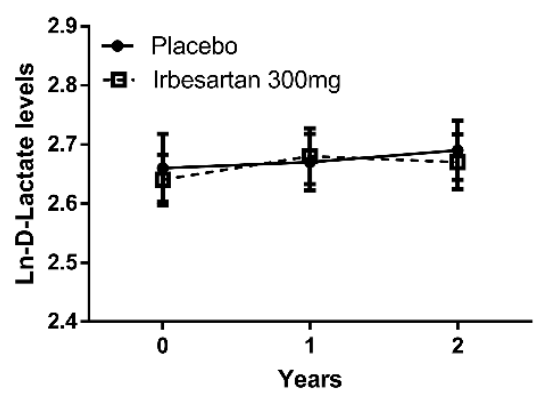

Figure 8.2. 2-way plot of plasma levels of D-lactate at baseline, 1-year and 2-year follow-up for the irbesartan (IRB) $300 \mathrm{mg}$ group and the placebo (PL) group. Data are presented as mean \pm standard error. ${ }^{*}<\mathrm{P} 0.05$ versus placebo. Differences between groups and over time were tested with repeated measures ANOVA after Ln-transformation of the outcome variable.

\section{Effects of $300 \mathrm{mg}$ irbesartan treatment on plasma levels of free CML, CEL and MG-H1}

We next analysed levels of the free plasma AGEs CML, CEL and MG-H1 (Table 8.2, Figure 8.3). At baseline, prior to treatment, plasma CML, CEL and MG-H1 appeared to be higher in the group randomised to placebo treatment, and this was statistically significant for CML and CEL (Table 8.2, Figure 8.3). However, at 1 and 2 years follow-up we observed no differences between the placebo or irbesartan groups.
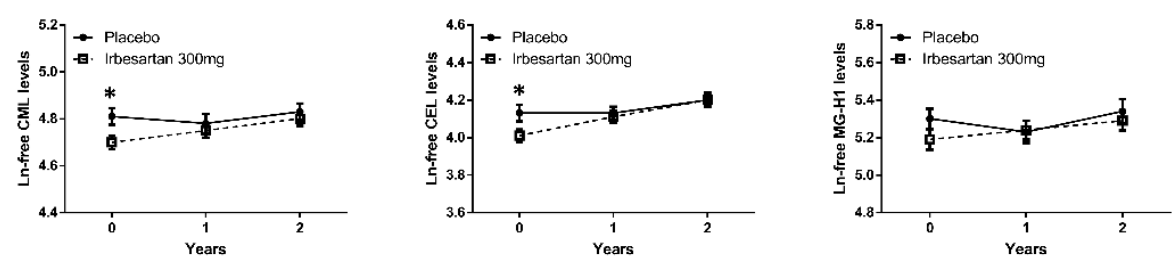

Figure 8.3. 2-way plots of plasma levels of free CML, CEL and MG-H1 at baseline, 1-year and 2-year follow-up for the irbesartan (IRB) 300mg group and the placebo (PL) group. Data are presented as mean \pm standard error. ${ }^{*}<P 0.05$ versus placebo. Differences between groups and over time were tested with repeated measures ANOVA after Ln-transformation of the outcome variable. 


\begin{tabular}{|c|c|c|c|c|c|c|}
\hline & Placebo & $\begin{array}{l}300 \mathrm{mg} \\
\text { Irbesartan }\end{array}$ & Placebo & $300 \mathrm{mg}$ Irbesartan & Placebo & $300 \mathrm{mg}$ Irbesartan \\
\hline Methylglyoxal (nmol/L) & 1119 (907-1590) & $1053(821-1448)$ & 1131 (873-1488) & 1147 (824-1539) & $1078(876-1448)$ & $1142(839-1565)$ \\
\hline Glyoxal (nmol/L) & $6079(4967-7164)$ & 6003 (5153-6939) & 6067 (5108-7959) & 6304 (5230-7642) & 6036 (4928-7758) & $6238(5169-7332)$ \\
\hline D-lactate (mmol/L) & $13.8(9.2-22.3)$ & $14.0(9.9-20.3)$ & $14.8(10.0-19.4)$ & $15.2(10.6-21.2)$ & $15.4(10.3-21.2)$ & $14.9(10.8-22.4)$ \\
\hline Free CML (nmol/L) & $116.8(98.4-158.1)$ & $107.0(84.6-134.9)$ & $116.5(92.5-154.8)$ & $111.9(92.6-134.5)$ & $125.2(98.8-155.3)$ & $121.1(96.5-154.7)$ \\
\hline Free CEL (nmol/L) & $63.3(49.1-81.1)$ & $52.6(42.4-70.4)$ & $63.4(43.4-80.7)$ & $58.1(47.6-77.6)$ & $66.2(51.0-84.7)$ & $63.5(50.2-82.9)$ \\
\hline
\end{tabular}

Table 8.2: Plasma dicarbonyls, D-lactate and free AGE levels at baseline and at 1- and 2-year follow-up

Data are expressed as median (interquartile range) and stratified according to treatment group (300 $\mathrm{mg}$ irbesartan or placebo). 


\section{Discussion}

The current analyses of the IRMA2 study showed that irbesartan at a concentration of $300 \mathrm{mg}$ versus placebo does not lower plasma levels of methylglyoxal or the other dicarbonyls glyoxal and 3-deoxyglucosone, D-lactate or the free plasma AGEs CML, CEL and MG-H1.

These results suggest that ARBs, or at least irbesartan, does not act as a potent agent to lower systemic dicarbonyl stress as reflected by changes in plasma dicarbonyl, D-lactate or free AGE levels, although the effectiveness of irbesartan has been demonstrated by its ability to reduce progression of albuminuria in the original trial. Since plasma dicarbonyl levels are not lower than in previous investigations we performed $8,9,19$, it seems unlikely that there was insufficient dicarbonyl stress in the current study to effectively detect a reduction by irbesartan. Our current finding is in line with prior analyses from our group in the IRMA2 subset, in which we found that the plasma protein-bound AGEs CML and CEL were not affected by irbesartan ${ }^{20}$. The current study expands upon this finding by direct measurements of dicarbonyls, as well as including free plasma AGEs and Dlactate as a potential marker of methylglyoxal detoxification by Glo1.

The IRMA2 study was performed in the clinical era prior to the newer glucoselowering drugs such as the sodium glucose reuptake inhibitors (SGLT2i) and glucagon-like peptide 1 (GLP1) analogues. This is actually an advantage in terms of specifying the effects of ARBs on plasma dicarbonyls, since we can exclude an interaction of these newer compounds with plasma dicarbonyls, which could have masked effects of irbesartan on plasma dicarbonyl levels. Adjustment for $\mathrm{HbA}_{1 \mathrm{c}}$ did not change our results which makes it less likely that changes in glucose and thus dicarbonyls, covered the effect of ARBs on dicarbonyls.

Previous experimental studies have mainly focused on in-depth analyses of the influence of ARBs on methylglyoxal and the glyoxalase expression in retinal and renal tissues 15,21,22 and it has been demonstrated that ARBs modulate methylglyoxal levels in specific microvascular beds ${ }^{15}$. This is likely achieved by blocking angiotensin II signalling and related down-regulation of Glo1. In this study, however, we did not find an effect of irbesartan on plasma levels of methylglyoxal. Since we do not have data about tissue methylglyoxal levels, we cannot rule out the possibility that there is an effect of irbesartan on methylglyoxal levels in specific tissues that are not reflected by changes in plasma glycation levels. This was indeed suggested by a rodent study that showed decreased CML levels in diabetic kidneys by the ARB valsartan, while overall plasma fluorescence as a reflection of glycation was not altered ${ }^{22}$. Therefore, we cannot disprove earlier pre-clinical studies based on our current investigation. Additionally, it might be that the beneficial effects of ARBs are restricted to experimental models of diabetes.

This study also has the limitation that we have only data about plasma levels of dicarbonyls and not urinary levels; we cannot exclude an effect of ARBs on urinary 
dicarbonyls. In fact, it has been demonstrated that irbesartan significantly decreased urinary excretion of the dicarbonyls-derived AGEs MG-H1 and glyoxalderived hydroimidasolone (G-H1). As urinary free MG-H1 and G-H1 are thought to originate mainly from proteolysis of methylglyoxal and glyoxal-modified proteins ${ }^{23}$, these changes may therefore indicate decreased dicarbonyl stress in renal tissues by irbesartan. This is in accordance with the effect of angiotensin blockade in regulation of glyoxalase 1 in vitro ${ }^{15}$. However, because of the potent effect of glucose lowering treatment on plasma methylglyoxal levels in T2D ${ }^{19,24}$, it is unlikely that ARBs constitute a main mitigating treatment to reduce dicarbonyl stress in diabetes.

\section{Conclusion}

In conclusion, irbesartan did not lower plasma dicarbonyls and it therefore it is less likely that ARBs attenuate renal and cardiovascular risk through attenuation of dicarbonyl stress. In addition, there is still an unmet need of compounds to effectively lower systemic dicarbonyl stress in order reduce the burden of CKD and CVD in diabetes. It is not known if more recent reno-protective agents like SGLT2 inhibitors and GLP1 receptor agonists have an effect on dicarbonyl stress. Particularly SGLT2 inhibitors have demonstrated renal benefits and although initially introduced for their glucose lowering effect this seems not to explain the renal and cardiovascular benefits.

\section{Novelty Statements}

- The Angiotensin receptor blocker (ARB) irbesartan reduces progression of diabetic kidney disease independently of blood pressure in individuals with type 2 diabetes.

- Methylglyoxal is a major driver of diabetic kidney disease and may be lowered by ARBs.

- Irbesartan (300mg) did not lower plasma levels of methylglyoxal, or any of the additional glycation markers we measured in this study.

- This indicates that increased dicarbonyls in type 2 diabetes are not targetable by irbesartan, and other approaches to lower systemic dicarbonyls are needed in type 2 diabetes 


\section{References}

1. Volpe M, Savoia C, De Paolis P, Ostrowska B, Tarasi D, Rubattu S. The Renin-Angiotensin System as a Risk Factor and Therapeutic Target for Cardiovascular and Renal Disease. Journal of the American Society of Nephrology. 2002;13(Suppl 3):S173-S178. doi:10.1097/01.ASN.0000032549.36050.78

2. Ruiz-Ortega $M$, Lorenzo $O$, Rupérez $M$, et al. Role of the renin-angiotensin system in vascular diseases: Expanding the field. Hypertension. 2001;38(6):1382-1387. doi:10.1161/hy1201.100589

3. Brenner BM, Cooper ME, De Zeeuw D, et al. Effects of losartan on renal and cardiovascular outcomes in patients with type 2 diabetes and nephropathy. New England Journal of Medicine. 2001;345(12):861-869. doi:10.1056/NEJMoa011161

4. Parving HH, Lehnert $\mathrm{H}$, Bröchner-Mortensen J, et al. The effect of irbesartan on the development of diabetic nephropathy in patients with type 2 diabetes. New England Journal of Medicine. 2001;345(12):870-878. doi:10.1056/NEJMoa011489

5. Perkovic V, Jardine MJ, Neal B, et al. Canagliflozin and Renal Outcomes in Type 2 Diabetes and Nephropathy. New England Journal of Medicine. 2019;380(24):2295-2306. doi:10.1056/NEJMoa1811744

6. Schalkwijk C, Stehouwer CD. Methylglyoxal, a highly reactive dicarbonyl compound, in diabetes, its vascular complications and other age-related diseases. Physiological Reviews. 2020;100(1):407-461. doi:10.1152/physrev.00001.2019

7. Maessen DE, Brouwers $\mathrm{O}$, Gaens $\mathrm{KH}$, et al. Delayed intervention with pyridoxamine improves metabolic function and prevents adipose tissue inflammation and insulin resistance in high-fat diet-induced obese mice. Diabetes. 2016;65(4):956-966. doi:10.2337/db15-1390

8. Hanssen NMJ, Scheijen JLJM, Jorsal A, et al. Higher Plasma Methylglyoxal Levels Are Associated With Incident Cardiovascular Disease in Individuals With Type 1 Diabetes: A 12-Year Follow-up Study. Diabetes. 2017;66(8):2278-2283. doi:10.2337/db16-1578

9. Hanssen NMJ, Westerink J, Scheijen JLJM, Van Der Graaf Y, Stehouwer CDA, Schalkwijk CG. Higher plasma methylglyoxal levels are associated with incident cardiovascular disease and mortality in individuals with type 2 diabetes. Diabetes Care. 2018;41(8):1689-1695. doi:10.2337/dc18-0159

10. Jensen TM, Vistisen D, Fleming T, et al. Methylglyoxal is associated with changes in kidney function among individuals with screen-detected Type 2 diabetes mellitus. Diabetic Medicine. 2016;33(12):1625-1631. doi:10.1111/dme.13201

11. Hanssen NMJ, Stehouwer CDA, Schalkwijk CG. Methylglyoxal and glyoxalase I in atherosclerosis. Biochemical Society Transactions. 2014;42(2):443-449. doi:10.1042/BST20140001

12. Qi W, Keenan HA, Li Q, et al. Pyruvate kinase M2 activation may protect against the progression of diabetic glomerular pathology and mitochondrial dysfunction. Nature Medicine. 2017;23(6):753762. doi: $10.1038 / \mathrm{nm} .4328$

13. Brouwers $\mathrm{O}$, Niessen PMG, Miyata $\mathrm{T}$, et al. Glyoxalase-1 overexpression reduces endothelial dysfunction and attenuates early renal impairment in a rat model of diabetes. Diabetologia. 2014;57(1):224-235. doi:10.1007/s00125-013-3088-5

14. Giacco F, Du X, D'Agati VD, et al. Knockdown of glyoxalase 1 mimics diabetic nephropathy in nondiabetic mice. Diabetes. 2014;63(1):291-299. doi:10.2337/db13-0316

15. Miller AG, Tan G, Binger KJ, et al. Candesartan attenuates diabetic retinal vascular pathology by restoring glyoxalase-I function. Diabetes. 2010;59(12):3208-3215. doi:10.2337/db10-0552

16. Scheijen JLJM, Schalkwijk CG. Quantification of glyoxal, methylglyoxal and 3-deoxyglucosone in blood and plasma by ultra performance liquid chromatography tandem mass spectrometry: Evaluation of blood specimen. Clinical Chemistry and Laboratory Medicine. 2014;52(1):85-91. doi:10.1515/cclm-2012-0878

17. Scheijen JLJM, Hanssen NMJ, Van De Waarenburg MPH, Jonkers DMAE, Stehouwer CDA, Schalkwijk CG. $L(+)$ and $\mathrm{D}(-)$ lactate are increased in plasma and urine samples of type 2 


\section{Chapter 8}

diabetes as measured by a simultaneous quantification of $L(+)$ and $D(-)$ lactate by reversed-phase liquid chromatography tandem mass spectrometry. Experimental Diabetes Research. 2012;2012. doi:10.1155/2012/234812

18. Scheijen JLJM, Hanssen NMJ, van Greevenbroek MM, et al. Dietary intake of advanced glycation endproducts is associated with higher levels of advanced glycation endproducts in plasma and urine: The CODAM study. Clinical Nutrition. 2018;37(3):919-925. doi:10.1016/j.clnu.2017.03.019

19. Maessen DE, Hanssen NM, Scheijen JL, et al. Post-glucose load plasma a-dicarbonyl concentrations are increased in individuals with impaired glucose metabolism and type 2 diabetes: The CODAM study. Diabetes Care. 2015;38(5):913-920. doi:10.2337/dc14-2605

20. Engelen L, Persson F, Ferreira I, et al. Irbesartan treatment does not influence plasma levels of the advanced glycation end products $N \varepsilon$ (1-carboxymethyl)lysine and $N \varepsilon$ (1-carboxyethyl)lysine in patients with type 2 diabetes and microalbuminuria. A randomized controlled trial. Nephrology Dialysis Transplantation. 2011;26(11):3573-3577. doi:10.1093/ndt/gfr102

21. Dhar I, Dhar A, Wu L, Desai KM. Methylglyoxal, a Reactive Glucose Metabolite, Increases Renin Angiotensin Aldosterone and Blood Pressure in Male Sprague-Dawley Rats. American Journal of Hypertension. 2014;27(3):308-316. doi:10.1093/ajh/hpt281

22. Forbes JM, Thomas MC, Thorpe SR, Alderson NL, Cooper ME. The effects of valsartan on the accumulation of circulating and renal advanced glycation end products in experimental diabetes.

Kidney International, Supplement. 2004;66(92):S105-S107. doi:10.1111/j.15231755.2004.09225.x

23. Karachalias N, Babaei-Jadidi R, Rabbani N, Thornalley PJ. Increased protein damage in renal glomeruli, retina, nerve, plasma and urine and its prevention by thiamine and benfotiamine therapy in a rat model of diabetes. Diabetologia. 2010;53(7):1506-1516. doi:10.1007/s00125-010$1722-z$

24. Beisswenger PJ, Howell SK, Touchette AD, Lal S, Szwergold BS. Metformin Reduces Systemic Methylglyoxal Levels in Type 2 Diabetes. Diabetes. 1999;48(1):198-202. 


\section{Supplemental Figure}

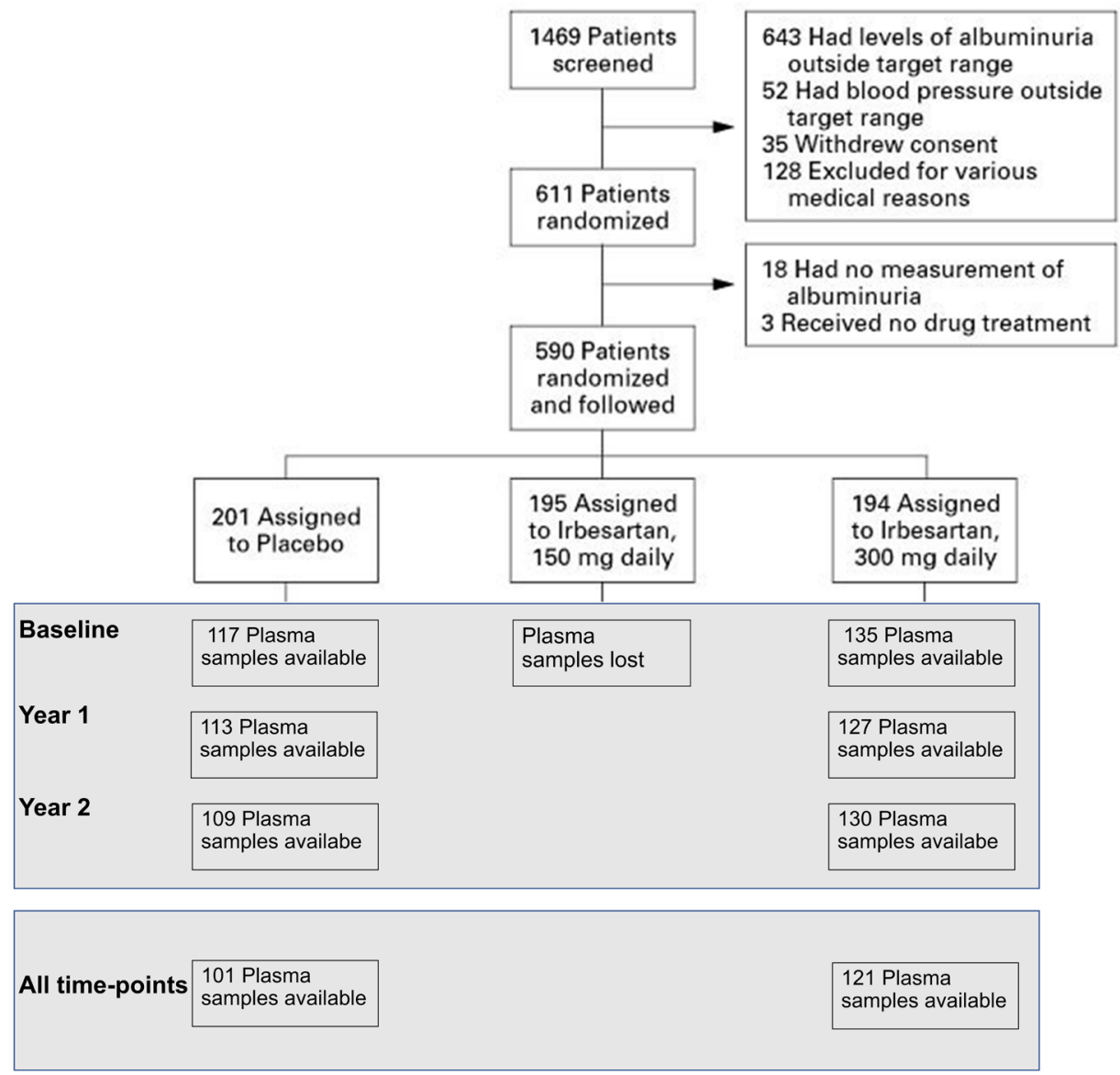

\section{Supplemental Figure S8.1.}

Consortium flow chart adapted from original publication ${ }^{1}$

\section{References}

1. Parving HH, Lehnert H, Bröchner-Mortensen J, Gomis R, Andersen S, Arner P, et al. The effect of irbesartan on the development of diabetic nephropathy in patients with type 2 diabetes. New England Journal of Medicine. 2001 Sep 20;345(12):870-8. 
Chapter 8 


\section{Chapter 9}

\section{Angiotensin II infusion decreases glyoxalase I expression and activity in kidney and liver of $\mathrm{C} 57 \mathrm{BL} / 6 \mathrm{~J}$ mice}

Maria Piazza, Nordin M.J. Hanssen, Marjo P.H. van de Waarenburg, Margee Robertus, Jean L. Scheijen, Annika R. Kuhn, Marc van Bilsen, Casper G. Schalkwijk

In preparation 
Chapter 9

\section{Abstract \\ Background}

The renin-angiotensin-aldosterone system (RAAS) and advanced glycation endproduct (AGEs) are both implicated in the development of renal and cardiovascular disease. Methylglyoxal (MGO) is a highly reactive glucosemetabolite and the main precursor in the formation of AGEs. Activation of the angiotensin II type I receptor (AT1R) has been linked to an increase of MGO, via downregulation of glyoxalase 1 (Glo1). We here investigated whether angiotensin II infusion reduces Glo1 expression and increases MGO levels and MGO-derived AGEs in kidney and the liver of C57BL/6J mice.

\section{Method}

C57BL/6J mice were infused with angiotensin II with a minipump $(2.5 \mathrm{mg} / \mathrm{kg} /$ day $)$ for 3 days $(n=4)$ or 28 days $(n=9)$ or vehicle (saline, $n=4$ for 3 days, $n=628$ days). The dicarbonyls MGO, glyoxal (GO) and 3-deoxyglucosone (3-DG), as well as the major dicarbonyl-derived AGEs 5-hydro-5 methylimidazolone (MG-H1), $\mathrm{N}^{\varepsilon_{-}}$ (carboxyethyl)lysine (CEL) and $\mathrm{N}^{\varepsilon}$-(carboxymethyl)lysine (CML) were measured, in plasma and in kidney and liver homogenates by ultra-performance liquid chromatography tandem mass-spectrometry (UPLC-MS/MS). Changes in Glo1 mRNA levels were measured in tissue by qRT-PCR.

\section{Results}

Relative to the controls, infusion of angiotensin II for 3 and 28 days reduced Glo1 mRNA and activity in liver and kidney. Although the several dicarbonyls and AGEs in tissues and in plasma showed mixed patterns, CML and MG-H1 were increased in the liver after 3 days of angiotensin II infusion and this was accompanied by an increase of plasma GO, MGO, CML and CEL levels.

\section{Conclusion}

Glo1 is downregulated in the kidney and the liver after angiotensin II infusion, with a concomitant increase in markers of dicarbonyl stress. Angiotensin II reduced expression of Glo1 accompanied by an increase in dicarbonyls stress may be implicated in the development of renal and cardiovascular disease. 


\section{Introduction}

Activation of the Renin-Angiotensin-Aldosterone System (RAAS) and accumulation of advanced glycation endproducts (AGEs) is increased in diabetes 1 and are both implicated in cardiovascular disease (CVD) and chronic kidney disease (CKD) in type 2 diabetes (T2D) ${ }^{1,2}$.

There are some indications that the RAAS and the AGE pathway are intertwined. Activation of the angiotensin II type I receptor (AT1R) by angiotensin II has been linked to an increase of methylglyoxal (MGO), a highly reactive glucosemetabolite and a major precursor in the formation of AGEs ${ }^{3}$. MGO and its derived AGEs are key players in the development of CVD and CKD 4,5. Glyoxalase 1 (Glo1) is the rate-limiting enzyme in the detoxification of MGO to Dlactate and increased activation of AT1R by angiotensin II has been linked to decreased expression of $\mathrm{Glo}^{1}{ }^{6}$. Glo1 expression is lower in kidneys affected by CKD in the setting of type 1 diabetes ${ }^{8}$. In line, Glo1 knockdown caused a CKDlike phenotype even in normoglycaemic mice ${ }^{9}$, while Glo1 overexpression attenuated albuminuria in diabetic rats ${ }^{10}$ and in diabetic ApoE deficient mice ${ }^{11}$. These findings indicate that Glo1 is a major protective enzyme against CKD.

Despite the indications in literature about the association of angiotensin II and MGO, we recently found in T2D that the angiotensin receptor blocker irbesartan does not lower plasma levels of MGO ${ }^{7}$. However, we cannot rule out the possibility that there is an effect of irbesartan on Glo1 and methylglyoxal levels in specific tissues that are not reflected by changes in plasma glycation levels. Therefore, we explored the effect of angiotensin II on the expression of Glo1 in kidney and liver and whether angiotensin II increases the dicarbonyls MGO, glyoxal (GO) and 3-deoxyglucosone (3-DG), as well as the major dicarbonylderived AGEs 5-hydro-5 methylimidazolone (MG-H1), $\mathrm{N}^{\varepsilon}$-(carboxyethyl)lysine $(\mathrm{CEL})$ and $\mathrm{N}^{\varepsilon}$-(carboxymethyl)lysine $(\mathrm{CML})$ in plasma and in kidney and liver homogenates.

\section{Methods}

\section{Animal}

Male 8-10-week-old C57BL/6J mice were fed standard mice chow and kept on a standard day/night cycle. Mice were injected with angiotensin II (Bachem) via Alzet Minipumps $(2.5 \mathrm{mg} / \mathrm{kg} /$ day $)$ for 3 days $(n=4)$ or 28 days $(n=9)$ or vehicle (saline) for 3 days $(n=4)$ or 28 days $(n=6)$. Systolic and diastolic blood pressure was monitored at 28 days by means of tail cuff (CODA, Kent Scientific, Torrington, CT). Animals were euthanized and plasma and organs were stored at $-80^{\circ} \mathrm{C}$ after snap-freezing. All animal experiments were performed according to the European Directive (2010/63/EU) and approved by the Animal Care and Use Committee of KU Leuven (P014/2014). 


\section{RNA extraction and quantitative real-time PCR}

RNA was isolated from liver and kidney tissues using Trizol reagent (SigmaAldrich). The RNA quantity and quality were determined by spectrophotometric readings at 260/280/230 $\mathrm{nm}$. RNA from tissue was reverse transcribed using the iScript CDNA synthesis kit (Bio-Rad). Gene expression of GLO1, was determined using IQ SensiMix SYBR master mix (Bioline) on a CFX96 Touch with CFX manager software (Biorad) using the comparative cycle threshold $\left(2^{-\Delta \Delta C t}\right)$ method: each sample was quantified against Cyclophillin (CYCLO) as a reference gene and normalized to the control group. The sequence of primer used in qRT-PCR were: GLO1-forward, 5'-ATGACGAGACTCAGAGTTACCACAA-3', GLO1reverse, 5'-TAGACATCAGGAACGGCAAATCC-3', CYCLO-forward, 5'TTCCTCCTTTCACAGAATTATTCCA-3', CCGCCAGTGCCATTATGG-3'

\section{Glo1 activity assay}

Glo1 activity was measured in protein lysates of the liver and kidney as previously described by McLellan et al. ${ }^{12}$ In brief, frozen liver and kidney tissues in liquid nitrogen, were crushed with a steel mortar and dissolved in phosphate buffer. Glo1 activity was assayed by a spectrophotometry analysis to monitor the increase in absorbance at $240 \mathrm{~nm}$ due to the formation of S-D-lactoylglutathione during $30 \mathrm{~min}$ at $25^{\circ} \mathrm{C}$. Glo1 activity was adjusted for protein-concentration measured as measured by the Pierce $\AA$ BCA Protein Assay Kit (Thermo Scientific) and expressed as units per milligram of protein. 1 Unit indicates the formation of $1 \mathrm{nmol} / \mathrm{S}$ S-D- lactoylglutathione per minute.

\section{Measurement of dicarbonyl, AGEs, D-lactate}

Levels of MGO, GO, 3-DG, free and protein bound AGEs, 5-hydro-5 methylimidazolone (MG-H1), $\quad \mathrm{N}^{\varepsilon_{-}}$(carboxyethyl)lysine $(\mathrm{CEL})$ and $\mathrm{N}^{\varepsilon_{-}}$ (carboxymethyl)lysine (CML), as well as D-lactate were analysed in plasma, liver and kidney homogenates by ultra-performance liquid chromatography tandem mass spectrometry (UPLC MS/MS) as previously described ${ }^{13-15}$.

\section{Statistical analysis}

Statistical analysis was performed with GraphPad Software ${ }^{\mathrm{TM}}$ (vers. 9.02, San Diego, CA). Unpaired data was tested for significance using a two-tailed Student's T-test. All data was expressed as the mean \pm SD and were considered statistically significant at $P<0.05$. 


\section{Results}

\section{Effect of angiotensin II on Glo1, dicarbonyl stress and D-lactate in mice}

To investigate the effect of angiotensin II on Glo1 expression and activity, dicarbonyls and AGEs levels, we subjected mice to angiotensin II infusion for 3 and for 28 days. At 28 days of exposure to angiotensin II, we found a significant increase in DBP and SBP as compared to sham mice, demonstrating the validity of the animal model (Table 9.1).

We determined the effect of angiotensin II on Glo1 expression. We found a significant decrease of Glo1 gene expression in kidney and liver tissue of mice infused with angiotensin II for 3 days and 28 days (Figure 9.1A). We found a consistent pattern for Glo1 activity in kidney and liver after infusion with angiotensin II which was significant in the liver after 28 days and in the kidney after 3 days (Figure 9.1B).

Table 9.1 Endpoint characteristics and plasma dicarbonyls, free and protein bound AGEs of mice after 3 days and 28 days of angiotensin II infusion.

$\begin{array}{llllll} & 3 \text { Days } & & & 28 \text { Days } \\ \text { Saline } & \text { Angiotensin II } & \text { P } & \text { Saline } & \text { Angiotensin II } & \text { P }\end{array}$

\begin{tabular}{|c|c|c|c|c|c|c|}
\hline Mouse (n) & 4 & 4 & & 6 & 9 & - \\
\hline $\mathrm{DBP}(\mathrm{mmHg})$ & - & - & - & $102 \pm 10$ & $155 \pm 34$ & 0.02 \\
\hline $\mathrm{SBP}(\mathrm{mmHg}))$ & - & - & - & $134 \pm 9$ & $189 \pm 35$ & 0.02 \\
\hline $\mathrm{HW} / \mathrm{TL}$ & $5.5 \pm 0.5$ & $7.1 \pm 1.5$ & 0.08 & $6.0 \pm 0.4$ & $7.1 \pm 0.6$ & 0.002 \\
\hline Weight (g) & $24 \pm 2.3$ & $23 \pm 0.6$ & 0.4 & $26 \pm 1.6$ & $27 \pm 1.2$ & 0.3 \\
\hline \multicolumn{7}{|l|}{ Protein-bound } \\
\hline $\mathrm{CML}$ & $748 \pm 42$ & $603 \pm 42$ & 0.003 & $1004 \pm 68$ & $982 \pm 150$ & 0.67 \\
\hline CEL & $343 \pm$ & $161 \pm 86$ & 0.1 & $389 \pm 196$ & $400 \pm 191$ & 0.9 \\
\hline MG-H1 & $829 \pm$ & $700 \pm 136$ & 0.2 & $947 \pm 169$ & $838 \pm 168$ & 0.2 \\
\hline \multicolumn{7}{|l|}{ Free AGEs } \\
\hline $\mathrm{CML}$ & $382 \pm 68$ & $550 \pm 79$ & 0.02 & $450 \pm 40$ & $593 \pm 245$ & 0.2 \\
\hline CEL & $77 \pm 16$ & $159 \pm 33$ & 0.004 & $86 \pm 8$ & $120 \pm 75$ & 0.3 \\
\hline MG-H1 & $81 \pm 22$ & $67 \pm 33$ & 0.5 & $61 \pm 15$ & $64 \pm 57$ & 0.9 \\
\hline \multicolumn{7}{|l|}{ Dicarbonyls } \\
\hline MGO & $703 \pm$ & $2373 \pm 1468$ & 0.06 & $823 \pm 437$ & $711 \pm 172$ & 0.5 \\
\hline GO & $1297 \pm$ & $1771 \pm 301$ & 0.03 & $1630 \pm$ & $2031 \pm 461$ & 0.1 \\
\hline 3DG & $2441 \pm$ & $2059 \pm 436$ & 0.4 & $2592 \pm$ & $2290 \pm 834$ & 0.4 \\
\hline D-Lactate & $11 \pm 4$ & $12 \pm 3$ & 0.6 & $27 \pm 6$ & $36 \pm 37$ & 0.52 \\
\hline L-Lactate & $3531 \pm$ & $2837 \pm 227$ & 0.2 & $6182 \pm$ & $5681 \pm 985$ & 0.3 \\
\hline
\end{tabular}

Data are presented as mean \pm SD. Diastolic blood pressure, DBP; Systolic blood pressure, SBP; heart weight, HW; tibia length, TL. 
A

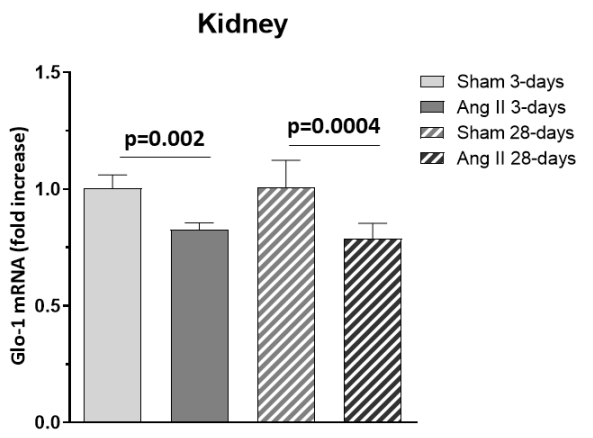

B

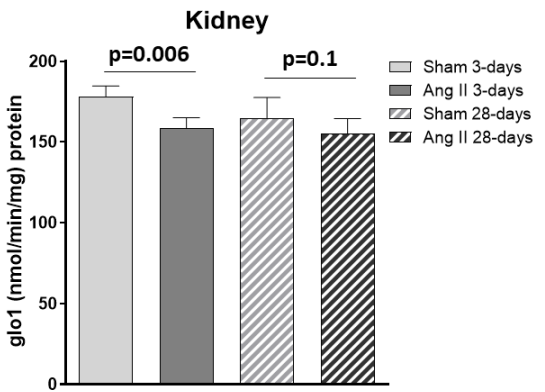

Liver

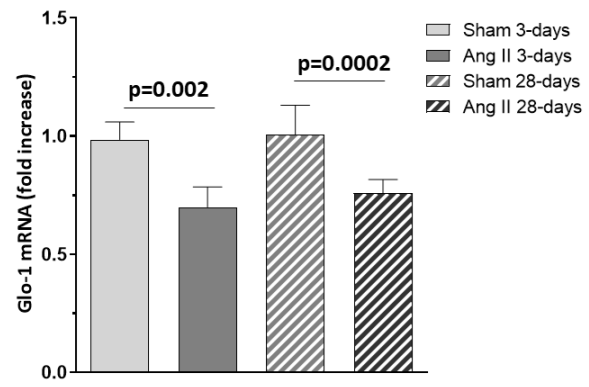

Liver

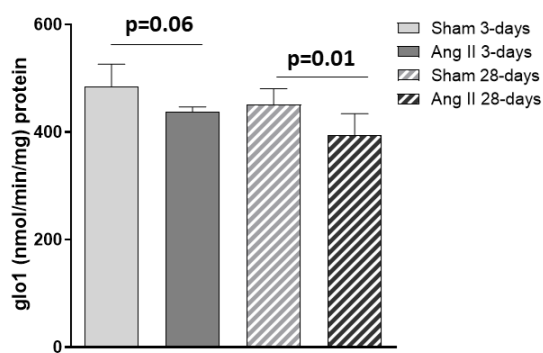

Figure 9.1. Effect of Angiotensin II on the expression of Glo1 in kidney and liver in mice. Glo1 gene expression (A) and Glo1 activity (B) in kidney and liver tissue after treatment of mice with angiotensin II (Ang II) for 3 and 28 days. Data represent mean \pm SD (Sham $n=4$; Ang II $n=4$ ).

We next determined the concentration of MGO and the other dicarbonyls and AGEs in tissues and in plasma. We observed after 3 days of angiotensin II infusion higher levels of CML and MG-H1 in the liver and for CML also in the kidney (Table 9.2) and a significant decrease of MGO and 3DG in the liver but not in the kidney (Table 9.2). In plasma, we found higher concentrations of $G O$ and MGO levels tended to be increased $(p=0.06)$ (Figure 9.2A). Regarding the AGEs levels in these animals, higher $C E L$ and $C M L$ concentration in free form was found in plasma after 3 days, but this was not the case for MG-H1 (Figure 9.2A). In mice infused for 28 days with angiotensin II we did not observe a change in plasma and tissues levels of dicarbonyls and AGEs (Figure 9.2B and Table 9.1). In addition, we found a significant decrease of protein-bound AGEs CML in plasma of these mice treated with angiotensin II after 3 days (Figure 9.2A and Table 9.1). Plasma levels of D-lactate did not change significantly in mice infused for 3 and for 28 days (Figure 9.2A and 9.2B and Table 9.1). 
Table 9.2. Tissue dicarbonyls and AGEs levels after 3 days and 28 days of exposure to angiotensin II.

\begin{tabular}{llllll}
\multicolumn{2}{c}{3 Days } & & \multicolumn{3}{c}{28 Days } \\
Sham Angiotensin II & P & Sham & Angiotensin II & P
\end{tabular}

$\begin{array}{lcccccc}\text { Mouse (n) } & 4 & 4 & - & 6 & 9 & - \\ \text { Kidney } \\ \text { Free AGEs }\end{array}$

Data are presented as mean \pm SD. 
A

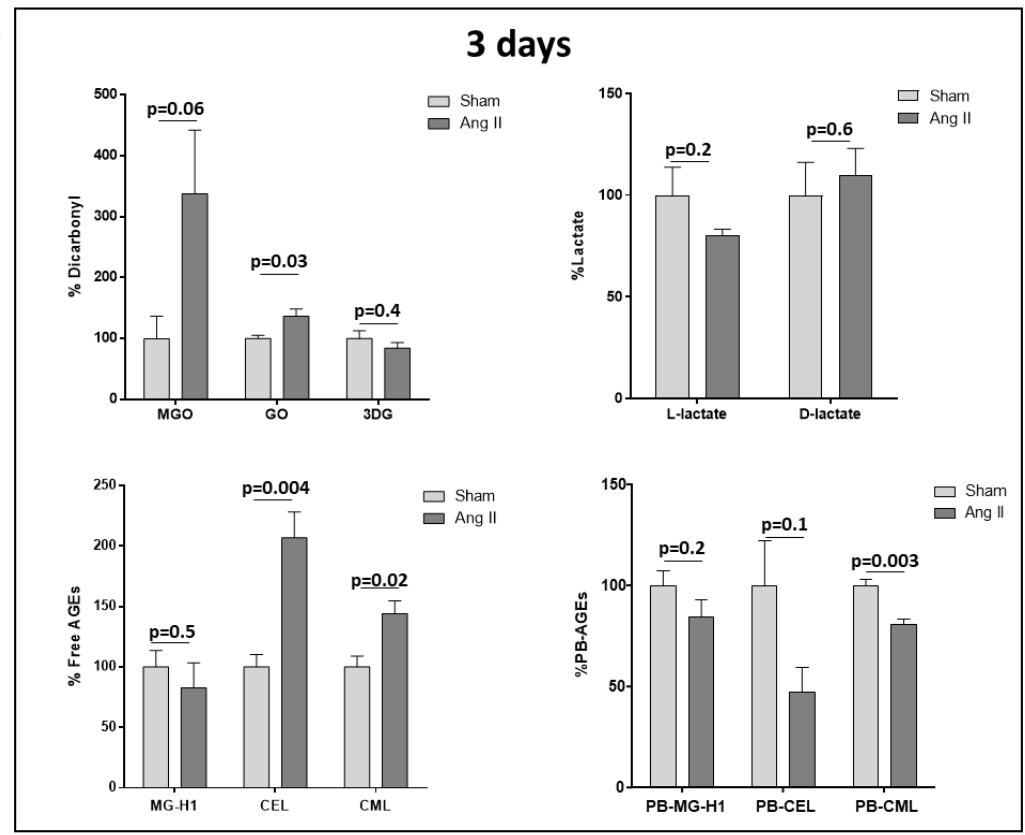

B

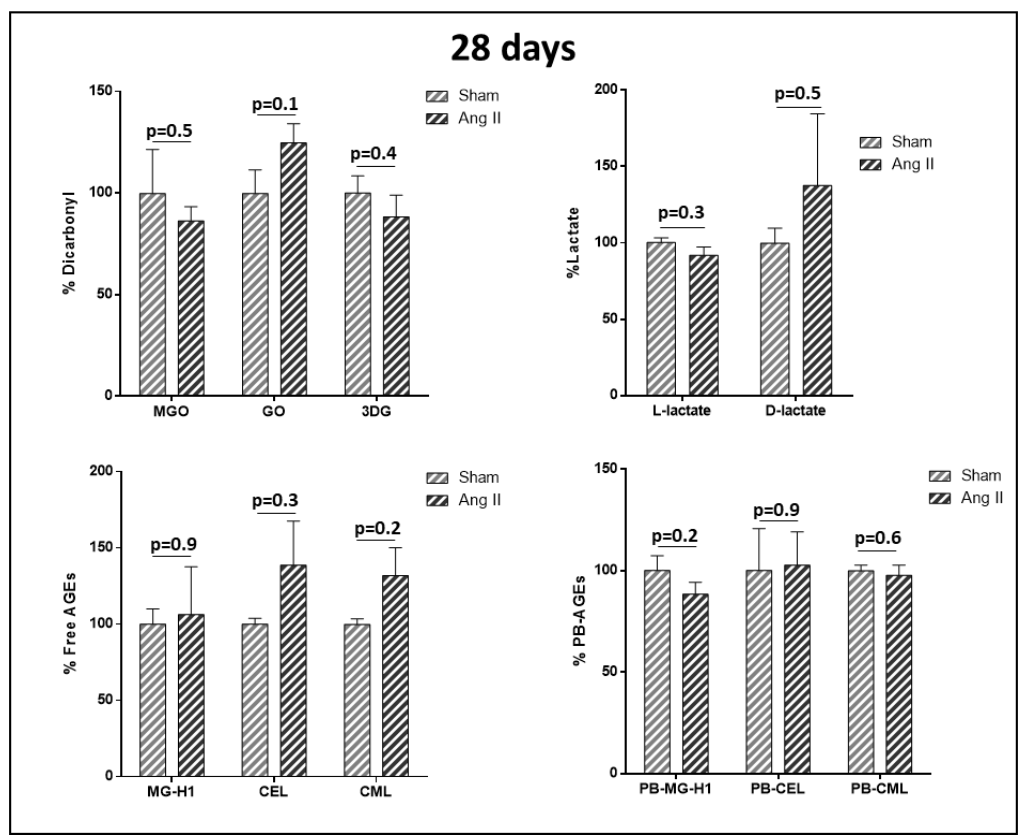

Figure 9.2. Effect of Angiotensin II on plasma levels of dicarbonyls, D-lactate and free and protein bound AGEs in mice. Plasma dicarbonyls, D-lactate, free and protein bound (PB) AGEs levels in mice after 3 days (Sham $n=4$; Ang II $n=4$ ) and 28 days (Sham $n=6$; Ang II $n=9$ ) of infusion with angiotensin II (Angll) $(\mathbf{A})$; Data represent mean $\pm \mathrm{S}$ 


\section{Discussion}

The major finding of this study is that infusion of angiotensin II for 3 and 28 days reduced mRNA Glo1 and activity in liver and kidney. The different dicarbonyls and AGEs in tissues and in plasma showed mixed patterns, but we found increased levels of CML and MG-H1 in the liver after 3 days of angiotensin II infusion and this was accompanied by an increase of plasma GO, MGO, CML and CEL.

At 3 days and 28 days of infusion with angiotensin II we observed a reduction of Glo1 mRNA expression and activity in liver and kidney tissue. This finding is in line with a previous study which have shown a decrease of Glo1 activity in retinal cells by angiotensin II 6 and that the ARB candesartan attenuates MGO formation and Glo1 activity in the retina of diabetic rats overexpressing the reninangiotensin system6.

Although Glo1 expression was reduced in the kidneys and liver of mice at two different time points, we observed an increase in plasma levels of dicarbonyls MGO and GO and free AGEs CML and CEL only after 3 days of angiotensin II exposure. In accordance, free CML was increased in liver and the kidney and MG-H1 only in the liver. In contrast, the dicarbonyls MGO and 3-DG were significantly decreased in the liver at 3 days. Because we have only data of plasma levels of dicarbonyls and AGEs and not urinary levels, we cannot exclude the possibility that renal clearance of dicarbonyls and AGEs may affect our results. In addition, several biological factors might explain some apparent contrasting findings between Glo1 and dicarbonyls and AGEs in tissues and plasma. First, whether Glo1 downregulation is directly attributable to angiotensin II remains uncertain, since angiotensin II is also associated with more inflammation and oxidative stress, i.e. conditions which are associated with increased levels of dicarbonyls and AGEs ${ }^{16}$ and reduced Glo1 activity. Furthermore, angiotensin II has indirect effects on cells and animals via its metabolites including Ang-1-7 that mediates antagonistic effects of angiotensin II through angiotensin-(1-7) receptor ${ }^{17,18}$. Finally, a potential molecular mechanism linking the AT1R with the receptor for advanced glycation endproducts (RAGE) was identified ${ }^{19}$. It was shown that angiotensin II by AT1R activation could induce the RAGE pathway regardless of RAGE ligands and maybe amplify the proinflammatory response or RAGE-dependent downregulation of Glo1 19,20. Although the relevance of these receptor interactions needs to be further elucidated, the activation of AT1R by angiotensin II and the transactivation of RAGE by AT1R may explain, at least partly, some of the contrasting effect between Glo1 expression in the liver and kidney and plasma and tissue dicarbonyls and AGEs. Nonetheless, a role of angiotensin II on glycation stress is very likely and the result of a reduced Glo1 expression and the accumulation of dicarbonyls stress and AGEs. 
Chapter 9

In conclusion, the present study showed that upon angiotensin II infusion, Glo1 was reduced in the liver and the kidney with effects on dicarbonyl stress, indicating a link between the glycation pathway and RAAS. Further studies should focus on many other biological aspects of angiotensin II in relation to dicarbonyl stress, in order to further elucidate how the RAAS and the AGE pathway are intertwined. 


\section{References}

1. Volpe M, Savoia C, De Paolis P, Ostrowska B, Tarasi D, Rubattu S. The Renin-Angiotensin System as a Risk Factor and Therapeutic Target for Cardiovascular and Renal Disease. Journal of the American Society of Nephrology. 2002;13(Suppl 3):S173-S178. doi:10.1097/01.ASN.0000032549.36050.78

2. Ruiz-Ortega $M$, Lorenzo $O$, Rupérez $M$, et al. Role of the renin-angiotensin system in vascular diseases: Expanding the field. Hypertension. 2001;38(6):1382-1387. doi:10.1161/hy1201.100589

3. Schalkwijk C, Stehouwer CD. Methylglyoxal, a highly reactive dicarbonyl compound, in diabetes, its vascular complications and other age-related diseases. Physiological Reviews. 2020;100(1):407-461. doi:10.1152/physrev.00001.2019

4. Hanssen NMJ, Stehouwer CDA, Schalkwijk CG. Methylglyoxal and glyoxalase I in atherosclerosis. Biochemical Society Transactions. 2014;42(2):443-449. doi:10.1042/BST20140001

5. Maessen DEM, Stehouwer CDA, Schalkwijk CG. The role of methylglyoxal and the glyoxalase system in diabetes and other age-related diseases. Clinical Science. 2015;128(12):839-861. doi:10.1042/CS20140683

6. Miller AG, Tan G, Binger KJ, et al. Candesartan attenuates diabetic retinal vascular pathology by restoring glyoxalase-I function. Diabetes. 2010;59(12):3208-3215. doi: $10.2337 / \mathrm{db} 10-0552$

7. Piazza M, Hanssen NMJ, Persson F, et al. Irbesartan treatment does not influence plasma levels of the dicarbonyls methylglyoxal, glyoxal and 3-deoxyglucosone in participants with type 2 diabetes and microalbuminuria: An IRMA2 sub-study. Diabetic Medicine. October 2020. doi:10.1111/dme.14405

8. Qi W, Keenan HA, Li Q, et al. Pyruvate kinase M2 activation may protect against the progression of diabetic glomerular pathology and mitochondrial dysfunction. Nature Medicine. 2017;23(6):753-762. doi:10.1038/nm.4328

9. Giacco F, Du X, D'Agati VD, et al. Knockdown of glyoxalase 1 mimics diabetic nephropathy in nondiabetic mice. Diabetes. 2014;63(1):291-299. doi:10.2337/db13-0316

10. Brouwers $O$, Niessen PMG, Miyata $T$, et al. Glyoxalase-1 overexpression reduces endothelial dysfunction and attenuates early renal impairment in a rat model of diabetes. Diabetologia. 2014;57(1):224-235. doi:10.1007/s00125-013-3088-5

11. Geoffrion M, Du X, Irshad Z, et al. Differential effects of glyoxalase 1 overexpression on diabetic atherosclerosis and renal dysfunction in streptozotocin-treated, apolipoprotein Edeficient mice. Physiological Reports. 2014;2(6). doi:10.14814/phy2.12043

12. McLellan AC, Thornalley PJ. Glyoxalase activity in human red blood cells fractioned by age. Mechanisms of Ageing and Development. 1989;48(1):63-71. doi:10.1016/00476374(89)90026-2

13. Scheijen JLJM, Hanssen NMJ, Van De Waarenburg MPH, Jonkers DMAE, Stehouwer CDA, Schalkwijk CG. $L(+)$ and $D(-)$ lactate are increased in plasma and urine samples of type 2 diabetes as measured by a simultaneous quantification of $L(+)$ and $D(-)$ lactate by reversedphase liquid chromatography tandem mass spectrometry. Experimental Diabetes Research. 2012;2012. doi:10.1155/2012/234812

14. Scheijen JLJM, Schalkwijk CG. Quantification of glyoxal, methylglyoxal and 3deoxyglucosone in blood and plasma by ultra performance liquid chromatography tandem mass spectrometry: Evaluation of blood specimen. Clinical Chemistry and Laboratory Medicine. 2014;52(1):85-91. doi:10.1515/cclm-2012-0878

15. Hanssen NMJ, Engelen L, Ferreira I, et al. Plasma Levels of Advanced Glycation Endproducts $\mathrm{N} \in$-(carboxymethyl)lysine, $\mathrm{N} \in$-(carboxyethyl)lysine, and Pentosidine Are not Independently Associated With Cardiovascular Disease in Individuals With or Without Type 


\section{Chapter 9}

2 Diabetes: The H. The Journal of Clinical Endocrinology \& Metabolism. 2013;98(8):E1369E1373. doi:10.1210/jc.2013-1068

16. Hanssen NMJ, Wouters K, Huijberts MS, et al. Higher levels of advanced glycation endproducts in human carotid atherosclerotic plaques are associated with a rupture-prone phenotype. European Heart Journal. 2014;35(17):1137-1146. doi:10.1093/eurheartj/eht402

17. Forrester SJ, Booz GW, Sigmund CD, et al. Angiotensin II signal transduction: An update on mechanisms of physiology and pathophysiology. Physiological Reviews. 2018;98(3):16271738. doi:10.1152/physrev.00038.2017

18. Alzayadneh EM, Chappell MC. Angiotensin-(1-7) abolishes AGE-induced cellular hypertrophy and myofibroblast transformation via inhibition of ERK1/2. Cellular Signalling. 2014;26(12):3027-3035. doi:10.1016/j.cellsig.2014.09.010

19. Pickering RJ, Tikellis C, Rosado CJ, et al. Transactivation of RAGE mediates angiotensininduced inflammation and atherogenesis. Journal of Clinical Investigation. 2019;129(1):406421. doi:10.1172/JCI99987

20. Schalkwijk CG. Vascular AGE-ing by methylglyoxal: the past, the present and the future. Diabetologia. 2015;58(8):1715-1719. doi:10.1007/s00125-015-3597-5 


\section{Chapter 10}

Summary and general discussion 



\section{Summary}

An important hormonal regulatory system for both fluid balance and blood pressure regulation is the renin-angiotensin-aldosterone system (RAAS). Activation of the RAAS is therefore a vital mechanism to maintain homeostasis in the setting of decreased circulating volume (such as blood loss or dehydration). However, when the RAAS is chronically activated in the setting of cardiometabolic diseases, the two main effector hormones of this system, aldosterone and angiotensin II, have significant pathogenic actions on the cardiovascular and renal system, which include the stimulation of fibrosis, inflammation, cell proliferation, neovascularization and oxidative stress ${ }^{1}$.

Aldosterone levels are increased in $50 \%$ to $80 \%$ of all hypertensive disorders and are associated with obesity and metabolic disorders such as impaired glucose and lipid metabolism and insulin resistance ${ }^{2}$. Moreover, patients with primary aldosteronism (PA), have increased cardiovascular risk, and more renal and metabolic complications than essential hypertension ${ }^{3}$. Despite several decades of investigation, the mechanism of excess aldosterone secretion in PA remains poorly understood.

In addition to activation of RAAS, accumulation of the reactive glucose-metabolite methylglyoxal (MGO) is recognised as key a driver of cardiovascular disease and vascular complications in diabetes. There are some indications that the RAAS and the MGO pathway interact, but this is relatively underexplored. MGO is formed as a glycolytic intermediate and a byproduct of glycolysis ${ }^{4}$. MGO is detoxified to Dlactate by the glyoxalase system with the enzyme glyoxalase 1 (Glo1) as the rate limiting step ${ }^{5}$. It has been demonstrated that Glo1 is impaired in diabetes, and that this impairment can be restored by the angiotensin receptor blocker (ARB) candesartan. In mice, has been demonstrated that candesartan prevents experimental diabetic retinopathy by restoring Glo1 function ${ }^{6}$. In type 1 (T1DM) and type 2 diabetes mellitus (T2DM), higher plasma MGO levels were associated with chronic kidney disease (CKD) and cardiovascular disease (CVD) ${ }^{7,8}$. Blockade of the RAAS is one of the most successful interventions to combat diabetic complications ${ }^{9-11}$, but whether the beneficial effects of the blockade of the RAAS is due to a reduction of MGO has not be fully explored.

The aims of this thesis were to explore: 1 . the mechanisms underlying the aldosterone production in primary aldosteronism; 2 . the implication of the RAAS in primary aldosteronism; 3 . the interaction of RAAS with glycation.

The topics covered in this thesis are introduced in the general introduction, described in Chapter 1. The main outcomes of this thesis were: 
- In Chapter 2, we reviewed the concept of epithelial-to-mesenchymal transition (EMT) and its role in renal diseases, with particular focus on hypertensive kidney disease, the second leading cause of end-stage renal disease after diabetes mellitus.

- In Chapter 3, we described the role of angiotensin II type 2 receptor (AT2R) and the angiotensin-(1-7) receptor (MasR) on aldosterone and cortisol synthesis using a pharmacological approach. We did not find a significant effect of nanomolar concentrations of Compound 21 (C21), an AT2R agonist, on CYP11B1 (cortisol synthase) or CYP11B2 (aldosterone synthase) gene expression in the $\mathrm{NCl}-\mathrm{H} 295 \mathrm{R}$ and $\mathrm{HAC} 15$ adrenocortical cells lines. Furthermore, no effect of $\mathrm{C} 21$ was observed in aldosteroneproducing adenoma (APA), a condition featuring hyperaldosteronism, and in APA-adjacent tissue. However, micromolar concentration of C21 markedly increased CYP11B1 and CYP11B2 gene expression through angiotensin II type 1 receptor (AT1R), as this effect was blunted by the angiotensin II type 1 receptor blocker irbesartan.

- In Chapter 4, we have investigated the effect of the macrolide antibiotic clarithromycin on aldosterone synthesis in cells isolated from APA with/without somatic mutations in the potassium channel Kir3.4 (KCNJ5). Clarithromycin lowered, in a concentration-dependent manner, the expression of the CYP11B2 gene However, whether and aldosterone secretion in aldosterone-producing cells $\left(\mathrm{CD}_{56}{ }^{+}\right.$cells) from $\mathrm{KCNJ} 5$ mutated APAs. However, when exposed to increasing concentrations of clarithromycin, the $\mathrm{CD} 56^{+}$cells obtained from wild-type APAs showed no change of CYP11B2 gene expression and aldosterone secretion in response to the macrolide.

- In Chapter 5, we described that in adrenocortical cells HAC15 and in tissue strips obtained ex vivo from patients with APA, the G proteincoupled estrogen receptor (GPER), is the main mediator of CYP11B2 expression in response to aldosterone exposure as this effect was abolished by the selective antagonist G36 or molecular silencing of GPER. Furthermore, angiotensin II potentiated the GPER-mediated effect of aldosterone on CYP11B2 through a crosstalk between GPER-1 and AT1R receptors.

- We have studied in Chapter 6 the titer of angiotensin II type-1 receptor autoantibodies (AT1AA) is APA patients. I described that the titer of AT1AA is increased in APA patients, which persisted after surgical cure of hyperaldosteronism. Moreover, I found in HAC15 cells, that the stimulation with IgG purified from sera of APA increased both CYP11B2 expression and aldosterone release. 
In part $\mathbf{2}$ of this thesis, I have studied the link between RAAS and glycation.

- In Chapter 7, we showed that in APA patients, serum levels of AT1AA are not associated with the serum dicarbonyls methylglyoxal, glyoxal and 3deoxyglucosone, or protein-bound and free advanced glycation endproducts (AGEs). Moreover, free AGEs $\mathrm{N}^{\varepsilon}$-(1-carboxymethyl)lysine (CML), $\quad \mathrm{N}^{\varepsilon}$-(1-carboxyethyl)lysine (CEL) and $\mathrm{N}^{\delta}$-(5-hydro-5-methyl-4imidazolon-2-yl)-ornithine (MG-H1) serum levels were increased after adrenalectomy.

- We reported in Chapter 8 that Irbesartan treatment did not change plasma levels of the dicarbonyls methylglyoxal, glyoxal and 3-deoxyglucosone, free AGEs or D-lactate in individuals with type 2 diabetes and albuminuria.

- Despite the null finding in chapter 8, we have studied the effect of angiotensin II in mice and reported in Chapter 9 that angiotensin II infusion in mice downregulated Glo1 gene expression in the kidney and the liver invivo with a concomitant increase in dicarbonyl stress.

The main findings are further discussed in the general discussion. 


\section{General Discussion}

The RAAS is the main regulator of aldosterone synthesis through the activation of AT1R in adrenocortical cells by angiotensin II. Dysregulation of the RAAS is known to contribute substantially to the pathophysiology of hypertension, renal disease and heart failure.

Given the protective role of the non-canonical pathway of the RAAS, this protective pathway in the regulation of the human adrenocortical hormones was investigated further and described in chapter 3. First, we investigated gene expression of the receptors AT1R, angiotensin II type 2 receptor (AT2R) and the angiotensin-(1-7) receptor (MasR), in aldosterone-producing adenoma (APA) and in APA-adjacent tissue. In line with previous studies ${ }^{12,13}$, we found in both tissues a high AT1R gene expression as compared to AT2R gene expression. Moreover, a significant decrease of AT2R gene expression in APA compared to APA-adjacent tissue was observed. The expression of AT1R and AT2R in APA and APA-adjacent tissue was in agreement with previous studies ${ }^{13,14}$, while the presence of Mas $R$ in the human adrenal gland is a novel finding. Immunoblots and immunohistochemistry confirmed the presence of AT1R and MasR in APA and in APA-adjacent tissue, with the highest MasR expression in the APA tissue. It has been demonstrated that AT2R and MasR play a cardiovascular protective role by counter-regulating AT1Rmediated effects in various tissues, and our data support this. Ang (1-7), by acting as a ligand for AT-2R and MasR, may oppose the cell proliferation and the sodiumretaining actions of angiotensin II 15 and ameliorate endothelial function in experimental models of atherosclerosis, heart failure, and inflammation ${ }^{16}$. In the fructose-fed rat model, used as a model of the metabolic syndrome, the Ang-(1-7) treatment had a chronic regulatory effect on aldosterone and plasma renin circulation ${ }^{17}$. However, whether the presence of MasR receptor in the APA tissue plays a protective role by blunting the production of aldosterone in hyperaldosteronism is still unknown.

The effects of the receptors/pathways involved in the protective arm of the RAAS on aldosterone and cortisol synthesis was investigated in chapter 4 using a pharmacological approach. A low concentration of Compound 21 (C21), an AT2R agonist, did not affect the gene expression of cortisol synthase (CYP11B1) and aldosterone synthase (CYP11B2) in the HAC15 and H295R adrenocortical cell lines. At these low concentrations, C21 had also no effect on aldosterone production such as in hyperaldosteronism. At higher concentrations, C21 increased CYP11B1 and CYP11B2 gene expression in the HAC15 and H295R cell lines, and enhanced the effect of angiotensin II in HAC15 cells only. Pretreatment with the AT1R antagonist irbesartan abolished the effect of angiotensin II. The effect of high concentrations of C21 on CYP11B1 and CYP11B2 gene expression, indicates that at higher concentrations C21 likely acts as an AT1R agonist. In addition to cell lines, we also used tissues from patients to study C21 effects on CYP11B2 and CYP11B1 gene expression. We found that at low concentrations C21 does not affect CYP11B2 expression. The low level of AT2R found in the adrenal cortex, 
along with the lack of any effect of C21 at low concentrations on CYP11B2, does not support the contention that the protective arm of RAAS blunts aldosterone synthase in the normal adrenal cortex and primary aldosteronism.

Aldosterone-producing adenoma, a major subtype of primary aldosteronism, involves somatic mutations in the potassium channel Kir3.4 (KCNJ5). These mutations cause a loss of $\mathrm{K}+$ selectivity, with increased sodium influx into APA cells, leading to membrane depolarization and activation of the calcium signaling pathway via opening calcium channels ${ }^{18}$. Increased intracellular $\mathrm{Ca}^{2+}$ leads to increased expression of CYP11B2 and thus increased aldosterone production from the tumor.

Some macrolide antibiotics and some synthesized derivatives without antibiotic activity, have been shown to specifically inhibit in vitro the altered function of somatic mutations (G151R or L168R) in the potassium channel KCNJ5 in cells with an overexpression of these channels ${ }^{19}$. These agents blunted concentrationdependently aldosterone production in vitro in HAC-15 cells that overexpress the KCNJ5 mutated channel ${ }^{19}$. In chapter 4 we demonstrated a similar concentrationdependent blunting of CYP11B2 gene expression and aldosterone production with the macrolide antibiotic clarithromycin in APA cells isolated ex vivo from human APA with G151R and L168R mutations. Importantly, these effects were found to be selective in that it was ineffective in cells obtained from wild-type APAs. Whether the same effects are present in patients with PA will require further investigations. These results open new views for the diagnosis and treatment of aldosteroneproducing adenoma carrying this specific kind of mutations. Insights from these studies may allow detection of mutated tumors of the adrenal gland in the free DNA of circulating cells, to distinguish between the two main forms of primary aldosteronism and thus avoiding invasive investigations such as adrenal vein sampling (AVS) as the gold standard. Future studies addressing this topic are currently underway ${ }^{20}$.

The adrenocortical zona glomerulosa is the main site of aldosterone biosynthesis. The molecular mechanisms underlying aldosterone oversecretion in primary aldosteronism are so far poorly understood, despite renin suppression and undetectable angiotensin II levels. Multiple observations have also suggested a role for oestrogens in the regulation of aldosterone under physiological and pathophysiological conditions 21,22 . GPER, a G-protein coupled receptor initially described as an oestrogen-specific receptor ${ }^{23,24}$ is a promiscuous receptor capable of binding of aldosterone or other steroids ${ }^{25}$ and to mediate mineralocorticoid receptor (MR)-independent aldosterone effects in different cell types. Moreover, GPER is highly expressed in the normal human adrenocortical zona glomerulosa ${ }^{26}$. In chapter 5, we propose an autocrine paracrine mechanism whereby aldosterone, acting via GPER, can swiftly increase its own biosynthesis. By using an in vitro model of the human adrenocortical cell line, that produces relatively small amounts of aldosterone, and tissue strips obtained ex vivo from APA that produce 
substantial amounts of aldosterone, we could identify GPER as the main mediator of CYP11B2 activation in response to aldosterone stimulation. After specifically blocking the MR or the GPER, or knock-down of GPER, aldosterone potently stimulated aldosterone synthase expression through a mechanism involving GPER stimulation. We could not find detectable changes of cytosolic $\mathrm{Ca}^{2+}$ levels in response to aldosterone. In line, a previously study demonstrated that GPERmediated stimulation of aldosterone secretion was associated with upregulation of CYP11B2 and appeared to be PKA/cAMP dependent but did not involve cytosolic $\mathrm{Ca}^{2+}$ mobilization ${ }^{26}$. However, the possibility that GPER activation of CYP11B2 can involve $\mathrm{Ca}^{2+}$ influx into the mitochondria need to be investigated by using mitochondria-specific $\mathrm{Ca}^{2+}$ sensitive probes. This autocrine-paracrine mechanism of aldosterone may play a pathophysiological role in maintaining inappropriately high secretion of aldosterone in PA patients and could explain the occurrence of aldosterone-producing cell clusters (APCCs), which can coexist with APA, and possibly represent an early stage of the latter ${ }^{27}$.

We found that APA patients have an increased titer of angiotensin II type-1 receptor autoantibodies (AT1AA) in serum (chapter 6). Our data were in line with previous reports ${ }^{28,29}$. We investigated the effect of surgical cure of PA by unilateral laparoscopic adrenalectomy on AT1AA titers. We found no rapid normalization of the raised autoantibodies titers, suggesting that PA by itself does not increase the titer of AT1AA, although we cannot fully exclude that at longer follow-up times after surgery, the AT1AA levels normalize. However, since blood pressure normalization already had been achieved, the persistence of AT1AA might not simply represent a biomarker of the excess cardiovascular damage, which in PA has been well documented at the level of the heart, kidney, and vasculature. Furthermore, we investigated AT1AA bioactivity towards AT1-R with multiple assays, showing an increase in aldosterone biosynthesis and secretion only when using a sensitive in vitro technique. Although these results suggest a pathogenetic role of AT1AA in raising aldosterone biosynthesis in primary aldosteronism, it is still not clear if a similar effect exists in vivo. 


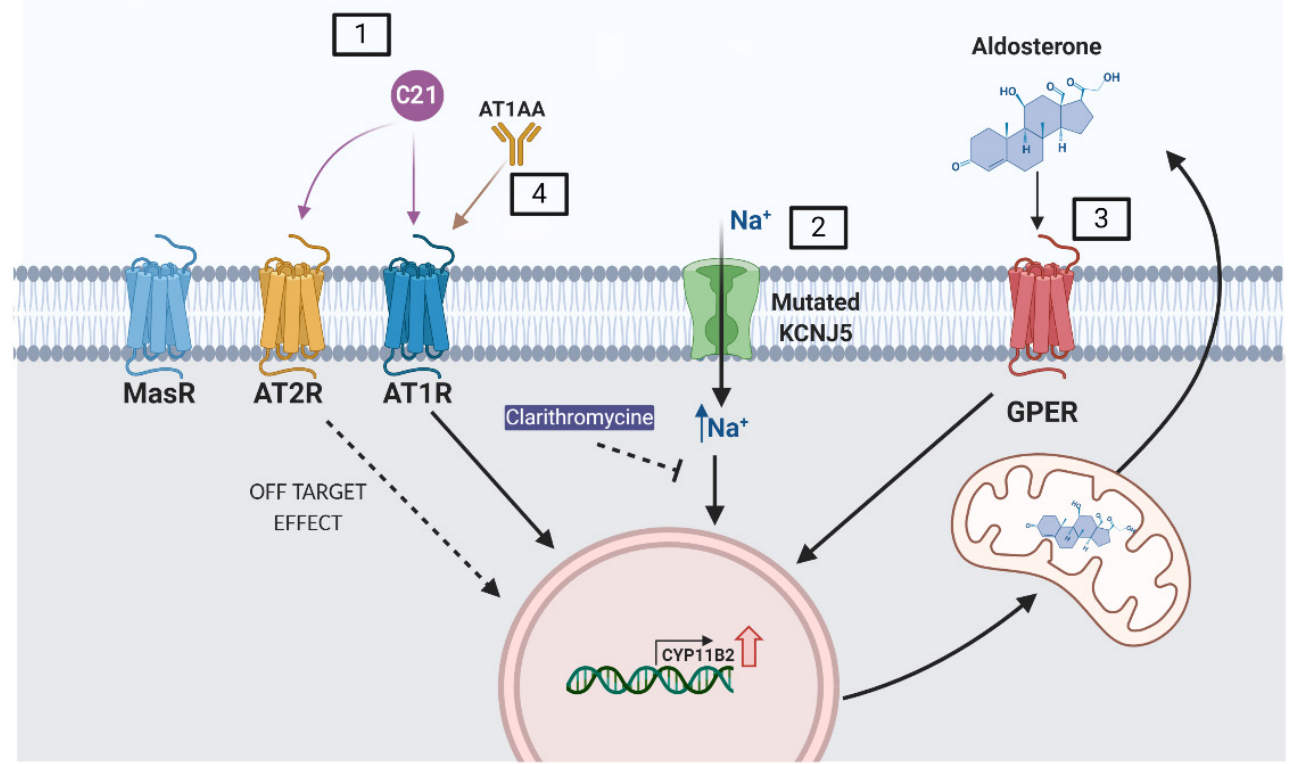

Figure 10.1 Overview of aldosterone production in adrenal cells. 1. C21 binds to AT1R and AT2R, but is effective on CYP11B2 gene expression only via AT1R; 2. Clarithromycin lowered the expression of the CYP11B2 gene and aldosterone secretion in aldosterone-producing cells; 3. Aldosterone, acting via GPER, can swiftly increase its own biosynthesis. 4. APA patients, have an increased titer of AT1AA that stimulate aldosterone biosynthesis.

Abbreviations: angiotensin II type 1 receptor (AT1R); angiotensin II type 2 receptor (AT2R); angiotensin(1-7) receptor (MasR); aldosterone synthase (CYP11B2); potassium channel Kir3.4 (KCNJ5); G-protein coupled estrogen receptor (GPER); angiotensin II type-1 receptor autoantibodies (AT1AA). Figure created with BioRender.com

In addition to RAAS, also methylglyoxal (MGO) and its derived advanced glycation endproducts (AGEs) are key players in the development of CVD ${ }^{4,5}$. MGO can be detoxified by glyoxalase 1 (Glo1), glyoxalase 2 and reduced glutathione into Dlactate, thereby preventing accumulation of MGO and MGO-derived AGEs ${ }^{30}$. Glo1 is the rate-limiting enzyme in this reaction. Literature provides evidence that Glo1 overexpression is able to prevent endothelial dysfunction and diabetic microvascular complications ${ }^{31,32}$. Accumulation of AGEs and activation of the RAAS are both implicated in diabetic vascular complications ${ }^{33,34}$.

The activation of AT1R by angiotensin II has been linked to an increase of $\mathrm{MGO}^{6}$. Since AT1AA have agonistic properties to the AT1R, at least in vitro, and similar to angiotensin II 29,35, we investigated the association between AT1AA and serum MGO levels in patients with APA. We found that serum AT1AA levels were not associated with serum levels of MGO or the other dicarbonyls GO and 3-DG, or the 


\section{Chapter 10}

free and protein-bound AGEs CML, CEL and MG-H1, and the MGO metabolite Dlactate. To our surprise, we found an increase of free AGEs CML, CEL and MG-H1 serum levels after-adrenalectomy, which are likely due to changes in kidney function or the use of less co-medication after surgery (chapter 7 ).

We next determined in chapter 8 the effect of the angiotensin receptor blocker (ARB) irbesartan treatment on plasma levels of the dicarbonyls MGO, GO and 3DG. Levels of these dicarbonyls were determined, in samples from a randomised double-blind, placebo-controlled randomised trial of irbesartan with hypertensive patients with type 2 diabetes (T2D) and persistent microalbuminuria ${ }^{11}$, at baseline and follow-up of 1 and 2 years. We reported in chapter 8 that irbesartan treatment did not change plasma levels of the dicarbonyls, free AGEs or D-lactate.

Although the results as described in chapter $\mathbf{8}$ suggest that ARBs are unlikely to mitigate renal and cardiovascular risk through the attenuation of plasma levels of dicarbonyl stress, we decided to investigate the role of angiotensin II on the expression and activity of Glo1 in tissues (chapter 9). In mice, we found decreased expression of Glo1 mRNA after infusion with angiotensin II and this was associated with slightly increased MGO levels. In addition, we also found that levels of free AGEs CML and protein-bound AGEs CEL were higher in plasma of mice subjected to 3 days of angiotensin II infusion. Moreover, angiotensin II promotes accumulation of the major AGE CML in kidney and liver and MG-H1 in liver after 3 days of treatment, indicating that the AGE accumulation in tissues is likely due to impaired detoxification of MGO i.e. the major precursor in the formation of AGEs. These findings are in line with in-vivo studies, since Glo1 expression was lower in ruptured carotid atherosclerotic plaques, in comparison with stable plaque segments $^{36}$ and in renal glomeruli in diabetic nephropathy ${ }^{37}$ indicating the importance of Glo1 against CKD. Furthermore, Glo1 knockdown caused a CKDlike phenotype even in non-diabetic mice ${ }^{38}$.

Although the glyoxalase system is considered to be the major pathway by which MGO is detoxified, other enzyme system have been described in relation to MGO detoxification. Since we have focused solely on Glo1, it is not known whether compensation pathways involving aldehyde dehydrogenases (ALDH) and aldoketo reductases (AKR) are also over important, as these pathways have also been linked to modulation of MGO levels by angiotensin II.

In summary, the inhibiting effects of ARBs on the concentration of AGEs in mice, as show in several studies ${ }^{6,9,39-41}$ are thus due, at least partly, to the inhibitory effects of ARBs on the accumulation of methylglyoxal, the major precursor in the rapid formation MGO-derived AGEs, via a reduction of glyoxalase 1. We can therefore not exclude that the positive effect of ARBs on outcomes may be partly due to this potentially protective mechanism. However, it is unlikely that ARBs can 
be used to effectively reduce systemic dicarbonyl stress, and other approaches should be evaluated to achieve this goal.

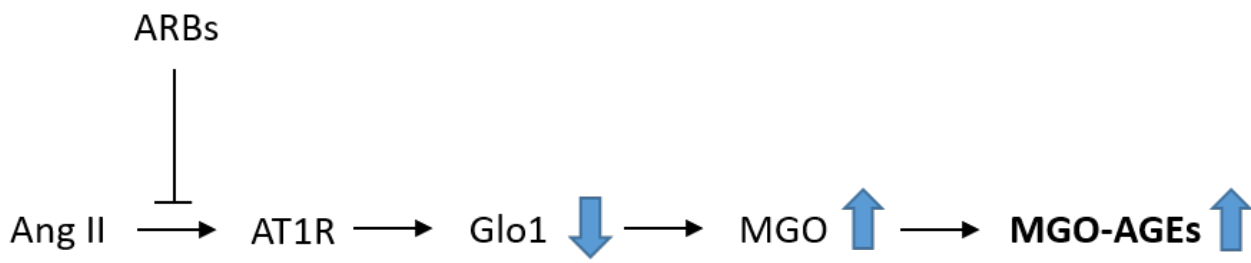

Figure 10.2 Overview of the role of angiotensin II on methylglyoxal stress. The glyoxalase system, is the main system involved in the detoxification of methylglyoxal to D-lactate. Angiotensin II (Ang II) contributes to methylglyoxal (MGO) stress by a reduction of glyoxalase 1 (Glo1) expression i.e. the rate-limiting enzyme in the glyoxalase system for the detoxification of MGO. MGO and MGOderived AGEs can impact on organs and tissues affecting their functions and structure. We showed in mice that angiotensin II treatment increased the concentrations of MGO-derived AGEs in liver and kidney. 


\section{Chapter 10}

\section{References}

1. Wilkinson-Berka JL, Suphapimol V, Jerome JR, Deliyanti D, Allingham MJ. Angiotensin II and aldosterone in retinal vasculopathy and inflammation. Experimental Eye Research. 2019;187:107766. doi:10.1016/j.exer.2019.107766

2. Briet M, Schiffrin EL. The role of aldosterone in the metabolic syndrome. Current Hypertension Reports. 2011;13(2):163-172. doi:10.1007/s11906-011-0182-2

3. Milliez P, Girerd X, Plouin PF, Blacher J, Safar ME, Mourad JJ. Evidence for an increased rate of cardiovascular events in patients with primary aldosteronism. Journal of the American College of Cardiology. 2005;45(8):1243-1248. doi:10.1016/j.jacc.2005.01.015

4. Maessen DEM, Stehouwer CDA, Schalkwijk CG. The role of methylglyoxal and the glyoxalase system in diabetes and other age-related diseases. Clinical Science. 2015;128(12):839-861. doi:10.1042/CS20140683

5. Hanssen NMJ, Stehouwer CDA, Schalkwijk CG. Methylglyoxal and glyoxalase I in atherosclerosis. Biochemical Society Transactions. 2014;42(2):443-449. doi:10.1042/BST20140001

6. Miller AG, Tan G, Binger KJ, et al. Candesartan attenuates diabetic retinal vascular pathology by restoring glyoxalase-I function. Diabetes. 2010;59(12):3208-3215. doi:10.2337/db10-0552

7. Hanssen NMJ, Scheijen JLJM, Jorsal A, et al. Higher Plasma Methylglyoxal Levels Are Associated With Incident Cardiovascular Disease in Individuals With Type 1 Diabetes: A 12-Year Follow-up Study. Diabetes. 2017;66(8):2278-2283. doi:10.2337/db16-1578

8. Hanssen NMJ, Westerink J, Scheijen JLJM, Van Der Graaf Y, Stehouwer CDA, Schalkwijk CG. Higher plasma methylglyoxal levels are associated with incident cardiovascular disease and mortality in individuals with type 2 diabetes. Diabetes Care. 2018;41(8):1689-1695. doi:10.2337/dc18-0159

9. Forbes JM, Thomas MC, Thorpe SR, Alderson NL, Cooper ME. The effects of valsartan on the accumulation of circulating and renal advanced glycation end products in experimental diabetes. Kidney International, Supplement. 2004;66(92):S105-S107. doi:10.1111/j.15231755.2004.09225.x

10. Brenner BM, Cooper ME, De Zeeuw D, et al. Effects of losartan on renal and cardiovascular outcomes in patients with type 2 diabetes and nephropathy. New England Journal of Medicine. 2001;345(12):861-869. doi:10.1056/NEJMoa011161

11. Parving HH, Lehnert $\mathrm{H}$, Bröchner-Mortensen $\mathrm{J}$, et al. The effect of irbesartan on the development of diabetic nephropathy in patients with type 2 diabetes. New England Journal of Medicine. 2001;345(12):870-878. doi:10.1056/NEJMoa011489

12. Wu Z, Ni D, Yan Y, et al. Expression of angiotensin II receptors in aldosterone-producing adenoma of the adrenal gland and their clinical significance. Journal of Huazhong University of Science and Technology - Medical Science. 2010;30(4):486-489. doi:10.1007/s11596-010-0454-0

13. Pawlikowski M, Winczyk K, Śledź B. Immunohistochemical detection of angiotensin receptors AT1 and AT2 in adrenal tumors. Folia Histochemica et Cytobiologica. 2008;46(1):51-55. doi:10.2478/v10042-008-0006-7

14. Tanabe A, Naruse M, Arai K, et al. Gene Expression and Roles of Angiotensin II Type 1 and Type 2 Receptors in Human Adrenals. Hormone and Metabolic Research. 1998;30(08):490-495. doi:10.1055/s-2007-978918

15. Santos RAS, Simoes e Silva AC, Maric $C$, et al. Angiotensin-(1-7) is an endogenous ligand for the $\mathrm{G}$ protein-coupled receptor Mas. Proceedings of the National Academy of Sciences of the United 


\section{Summary and general discussion}

States of America. 2003;100(14):8258-8263. doi:10.1073/pnas.1432869100

16. Mercure C, Yogi A, Callera GE, et al. Angiotensin(1-7) blunts hypertensive cardiac remodeling by a direct effect on the heart. Circulation Research. 2008;103(11):1319-1326. doi:10.1161/CIRCRESAHA.108.184911

17. Marcus $Y$, Shefer $G$, Sasson K, et al. Angiotensin 1-7 as means to prevent the metabolic syndrome lessons from the fructose-fed rat model. Diabetes. 2013;62(4):1121-1130. doi:10.2337/db12-0792

18. Caroccia B, Prisco S, Seccia TM, Piazza M, Maiolino G, Rossi GP. Macrolides blunt aldosterone biosynthesis: A proof-of-concept study in KCNJ5 mutated adenoma cells ex vivo. Hypertension. 2017;70(6):1238-1242. doi:10.1161/HYPERTENSIONAHA.117.10226

19. Scholl UI, Abriola L, Zhang C, et al. Macrolides selectively inhibit mutant KCNJ5 potassium channels that cause aldosterone-producing adenoma. Journal of Clinical Investigation. 2017;127(7):2739-2750. doi:10.1172/JCI91733

20. Maiolino G, Ceolotto G, Battistel M, et al. Macrolides for KCNJ5-mutated aldosterone-producing adenoma (MAPA): design of a study for personalized diagnosis of primary aldosteronism. Blood Pressure. 2018;27(4):200-205. doi:10.1080/08037051.2018.1436961

21. Fommei E, Ghione S, Ripoli A, et al. The ovarian cycle as a factor of variability in the laboratory screening for primary aldosteronism in women. Journal of Human Hypertension. 2009;23(2):130135. doi:10.1038/jhh.2008.109

22. Ahmed AH, Gordon RD, Ward G, Wolley M, Kogovsek C, Stowasser M. Should aldosterone suppression tests be conducted during a particular phase of the menstrual cycle, and, if so, which phase? Results of a preliminary study. Clinical Endocrinology. 2015;83(3):303-307. doi:10.1111/cen.12705

23. Filardo EJ, Quinn JA, Frackelton AR, Bland KI. Estrogen Action Via the G Protein-Coupled Receptor, GPR30: Stimulation of Adenylyl Cyclase and cAMP-Mediated Attenuation of the Epidermal Growth Factor Receptor-to-MAPK Signaling Axis. Molecular Endocrinology. 2002;16(1):70-84. doi:10.1210/mend.16.1.0758

24. Carmeci C, Thompson DA, Ring HZ, Francke U, Weigel RJ. Identification of a gene (GPR30) with homology to the G-protein-coupled receptor superfamily associated with estrogen receptor expression in breast cancer. Genomics. 1997;45(3):607-617. doi:10.1006/geno.1997.4972

25. Prossnitz ER, Arterburn JB. International union of basic and clinical pharmacology. XCVII. G protein-coupled estrogen receptor and its pharmacologic modulators. Pharmacological Reviews. 2015;67(3):505-540. doi:10.1124/pr.114.009712

26. Caroccia B, Seccia TM, Gonzalez-Campos A, et al. GPER-1 and estrogen receptor- $\beta$ ligands modulate aldosterone synthesis. Endocrinology. 2014;155(11):4296-4304. doi:10.1210/en.20141416

27. Gomez-Sanchez CE, Gomez-Sanchez CE, Gomez-Sanchez CE, Gomez-Sanchez EP, Nishimoto K, Nishimoto K. Immunohistochemistry of the Human Adrenal CYP11B2 in Normal Individuals and in Patients with Primary Aldosteronism. Hormone and Metabolic Research. 2020;52(6):421-426. doi:10.1055/a-1139-2079

28. Rossitto G, Regolisti G, Rossi E, et al. Elevation of angiotensin-Il type-1-receptor autoantibodies titer in primary aldosteronism as a result of aldosterone-producing adenoma. Hypertension. 2013;61(2):526-533. doi:10.1161/HYPERTENSIONAHA.112.202945

29. Kem DC, Li H, Velarde-Miranda C, et al. Autoimmune mechanisms activating the angiotensin AT1 receptor in "primary" aldosteronism. Journal of Clinical Endocrinology and Metabolism. 2014;99(5):1790-1797. doi:10.1210/jc.2013-3282 


\section{Chapter 10}

30. Sousa Silva M, Gomes RA, Ferreira AEN, Ponces Freire A, Cordeiro C. The glyoxalase pathway: The first hundred years... and beyond. Biochemical Journal. 2013;453(1):1-15. doi:10.1042/BJ20121743

31. Brouwers $\mathrm{O}$, Niessen PMG, Miyata $\mathrm{T}$, et al. Glyoxalase-1 overexpression reduces endothelial dysfunction and attenuates early renal impairment in a rat model of diabetes. Diabetologia. 2014;57(1):224-235. doi:10.1007/s00125-013-3088-5

32. Brouwers O, Niessen PM, Haenen G, et al. Hyperglycaemia-induced impairment of endotheliumdependent vasorelaxation in rat mesenteric arteries is mediated by intracellular methylglyoxal levels in a pathway dependent on oxidative stress. Diabetologia. 2010;53(5):989-1000. doi:10.1007/s00125-010-1677-0

33. Hanssen NMJ, Stehouwer CDA, Schalkwijk CG. Methylglyoxal stress, the glyoxalase system, and diabetic chronic kidney disease. Current Opinion in Nephrology and Hypertension. 2019;28(1):2633. doi:10.1097/MNH.0000000000000465

34. Volpe M, Savoia C, De Paolis P, Ostrowska B, Tarasi D, Rubattu S. The Renin-Angiotensin System as a Risk Factor and Therapeutic Target for Cardiovascular and Renal Disease. Journal of the American Society of Nephrology. 2002;13(Suppl 3):S173-S178. doi:10.1097/01.ASN.0000032549.36050.78

35. Piazza M, Seccia TM, Caroccia B, et al. AT1AA (Angiotensin II Type-1 Receptor Autoantibodies) Cause or Consequence of Human Primary Aldosteronism? Hypertension. 2019;74(4):793-799. doi:https://doi.org/10.1161/HYPERTENSIONAHA.119.13388

36. Hanssen NMJ, Wouters K, Huijberts MS, et al. Higher levels of advanced glycation endproducts in human carotid atherosclerotic plaques are associated with a rupture-prone phenotype. European Heart Journal. 2014;35(17):1137-1146. doi:10.1093/eurheartj/eht402

37. Gordin D, Shah H, Shinjo T, et al. Characterization of Glycolytic Enzymes and Pyruvate Kinase M2 in Type 1 and 2 Diabetic Nephropathy. Diabetes Care. 2019;42:1263-1273. doi:10.2337/dc182585

38. Giacco F, Du X, D’Agati VD, et al. Knockdown of glyoxalase 1 mimics diabetic nephropathy in nondiabetic mice. Diabetes. 2014;63(1):291-299. doi:10.2337/db13-0316

39. Sugiyama $T$, Okuno $T$, Fukuhara $M$, et al. Angiotensin II receptor blocker inhibits abnormal accumulation of advanced glycation end products and retinal damage in a rat model of type 2 diabetes. Experimental Eye Research. 2007;85(3):406-412. doi:10.1016/j.exer.2007.06.008

40. Nangaku M, Miyata T, Sada T, et al. Anti-hypertensive agents inhibit in vivo the formation of advanced glycation end products and improve renal damage in a type 2 diabetic nephropathy rat model. Journal of the American Society of Nephrology. 2003;14(5):1212-1222. doi:10.1097/01.ASN.0000062961.76776.C1

41. Miyata T, Van Ypersele De Strihou C, Ueda Y, et al. Angiotensin II receptor antagonists and angiotensin-converting enzyme inhibitors lower in vitro the formation of advanced glycation end products: Biochemical mechanisms. Journal of the American Society of Nephrology. 2002;13(10):2478-2487. doi:10.1097/01.ASN.0000032418.67267.F2 
Research Impact 



\section{Research impact}

This thesis evaluated 1) several aspects that regulate the biosynthesis of aldosterone in primary aldosteronism 2) the interaction between the glycation pathway and renin-angiotensin-aldosterone system (RAAS). Inhibition of the RAAS in the context forms the cornerstone of the treatment of hypertension, diabetes and chronic kidney disease, and therefore a deeper insight and further optimisation of the RAAS is likely to have a large impact on clinical practice.

In the last decade, multiple discoveries have made primary aldosteronism (PA) a model for improving mechanistic knowledge in hypertension. Several mechanisms were identified to cause the inappropriate over-secretion of aldosterone in PA, such as elevated serum levels of parathyroid hormone, downregulation of TASK-2 K+ channel, gene mutations affecting ion channel ${ }^{1}$. In addition, PA patients show a higher cardiovascular disease (CVD) rate at the time of diagnosis than primary hypertensives 2,3. Despite the identification of these mechanistic markers, understanding the molecular mechanisms involved in primary aldosteronism is important to improve diagnosis and therapeutic approaches of the disease.

The first part of this thesis provided compelling evidence that over secretion of aldosterone can be specifically blunted ex-vivo in aldosterone producing adenoma (APA) with KCNJ5 mutations by the use of macrolides, opening a new perspective for the diagnosis and treatment of PA patients. Current ongoing clinical studies aim to determine the diagnostic and therapeutic effect of macrolide treatment in patients with APA carrying KCNJ5 mutations, allowing non-invasive diagnosis and targeted treatment ${ }^{4}$. Currently APA is often treated with adrenal surgery, but not all individuals are eligible for this procedure, and therefore my findings in chapter chapter 4 are of potential interest for patients with APA.

In chapter 6 we focussed on the measurement of angiotensin II type-1 receptor autoantibodies (AT1AA).

The possibility to measure serum levels of AT1AA is a promising step to improve the diagnosis of primary aldosteronism. These AT1AA autoantibodies indicate loss of immunological tolerance towards tissues that express the angiotensin II type I receptor (AT1R) and are a target of arterial hypertension. This will be a major focus of future research. However, the presence of AT1AA not only in APA but also in some healthy donors, requires more studies to investigate the cut-off between normal subjects and APA patients and the specificity of these antibodies. Furthermore, as we identified a G protein-coupled estrogen receptor (GPER) as additional mediator of aldosterone secretion, GPER may also be a useful mechanism to be investigate in more detailed as a potential drug target. 
In the second part of this thesis, the relation between advanced glycation endproducts (AGEs) and the activation of RAAS as a key driver of CVD and vascular complications are described.

Higher levels of specific AGEs are associated with a higher risk of CVD and inhibition of AGE formation and/or the blockade of the interaction between the RAAS and AGEs could be a viable option for therapy to prevent the progression of chronic kidney disease (CKD) and CVD in diabetic individuals.

Several compounds have been identified that lower AGE levels and/or inhibit AGE formation, including anti-hypertensive drugs such as angiotensin receptor blockers (ARBs) and angiotensin converting enzyme (ACE) inhibitors ${ }^{5-8}$. Although it has been demonstrated in a major clinical trial that the ARB irbesartan reduced progression of albuminuria, independently of blood pressure ${ }^{9}$ and that this can have beneficial effects on cardiovascular outcome, we could not show any changes in plasma of dicarbonyl stress. However, it remains possible that the potential beneficial effects of ARBs are restricted to experimental models of diabetes. This finding is important for clinical practice as we show that at least the ARB irbesartan is unlikely to lower systemic glycation markers and therefore the glycation pathway likely remains untargeted in individuals with diabetes.

Furthermore, as we show in the first part of the thesis, higher levels of AT1AA are identify in APA, and persisted after cure of hyperaldosteronism suggesting a pathogenetic role of AT1AA in raising aldosterone biosynthesis in primary aldosteronism; it may be worth considering whether these antibodies that activate AT1-R are associated with higher methylglyoxal MGO levels and MGO-derived AGEs in individuals with APA. Experimental studies have shown that increased activation of AT1R by Ang II has been linked to increased formation of methylglyoxal ${ }^{10}$. However, our findings of no associations of plasma AT1AA with AGEs suggest that plasma levels of AT1AA may not adequately represent AGE accumulation in plasma, although we found an increase of AGEs after adrenalectomy. Larger studies with a long-term follow-up time are required to further clarify the importance of post-adrenalectomy levels on AGEs.

Evidence of the interconnection between the RAAS and the glycation pathway on cardiovascular disease remains incomplete, although our studies have added some evidence for a role of angiotensin II to decreased expression of Glo1 enzyme and subsequent increase formation of AGEs. Based on these findings future research should focus on many other biological aspects of angiotensin II in relation to dicarbonyl stress, to further elucidate how the RAAS and the AGE pathway are intertwined.

In conclusion, the glycation pathways and RAAS may be promising targets improve both prediction and treatment of CVD, and that additional research may lead to the identification of novel targets to reduce the global impact of CVD and diabetic complications. 


\section{References}

1. Seccia TM, Caroccia B, Gomez-Sanchez EP, Gomez-Sanchez CE, Rossi GP. The Biology of Normal Zona Glomerulosa and Aldosterone-Producing Adenoma: Pathological Implications. Endocrine Reviews 2018;39(6):1029-1056.

2. Milliez P, Girerd X, Plouin PF, Blacher J, Safar ME, Mourad JJ. Evidence for an increased rate of cardiovascular events in patients with primary aldosteronism. Journal of the American College of Cardiology 2005;45(8):1243-1248.

3. Savard S, Amar L, Plouin PF, Steichen O. Cardiovascular complications associated with primary aldosteronism: A controlled cross-sectional study. Hypertension 2013;62(2):331-336.

4. Maiolino G, Ceolotto G, Battistel M, Barbiero G, Cesari M, Amar L, Caroccia B, Padrini R, Azizi M, Rossi GP. Macrolides for KCNJ5-mutated aldosterone-producing adenoma (MAPA): design of a study for personalized diagnosis of primary aldosteronism. Blood Pressure 2018;27(4):200-205.

5. Miyata T, Van Ypersele De Strihou C, Ueda Y, Ichimori K, Inagi R, Onogi H, Ishikawa N, Nangaku $\mathrm{M}$, Kurokawa K. Angiotensin II receptor antagonists and angiotensin-converting enzyme inhibitors lower in vitro the formation of advanced glycation end products: Biochemical mechanisms. Journal of the American Society of Nephrology 2002;13(10):2478-2487.

6. Monacelli F, Poggi A, Storace D, Durante A, Traverso N, Viviani GL, Odetti P. Effects of valsartan therapy on protein glycoxidation. Metabolism: Clinical and Experimental 2006;55(12):1619-1624.

7. Forbes JM, Cooper ME, Thallas V, Burns WC, Thomas MC, Brammar GC, Lee F, Grant SL, Burrell LM, Burrell LA, Jerums G, Osicka TM. Reduction of the accumulation of advanced glycation end products by ACE inhibition in experimental diabetic nephropathy. Diabetes 2002;51(11):3274-82.

8. Forbes JM, Thomas MC, Thorpe SR, Alderson NL, Cooper ME. The effects of valsartan on the accumulation of circulating and renal advanced glycation end products in experimental diabetes. Kidney International, Supplement 2004;66(92):S105-S107.

9. Parving HH, Lehnert H, Bröchner-Mortensen J, Gomis R, Andersen S, Arner P, Irbesartan in Patients with Type 2 Diabetes and Microalbuminuria Study Group. The effect of irbesartan on the development of diabetic nephropathy in patients with type 2 diabetes. New England Journal of Medicine 2001;345(12):870-8.

10. Miller AG, Tan G, Binger KJ, Pickering RJ, Thomas MC, Nagaraj RH, Cooper ME, WilkinsonBerka JL. Candesartan attenuates diabetic retinal vascular pathology by restoring glyoxalase-I function. Diabetes 2010;59(12):3208-3215. 
Research Impact 


\section{Acknowledgements (Dankwoord)}



My thesis is ready! Years of work are now collected into this book. The research described in this thesis and the writing and completion of the booklet itself was of course only possible with the support and guidance that I received from many people.

Therefore, I would like to thank everyone who contributed to this thesis in any way. In particular, Prof. Dr. C.G. Schalkwijk, Prof. Dr. Rossi., Prof. Dr Seccia and Dr. Hanssen, my promotion team.

Dear Gian Paolo and Teresa, I want to thank you for passing on the knowledge during the course and for giving me the opportunity to do this joint doctorate. All this not only contributed to my scientific development, but also created (even more) enthusiasm for science.

Dear Casper and Nordin l'm so gratefully for your help and guidance. The second part of this thesis could never have been completed without your generous cooperation. Your door was always open for me, and I really appreciated that. Dear Casper, I have great admiration for the consistent and professional manner on which you conduct and I appreciated also your hospitality at lab outings and Christmas dinner.

I would like to thank the members of the assessment committee, Prof. Dr. AA Kroon, Prof. Dr. G. Albertin, Prof. Dr. AHJ Danser, Prof. Dr. G Haenen, Dr. S. Foulquier and Dr. O. Brouwers for their critical reading and review of my thesis.

Dear Brasilina, my colleague, my friend, thank you so much for the wonderful time together. I really enjoyed the pleasant discussions about anything and everything, and simply all the time we spent together. It is also because of you that I have enjoyed coming to work every day.

Dear Selene, from the beginning to the end of our PhD, we have done so much together. We had very nice discussions and conversations together, laughed together and did many fun things together. I really enjoyed the experience in Maastricht and the fact that there was always someone who had been through the same thing from the beginning. I could also always count on you for help and support.

Dear Riccardo, my "mental coach", thank for your passion and enthusiasm for science, which is simply incredible and inspiring.

It was a great honour to work with so many talented colleagues in Padua. Francesca, Filippo, Rui, Giacomo, Donatella, Sofia, Livia, Alessandro, Ilaria and Giulio. 
I would also like to thank the $\mathrm{PhD}$ students and other investigators I have met in Padua, in particular the group of Vascular Biology (Betti, Elisa, Maristella), Nephrology (Verdiana and Giovanni), Haematology (Serena, Edoardo, Samuela, Jessica) Metabolic Disease (Elisabetta, Monica, Andrea, Alessandra) and Rheumatology (Chiara) for their help, support and in general for the great time.

For the joint PhD I had the opportunity to spend a year at the University of Maastricht. It was an exciting experience and I worked on an interesting project. Some people I would like to thank:

Dear Marjo, thank you for your contribution in this thesis. You have done dozens of AGE measurements for me. Dear Margee thank for your help in daily work. Dear Vichy, Jean, Maria, Joseè and Petra thank you for the kindness and care you have shown me.

I would like to thank all my colleagues from Maastricht, Amée, Kim, Ying, Shunxin, Nynke, Xiaodi, Wenjie, Kim, Evelien, Pomme, Mathias, Armand, and Tate for all their help and all the fun.

I would also like to thank the amazing international people of the "science party squad", especially Nicolò, Robin, Gina, Matteo, Delia, Hessel, Isabella, Cengiz, Greg (but of course all the others too) for all the hospitality during the dinners, parties, and outings. I had a wonderful time!

A special thanks to all my friends who have stood by me with sincere affection, sharing the stages of this journey.

Un ringraziamento doveroso ai miei genitori, per tutto quello che fate per me e per avermi sempre lasciata libera di fare le mie scelte. Senza il vostro sostegno incondizionato questa tesi non sarebbe stata possibile. A Emanuele e Daniele, miei splendidi fratelli ai quali auguro la possibilità di realizzare il loro sogni.

And finally to Andrea, who has been by my side throughout this PhD, living every single minute of it, and without whom, I would not have had the courage to embark on this journey in the first place. Thank you for all your love and for believing in me. 
Curriculum Vitae 



\section{Curriculum Vitae}

Maria Piazza was born in Salemi, Italy. She graduate from secondary school in 2005 (Liceo scientifico "M. Cipolla", Castelvetrano,Italy). In September 2005, she started with her master study in Pharmaceutical Chemistry and Technology, at University of Padova. In 2014, she received her master's degree. Her internship was performed at the department of Internal Medicine under the supervision of Prof. dr Giorgia Miolo and Prof. dr.Teresa Maria Seccia which resulted in the thesis entitled: "Endothelin-1 activates the epithelial-mesenchymal transition (EMT) in renal tubular cells. In vitro study in the human kidney-2 line (HK-2)". The data generated during her internship were published in 2016 in the Journal of the America Heart Association. In November 2016 she started a joint PhD project between University of Padova and University of Maastricht. This PhD project was conducted under the supervision of Prof. Dr. Teresa Maria Seccia Prof. Dr. Gian Paolo Rossi, Prof. Dr. Casper Schalkwijk and Dr. Nordin M.J. Hanssen. During her $\mathrm{PhD}$, Maria studied several aspects that regulate the biosynthesis of aldosterone in primary aldosteronism and the interaction between the renin-angiotensinaldosterone system and glycation. The results of her research are presented in this thesis. 
Curriculum Vitae 


\section{Scientific output}





\section{List of publications}

Piazza M, Hanssen NMJ, Persson F, Scheijen JL, Van de Waarenburg MPH, Van Greevenbroek MMJ, Rossing P, Hovind P, Stehouwer CDA, Parving $\mathrm{H}-\mathrm{H}$, Schalkwijk CG. Irbesartan treatment does not influence plasma levels of the dicarbonyls methylglyoxal, glyoxal and 3-deoxyglucosone in participants with type 2 diabetes and microalbuminuria: An IRMA2 sub-study. Diabetic Medicine 2020;00:e14405.

Piazza M, Seccia TM, Caroccia B, Rossitto G, Scarpa R, Persichitti P, Basso D, Rossi GP. AT1AA (Angiotensin II Type-1 Receptor Autoantibodies): Cause or Consequence of Human Primary Aldosteronism? Hypertension. 2019 Oct:74(4):793-799. doi:10.1161/HYPERTENSIONAHA.119.13388. Epub 2019 Sep 3. PubMed PMID: 31476908.

Seccia TM, Caroccia B, Piazza M, Rossi GP. The Key Role of Epithelial to Mesenchymal Transition (EMT) in Hypertensive Kidney Disease. Int J Mol Sci. 2019 Jul 21;20(14). pii: E3567.

doi: 10.3390/ijms20143567. Review. PubMed PMID: 31330886; PubMed Central PMCID: PMC6679134.

Caroccia B, Seccia TM, Piazza M, Prisco S, Zanin S, lacobone M, Lenzini L, Pallafacchina G, Domening O, Poglitsch M, Rizzuto R, Rossi GP. Aldosterone Stimulates Its Biosynthesis Via A Novel GPER Mediated Mechanism. J Clin Endocrinol Metab. 2019 May 24. pii: jc.2019-00043. doi: 10.1210/jc.2019-00043. [Epub ahead of print] PubMed PMID: 31125081.

Vanderriele PE, Caroccia B, Seccia TM, Piazza M, Lenzini L, Torresan F, lacobone $M$, Unger T, Rossi GP. The angiotensin type 2 receptor in the human adrenocortical zona glomerulosa and in aldosterone-producing adenoma: low expression and no functional role. Clin Sci (Lond). 2018 Mar 20;132(6):627-640. doi: 10.1042/CS20171593. Print 2018 Mar 30. PubMed PMID: 29436482.

Caroccia B, Prisco S, Seccia TM, Piazza M, Maiolino G, Rossi GP. Macrolides Blunt Aldosterone Biosynthesis: A Proof-of-Concept Study in KCNJ5 Mutated Adenoma Cells Ex Vivo. Hypertension. 2017 Dec;70(6):1238-1242. doi: 10.1161/HYPERTENSIONAHA.117.10226. Epub 2017 Oct 9. PubMed PMID: 28993452.

Seccia TM, Caroccia B, Gioco F, Piazza M, Buccella V, Guidolin D, Guerzoni E, Montini B, Petrelli L, Pagnin E, Ravarotto V, Belloni AS, Calò LA, Rossi GP. Endothelin-1 Drives Epithelial-Mesenchymal Transition in Hypertensive Nephroangiosclerosis. J Am Heart Assoc. 2016 Jul 21;5(7). pii: e003888. doi: 10.1161/JAHA.116.003888. PubMed PMID: 27444511; PubMed Central PMCID: PMC5015413 


\section{Additional manuscript}

Cinetto F, Ceccato J, Caputo I, Cangiano D, Montini B, Lunardi F, Piazza M, Agostini C, Calabrese F, Semenzato G, Rattazzi M, Gurrieri M, Scarpa R, Felice C, Vianello F. GSK-3 Inhibition Modulates Metalloproteases in a Model of Lung Inflammation and Fibrosis. Frontiers in Molecular Biosciences;2021;8:518.

Caroccia B, Vanderriele PE, Seccia TM, Piazza M, Lenzini L, Prisco S, Torresan F, Domening $\mathrm{O}$, lacobone $\mathrm{M}$, Poglitsch M, Rossi GP. Aldosterone and cortisol synthesis regulation by angiotensin-(1-7) and angiotensin-converting enzyme 2 in the human adrenal cortex. Journal of Hypertension 2021; Volume Publish Ahead of Print.

\section{Presentations}

- XXXVI National Congress SIIA, 2019 (Rome;oral presentation): Angiotensin II type 1 receptor autoantibodies: cause or consequence of human primary aldosteronism?

- 29th European Meeting on Hypertension and Cardiovascular Protection, 2019 (Milan; poster presentation): Angiotensin II type 1 receptor autoantibodies: cause or consequence of human primary aldosteronism?

- 28th European Meeting on Hypertension and Cardiovascular Protection, 2018 (Barcelona; poster presentation): AT1 and GPER-1 heterodimerization potentiates CYP11B2 gene expression in aldosterone producing adenoma 
